\title{
Analysis of the Total System Life Cycle Cost for the Civilian Radioactive Waste Management Program
}

May 1989

U.S. Department of Energy

Office of Civilian Radioactive Waste Management

Washington, DC 20585 



\section{DISCLAIMER}

This report was prepared as an account of work sponsored by an agency of the United States Government. Neither the United States Government nor any agency thereof, nor any of their employees, make any warranty, express or implied, or assumes any legal liability or responsibility for the accuracy, completeness, or usefulness of any information, apparatus, product, or process disclosed, or represents that its use would not infringe privately owned rights. Reference herein to any specific commercial product, process, or service by trade name, trademark, manufacturer, or otherwise does not necessarily constitute or imply its endorsement, recommendation, or favoring by the United States Government or any agency thereof. The views and opinions of authors expressed herein do not necessarily state or reflect those of the United States Government or any agency thereof. 


\section{DISCLAIMER}

Portions of this document may be illegible in electronic image products. Images are produced from the best available original document. 
The total-system life-cycle cost (TSLCC) analysis for the Department of Energy's (DOE) Civilian Radioactive Waste Management Program is an ongoing activity that helps determine whether the revenue-producing mechanism established by the Nuclear Waste Policy Act of 1982--a fee levied on electricity generated in commercial nuclear power plants--is sufficient to cover the cost of the program. This report provides cost estimates for the sixth annual evaluation of the adequacy of the fee and is consistent with the program strategy and plans contained in the DOE's Draft 1988 Mission P1an Amendment. The tota1-system cost for the system with a repository at Yucca Mountain, Nevada, a facility for monitored retrievable storage (MRS), and a transportation system is estimated at $\$ 24$ billion (expressed in constant 1988 dollars). In the event that a second repository is required and is authorized by the Congress, the total-system cost is estimated at $\$ 31$ to $\$ 33$ billion, depending on the quantity of spent fuel to be disposed of.

The \$7-billion cost savings for the single-repository system in comparison with the two-repository system is due to the elimination of $\$ 3$ billion for second-repository development and $\$ 7$ billion for the second-repository facility. These savings are offset by $\$ 2$ billion in additional costs at the first repository and $\$ 1$ billion in combined higher costs for the MRS facility and transportation.

The revised TSLCC estimates have changed from the June 1987 analysis because of two major types of changes: (1) cost impacts due to changes in design assumptions and cost data and (2) the passage of the Nuclear Waste Policy Amendments Act of 1987 (the Amendments Act). For a two-repository system, the changes in design assumptions and cost data result in a $\$ 6$ billion increase in total-system costs. However, the provisions of the Amendments Act cause a cost reduction of $\$ 6$ billion in total-system costs. Therefore, for a two-repository system, this TSLCC estimate is only slightly lower than that for the comparable reference case from the previous TSLCC analysis.

To estimate the share of the total-system costs that should be allocated to the disposal of defense high-level waste in the civilian repositories, the methodology announced by the DOE in the Federal Register in August 1987 was used. Estimates of the defense-waste share of the costs are about $\$ 4$ billion (15 percent of the total) for the single-repository system and about $\$ 6$ billion (19 percent of the total) for the two-repository system. 
1. INTRODUCTION AND SUMMARY . . . . . . . . . . . . . . . 1-1

1.1 Purpose and Scope . . . . . . . . . . . . . . . . . 1-1

1.2 Program Changes Reflected in the TSLCC Analysis ....... 1-2

1.3 Results ....................... . . 1-5

1.4 Changes from the June 1987 TSLCC Analysis . . . . . . . . 1-7

References ..................... 1-14

2. CASE STRUCTURE, ASSUMPTIONS, AND WASTE LOGISTICS . . . . . . . 2-1

2.1 Cases Examined in the TSLCC Analysis............ 2-1

2.1.1 Spent-fuel consolidation ............. 2-1

2.1.2 Projections of spent-fuel discharges ........ 2-2

2.1.3 Number of repositories ............. 2-6

2.1 .4 Case structure ................ 2-7

2.2 Key Assumptions .................... 2-9

2.3 Waste Logistics . . . . . . . . . . . . . . 2-9

References......................... 2-16

3. DEVELOPMENT AND EVALUATION COSTS . . . . . . . . . . . . . 3-1

3.1 Method and Assumptions . . . . . . . . . . . . . . 3-1

3.1.1 D\&E costs for the first and second repositories... . 3-2

3.1.1.1 First-repository D\&E costs........ 3-3

3.1.1.2 Second-repository D\&E costs ....... 3-4

3.1.2 Other D\&E cost categories . . . . . . . . . 3-5

3.2 Results . . . . . . . ............ 3-7

3.3 Comparison with Previous Cost Estimates . . . . . . . . 3-8

3.3.1 First repository ............... 3-10

3.3.2 Second repository ................ 3-10

3.3.3 Other D\&E cost categories ........... . . 3-11

References .................... . . 3-12

4. TRANSPORTATION COSTS .................... 4-1

4.1 General Description ................. . 4-1

4.2 Method of Analysis ................ . 4-2

4.2.1 Transportation logistics ............ 4-3

4.2.2 Approach to calculating transportation costs . . . . . 4-4

4.2.2.1 Shipping and security .......... . 4-4

4.2.2.2 Cask purchase and maintenance .... . . . 4-4

4.2.2.3 Other costs ............. 4-4

4.2.3 Calculation of the principal charges for each
mode of transportation ............. 4-5

mode of transportation . ........... 4-5

4.2.3.2 Transportation by rail............ 4-6

4.3 Results . . . . . . . . . . . . . . . . 4-6

4.4 Comparison with Previous Cost Estimates ......... . 4-9

References ........................ 4-14 
5. REPOSTTORY COSTS .....................

5.1 Pertinent Provisions of the Amendments Act . . . . . . . .

5.2 Assumptions about the Design and Operation of the Repositories

5.3 Scope of Repository-Cost Estimates .............

5.3.1 Engineering costs ................

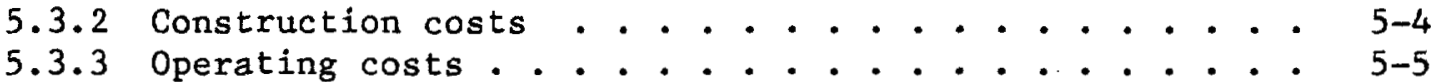

$5-2$

$5-4$

$5-4$

$5-4$

5.3.4 The costs of closure and decommissioning ...... . 5-5

5.4 Method of Analysis . . . . . . . . . . . . . . . 5-5

5.4.1 Site and surface facilities . . . . . . . . . 5-6

5.4 .2 Shafts and ramps ................. 5-7

5.4.3 Underground development and operation....... . 5-7

5.4 .4 Waste packages ................ 5-9

5.4.5 Total costs................. 5-10

5.5 Results ..................... 5-10

5.6 Comparison with Previous Results . . . . . . . . . . 5-15

References ...................... 5-18

6. COSTS FOR AN MRS FACILITY ................... . . 6-1

6.1 The MRS Facility and the Provisions of the Amendments Act. . . 6-1

6.2 The Design and Operation of an MRS Facility . . . . . . . . 6-2

6.2.1 MRS facility that consolidates spent fuel ...... 6-3

6.2.2 MRS facility with intact-fuel disposal. . . . . . . 6-4

6.2.3 MRS waste logistics and schedule ......... 6-4

6.3 Method of Analysis................. 6-5

6.4 Results ..................... . . 6-6

6.5 Comparison with Previous Estimates ............ . 6-7

References................... . . 6-11

7. BENEFITS PAYMENTS ........................ . . . . . 7-1

7.1 The Benefits Provisions of the Amendments Act . . . . . . 7-1

7.2 Method of Analysis............... . . $7-2$

7.3 Results ................... $7-3$

References .................... . . 7-5

8. COSTS FOR THE DISPOSAL OF DEFENSE WASTE . . . . . . . . . . 8-1

8.1 Background Information . . . . . . . . . . . . . . 8-1

8.1.1 Description of the waste ............ 8-1

8.1.2 Current plans for the transportation and disposal of defense high-level waste .......... 8-1

8.1.3 Payment for the transportation and disposal of defense high-level waste ........... 8-2

8.2 Cost-Allocation Method for Defense High-Level Waste . . . 8-3

8.3 Results ...................... . 8-7

8.4 Comparison with Previous Estimates . . . . . . . . . . 8-7

References ..................... 8-11

9. RESULTS OF THE TSLCC ANALYSIS . . . . . . . . . . . . . . 9-1

9.1 Single Repository with Intact-Fuel Disposal . . . . . . . . 9-1

9.2 Single Repository with Consolidation . . . . . . . . . . 9-1 
9.3 Two Repositories with Intact-Fuel Disposal . . . . . . . . 9-2

9.4 Two Repositories with Consolidation . . . . . . . . . . . 9-5

9.5 Two Repositories with Consolidation--Upper Reference Case . . 9-5

9.6 Summary .. . . . . . . . . . . . . . . . 9-6

References ....................... . 9-7

Appendix A WASTE ACCEPTANCE TABLES . . . . . . . . . . . . . . . A-1

Appendix B ASSUMPTIONS FOR THE MAY 1989 ANALYSIS OF THE TOTAL-SYSTEM

LIFE-CYCLE COSTS. . . . . . . . . . . . . . B-1

Appendix C ANNUAL TOTAL-SYSTEM COSTS BY MAJOR COST COMPONENT . . . . $\mathrm{C}-1$

Appendix D ANNUAL DEFENSE-WASTE COSTS BY MAJOR COMPONENT . . . . . . . D-1

Appendix E SUMMARY OF TOTAL-SYSTEM COSTS . . . . . . . . . . . . E-1

Appendix F REFERENCE DEFENSE-WASTE COST ALLOCATION FACTORS . . . . . F-1 
Summary of total-system life-cycle cost estimates . . . . 1-6 system: no-new-orders, end-of-reactor-life case, intact-fuel disposal . . . . . . . . . . . . 2-8

Current TSLCC assumptions about the waste and the components of the waste-management system . . . . . 2-10 
1-1 Evolution of total-system life-cycle cost ranges for cases with the reference TSLCC forecast . . . . . . . . 1-12

Annual spent-fuel generation .............. . 2-5

Cumulative spent-fuel generation . . . . . . . . . . . 2-5

3-1

Comparison of D\&E costs to previous estimates . . . . . . 3-9

4-1

Total transportation costs by major component for a one-repository system with intact-fuel disposal . . . . . . 4-9

4-2 Total transportation costs by type of shipment for a one-repository system with intact-fuel disposal . . . . 4-10

4-3 Total transportation costs by type of shipment for a two-repository system with consolidated-fuel disposal . . 4-10

$5-1$

5-2

Repository costs by phase for a single repository in tuff . . 5-12

Repository costs by account for a single repository in tuff.................... 5-12

5-3

Comparison of tuff first repository costs to previous estimates ................ . 5-16

6-1

MRS costs by account for a one-repository system basic MRS facility ................. 6-8

MRS costs by account for a one-repository system with an MRS facility that consolidates into canisters . . . 6-8

Comparison of MRS costs to previous estimates . . . . . . . . 6-9

Summary of defense-waste, civilian-waste, and total-system life-cycle costs... . . . . . . . . . . . . . 8-8

8-2 Comparison of defense-waste cost allocation to previous estimates .................... 8-10

9-1 Total system costs by major cost component for a one-repository system with intact-fuel disposal and a basic MRS .................... 9-3

9-2 Total system costs by major cost component for a one-repository system with an MRS facility that consolidates into canisters . . . . . . . . . . 9-3 
Chapter 1

INTRODUCTION AND SUMMARY

\subsection{PURPOSE AND SCOPE}

Each year a comprehensive analysis of the total cost of the radioactivewaste-management system over its complete life cycle is performed as a reference planning document that aids in the financial planning for the Department of Energy's (DOE) Civilian Radioactive Waste Management Program. The analysis is intended to reflect as closely as possible the most current program strategy, plans, and policies. The primary use for the total-system life-cycle cost (TSLCC) analysis is to help determine whether the fees paid by waste generators will be sufficient to fully cover the costs of the program. This report summarizes the TSLCC analysis performed for the sixth annual evaluation of the adequacy of the fees collected for the Nuclear Waste Fund. Presented in this report are the rationale for the various cases studied, analytical interpretations of the DOE's waste-management strategy, brief descriptions of the cost-estimation methods by cost component, summaries of the cost estimates, and comparisons of the estimates with the results of previous TSLCC analyses.

The TSLCC analysis is performed with substantial rigor and accountability since its estimates represent the official long-term (near1y 100 years) financial plan for the program. By providing a detailed set of cost estimates for all components of the currently planned waste-management system, the results of the analysis are used in several program applications. Despite the rigor and accountability of the analytical techniques, there are considerable uncertainties inherent in the cost estimates for a conceptual system like the waste-management system. Consequently, the TSICC analysis is performed annually to incorporate changes due to advances in program definition. By analyzing the differences in the cost estimates from year to year, the TSLCC analysis provides an ongoing chronicle of the planned cost of the entire program as it evolves through time and the cost impacts associated with major program developments.

The TSLCC analysis examines costs for cases that are distinguished by such features as the quantity of waste to be disposed of, the number of repositories (one or two), the functions of a monitored retrievable storage (MRS) facility, and the inclusion of spent-fuel-rod consolidation in the system. However, it is not intended to be a system analysis of alternative engineering designs and assumptions. On the contrary, the TSLCC analysis builds on the results of such system studies to the degree that they have been incorporated into the program strategy. In general, the analysis is based on a single set of engineering assumptions; these assumptions are combined with the current program strategy under a variety of appropriate conditions to produce a range of tota1-system cost estimates. It should be noted, however, that the assumptions being used in the TSLCC analysis have not been baselined and should not be interpreted as system requirements. 
The TSLCC analysis encompasses all components of the waste-management system that are financed by disbursements from the Nuclear Waste Fund. It covers five major cost components: development and evaluation (D\&E), transportation, repository(ies), MRS facility, and benefits payments. The D\&E cost component covers all siting, preliminary design development, testing, regulatory compliance, and institutional activities for the program. This category also includes the costs of program administration by the Federal Government and the fees charged by the Nuclear Regulatory Commission (NRC) for licensing. The transportation category includes the capital costs of providing the transportation system and the costs of operating the transportation system. The repository category covers the engineering, construction, operation, closure, and decommissioning of the repository. Similarly, the MRS category covers the engineering, construction, operation, and decommissioning of the MRS facility. The final cost component is the benefits payments authorized by the Nuclear Waste Policy Amendments Act of 1987 (the Amendments Act).1

The remainder of this chapter discusses the major changes in the program from the previous TSLCC analysis, focusing on the changes that are pertinent to the cost analysis; presents a summary of the results; and compares the current estimates to previous TSLCC estimates. Chapter 2 of this report summarizes the major programmatic assumptions used in the analysis and the rationale for the cases that were studied. Chapters 3 through 7 present descriptions of the cost estimates for each of the components discussed above. The cost allocations for the disposal of defense high-level waste (DHLW) are explained in Chapter 8. Chapter 9 summarizes the results of the total-system cost analysis. More-detailed information is given in six appendixes: wasteacceptance tables are shown in Appendix A; a detailed list of the underlying assumptions is presented in Appendix B; annual total-system costs and DHLWdisposal costs are given in Appendixes $C, D$, and $E$; and the factors used in allocating costs for DHLW disposal are presented in Appendix F. For more information on the cost estimates presented in this report, the companion document, Cost Estimating Methods for the Total-System Life-Cycle Cost Analysis, ${ }^{2}$ should be consulted. The companion document is a notebook containing in-depth descriptions of the methods and the information used in this analysis.

\subsection{PROGRAM CHANGES REFLECTED IN THE TSLCC ANALYSIS}

This year's TSLCC analysis reflects several important changes in the waste-management program. Among them are the provisions of the Amendments Act, which was signed into law on December 22, 1987. The pertinent provisions of the Amendments Act are as follows:

- Site characterization for the first repository is limited to the Yucca Mountain site in Nevada.

- Site-specific activities for the second repository are prohibited, but the Secretary of Energy is to report between January 1, 2007, and January 1, 2010, on the need for a second repository. 
- The construction of an MRS facility is authorized subject to certain conditions.

- The DOE may enter into a benefits agreement with a State or Indian Tribe willing to host a repository or an MRS facility.

Since the Amendments Act authorized only one repository and 1imits site characterization for the first repository to the Yucca Mountain site in Nevada, the first-repository costs in this year's analysis address only a repository in tuff. In the June 1987 analysis, 3 costs for a first repository in basalt and in salt were also estimated. This provision also affects development-and-evaluation costs; this year's analysis covers the characterization of the Yucca Mountain site only. The previous analysis included the costs of characterizing, in addition to the Yucca Mountain site, the Deaf Smith County site (sa1t) in Texas and the Hanford site (basalt) in Washington.

The Amendments Act prohibits any site-specific activities for a second repository and requires the DOE to phase out all research directed at evaluating the suitability of crystalline rock; however, the Amendments Act also directs the DOE to report to the President and to the Congress between January 1, 2007, and January 1, 2010, on the need for a second repository. As explained in the Draft 1988 Mission Plan Amendment, 4 the need for a second repository will depend on a number of factors, including the quantity of waste requiring disposal and the potential capacity of the Yucca Mountain site. Hence, although the site-characterization activities at the Yucca Mountain site are directed at an area large enough for 70,000 metric tons of heavy metal (MTHM) (the statutory limit for the first repository until a second repository starts waste acceptance), further characterization studies may be conducted in the future in conjunction with other analyses examining the need for a second repository. If the DOE determines that a second repository is required, specific Congressional guidance will be required to resume the second-repository program. Consequently, this TSLCC analysis focuses on a single-repository scenario. However, the Amendments Act retained the 70,000-MTHM limitation on the capacity of the first repository. In view of these considerations and in order to prepare cost estimates that reflect a reasonable range of possible outcomes, the TSLCC analysis includes not only a case for the authorized system (i.e., a one-repository system) but also cases with a hypothetical second repository.

The authorized waste-management system now contains an MRS facility, which the Amendments Act has authorized subject to certain conditions, including those that establish a link between the schedules of the MRS facility and the repository. The most significant is the condition that the construction of the MRS facility cannot begin until the NRC has issued a construction authorization for the repository. The conditions imposed by the Amendments Act were considered in developing for the Draft 1988 Mission Plan Amendment ${ }^{4}$ a preliminary waste-acceptance schedule for the waste-management system. This schedule, which forms the basis of the waste-acceptance schedules used in this TSLCC analysis, shows that an MRS facility that performs waste-preparation and waste-packaging functions could start accepting waste in 2003. 
In view of the authorization of the MRS facility, the DOE has begun to reevaluate the role and the functions of the MRS facility. In addition, the DOE is evaluating ways to accelerate the MRS schedule. Toward these ends, the DOE has completed a series of MRS systems studies. 5

In addition to reevaluating the role of the MRS facility in the wastemanagement system, the DOE is reevaluating other system functions as well. The main function being reviewed is spent-fuel consolidation. Consolidation involves disassembling fuel assemblies and placing the fuel rods into a more compact array. The DOE is evaluating whether the waste-management system should perform consolidation and, if so, at which facility this function should take place. The results of the DOE's studies indicate that intact spent fuel as received from reactors should be the waste form used as the basis for the advanced conceptual designs for the repository and the waste package. However, the desirability of consolidation will be evaluated during the advanced conceptual design of the repository and the waste package. Because of uncertainties surrounding the issue of consolidation, the TSLCC analysis has included both types (with and without consolidation) of cases.

It was assumed in the MRS systems studies that an MRS facility could start earlier if the consolidation function was not included and no packaging functions were performed. The TSLCC analysis has followed this assumption, and therefore it was assumed that the MRS facility would start in 2000 in the intact-fuel disposal cases with no packaging at the MRS facility and in 2003 in the cases where the MRS facility consolidates and places the fuel in canisters.

It should be noted that the TSLCC analysis includes alternative cases to ensure that the fee-adequacy assessment is broad enough to capture the appropriate program strategy. However, the analysis is consistent with the assumptions and cost estimates of the MRS System Study Summary Report. 5 For example, there are two cases that are contained in both the TSLCC analysis and the MRS systems studies: two repositories and an MRS facility that starts in 2003 and consolidates spent fuel into canisters, and two repositories that emplace intact fuel and a "basic" MRS facility that starts in 2000 . The two studies report the same costs for these two cases. Furthermore, the two studies used the same analytical assumptions and cost-estimation methods for all cases.

Two other program developments are pertinent to the TSLCC analysis but independent of the Amendments Act:

- In August 1987 , the DOE published a notice ${ }^{6}$ containing a refined approach to estimating the allocation of disposal costs for defense high-1eve1 waste.

- As stated in the Draft 1988 Mission Plan Amendment, the DOE has decided to use the no-new-orders projection of spent-fuel discharges as the primary basis for planning the waste-management program.

On August 20, 1987, the DOE issued in the Federal Register 6 a notice of its approach for allocating the total-system 1 ife-cycle costs between the producers of civilian radioactive wastes and the producers of defense high-level 
waste. The new approach is a refined version of the preferred approach outlined in the notice of inquiry published in December 1986.7 The methodology for calculating the costs of DHLW disposal in this year's analysis follows that contained in the more recent Federal Register notice and is briefly discussed in Chapter 8 ("Costs for the Disposal of Defense Waste"). For a more detailed description of the methodology, the reader is referred to the August 20, 1987, Federal Register notice.

The TSLCC analysis has always used the spent-fuel-discharge forecasts published annually by the Energy Information Administration (EIA). The EIA forecasts are based on three distinct scenarios for the domestic nuclear energy capacity through the year 2020. These scenarios are the "upper reference," "lower reference," and "no-new-orders" cases, which differ in the underlying assumptions about future orders for nuclear power plants in the United States. The TSLCC analysis has always considered a range of the EIA forecasts, but the earlier analyses used a set of TSLCC "reference cases" that were based on the EIA upper reference forecast. The Draft 1988 Mission Plan Amendment states that the OCRWM has now decided to use the no-new-orders case as its primary basis for planning. The no-new-orders case is essentially based on nuclear plants currently operating and under active construction; it represents the minimum expected quantity of spent fuel. The decision to use this case was based on recommendations by the General Accounting of $f$ ice, 8 on discussions with representatives of the utility industry, and on the following reasons:

- The no-new-orders case provides a more reasonable basis for planning than the upper reference case because no new orders for nuclear plants have been placed for several years.

- The no-new-orders case provides a more conservative estimate of the amounts of money paid by the utilities into the Nuclear Waste Fund.

This analysis has focused on the "end-of-reactor-1ife" version of the no-new-orders forecast. This forecast projects that the quantity of spent fuel discharged through the year 2037 will be approximately 86,800 MTHM. 9 The TSLCC analysis includes the costs of disposing of a projected 17,470 canisters (assumed to equal 8735 MTHM) of defense high-level waste in addition to the spent fuel. The spent-fuel and defense-waste forecasts are discussed in detail in Section 2.1.2 of this report.

\subsection{RESULTS}

Total-system 1ife-cycle costs were estimated for five cases and are summarized by major cost component in Table 1-1. The cases are distinguished by the number of repositories, the form of the spent fuel that is emplaced in the repository (intact or consolidated), and the quantity of spent fuel. For the intact-fuel disposal cases, the MRS facility was assumed to start in 2000; for the consolidated-fuel disposal cases, the MRS facility, which performs the consolidation function, was assumed to start in 2003. The first repository was assumed to start in 2003 in all cases, and the second repository, when included, was assumed to start 20 to 25 years after the resumption of the second-repository program. A11 cases include a repository in tuff and an MRS 
Table 1-1. Summary of total-system life-cycle cost estimaies (Billions of 1988 dollars)

\begin{tabular}{|c|c|c|c|c|c|}
\hline \multirow[b]{2}{*}{ Cost category } & \multicolumn{2}{|c|}{ Single repository } & \multicolumn{3}{|c|}{ Two repositories } \\
\hline & $\begin{array}{l}\text { Intact fuel } \\
\text { basic } \\
\text { MRS }\end{array}$ & $\begin{array}{l}\text { Consolidate } \\
\text { into canisters } \\
\text { at MRS }\end{array}$ & $\begin{array}{c}\text { Intact fuel } \\
\text { basic } \\
\text { MRS }\end{array}$ & $\begin{array}{l}\text { Consolidate } \\
\text { into canisters } \\
\text { at MRS }\end{array}$ & $\begin{array}{l}\text { Consolidate into } \\
\text { canisters at MRS, } \\
\text { upper reference }\end{array}$ \\
\hline Development and evaluation & 9.7 & 9.7 & 13.1 & 13.1 & 13.1 \\
\hline Trensportation & 2.6 & 2.6 & 2.3 & 2.3 & 2.4 \\
\hline First repository & 9.1 & 8.7 & 7.0 & 6.7 & 6.6 \\
\hline Second repository & $N A^{b}$ & MA & 6.6 & 6.8 & 7.4 \\
\hline MRS facility & 1.8 & 3.1 & 1.4 & 2.3 & 2.3 \\
\hline Benefits & 0.7 & 0.7 & 0.9 & 0.9 & 0.9 \\
\hline Total-system costs ${ }^{c}$ & 23.8 & 24.8 & 31.2 & 32.0 & 32.7 \\
\hline
\end{tabular}

\footnotetext{
These cases are based on the assumption that a single repository disposes of the entire quantity of waste

Bot applicable.

Colums may not add to totals because of independent rounding.
}

facility that services only one repository (i.e., the first repository in two-repository cases). A11 cases also include the disposal and transportation of 17,750 canisters of defense high-level waste and the disposal of 640 MTHM of civilian high-level waste. For the cases that include a second repository, a generic rock in an unspecified location was assumed for cost-estimating purposes.

The principal findings of this analysis are as follows:

- The total-system cost for the one-repository system is estimated at $\$ 23.8$ to $\$ 24.8$ billion (in constant 1988 dollars), depending on whether intact or consolidated spent fuel is as sumed.

- The total-system cost for the two-repository cases is estimated at $\$ 31.2$ to $\$ 32.7$ billion, depending on the spent-fuel projection assumed.

- The total-system costs for the cases with spent-fuel consolidation at the MRS facility are $\$ 0.8$ to $\$ 1.0$ billion higher than the costs for comparable cases with intact-fuel disposal. 
- The defense-waste share of the total-system costs is estimated to range from $\$ 3.6$ (one-repository system) to $\$ 6.4$ billion (two-repository system), or 15 to 20 percent of the total-system cost (see Chapter 8).

- The upper reference case includes about 11 percent more waste than the no-new-orders, end-of-reactor-life case, but the costs are less than 3 percent higher for a two-repository system. This points out the "fixed" costs of the system. In the two-repository cases, the costs of development and evaluation, benefits payments, the first repository, and the MRS facility are virtually fixed for any waste quantity over 70,000 MTHM.

Generally, the costs for the individual cost components are reported here in "millions of 1988 constant dollars" as a matter of analytical convention. However, the reader is advised against assuming that the cost estimates are absolutely accurate to this level of detail. Generally, the analysis focuses on "relative costs." Cost impacts of $\$ 100$ million ( $\$ 0.1$ billion) or more can be considered significant, and they are routinely discussed in the chapters on individual cost components.

\subsection{CHANGES FROM THE JUNE 1987 TSLCC ANALYSIS}

The TSLCC estimates presented in this report have changed from the estimates in previous TSLCC analyses for a variety of reasons. The causes of the changes may be grouped into two categories: (1) cost impacts due to changes in design assumptions and cost data and (2) cost impacts due to the passage of the Amendments Act. The changes in the first category result largely from changes in the technical definition of the program and are typical of the year-to-year changes that have been represented in previous TSLCC analyses. On the other hand, the changes in the second category are unique to the passage of the Amendments Act, and therefore they are unique to this TSLCC analysis.

Table 1-2 isolates the cost changes from the June 1987 TSLCC analysis that are due to changes in design assumptions and cost data. The impact of these changes was isolated by preparing an "update" to the June 1987 TSLCC. This update case includes all of the changes in design assumptions and cost data that are reflected in this May 1989 TSLCC, but the case does not include the impacts of the Amendments Act. For example, the case retains the characterization of three sites for the first repository and the second repository start date of 2023. This updated June 1987 case was compared with the most comparable reference case from the June 1987 TSLCC analysis. Both cases include a repository at Yucca Mountain and an MRS facility. The comparison is based on a two-repository scenario in which the MRS facility consolidates spent fuel because the June 1987 TSLCC analysis did not include scenarios with either a single repository or intact-fuel disposal. The second repository in the updated 1987 estimate is in a generic rock; last year's analysis was based on a second repository in salt. The cost estimates for last year's report are shown in constant 1986 dollars (as they appeared in the 1987 TSLCC report), while the updated 1987 cost estimates are expressed in 1988 constant dollars (consistent with this year's analysis). 
Table 1-2. Total-system cost impacts due to changes in design assumptions and data

(Billions of constant dollarsa)

\begin{tabular}{lccc}
\hline & $\begin{array}{c}\text { June } 1987 \text { TSLCC, } \\
\text { reference case, } \\
\text { tuff/salt }\end{array}$ & $\begin{array}{c}\text { Updated June } \\
\text { 1987 TSLCC, } \\
\text { tuff/generic rock }\end{array}$ & $\begin{array}{c}\text { Cost impacts } \\
\text { due to new } \\
\text { design assump- } \\
\text { tions and data }\end{array}$ \\
\hline $\begin{array}{l}\text { Development and } \\
\text { evaluation }\end{array}$ & 14.6 & 18.7 & +4.1 \\
Transportation & 2.2 & 2.4 & +0.2 \\
First repository & 5.5 & 6.7 & +1.2 \\
Second repository & 7.1 & 7.4 & +0.3 \\
MRS facility & 2.7 & 2.7 & 0.0 \\
Benefits & NA & NA & NA \\
Totald & & 37.9 & +5.8 \\
\hline
\end{tabular}

aThe June 1987 estimates are expressed in 1986 constant dollars, while the updated June 1987 estimates are expressed in 1988 constant dollars.

${ }^{b}$ In order to isolate the cost impacts of new design assumptions and cost data this case does not include the provisions of the Amendments Act.

$c_{\text {Not applicable. }}$

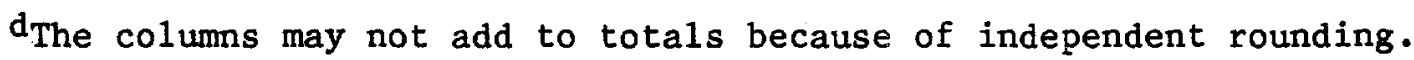

Table 1-2 shows that the TSLCC estimates would have increased by $\$ 5.8$ billion (18 percent) if the Amendments Act had not been passed. The major cost increases are found in the $D \& E$ cost category and are attributable mainly to an increase in the work scope of the site-characterization activities for the three candidate sites and the addition of "NRC fees." The transportation costs would have increased slightly because of a number of changes in assumptions about design and operation. The repository costs would have increased, mainly because of changes in waste-package costs and assumptions about design and operation. Finally, the updated June 1987 estimate is stated in 1988 constant dollars, which are about 7 percent higher than the 1986 constant dollars used in the June 1987 analysis; therefore, about \$2 billion of the increase is due to 2 years' worth of inflation. The cost impacts for each individual cost category are explained in more detail in Chapters 3 through 7. 
Table 1-3 isolates the cost impacts of the Amendments Act. The impact of the Amendments Act was measured by comparing the most comparable case from the current (May 1989) TSLCC estimate with the updated June 1987 TSLCC estimate that did not include the provisions of the Amendments Act. In summary, the provisions of the Amendments Act reduce program costs by $\$ 5.9$ billion. The major impact is observed in the D\&E cost category and is due

Table 1-3. Tota1-system cost impacts due to the Amendments Act (Billions of 1988 constant dollars)

$\begin{array}{lll}\text { Updated June } & & \\ & 1987 \text { TSLCC, } & \text { May } 1989 \text { TSLCC, } \\ \text { Cost category } & \text { tuff/generic rock } & \text { Cost impacts due } \\ \text { tuff/generic rock } & \text { to Amendments Act }\end{array}$

Development and

evaluation

18.7

2.4

Transportation

First repository

Second repository

MRS facility

Benefits

Totalc

\section{7}

7.4

2.7

$\mathrm{NA}^{\mathrm{b}}$

37.9

$\begin{array}{r}13.1 \\ 2.3 \\ 6.7 \\ 6.8 \\ 2.3 \\ 0.9 \\ \hline 32.0\end{array}$

$-5.6$

$-0.1$

$-0.0$

$-0.6$

$-0.4$

$+0.9$

$-5.9$

aThis case is an update of the June 1987 analysis, and was conducted without including the provisions of the Amendments Act.

bot applicable.

cThe columns may not add to totals because of independent rounding.

mainly to the reduction in the number of sites to be characterized for both the first and the second repository. Most of the repository cost decrease is found in the second repository and is due to the change in the assumed date for the second-repository startup--a change necessitated by the deferral of work on the second repository. By deferring the startup of the second repository (compared to last year's assumed startup date of 2023), the repository will be able to operate more efficiently over a much shorter time. The delay in startup also allows the second repository to accept spent fuel that has had a longer cooling. time; this reduces waste-package costs and underground-emplacement requirements. The MRS costs are also reduced due to the change in the assumed startup date (2003 this year versus 1998 in the June 1987 analysis) caused by the provisions of the Amendments Act, which 1ink 
MRS development to repository development. The MRS peak storage inventory is reduced by the assumption that the MRS facility that consolidates does not accept spent fuel significantly earlier than the repository; this reduces MRS storage costs. In addition, the MRS facility accepts spent fuel that is slightly older and thus colder because of the 5-year delay in the assumed startup; this reduces waste-canister requirements and helps to further reduce storage requirements. The final impact of the Amendments Act was the cost increase due to the establishment of the benefits agreements and the associated benefits payments. The benefits payments for two repositories and an MRS facility are estimated to total nearly $\$ 0.9$ billion. As was mentioned previously, the comparison is based on a two-repository scenario in which the MRS facility consolidates spent fuel because the June 1987 TSLCC analysis did not include scenarios with either a single repository or intact-fuel disposal.

The net cost difference in this year's TSLCC results from the June 1987 results is therefore a function of changes in design assumptions and cost data as well as the changes due to the Amendments Act. The changes in design assumptions and cost data generally tend to increase costs, and the provisions of the Amendments Act significantly decrease costs. The net effect of these two types of cost impacts is a small cost decrease ( $\$ 0.1$ billion) from the most comparable June 1987 TSLCC case. However, additional cost savings on the order of $\$ 0.8$ to $\$ 1.0$ billion may be possible if consolidation is not necessary, and if the single-repository case is assumed, cost savings of about $\$ 7.3$ billion would be realized from the two-repository case. Detailed comparisons between this analysis and the June 1987 analysis are given in Chapters 3 through 7 of each cost component. A similar comparison for defense waste is given in Chapter 8 .

Table 1-4 compares the two-repository, no-new-orders case with consolidation (selected for comparability) with the reference cases of all previous TSLCC analyses. The top half of this table presents the costs exactly as they appeared in the cited documents. However, to assess how the "real" (excluding the impact of general inflation in the economy) program costs have changed since the first fee-adequacy analysis was performed, the cost estimates for the previous studies were adjusted to constant 1988 dollars to be comparable with the current estimate. The evolution of a comparable set of cost estimates is shown graphically in Figure 1-1.

Although the cost estimates have changed significantly from the July 1983 and April 1984 analyses, the costs estimated in the last four TSLCC analyses are relatively stable. This year's estimate is within the boundaries of the reference-case costs of the last two TSLCC analyses (April 1986 and June 1987), even without taking inflation into account. When inflation is accounted for, this year's estimate is within the boundaries of the referencecase costs for the April 1985 and the April 1986 TSLCC analyses and below the boundaries of the reference-case costs in last year's TSLCC. 
Table 1-4. Comparison of total-system cost estimates, 1983-1988 ${ }^{a}$

(Billions of constant dollars)

\begin{tabular}{|c|c|c|c|c|c|c|}
\hline Cost category & $\begin{array}{c}\text { July } 1983 \\
\text { fee adequacy } \\
\text { ('82 dollars) }\end{array}$ & $\begin{array}{c}\text { April } 1984 \\
\text { TSLCC } \\
\text { ('83 dollars) }\end{array}$ & $\begin{array}{c}\text { April } 1985 \\
\text { TSLCC } \\
\text { ('84 dollars) }\end{array}$ & $\begin{array}{c}\text { April } 1986 \\
\text { TSLCC } \\
\text { ('85 dollars) }\end{array}$ & $\begin{array}{c}\text { June } 1987 \\
\text { TSLCC } \\
\text { ('86 dollars) }\end{array}$ & $\begin{array}{c}\text { May } 1989 \\
\text { TSLCC } \\
\text { ('88 dollars) }\end{array}$ \\
\hline $\begin{array}{l}\text { Development and evaluation } \\
\text { Transportation } \\
\text { Repository } \\
\text { MRS facility } \\
\text { Benefits }\end{array}$ & $\begin{array}{c}4.7 \\
3.9 \\
10.7-11.2 \\
\text { NA } \\
\text { NA }\end{array}$ & $\begin{array}{c}7.6 \\
2.5 \cdot 3.9 \\
10.5-12.9 \\
\text { NA } \\
\text { NA }\end{array}$ & $\begin{array}{c}7.8 \\
3.3-5.1 \\
12.5-16.9 \\
\text { NA } \\
\text { NA }\end{array}$ & $\begin{array}{c}9.2-9.5 \\
1.7-2.3 \\
11.9-19.7 \\
2.8-2.9 \\
\text { NA }\end{array}$ & $\begin{array}{c}14.6-14.7 \\
2.0-2.2 \\
12.6-18.7 \\
2.7 \\
\text { NA }\end{array}$ & $\begin{array}{r}13.1 \\
2.3 \\
13.4 \\
2.3 \\
0.9\end{array}$ \\
\hline \multirow[t]{2}{*}{ Total-system costs ${ }^{d}$} & $19.3-19.8$ & $20.9-24.4$ & $23.8-29.7$ & $26.2-34.0$ & $32.1-38.2$ & 32.0 \\
\hline & \multicolumn{4}{|c|}{ Adjusted to 1988 dollars } & & \\
\hline $\begin{array}{l}\text { Development and evaluation } \\
\text { Transportation } \\
\text { Repository } \\
\text { MRS facility } \\
\text { Benefits }\end{array}$ & $\begin{array}{c}5.8 \\
4.8 \\
13.1 .13 .7 \\
\text { NA } \\
\text { NA }\end{array}$ & $\begin{array}{c}9.0 \\
3.0-4.6 \\
12.4-15.2 \\
\text { NA } \\
\text { NA }\end{array}$ & $\begin{array}{c}8.9 \\
3.8-5.8 \\
14.2-19.2 \\
\text { NA } \\
\text { NA }\end{array}$ & $\begin{array}{c}10.1-10.4 \\
1.9-2.5 \\
13.1-21.7 \\
3.1-3.2 \\
\text { NA }\end{array}$ & $\begin{array}{c}16.1-15.8 \\
2.1-2.4 \\
13.5-20.1 \\
2.9 \\
\text { NA }\end{array}$ & $\begin{array}{r}13.1 \\
2.3 \\
13.4 \\
2.3 \\
0.9\end{array}$ \\
\hline Total-system costs ${ }^{d}$ & $23.7-24.3$ & $24.7-28.8$ & $27.1-33.8$ & $28.9-37.4$ & $34.5-41.0$ & 32.0 \\
\hline
\end{tabular}

Data from Reference 10 for the 1983 fee-adequacy analysis and References 11, 12, 13, and 3 for the 1984, 1985, 1986, and 1987 TSLCC analyses, respectively.

The April 1986 analys is was the first TSLCC analysis to include an integral MRS facility; this faciljty is included in all subsequent estimates.

Not applicable.

The colums may not add to totals because the component-cost ranges reflect specific cases.

Source estimates adjusted by applying the appropriate percent change in the GNP implicit price deflator: for 1987-1988, 4.2 percent; for 1986-1987, 3.0 percent; for 1985-1986, 2.6 percent; for 19841985, 3.3 percent; for 1983-1984, 3.8 percent; and for 1982-1983, 3.9 percent. Sources: National Income and Product Accounts, Table 8-1, March 1987 and April 1988. 


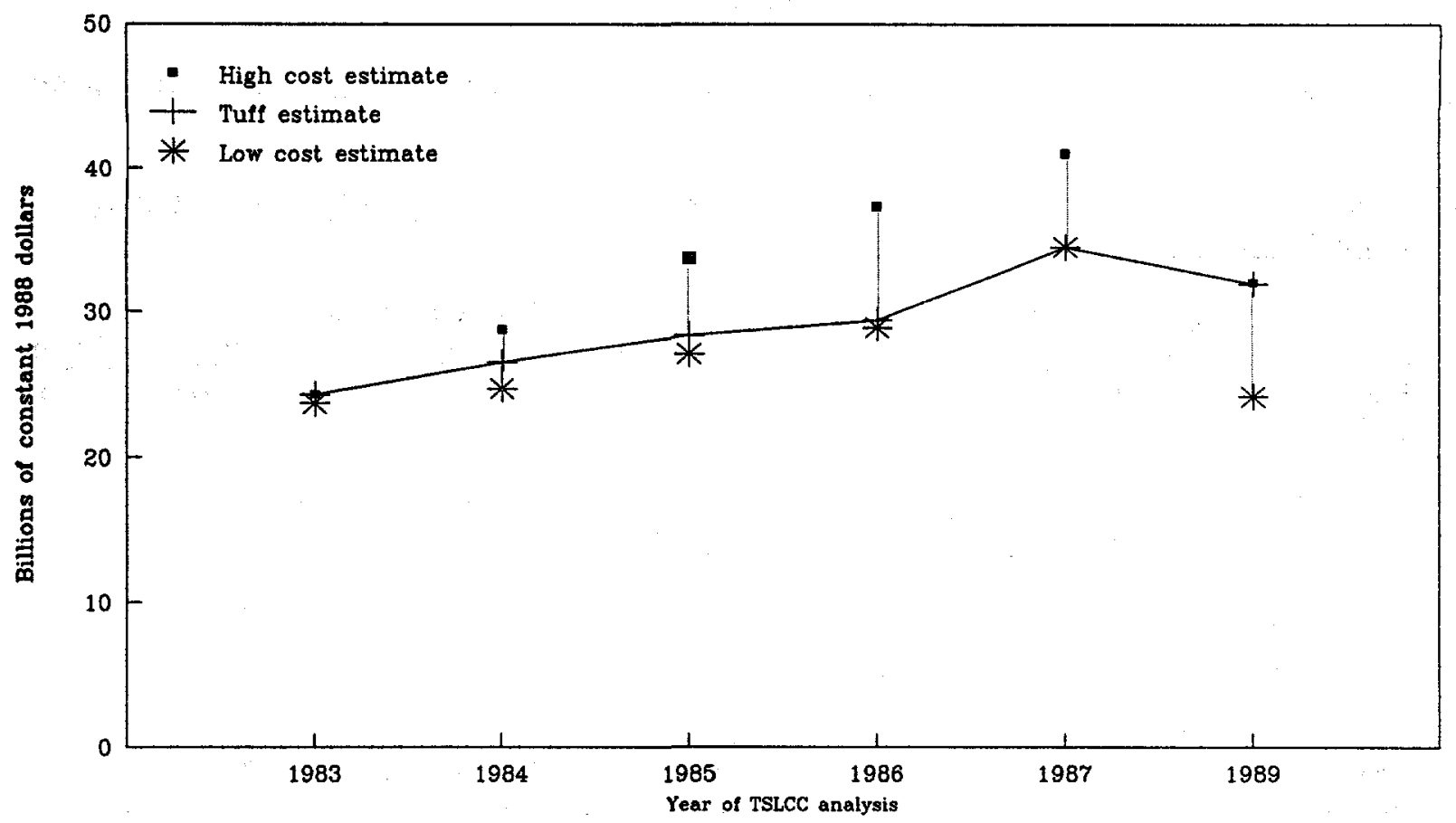

Figure 1-1. Evolution of total-system life-cycle cost ranges for cases with the reference TSLCC forecast. In the years 1983 through 1987 the TSLCC and fee-adequacy reference cases were based on the EIA middle or upper reference case forecast, while the May 1989 estimate is based on the EIA no-new-orders. end-of-reactor-life forecast. The May 1989 estimate is for a tuff/generic rock combination, the other estimates are for a tuff/salt combination. The 1989 low cost estimate assumes a single repository. 
1. Nuclear Waste Policy Amendments Act of 1987, Pub1ic Law 100-203, December $22,1987,42$ USC 10101 et seq.

2. Roy F. Weston, Inc., Cost Estimating Methods for the 1988 Total-System Life-Cycle Cost Analysis, draft (to be pub1ished).

3. U.S. Department of Energy, Office of Civilian Radioactive Waste Management, Analysis of the Total-System Life-Cycle Cost for the Civilian Radioactive Waste Management Program, DOE/RW-0047, Washington, D.C., June 1987 .

4. U.S. Department of Energy, Draft 1988 Mission Plan Amendment, DOE/RW-0187, Washington, D.C., June 1988 .

5. U.S. Department of Energy, Office of Civilian Radioactive Waste Management, MRS System Study Summary Report (to be published).

6. U.S. Department of Energy, "Civilian Radioactive Waste Management: Calculating Nuclear Waste Fund Disposal Fees for Department of Energy Defense Program Waste," Federal Register, Vo1. 52, No. 161, August 20, 1987 .

7. U.S. Department of Energy, "Office of Civilian Radioactive Waste Management: Calculating Nuclear Waste Final Disposal Fees for DOE Defense Program Waste; Inquiry and Request for Public Comment," Federal Register, Vo1. 51, No. 231, December 2, 1986.

8. U.S. General Accounting office, Nuclear Waste--A Look at Current Use of Funds and Cost Estimates for the Future, Report to Congressional Requestors, GAO/RCED-87-121, Washington, D.C., 1987.

9. U.S. Department of Energy, Energy Information Administration, Wor.1d Nuclear Fuel Cycle Requirements--1988, DOE/EIA-0436(88), Washington, D.C., September 1988.

10. U.S. Department of Energy, Nuclear Waste Policy Act Project Office, Report on Financing the Disposal of Commercial Spent Nuclear Fuel and Processed High-Leve1 Radioactive Waste, DOE/5-0020/1, Washington, D.C., July 1983.

11. Roy F. Weston, Inc., Preliminary Analysis of the Total-System Life-Cycle Cost of the Commercial High-Level Radioactive Waste Disposal Program draft final report, prepared for the U.S. Department of Energy, Rockville, MD., Apri1 27, 1984.

12. U.S. Department of Energy, Office of Civilian Radioactive Waste Management, Analys is of the Total-system Life-Cycle Cost for the Civilian Radioactive Waste Management Program, DOE/RW-0024, Washington, D.C., Apri1 1985. 
13. U.S. Department of Energy, Office of Civilian Radioactive Waste Management, Analysis of the Total-System Life-Cycle Cost for the Civilian Radioactive Waste Management Program, DOE/RW-0047, Washington, D.C., April 1986. 
CASE STRUCTURE, ASSUMPTIONS, AND WASTE LOGISTICS

The cases included in the total-system life-cycle cost (TSLCC) analysis reflect the current plans of the Department of Energy (DOE) for the wastemanagement system being developed to meet the requirements of the Nuclear Waste Policy Amendments Act of $1987^{1}$ (the Amendments Act). They are based on the waste-management system outlined in the Draft 1988 Mission Plan Amendment. 2 The system consists of a repository in tuff at Yucca Mountain, Nevada, a monitored retrievable storage (MRS) facility, and a transportation system.

This chapter discusses the principal assumptions on which the analysis was based, including the expected quantities and characteristics of the wastes and the schedule for the start of waste acceptance at the DOE's wastemanagement facilities.

The final component of this chapter is the analysis of the waste logistics, which determines the yearly transfer of wastes from their points of origin or storage locations to their final destination at the repository(ies), including any intermediate transfers that may be required, such as those to the MRS facility. Therefore, the logistics analysis integrates all assumptions about waste generation, the annual waste-receipt capability, the maximum facility capacities, and routing priorities to define the life-cycle operation schedule for the entire system.

\subsection{CASES EXAMINED IN THE TSLCC ANALYSIS}

This TSLCC analysis examined five cases based on different assumptions about the inclusion of spent-fuel consolidation, the quantity of spent fuel to be discharged from commercial U.S. reactors, and the number of repositories. All of the cases include the elements of the waste-management system described in the Draft 1988 Mission P1an Amendment.

\subsubsection{Spent-fuel consolidation}

Spent-fuel consolidation is a process that involves dismant1ing spentfuel assemblies, removing the spent-fuel rods, and rearranging the rods into a much denser array, thus reducing the number of containers requiring disposal. An alternative would be to dispose of the spent-fuel assemblies asreceived, that is, without the dismantling step. This alternative, generally referred to as "intact-fuel disposal," decreases the amount of spent-fuel handling, but increases the number of waste containers requiring disposal. 
The previous TSLCC analyses have all been based on the assumption that the spent fuel would be consolidated. However, the DOE is currently reexamining the desirability of consolidation, and has determined that intact spent-fuel will be assumed for the development of the repository and waste package advanced conceptual designs. On the other hand, the DOE will continue to evaluate the desirability of consolidation while the advanced conceptual designs for the repository and the waste package are developed. Therefore, this TSLCC analysis has included both cases based on intact-fuel disposal and cases based on consolidated-fuel disposal.

In the cases where intact spent fuel is to be disposed of, the MRS facility was assumed to commence operations in the year 2000. No packaging functions are performed at this facility, and it is referred to as a "basic" MRS facility. In the cases where spent-fuel consolidation is included, it was assumed that the spent fuel to be disposed of at the Yucca Mountain repository would be consolidated at the MRS facility. Because of the complexity of the consolidation process, the construction schedule for such an MRS facility is longer than that for the basic MRS facility. Therefore, it was assumed that the MRS facility with consolidation would commence operations in 2003. Both of these assumed scenarios satisfy the conditions of the Amendments Act.

\subsubsection{Projections of spent-fuel discharges}

As a basis for planning, the DOE's Office of Civilian Radioactive Waste Management (OCRWM) has been using a range of forecasts ${ }^{3}$ prepared by the DOE's Energy Information Administration (EIA) of the rates at which spent fuel will be discharged from U.S. reactors through the year 2020. The EIA forecasts are generated by models that predict the amount of nuclear energy that will be supplied as well as the corresponding spent-fuel discharges. Using macroeconomic assumptions and data supplied by the nuclear utility industry, the models generate forecasts of the future development and operation of commercial reactors.

The EIA defines three cases that project the domestic nuclear-energy capacity from 1988 through the end of the projection period. The three cases reflect different assumptions about schedules for the construction of nuclear power plants, cancellations of nuclear power plants under construction or on order, and new orders for nuclear power plants. The no-new-orders case includes spent fuel discharge projections through the year 2037 and is based on the premise that no new nuclear power plants will be ordered and brought on-line in the projection period. The upper reference case and the lower reference case include spent-fuel-discharge projections through the year 2020; these cases are based on the premise that new nuclear plants will be ordered and constructed in the projection period.

In the Draft 1988 Mission Plan Amendment, the OCRWM announced that, instead of using a range of forecasts, it will use the no-new-orders case as the primary basis for planning. The no-new-orders case is essentially based on nuclear plants currently operating and under active construction; thus, it provides a reasonable basis for planning. The decision to use this case is 
based on recommendations by the General Accounting office 4 and on discussions with representatives of the utility industry. Therefore, four of the five TSLCC cases in this analysis are based on the no-new-orders case; the fifth TSLCC case is based on the upper reference case to assess the cost: impacts of larger spent-fuel quantities.

As already mentioned, the no-new-orders case represents nuclear plants that are current1y operating or under active construction. It assumes that there is no growth in the U.S. nuclear generating capacity over the projection period; a few additional reactors (currently in construction) are completed, but no orders for new nuclear plants are received. The no-new-orders case thus represents the minimum quantity of spent fuel, providing a conservative estimate of the total fees paid into the Nuclear Waste Fund.

Another element to consider in the TSLCC analysis is the timeframe of the forecasts. In the TSLCC analysis, the no-new-orders case was examined to the end of reactor life--that is, the analysis accounts for all of the spent fuel that is generated by the limited universe of reactors. The current analysis projects that the last discharge of spent fuel in the no-new-orders case will occur in the year 2037. This last discharge represents the "end of 1ife" for the U.S. commercial reactors currently operating and under construction. Therefore, this case is referred to as the "no-new-orders, end-of-reactorlife" case.

The upper reference case, which before 1986 was known as the "middle case," assumes that the commercial nuclear generating capacity will continue to grow, essentially doubling the current capacity by 2020 and reaching nearly 25 percent of the total electricity generated in the United States. As a:n? result of this growth, there is no "end" to the forecast. Therefore, a reasonable "cutoff" point for the upper reference case was picked. As a matter of analytical convention, the upper-reference forecast has typically been carried through the year 2020 .

The two nuclear-capacity forecasts ${ }^{5}$ used in the TSLCC analysis and the associated spent-fuel discharges are shown in Table 2-1. The no-new-orders case shows the nuclear capacity at about 100 gigawatts electrical in 1990; the capacity stays near this level through 2010 and declines thereafter as plants are removed from service, decreasing to only 51 net gigawatts electrical in 2020. This decrease is caused by the assumption that nuclear power plants will be retired 40 years after the issuance of their operating licenses. The upper reference case shows capacities slowly increasing to about 110 gigawatts electrical in 2005, at which point capacities begin to increase more rapidly. as new nuclear plants are brought on line; the capacity in 2020 is about 190 . gigawatts electrical. The total spent-fuel discharges are projected to bet:" about 86,800 metric tons of heavy metal (MTHM) for the no-new-orders, end-oflife forecast and about 96,800 MTHM for the upper reference forecast. Fig ures 2-1 and 2-2 show the annual and the cumulative spent-fuel discharges, respectively. 
Table 2-1. Projections of nuclear capacity and spent-fuel discharges (Thousands of metric tons of heavy metal)

\begin{tabular}{|c|c|c|c|c|c|c|}
\hline \multirow[b]{2}{*}{ Year } & \multirow{2}{*}{$\begin{array}{l}\text { No-new-order } \\
\text { Total net } \\
\text { capacityc } \\
\text { (gigawatts) }\end{array}$} & \multicolumn{2}{|c|}{$\begin{array}{l}\text { end-of-reactor-life case } \\
\text { Soent-fuel discharges }\end{array}$} & \multicolumn{3}{|c|}{ Upper reference case } \\
\hline & & $\begin{array}{l}\text { Spent-fu } \\
\text { Annual }\end{array}$ & $\begin{array}{l}\text { discharges } \\
\text { Cumulative }\end{array}$ & $\begin{array}{l}\text { Total net } \\
\text { capacityc } \\
\text { (gigawatts) }\end{array}$ & $\begin{array}{l}\text { Spent-fl } \\
\text { Annual }\end{array}$ & $\begin{array}{l}\text { discharge, } \\
\text { Cumulative }\end{array}$ \\
\hline $\begin{array}{l}1987 \\
1988 \\
1989 \\
1990 \\
1991 \\
1992 \\
1993 \\
1994 \\
1995 \\
1996 \\
1997 \\
1998 \\
1999 \\
2000 \\
2001 \\
2002 \\
2003 \\
2004 \\
2005 \\
2006 \\
2007 \\
2008 \\
2009 \\
2010 \\
2011 \\
2012 \\
2013 \\
2014 \\
2015 \\
2016 \\
2017 \\
2018 \\
2019 \\
2020 \\
2021 \\
2022 \\
2023 \\
2024 \\
2025 \\
2026 \\
2027 \\
2028 \\
2029 \\
2030 \\
2031 \\
2032 \\
2033 \\
2034 \\
2035 \\
2036 \\
2037\end{array}$ & $\begin{array}{r}94 \\
95 \\
97 \\
97 \\
102 \\
102 \\
102 \\
102 \\
102 \\
102 \\
103 \\
103 \\
103 \\
103 \\
103 \\
103 \\
103 \\
103 \\
103 \\
103 \\
102 \\
102 \\
99 \\
97 \\
93 \\
89 \\
80 \\
69 \\
66 \\
60 \\
56 \\
55 \\
55 \\
51\end{array}$ & $\begin{array}{l}2.0 \\
1.4 \\
2.0 \\
1.8 \\
2.1 \\
1.9 \\
1.8 \\
1.9 \\
1.9 \\
1.8 \\
2.0 \\
1.5 \\
2.2 \\
1.7 \\
2.0 \\
1.9 \\
2.0 \\
2.0 \\
1.9 \\
2.0 \\
1.9 \\
2.3 \\
2.2 \\
2.1 \\
2.1 \\
2.4 \\
2.5 \\
1.7 \\
1.6 \\
1.4 \\
1.4 \\
1.0 \\
1.1 \\
1.3 \\
1.5 \\
1.0 \\
1.2 \\
1.2 \\
0.9 \\
1.0 \\
0.3 \\
0.4 \\
0.1 \\
0.4 \\
0.0 \\
0.0 \\
0.0 \\
0.0 \\
0.0 \\
0.1\end{array}$ & $\begin{array}{l}15.9 \\
17.9 \\
19.3 \\
21.3 \\
23.1 \\
25.2 \\
27.1 \\
28.9 \\
30.8 \\
32.7 \\
34.5 \\
36.5 \\
38.0 \\
40.2 \\
41.9 \\
43.9 \\
45.8 \\
47.8 \\
49.8 \\
51.7 \\
53.7 \\
55.6 \\
57.9 \\
60.1 \\
62.2 \\
64.3 \\
66.7 \\
69.2 \\
70.9 \\
72.5 \\
73.9 \\
75.3 \\
76.3 \\
77.4 \\
78.7 \\
80.2 \\
81.2 \\
82.4 \\
83.6 \\
84.5 \\
85.5 \\
85.8 \\
86.2 \\
86.3 \\
86.7 \\
86.7 \\
86.7 \\
86.7 \\
86.7 \\
86.7 \\
86.8\end{array}$ & $\begin{array}{r}94 \\
95 \\
99 \\
103 \\
104 \\
104 \\
104 \\
104 \\
105 \\
107 \\
107 \\
107 \\
107 \\
107 \\
107 \\
106 \\
108 \\
108 \\
108 \\
114 \\
120 \\
126 \\
132 \\
138 \\
143 \\
149 \\
154 \\
160 \\
165 \\
170 \\
175 \\
180 \\
185 \\
189\end{array}$ & $\begin{array}{l}2.0 \\
1.4 \\
2.0 \\
1.9 \\
2.2 \\
1.9 \\
1.9 \\
2.0 \\
2.0 \\
1.9 \\
2.1 \\
1.6 \\
2.2 \\
1.9 \\
1.9 \\
2.0 \\
2.0 \\
2.1 \\
1.8 \\
2.2 \\
2.1 \\
2.6 \\
2.9 \\
2.8 \\
3.0 \\
3.5 \\
3.9 \\
3.0 \\
3.8 \\
3.2 \\
3.7 \\
3.6 \\
3.7\end{array}$ & $\begin{array}{l}15.9 \\
17.9 \\
19.3 \\
21.3 \\
23.2 \\
25.4 \\
27.3 \\
29.2 \\
31.2 \\
33.2 \\
35.1 \\
37.2 \\
38.8 \\
41.0 \\
42.9 \\
44.8 \\
46.8 \\
48.8 \\
50.9 \\
52.7 \\
54.9 \\
57.0 \\
59.6 \\
62.5 \\
65.3 \\
68.3 \\
71.8 \\
75.7 \\
78.7 \\
82.5 \\
85.8 \\
89.5 \\
93.1 \\
96.8\end{array}$ \\
\hline
\end{tabular}

aU.S. Department of Energy, Energy Information Administration, World Nuclear Fuel Cycle Requirements 1988, DOE/EIA-0436(88), 1988.

bspent-fuel discharge projections are based on an assumed 30-percent increase in fuel burnup by 2000 .

CSource: U.S. Department of Energy, Energy Information Administration, Commercial Nuclear Power: Prospects for the United States and the World, DOE/EIA-0436(88), 1988. 


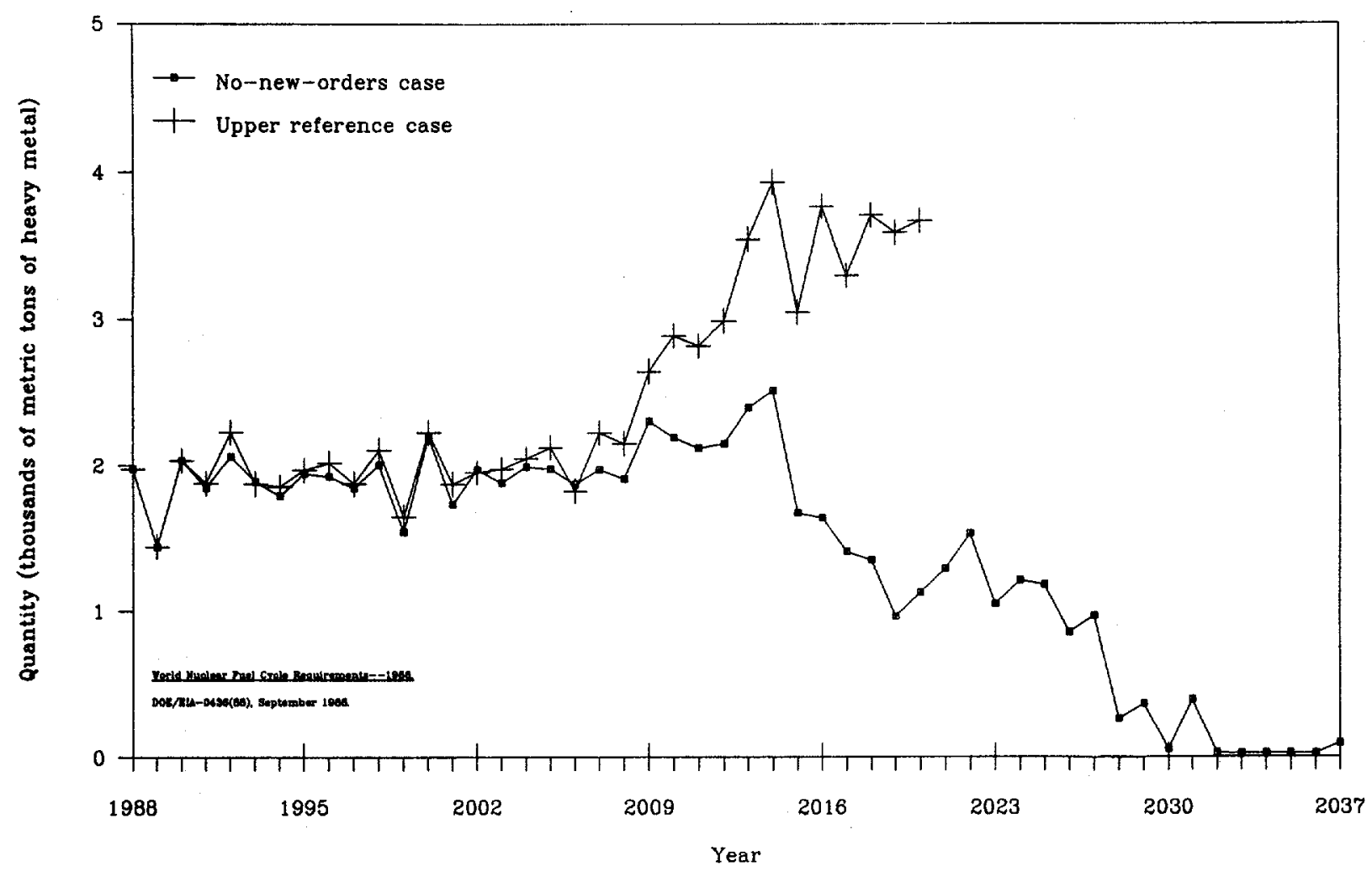

Figure 2-1. Annual spent-fuel generation.

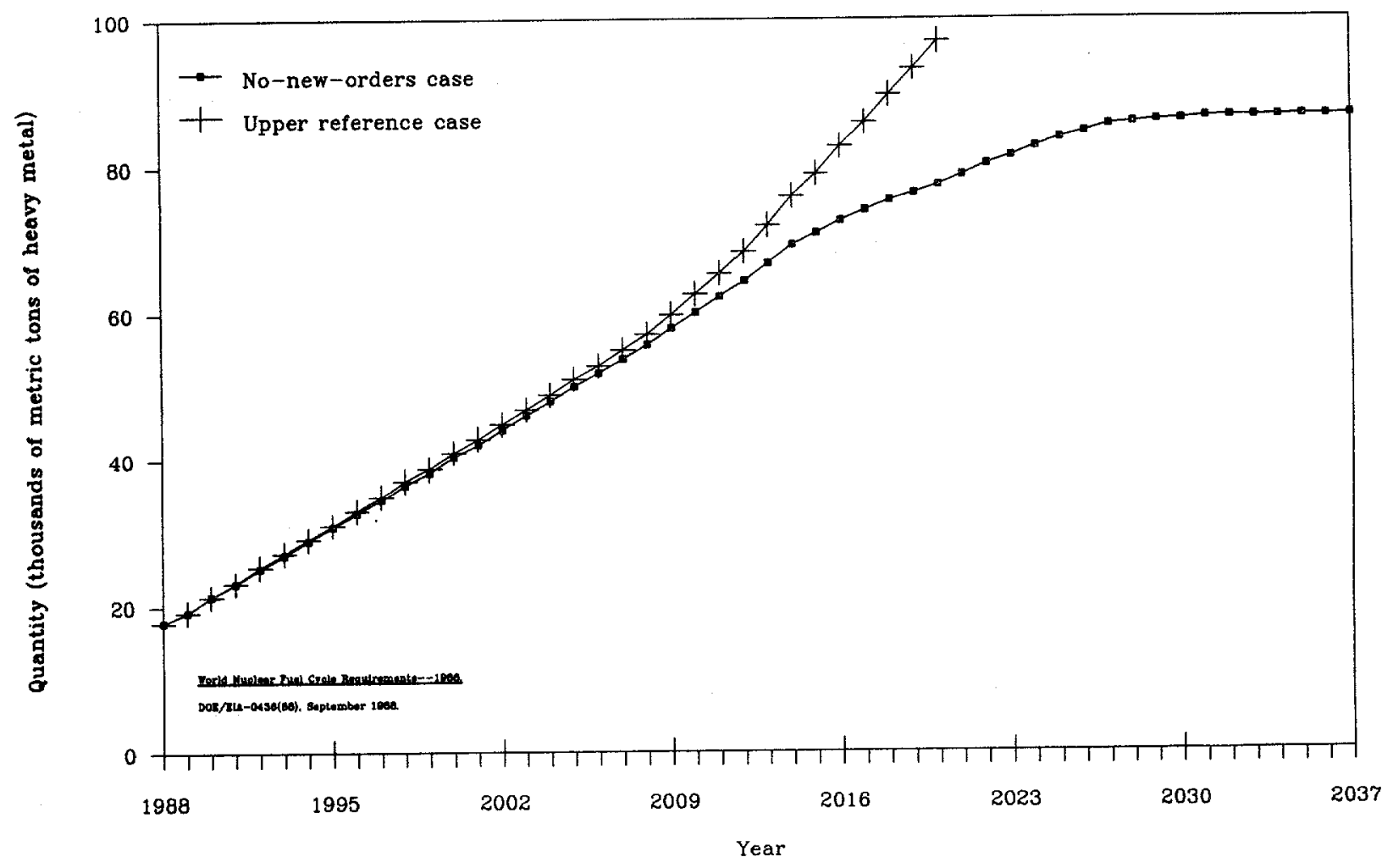

Figure 2-2. Cumulative spent-fuel generation. 


\subsubsection{Number of repositories}

The Amendments Act prohibits the DOE from conducting site-specific activities for the second repository unless the Congress specifically authorizes and appropriates funds for that purpose. The Amendments Act also requires the DOE to phase out all research programs designed to evaluate the suitability of crystalline rock as a potential host rock for a repository. However, though the Amendments Act directs the DOE to stop site-specific work for the second repository, it does not abolish the conditional statutory limit on the first repository specified by the Nuclear Waste Policy Act 6 : the NRC is directed to prohibit the emplacement in the first repository of more than 70,000 MTHM until the second repository starts operations. Furthermore, the Amendments Act requires the DOE to report to the President and the Congress between 2007 and 2010 on the need for a second repository. As a consequence, the wasteacceptance schedule included in the Draft 1988 Mission P1an Amendment ends when 70,000 MTHM has been accepted at the first repository. The acceptance schedule for waste received after the 70,000-MTHM 1 imit is reached will be developed after the DOE reports to the Congress on the need for a second repository.

The need for a second repository will depend on the quantity of waste* requiring disposal and the ultimate capacity of the first-repository site. The projections of spent-fuel quantities have been decreasing; the latest estimates used as the DOE's current basis for planning (the no-new-orders, end-of-reactor-1ife forecast) indicate that the total quantity of spent fuel discharged from U.S. reactors now operating or in active construction will be about 86,800 MTHM. The quantity of defense and commercial high-1evel waste that is currently expected to be available for disposal through the year 2030 is about 9500 MTHM. The available data on the Yucca Mountain site indicate that the site has the potential capacity to accept at least 70,000 MTHM of waste, but only after site characterization will it be possible to determine the total quantity of waste that could be accommodated at this site.

The total-system life-cycle cost analysis must, by definition, cover the total waste-management program over its entire life cycle. Thus, though the decision on the need for a second repository need not be made before the year 2010, the TSLCC analysis must consider the potential development and operation of a second repository. This TSLCC analysis therefore considered two configurations for the waste-management system: a one-repository configuration and a two-repository configuration. For the one-repository configuration, it was assumed that all of the waste (i.e., 96,300 MTHM) will be emplaced in the first repository. For the two-repository configuration it was assumed that 70,000 MTHM of waste will be emplaced in the first repository, with the remainder going to the second repository.

It is important to note that the above-mentioned two- and one-repository systems were postulated solely for the purposes of the TSLCC analysis to provide bounding estimates of costs. The DOE has not made a decision to develop

*The term "waste" is frequently used in this report to mean both spent fuel and high-level waste. 
a second repository, and no decision on this issue is needed for nearly 20 years (at least until the year 2007). Similarly, no decision has been made to emplace all wastes requiring geologic disposal in the first repository, and the DOE cannot make such a decision so long as the statutory limit of 70,000 MTHM for the first repository remains in effect. It is important to recognize, however, that the need to develop a second repository would have significant effects on the waste-management system, including operations at the first repository and waste transportation and logistics.

In the TSLCC analysis, it was assumed that the second repository would be centrally located to most of the U.S. commercial power reactors. Generic assumptions were made for the host rock of the second repository, because no specific host rock for the second repository is being considered at present. These necessary assumptions were made solely for the purposes of the TSLCC analysis to allow a set of reasonable costs to be included for a system that contains two repositories.

\section{1 .4 Case structure}

The description of the five TSLCC cases can be summarized as follows:

\begin{tabular}{|c|c|c|c|c|}
\hline Case & $\begin{array}{l}\text { Number } \\
\text { of } \\
\text { reposi- } \\
\text { tories } \\
\end{array}$ & $\begin{array}{l}\text { Repository } \\
\text { host rock }\end{array}$ & $\begin{array}{l}\text { Consol- } \\
\text { idation }\end{array}$ & Spent-fuel forecast \\
\hline 1 & 1 & Tuff & No & No-new-orders, end-of-reactor-life \\
\hline 2 & 1 & Tuff & Yes & No-new-orders, end-of-reactor-life \\
\hline 3 & 2 & Tuff/generic & No & No-new-orders, end-of-reactor-1ife \\
\hline 4 & 2 & Tuff/generic & Yes & No-new-orders, end-of-reactor-life \\
\hline 5 & 2 & Tuff/generic & Yes & Upper reference \\
\hline
\end{tabular}

A11 five cases included an MRS facility. In a11 cases the first repository was assumed to start operations in 2003; the second repository, when included, was assumed to start 20 to 25 years after the resumption of the second-repository program. Consolidation, if included in a case, was assumed to take place at the MRS facility and, in the two-repository cases, at the second repository as well. In the case of intact-fuel disposal, the basic MRS facility was assumed to start in the year 2000. When consolidation was included and performed at the MRS facility, the MRS facility was assumed to start in 2003. The rates at which the MRS facility and the repository reach their design annual waste-acceptance rates are the same in all five cases. Cases 3 and 4 are also covered in the MRS system studies report, 7 and, as discussed in Chapter 1 , the costs and assumptions for these cases are identical with those presented in that report.

The complete waste-acceptance schedule for the single-repository case with intact-fuel disposal is shown in Table 2-2. The complete waste-acceptance schedules for all five TSLCC cases are shown in Appendix A. These acceptance 
Table 2-2. Waste-acceptance schedule for the single-repository system: no-new-orders, end-of-reactor-life case, intact-fuel disposal

(Thousands of metric tons of heavy metal)

\begin{tabular}{|c|c|c|c|c|c|c|}
\hline \multirow[b]{2}{*}{ Year } & \multicolumn{2}{|c|}{ MRS facility } & \multicolumn{2}{|c|}{ Single repository } & \multicolumn{2}{|c|}{$\begin{array}{l}\text { Total-system acceptance } \\
\text { from waste generators }\end{array}$} \\
\hline & $\begin{array}{l}\text { Spent fuel } \\
\text { Received }\end{array}$ & $\begin{array}{l}\text { Stored } \\
\text { at MRS }\end{array}$ & $\begin{array}{l}\text { Spent fuel } \\
\text { from MRS }\end{array}$ & $\begin{array}{l}\text { High-level } \\
\text { waste }\end{array}$ & $\begin{array}{l}\text { Spent } \\
\text { fuel }\end{array}$ & $\begin{array}{l}\text { Spent fuel and } \\
\text { high-level waste }\end{array}$ \\
\hline 2000 & 1,200 & 1,200 & & & 1,200 & 1,200 \\
\hline 2001 & 1,200 & 2,400 & & & 1,200 & 1,200 \\
\hline 2002 & 2,000 & 4,400 & & & 2,000 & 2,000 \\
\hline 2003 & 2,000 & 6,000 & 400 & & 2,000 & 2,000 \\
\hline 2004 & 2,700 & 8,300 & 400 & & 2,700 & 2,700 \\
\hline 2005 & 3,000 & 10,900 & 400 & & 3,000 & 3,000 \\
\hline 2006 & 3,000 & 13,000 & 900 & & 3,000 & 3,000 \\
\hline 2007 & 3,000 & 14,200 & 1,800 & & 3,000 & 3,000 \\
\hline 2008 & 3,000 & 14,200 & 3,000 & 400 & 3,000 & 3,400 \\
\hline 2009 & 3,000 & 14,200 & 3,000 & 400 & 3,000 & 3,400 \\
\hline 2010 & 3,000 & 14,200 & 3,000 & 400 & 3,000 & 3,400 \\
\hline 2011 & 3,000 & 14,200 & 3,000 & 400 & 3,000 & 3,400 \\
\hline 2012 & 3,000 & 14,200 & 3,000 & 400 & 3,000 & 3,400 \\
\hline 2013 & 3,000 & 14,200 & 3,000 & 400 & 3,000 & 3,400 \\
\hline 2014 & 3,000 & 14,200 & 3,000 & 400 & 3,000 & 3,400 \\
\hline 2015 & 3,000 & 14,200 & 3,000 & 400 & 3,000 & 3,400 \\
\hline 2016 & 3,000 & 14,200 & 3,000 & 400 & 3,000 & 3,400 \\
\hline 2017 & 3,000 & 14,200 & 3,000 & 400 & 3,000 & 3,400 \\
\hline 2018 & 3,000 & 14,200 & 3,000 & 400 & 3,000 & 3,400 \\
\hline 2019 & 3,000 & 14,200 & 3,000 & 400 & 3,000 & 3,400 \\
\hline 2020 & 3,000 & 14,200 & 3,000 & 400 & 3,000 & 3,400 \\
\hline 2021 & 3,000 & 14,200 & 3,000 & 400 & 3,000 & 3,400 \\
\hline 2022 & 3,000 & 14,200 & 3,000 & 400 & 3,000 & 3,400 \\
\hline 2023 & 3,000 & 14,200 & 3,000 & 400 & 3,000 & 3,400 \\
\hline 2024 & 3,000 & 14,200 & 3,000 & 400 & 3,000 & 3,400 \\
\hline 2025 & 3,000 & 14,200 & 3,000 & 400 & 3,000 & 3,400 \\
\hline 2026 & 3,000 & 14,200 & 3,000 & 400 & 3,000 & 3,400 \\
\hline 2027 & 3,000 & 14,200 & 3,000 & 400 & 3,000 & 3,400 \\
\hline 2028 & 3,000 & 14,200 & 3,000 & 400 & 3,000 & 3,400 \\
\hline 2029 & 425 & 11,625 & 3,000 & 400 & 425 & 825 \\
\hline 2030 & 425 & 9,050 & 3,000 & 400 & 425 & 825 \\
\hline 2031 & 425 & 6,475 & 3,000 & 315 & 425 & 740 \\
\hline 2032 & 425 & 3,900 & 3,000 & & 425 & 425 \\
\hline 2033 & 425 & 1,325 & 3,000 & & 425 & 425 \\
\hline 2034 & 425 & 1,200 & 550 & & 425 & 425 \\
\hline 2035 & 425 & 1,075 & 550 & & 425 & 425 \\
\hline 2036 & 425 & 950 & 550 & & 425 & 425 \\
\hline 2037 & 425 & 825 & 550 & & 425 & 425 \\
\hline 2038 & 425 & 700 & 550 & & 425 & 425 \\
\hline 2039 & 425 & 575 & 550 & & 425 & 425 \\
\hline 2040 & 425 & 450 & 550 & & 425 & 425 \\
\hline 2041 & 425 & 325 & 550 & & 425 & 425 \\
\hline 2042 & 132 & 0 & 457 & & 132 & 132 \\
\hline TOTALS & 86,757 & & 86,757 & 9515 & 86,757 & 96,272 \\
\hline
\end{tabular}


schedules are based on the waste-acceptance schedule contained in the Draft 1988 Mission Plan Amendment. ${ }^{2}$ A discussion of some of the remaining key assumptions follows.

\subsection{KEY ASSUMPTIONS}

The TSLCC analysis is based on program plans outlined in the Draft 1988 Mission Plan Amendment. However, to support the comprehensive cost analysis, additional detailed assumptions were developed, using data from a wide variety of sources. These assumptions are intended to represent the waste-management system as currently envisioned, both in terms of requirements and the functions of the system that will satisfy those requirements. However, the assumptions contained in the TSLCC must not be interpreted as DOE policy or design decisions; the waste-management system is still evolving, and the exact configuration of the system is yet to be developed. In essence, the TSLCC analysis provides a "snapshot" of the program as it progresses over time. Therefore, the assumptions made here may need to be revised in future TSLCC analyses.

The current set of key assumptions is tabulated in Table 2-3, with a more comprehensive 1 ist of assumptions presented in Appendix B.

\subsection{WASTE LOGISTICS}

As discussed at the beginning of this chapter, the logistics analysis integrates all the assumptions about waste generation as well as the annual and total facility-receipt capabilities to define the flows of waste between the various facilities in the system. By so doing, the logistics analysis determines the number of years of operation for each of the facilities and is the first step in a cost analysis.

The overall waste-acceptance strategy assumed for the TSLCC analysis specifies that the basis for establishing acceptance priorities for spent fuel was the age of the spent fue1. In addition, the TSLCC analysis assumed that the spent-fuel delivery schedule was based on accepting the oldest fuel first. However, the actual delivery schedule used in the waste-management system will be established by the process outlined in the Annual Capacity Report 8 which is published annually.

The priority for shipping defense high-level waste was assumed to be oldest canister first, as in the oldest-fuel-first priority for spent fuel.

After the August 1987 Federal Register notice ${ }^{9}$, the civilian and defense high-level wastes were assumed to be accepted proportionally at the two repositories in the two-repository cases. That is, equal proportions of civilian waste (spent fuel and high-level waste from West Valley) and defense-high level waste will be accepted at the two repositories. For example, in the no-new-orders, end-of-reactor-life case, the first repository accepts 73 percent of the total defense high-level waste and 73 percent of the combined spent fuel and West Valley waste. (A11 of the West Valley waste was assumed to be accepted at the first repository.) 
Table 2-3. Current TSLCC assumptions about the waste and the components of the waste-management system

\section{ASSUMPTIONS ABOUT THE WASTE}

\section{A. Waste types}

1. Spent fuel from commercial 1ight-water nuclear reactors is the dominant waste form.

2. Existing commercial high-level waste (from the West Valley Demonstration Project) was assumed to be accepted for disposal after it has been solidified to borosilicate glass. No new commercial high-level waste was assumed to require disposal.

3. Defense high-level waste requiring deep geologic disposal will be accepted by the repository after solidification.

\section{B. Waste quantities}

1. The cumulative commercial-spent-fuel discharges were assumed to be--

a. For the no-new-orders, end-of-reactor-1ife case: about 86,800 MTHM through the year 2037.

b. For the upper reference case: about 96,800 MTHM through the year 2020.

2. It was assumed that a total of 17,750 canisters (about 8875 MTHM) of solidified defense high-level waste will be available for geologic disposal through the year 2030.

3. Approximately 640 MTHM equivalent of commercial high-level waste from the West Valley Demonstration Project will be accepted at the repository. It was assumed that no additional commercial spent fuel will be reprocessed, but the system will be capable of accommodating additional solidified high-level waste from commercial reprocessing should commercial reprocessing in the United States begin again.

\section{Waste age}

It was assumed that spent fuel will be at least 5 years of age (out of the reactor) before it is accepted by the DOE. 
Table 2-3. Current TSLCC assumptions about the waste and the components of the waste-management system (continued)

\section{ASSUMPTIONS ABOUT TRANSPORTATION}

\section{A. Waste acceptance}

Spent fuel was assumed to be accepted in order of age (i.e., oldest fuel first). The fuel was assumed to be accepted in full transportation-cask loads.

\section{B. Transportation modes}

1. All reactors that can at present ship by rail were assumed to do so.

2. Shipments from any projected "generic reactors" (reactors that are ordered in the future in EIA nuclear growth scenarios) were assumed to be made by rail.

3. Shipments from the MRS facility were assumed to be made by rail.

4. Shipments of defense high-level waste (DHLW) were assumed to be made by rail.

\section{Transportation-cask capacities}

1. Spent Fue1

a. Truck: 3 PWR or 7 BWR assemblies ${ }^{a}$

b. Rail, from reactors: 21 PWR or 48 BWR assemblies

c. Rail, from MRS facility:

Intact

Intact-fuel disposa1 34 PWR/80 BWR

Consolidated-fue1 disposal

Consolidated

Not applicable

28 PWR/61 BWR

Hardware ${ }^{b}$

Not applicable

56 PWR $/ 140$ BWR

4 canisters

d. Rail, from DHLW sites: five canisters

\section{ASSUMPTIONS ABOUT THE MRS FACILITY}

\section{A. Waste-acceptance rate}

The assumed steady-state waste-acceptance rate at the MRS facility may vary with system requirements, but is currently expected to be approximately 3000 MTHM of spent fuel per year. 
Table 2-3. Current TSLCC assumptions about the waste and the components of the waste-management system (continued)

\section{ASSUMPTIONS ABOUT THE MRS FACILITY (CONTINUED)}

\section{B. MRS startup dates}

In the intact-fuel disposal cases, the basic MRS facility was assumed to start in the year 2000. In the cases with consolidation, the MRS facility was assumed to start in the year 2003. In both cases, the MRS facility achieves its full waste-acceptance rate of 3000 MTHM in 6 years.

\section{MRS storage concept and capacity}

1. The MRS facility was assumed to use concrete-cask storage.

2. The MRS inventory varies from case to case, depending on the system logistics, but in no case does the MRS facility store more than 15,000 MTHM.

\section{MRS functions}

In the intact-fuel disposal cases, the MRS facility was assumed to be a "basic" facility. In these cases, the MRS facility receives spent fuel from the reactors, stores it, and ships it to the repository. In the cases with consolidation, the MRS facility receives spent fuel, consolidates approximately 95 percent of the fuel, places all fuel and hardware into canisters, stores the canisters as necessary, and ships the canisters to the repository.

\section{ASSUMPTIONS ABOUT THE REPOSITORIES}

\section{A. Number of repositories}

The TSLCC analysis included two cases with a single repository and three cases with two repositories.

\section{B. Repository startup dates}

1. The first repository was assumed to start in 2003 .

2. The second repository was assumed to start 20 to 25 years after the resumption of the second-repository program.

\section{Waste-acceptance rate}

Both repositories were assumed to have a maximum annual acceptance of 3400 MTHM: 3000 MTHM of spent fuel and 400 MTHM of high-level waste. 
Table 2-3. Current TSLCC assumptions about the waste and the components of the waste-management system (continued)

IV. ASSUMPTIONS ABOUT THE REPOSITORIES (CONTINUED)

D. Waste-package capacity

1. Intact-fuel disposal

Waste form

First

repository

Second

repository

Intact spent-fuel assemblies

High-level-waste canisters

3 PWR and 4 BWR $^{\mathrm{C}}$

1

4 PWR and 9 BWR 1

2. Consolidated-fuel disposal

Waste form

Intact spent-fuel assemblies

4 PWR and 9 BWR

4 PWR and 9 BWR

Consolidated-fuel assemblies

8 PWR and 20 BWR

High-level-waste canisters

Hardware canisters ${ }^{b}$

1

12 PWR and $30 \mathrm{BWR}$

1

1

1

E. Number of sites characterized

1. Only the Yucca Mountain site was assumed to be characterized for the first repository.

2. Only one site was assumed to be characterized for the second repository in the two-repository cases.

F. Other design assumptions

The design includes provisions to maintain capability for waste retrieval for 50 years from the start of waste emplacement.

${ }^{\text {a }}$ PWR = pressurized-water reactor; $\mathrm{BWR}=$ boiling-water reactor.

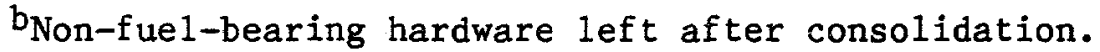

cIn the intact-fuel disposal cases, PWR and BWR assemblies are mixed in the disposal containers for the first repository; all other waste packages in all cases contain only one fuel type per package. Additional containers that contain either 4 PWR assemblies or 10 BWR assemblies are used as needed at the first repository in the intact-fuel disposal cases. 
The waste logistics were calculated in two steps: the first step involved the determination of the "aggregate logistics," which are primarily concerned with the receipt rates of the MRS facility, the first repository, and the second repository (if one is included). Appendix A shows the aggregate waste-acceptance schedules for the five ISLCC cases.

In developing the aggregate logistics, it was assumed that all spent fue 1 to be disposed in the first repository is shipped to the MRS facility from the reactors. After processing and storage as necessary at the MRS facility, the spent fuel is shipped to the first repository. Therefore, the MRS-shipment rate is identical with the spent-fuel acceptance rate at the first repository. High-level waste was assumed to be sent directly to the repository or repositories. With a single-repository, all of the spent fuel in the no-new-orders, end-of-reactor- 1 ife case $(86,800 \mathrm{MTHM})$ and all of the high-level waste (9500 MTHM) was assumed to be emplaced in the first repository. With two repositories the first repository accepts a combined total of 70,000 MTHM of spent fuel and high-level waste. The second repository accepts the remaining waste, approximately 26,300 MTHM in the no-new-orders, end-of-reactor-1ife case and 36,400 MTHM in the upper reference case. The second repository was assumed to accept all spent-fuel and high-level waste directly from the generators.

After the aggregate waste logistics were developed, the second step of the logistics analysis was begun. The second step, which is commonly referred to as the "reactor-specific logistics," is primarily concerned with the spent fuel and high-level waste shipped from reactors and defense-waste sites within the constraints of the aggregate logistics. In this analysis, the WASTES mode $1^{10}$ was used to determine the time and order of spent-fuel shipments from individual reactors. An additional model (DHLWLOG) was used to determine the time and the order of high-level-waste shipments. The WASTES model uses a reactor-specific data base and a number of assumptions to determine the shipping queue by reactor by year. Chapter 4 also includes a brief discussion of the logistics for transportation costing purposes.

The individual facility waste-acceptance ramp-up rates were identical for all five cases. The facility ramp-up rates are shown below in Table 2-4. The complete acceptance schedules are given in Appendix A.

Table 2-4. Facility ramp-up rates

(Metric tons of heavy metal per year)

\begin{tabular}{lccc}
\hline Start date & $\begin{array}{c}\text { MRS facility, } \\
2000 \text { or 2003 }\end{array}$ & $\begin{array}{c}\text { First repository } \\
2003\end{array}$ & Second repository \\
\hline Year 1 & 1,200 & 400 & \\
Year 2 & 1,200 & 400 & 900 \\
Year 3 & 2,000 & 400 & 1,800 \\
Year 4 & 2,000 & 900 & 3,000 \\
Year 5 & 2,700 & 1,800 & 3,000 \\
Year 6 & 3,000 & $3,000^{\mathrm{a}}$ & 3,000 \\
& & & 3,000
\end{tabular}

an these years, the repositories begin accepting 400 MTHM of high-level waste in addition to the 3000 MTHM of spent fuel. 
For both one- and two-repository no-new-orders, end-of-reactor-1ife cases, the limited supply of 5-year-old fuel limits the acceptance. When the annual acceptance rate of 3000 MTHM cannot be sustained because of the 5-year age constraint, the remaining fuel is accepted at a lower levelized rate that is subject to the 5-year constraint. The 5-year age constraint was not a factor in the cases based on the upper-reference-case forecast.

Once the total-system logistics were calculated, the results were used as input into the various methodologies and models that estimate the costs for the various components of the total system. 


\section{REFERENCES}

1. Nuclear Waste Policy Amendments Act of 1987, Public Law 100-203, December $22,1987,42$ USC 10101 et seq.

2. U.S. Department of Energy, Draft 1988 Mission Plan Amendment, DOE/RW-0187, Washington, D.C., June 1988.

3. U.S. Department of Energy, Energy Information Administration, Commercial Nuclear Power: Prospects for the United States and the World, DOE/EIA-0438(88), Washington, D.C., September 1988.

4. U.S. General Accounting office. Nuclear Waste--A Look at Current Use of Funds and Cost Estimates for the Future, Report to Congressiona1 Requesters, GAO/RCED-87-121, Washington, D.C., August 1987.

5. U.S. Department of Energy, Energy Information Administration, World Nuclear Fuel Cycle Requirements 1988 DOE/EIA 0436(88), Washington, D.C., September 1988.

6. Nuclear Waste Policy Act of 1982 (NWPA), Public Law 97-425, January 7, 1983,42 USC 10101 et seq.

7. U.S. Department of Energy, Office of Civilian Radioactive Waste Management, MRS System Study Summary Report (to be published).

8. U.S. Department of Energy, Office of Civilian Radioactive Waste Management, Annual Capacity Report, DOE/RW-0191, Washington, D.C., June 1988.

9. U.S. Department of Energy, "Office of Civilian Radioactive Waste Management: Calculating Nuclear Waste Final Disposal Fees for Department of Energy Defense Program Wastes," Federal Register, Vo1. 52, No. 161, August 20, 1987.

10. Pacific Northwest Laboratory, WASTES: Waste System Transportation and Economic Simulation-Release-24 User's Guide, PNL-5714-1, Richland, Washington, December 1988. 
The development and evaluation ( $D \& E$ ) cost category covers all the siting, preliminary design development, testing, regulatory, and institutional activities associated with the repositories, the facility for monitored retrievable storage (MRS), and the transportation system; it also includes the cost of administration by the Federal Government. Beginning with this year's TSLCC analysis, a new cost is added to the D\&E category--namely, the charges of the Nuclear Regulatory Commission (NRC) for licensing the waste-management facilities and certifying the transportation casks. By definition, the D\&E category encompasses all current program expenditures and all program expenditures for the next several years. In addition, some D\&E costs, such as the NRC charges and the costs of regulatory activities and administration by the Federal Government, will continue throughout the life cycle of the program.

As a result of the Nuclear Waste Policy Amendments Act of $1987^{1}$ (the Amendments Act), payments to States, Indian Tribes, and affected units of local government for the mitigation of socioeconomic impacts have been removed from D\&E costs in this year's TSLCC. This change reflects the TSLCC assumption that any State or Indian Tribe that hosts a repository or an MRS facility will be willing to enter into the benefits agreement provided for by the Amendments Act. On entering into such an agreement, the host State or Indian Tribe becomes eligible for annual benefits payments on a specified schedule but in return is required to waive its right to disapprove the siting of a repository or an MRS facility and its right to impact-mitigation assistance. Because of the importance and magnitude of the benefits payments, this cost component of the TSLCC is treated as a major separate cost category (see Chapter 7).

\subsection{METHOD AND ASSUMPTIONS}

The $D \& E$ costs are estimated only for the activities that are covered by the Nuclear Waste Fund and do not include costs incurred before the Nuclear Waste Policy Act of $1982^{2}$ was passed and the fund was established (before 1983). The D\&E activities are assigned to seven major categories: first repository, second repository, MRS facility, transportation, systems integration, NRC charges, and administration by the government. In view of the relative size of each of these categories, most of the emphasis is concentrated on the $D \& E$ costs for the first and the second repositories.

Throughout this analysis, the D\&E costs for fiscal years (FY) 1983 through 1988 were based on actual costs as reported by the DOE's Financial Information System; these costs are presented in Table 3-1. The primary source of data for the costs of program activities starting in FY 1989 and extending through FY 1994 was the information developed for the FY 1990 budget request submitted to the Congress in January 1989. The program's actual costs and the budget estimates were adjusted to allow the D\&E cost estimates to be expressed in constant 1988 dollars for consistency with the other TSLCC components. 
Table 3-1. Actual program costs

(Millions of dollars)

Fiscal

Actual cost in

year

year-of-expenditure dollars

Constant 1988 do1lars

\section{3}

1984

1985

1986

1987

1988

175

271

314

399

469

382
207

310

346

428

488

382

There are two basic sets of D\&E costs for the five TSLCC cases--those for a one-repository system and those for a two-repository system. The major difference between the two systems is in the $D \& E$ cost for the second repository: the costs for the two-repository system include the development of the second repository through the start of operations, whereas the costs for the onerepository system only include historical second-repository expenditures through FY 1988, the year in which the second-repository activities were terminated as directed by the Amendments Act. The other D\&E cost components are also affected by the number of repositories in the system: in comparison with the two-repository system, costs for transportation, NRC fees, and government administration are reduced in the one-repository system while first-repository D\&E costs are increased because of the additional site characterization that was assumed to be necessary if the Yucca Mountain site was to accept a11 of the waste.

The method of D\&E cost estimation is discussed below in two separate sections--Section 3.1.1 for the first and the second repository and Section 3.1.2 for all other D\&E cost categories. For a detailed description of the methods and assumptions used in the D\&E cost estimation, the reader is referred to the notebook on cost-estimating methods. 3

\subsubsection{D\&E costs for the first and the second repository}

The starting point for the estimation of D\&E costs for the first and the second repository was the schedule of major program milestones. This schedule is used to determine the activities that are necessary for completing the milestones. Then the costs of performing each of these activities are judgmentally estimated, using the cost-activity relationships of the current and near-term activities and independent cost estimates of activities, where available. 
The schedule of milestones used in the TSLCC analysis represents the program schedule as of March 1989. The schedule is consistent with the schedule given in the Draft 1988 Mission Plan Amendment, ${ }^{4}$ and, except for some of the near-term milestones, is the same as the schedule used in last year's TSLCC analysis. ${ }^{5}$ Table 3-2 summarizes the major first repository milestones upon which this cost estimation is based.

Table 3-2. Summary of assumptions about the first-repository schedule

\begin{tabular}{lc}
\hline \multicolumn{1}{c}{ Milestone } & Year \\
\hline Submit license application to the NRC & 1995 \\
$\begin{array}{l}\text { Receive construction authorization from } \\
\text { the NRC }\end{array}$ & 1998 \\
$\begin{array}{l}\text { Submit updated license application } \\
\text { to the NRC }\end{array}$ & 2000 \\
$\begin{array}{l}\text { NRC grants 1icense, repository } \\
\text { starts operations }\end{array}$ & 2003 \\
\hline
\end{tabular}

\subsubsection{First-repository D\&E costs}

In this year's TSLCC analysis, the D\&E costs for the first repository consist of the following elements: the tuff repository project at Yucca Mountain, technical support for the first repository, the repositorytechnology program (RTP), and reclamation at the eight potentially acceptable sites in basalt and salt, including the phase-out of site-specific activities at the Hanford and the Deaf Smith County sites. The D\&E costs for these repository elements for FY 1989 through FY 1994 are consistent with the budget estimates contained in the FY 1990 budget request submitted to the Congress. The process for estimating $D \& E$ costs for periods beyond those included in the budget (i.e., after FY 1994) is described below.

Technical support and RTP activities were assumed to continue supporting the first-repository project through the start of operations (2003) at a constant leve1. Close-out and reclamation activities at the nonselected sites were assumed to be completed by FY 1992.

The estimation of postbudget $D \& E$ costs for the tuff repository project was based on the repository work-breakdown structure (WBS) ${ }^{6}$ that has been used in previous TSLCC analyses. Also used again in this year's analysis was the phase classification by WBS category that relates the work activities to specific milestones. A detailed explanation of this WBS phase classification is presented in the notebook on cost-estimating methods. 3 
To estimate the postbudget $D \& E$ costs for the tuff repository project, the average monthily spending rates for each WBS activity phase were determined by using the average monthly rate of expenditure for 1994, the last year for which budget data were available. Next, factors for the monthly spending level for selected activities in the various WBS phases were applied to this rate to determine the new monthly rate for the selected activities. Finally, monthly costs were summed up for the various activities to arrive at a yearly estimate of the first-repository $D \& E$ cost. The specific cost factors assumed for the first repository are also given in the notebook on cost-estimating methods. ${ }^{3}$

For the one-repository cases, the analysis included site-characterization activities at Yucca Mountain beyond those currently planned. It assumed that the additional site characterization will take place over a 3-year period beginning in 2003 after the repository construction is completed. It further assumed that, at this point in time, a significant amount of underground drifting and accumulation of test data from the original site-characterization area will have been completed so that a limited number of additional activities would be required. The costs for these activities were judgmentally derived from the 1989-1995 costs for site-characterization activities that are currently planned. For the two-repository cases, these additional site-characterization costs were not included because it was assumed that the area currently being characterized would be able to accommodate 70,000 MTHM of waste (i.e., the contents of the first repository assumed for this analysis).

\subsubsection{Second-repository D\&E costs}

In this year's TSLCC analysis, the method for estimating D\&E costs for the second repository differs from the methods used in preceding analyses, the difference being attributable to the different status of the second repository. Site-specific activities for the second repository have been prohibited by the Amendments Act unless they are specifically authorized by the Congress. The DOE is to report to the Congress between 2007 and 2010 on the need for a second repository. Thus, there is no formal schedule for the second repository, and the cost estimates are based on simplified assumptions about the potential schedule. In all of the cases examined in the TSLCC analysis, it was assumed that the D\&E costs for the second repository cease after FY 1988, in accordance with the requirements of the Amendments Act. For the TSLCC cases that include a second repository, it was assumed that the second-repository program is resumed after the DOE reports to the Congress in the 2007-2010 timeframe and after the Congress authorizes the DOE to proceed with the development of the second repository. It was further assumed that once a candidate site was selected, the second repository would follow a development process that is similar to that of the first repository, with a similar amount of time allotted for the completion of each major milestone. It was also assumed that only one site will be selected for site characterization for the second repository. 
For the purposes of the TSLCC analysis, the entire D\&E process for the second repository was assumed to take 20 to 25 years from the time the program is resumed. The development process was divided into two phases: the selection of a single site for characterization and the remaining activities necessary for the start of operations. The estimation of costs for the first phase was based on the costs incurred in the earlier site-screening process for the second repository and the costs projected in the 1987 TSLCC analysis for the activities leading to the President's approval of sites for characterization for the second repository. For the second phase, the costs were derived from the first-repository D\&E costs on an annual basis. In other words, the second-repository $D \& E$ costs for the period after which a single site is selected for site characterization were assumed to be the same as the first-repository D\&E costs for 1988 to 2003, except that cost savings were assumed for selected activities to account for the economies to be realized from the experience of the first repository. The notebook on cost-estimating methods ${ }^{3}$ explains this in more detail.

\subsubsection{Other D\&E cost categories}

For D\&E cost categories other than the first and the second repository, the estimation procedure was much less rigorous. The methods and the key assumptions used for each are summarized here, while details are given in the notebook. ${ }^{3}$

The six-category transportation WBS currently in place was used to develop the transportation D\&E costs. These categories are--

1. Cask-system acquisition

2. Institutional

3. Systems analysis

4. Support systems

5. Program management

6. Operations

This WBS breakdown differs slightly from the five-category WBS breakdown used in last year's TSLCC analysis: one of last year's WBS elements is divided into two WBS elements this year.

To derive the costs for each transportation WBS element, the FY 1990 budget request submitted to the Congress was used for estimating program costs from FY 1989 to FY 1994. For FY 1995 and beyond, extrapolations were made for each WBS element to preserve the spending trends depicted in last year's TSLCC analysis. This was done by applying factors to maintain the spending ratio at comparable points in time to the new cost data and the new schedule. The notebook on cost-estimating methods ${ }^{3}$ outlines this process in more detail. As in last year's analysis, transportation $D \& E$ activities were assumed to continue through the start of the second repository in the two-repository cases or through the same year in the one-repository cases, but at a substantially reduced level since many of these long-term D\&E activities related to the second repository are not needed. In the two-repository system, the additional transportation D\&E activities are primarily for 
continuing to fund institutional-related activities and for refining the development of transportation operations once the repository site is known.

As explained in the Draft 1988 Mission Plan Amendment, 4 the location of the MRS facility is not known at present, and its functions are being reevaluated by the DOE. The costs for MRS development are based on the FY 1990 Congressional budget request, which shows that, after the MRS Review Commission submits its report to the Congress in November 1989, the DOE starts MRS siting activities that culminate in the selection of an MRS site by 1995, the year in which the repository license application is scheduled for submittal to the NRC. Beyond the FY 1994 budget estimate, the cost estimates from the 1987 Proposal to Congress ${ }^{7}$ were used for the time period corresponding to preparing the MRS license application through start of MRS operations since the costs from this source already assumed the selection of a site. MRS D\&E costs vary slightly by type of MRS facility (i.e., a basic MRS facility versus an MRS facility that consolidates and loads into canisters) because of different cost estimates for conceptual design activities that were used from the MRS system studies.8 If an MRS site is found through the office of the Nuclear Waste Negotiator (see Chapter 6), the siting process assumed in the TSLCC analysis would be invalidated and the cost estimates would need to be reviewed.

The D\&E costs for systems integration cover the systems-analysis activities needed to integrate the entire system and engineering-development activities, such as demonstrations of spent-fuel consolidation. Estimated costs through FY 1994 were based on the FY 1990 Congressional budget request. For costs beyond 1994, the estimates were extrapolated by applying percentage factors to the FY 1994 estimates. System-analysis activities were assumed to continue through the start of the first repository, while engineering development was assumed to end in FY 1994.

The new D\&E category in this year's TSLCC analysis covers charges by the NRC for costs incurred in the OCRWM program. The NRC activities in the program extend from the certification of transportation casks to the license amendment needed to terminate the repository license after permanent closure. The D\&E estimates of the NRC charges for the first repository, the MRS facility, and transportation for FY 1989 and FY 1990 were based on the FY 1990 Congressional budget estimates. After FY 1990, the Congressional budget request states that NRC fees will continue to be financed from the Nuclear Waste Fund, but this will be done directly as part of the NRC budget process, independent of the OCRWM budget. For FY 1991 and FY 1992, the estimates in the FY 1990 Internal Review Budget were assumed. The FY 1992 level of payments was assumed to be maintained through the start of repository operations in 2003. After the start of operations, annual charges of $\$ 3$ million were assumed for each facility through the last year of waste emplacement in the case of the repository or the last year of waste shipment in the case of the MRS facility. Thereafter, the NRC charges were assumed to be $\$ 1$ million annually until the last year of MRS decommissioning or the last year of repository closure and decommissioning. For the development phase of the second repository, NRC activities were assumed to have the same duration as those for the first repository (i.e., 15 years). The annual NRC charges during the preoperational period for the second repository were assumed to be 
half of the FY 1991 combined charges for the first repository, the MRS facility, and transportation. After the start of operations, the annual charges were assumed to be the same as those for the first repository.

The final $D \& E$ cost category, administration by the Federal Government, includes the administrative costs incurred by both DOE headquarters and DOE operations offices, the services performed by the headquarters technical support contractor, the operation of some test facilities, the management of the Nuclear Waste Fund, and systems-support studies. The budget estimates for "program management and technical support" in the FY 1990 budget submittal to the Congress were used as the basis for the costs of program administration. by the government through FY 1994. Beyond 1994, these administrative costs were assumed to be a fixed percentage ( 10 percent) of all other D\&E costs until a defined minimum level is reached. This threshold was assumed to be $\$ 25$ million per year and continues, for purposes of the TSLCC analysis, until the end of the waste-emplacement period for both repositories. After this period, both repositories will be in the caretaker phase, during which administration costs were assumed to decrease to an annual rate of $\$ 15$ million and to continue through closure (backfil1) until both repositories are decommissioned. These assumptions are the same as those used in last year's TSLCC analysis.

\subsection{RESULTS}

Table 3-3 presents a summary of the D\&E costs by major component for the five TSLCC cases.

The total D\&E cost for the one-repository system is $\$ 9.7$ billion. This is apportioned as follows: first repository, 57 percent; second repository, 1 percent; government administration, 24 percent; transportation, 7 percent; systems integration, 2 percent; NRC charges, 6 percent; and MRS facility, 3 percent. For the two-repository system, the total D\&E cost of $\$ 13.1$ billion is apportioned as follows: first repository, 40 percent; second repository, 23 percent; government administration, 20 percent; transportation, 7 percent; systems integration, 2 percent; NRC charges, 6 percent; and MRS facility, 2 percent.

The difference of $\$ 3.4$ billion between the two systems is almost entirely due to the addition of second-repository activities in the two-repository system. The second-repository D\&E cost is estimated to be about $\$ 3.0$ billion. Transportation D\&E costs are $\$ 0.3$ billion higher in the tworepository system on account of the additional transportation operations that would be required by the addition of another site. Government administration costs are $\$ 0.3$ billion higher in the two-repository system because of the extension of the life cycle (2087 versus 2068 in the one-repository system). NRC fees increase by about $\$ 0.1$ billion for the additional facility in the two-repository system. This collective increase of $\$ 3.7$ billion for the two-repository system is partially offset by a $\$ 0.3$ billion reduction in first-repository D\&E costs. This savings is for the cost of sitecharacterization activities beyond those currently planned to provide emplacement capability for the first 70,000 MTHM of waste. It was assumed that in the two-repository scenario these costs would be avoided. 
Table 3-3. Summary of D\&E cost estimates (Millions of 1988 dollars)

\begin{tabular}{|c|c|c|c|c|c|}
\hline \multirow[b]{2}{*}{ Cost category } & \multicolumn{2}{|c|}{ Single repository } & \multicolumn{3}{|c|}{ Two repositories } \\
\hline & $\begin{array}{l}\text { Intact fuel } \\
\text { basic } \\
\text { MRS }\end{array}$ & $\begin{array}{c}\text { Consolidate } \\
\text { into canisters } \\
\text { at MRS }\end{array}$ & $\begin{array}{c}\text { Intact fuel } \\
\text { basic } \\
\text { MRS }\end{array}$ & $\begin{array}{l}\text { Consolidate } \\
\text { into canisters } \\
\text { at MRS }\end{array}$ & $\begin{array}{l}\text { Consol idate into } \\
\text { canisters at MRS, } \\
\text { upper reference }\end{array}$ \\
\hline First repository & 5497 & 5497 & 5,206 & 5,206 & 5,206 \\
\hline Second repository & 110 & 110 & 3,051 & 3,051 & 3,051 \\
\hline MRS facility & 292 & 311 & 292 & 311 & 311 \\
\hline Transportation & 663 & 663 & 976 & 976 & 976 \\
\hline Systems integration & 249 & 249 & 249 & 249 & 249 \\
\hline NRC fees & 570 & 572 & 718 & 720 & 724 \\
\hline Goverment administration & 2269 & 2269 & 2,563 & 2,563 & 2,583 \\
\hline Total D\&E costs & 9650 & 9671 & 13,055 & 13,076 & 13,100 \\
\hline
\end{tabular}

As the results in Table 3-3 indicate, D\&E costs are virtually independent of the quantity of fuel accepted for disposal. There is no significant D\&E cost difference between the cases based on the EIA's upper reference forecast and the no-new-orders, end-of-reactor-1ife case. Small differences in MRS D\&E costs, NRC fees, and government administration across MRS system configurations are caused by the different assumptions about MRS start up dates (2000 for a basic MRS facility and 2003 for an MRS facility that consolidates spent fuel into canisters) and slightly different cost estimates for MRS design activities by type of facility.

\subsection{COMPARISON WITH PREVIOUS COST ESTIMATES}

The D\&E costs for a two-repository system show a decrease of approximately 11 percent, or $\$ 1.6$ billion, from the comparable system in the 1987 TSLCC analysis. Table 3-4 compares these estimates by individual D\&E cost category, while Figure 3-1 shows the same comparison graphically. The costs for the first repository in Table 3-4 are further divided into site characterization/selection (defined as al1 project costs through submittal of the license application to NRC), subsequent D\&E activities through the start of operations (2003), technical support and the repository-technology program, and reclamation for the nonselected sites. The comparison shows that this year's $\$ 1.6$ billion decrease in the total D\&E cost is caused by a $\$ 5.6$ billion savings on account of the provisions of the Amendments Act and a $\$ 4.0$ billion increase caused by the addition of NRC charges and changes in data (including 2 years' worth of inflation by comparing 1986 dollars in the last TSLCC analysis to 1988 dollars in this year's analysis) and assumptions that are independent of the Amendments Act. The remainder of this section discusses the reasons for the changes in the D\&E costs for each cost component. 
Table 3-4. Comparison of D\&E costs to previous estimates (Millions of constant dollars)

Changes

Cost category

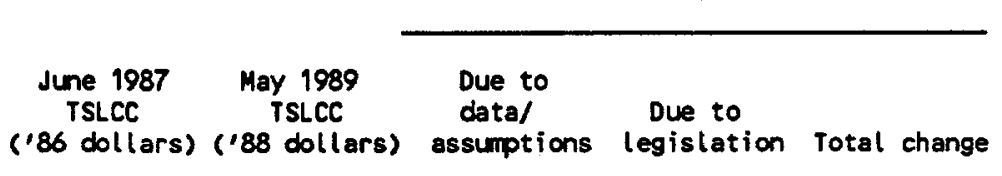

First repository

Site characterization/selection(1983-1/95)

Selected site (through 2003)

Technical support

closeout and reclamation

Total first repository

\begin{tabular}{rrrrr}
4,926 & 3,124 & +1209 & -3011 & -1802 \\
705 & 1,317 & +109 & +503 & +612 \\
- & 585 & +366 & +219 & +585 \\
& 180 & - & +180 & +180 \\
\hline 5,631 & & & - & - \\
4,711 & 5,206 & +1684 & -2109 & -425 \\
924 & 3,051 & +968 & -2628 & -1660 \\
156 & 976 & +254 & -202 & +52 \\
660 & 249 & +132 & -39 & +93 \\
125 & - & - & -660 & -660 \\
2,427 & 311 & +9 & +177 & +186 \\
$N A$ & 2,563 & +311 & -175 & +136 \\
& 720 & +688 & +32 & +720 \\
\hline 14,634 & 13,076 & +4046 & -5604 & -1558 \\
\hline
\end{tabular}

$a_{\text {Not applicable. }}$

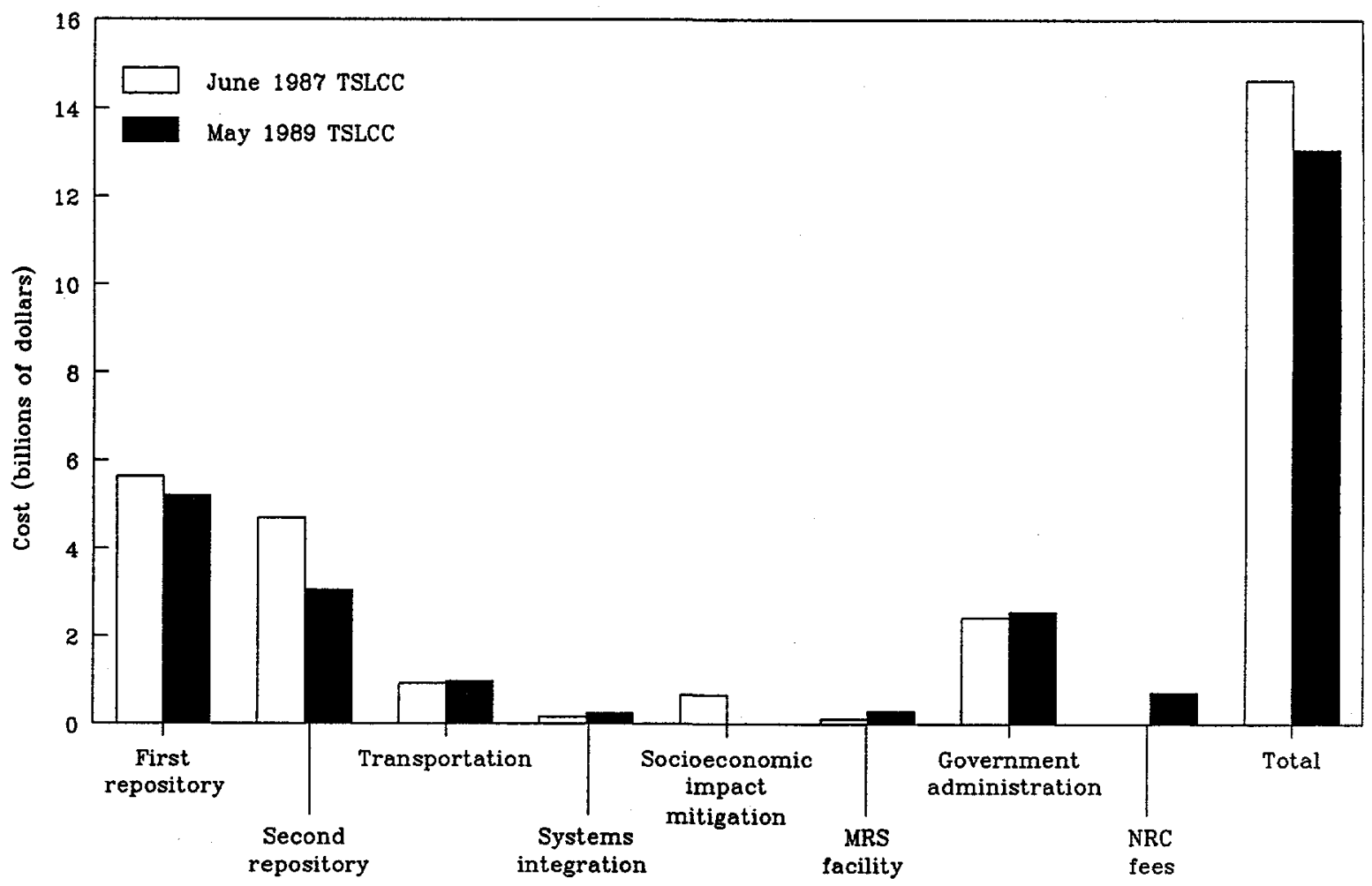

Figure 3-1. Comparison of D\&E costs to previous estimates. 


\subsubsection{First repository}

The first-repository D\&E cost category shows a net decrease of $\$ 0.4$ billion from last year, which was the result of a $\$ 1.7$ billion increase on account of new data and changes in assumptions and a $\$ 2.1$ billion decrease due to the provisions of the Amendments Act. Most (about $\$ 1.2$ billion) of the $\$ 1.7$ billion cost increase from the June 1987 TSLCC analysis was in the site characterization/selection component of the first repository D\&E cost. This cost increase was primarily caused by the increased scope of work planned for site characterization activities to be evaluated at the three candidates sites -- Yucca Mountain, Hanford, and Deaf Smith County, as reflected in the preliminary FY 1989 budget request for the repository program. This budget request developed in the summer of 1987, was the last budget formulated prior to the passage of the Amendments Act and included significant site characterization cost increases from the FY 1988 budget request submitted to Congress in January 1987 and which served as the basis of the June 1987 TSLCC D\&E costs. The Yucca Mountain portion of this site characterization cost increase from the previous TSLCC analysis is about $\$ 0.4$ billion. The 1987 TSLCC analysis was based on the work scope for a preliminary version of the site characterization plan (SCP) and did not reflect the content of either the consultation draft SCP ${ }^{9}$ issued in January 1988 or the SCP 10 issued in December 1988 . The other major contributor to the increase in first-repository costs was a change in accounting procedures, which transferred technical support from the "government-administration" category to the "first-repository" category.

The $\$ 2.1$ billion decrease due to the Amendments Act consisted of a $\$ 3.0$ billion decrease attributable to the elimination of two sites from the sitecharacterization program and increases in the other first-repository $D \& E$ costs, the most notable being the $\$ 0.5$ billion increase for activities occurring after the submittal of the 1icense application.

\subsubsection{Second repository}

In comparison with last year, this year's analysis shows a net decrease of $\$ 1.7$ billion in the D\&E costs for the second repository. This decrease is attributed to a $\$ 2.6$ billion decrease caused by assumptions prompted by the Amendments Act and an increase of more than $\$ 0.9$ billion caused by changes in data and methods. A major contributor to the $\$ 2.6$ billion decrease was the assumption that the siting of the second repository will follow the process specified in the Amendments Act for the first repository. This eliminated two sites from the characterization program, including the costs of characterizing for the second-repository a carryover site (a nonselected site) from the first repository. The increase of $\$ 0.9$ billion is caused by the higher base used for estimating second-repository costs-a base resulting from the increase in first-repository costs for D\&E activities because of the increased work scope. 


\subsubsection{Other D\&E categories}

The slight increase in the cost of transportation results from a $\$ 0.3$ billion increase caused by changes in data and methods and an offsetting $\$ 0.2$ billion decrease due to the Amendments Act. The $\$ 0.2$ billion decrease is predominantly a result of the decrease in the budget estimates available for the transportation system after the Amendments Act. The slight increase in costs for systems-integration activities is caused by the availability of new estimates for these activities. The elimination of $\$ 0.7$ billion for the mitigation of socioeconomic impacts is a result of the Amendments Act, as explained at the beginning of the chapter. The $\$ 0.2$ billion increase in MRS costs is primarily due to the Amendments Act requirement to restart (in the absence of a negotiated site) an MRS siting program. The $\$ 0.1$ billion increase in the costs of administration by the Federal Government is the combined effect of a $\$ 311$ million increase resulting from the new data available for the other D\&E categories and a $\$ 175$ million decrease resulting from the Amendments Act. Finally, the $\$ 0.7$ billion for NRC charges represents a new category in this year's analysis. 


\section{REFERENCES}

1. Nuclear Waste Policy Amendments Act of 1987, Public Law 100-203, December 22, 1987, 42 USC 10101 et seq.

2. Nuclear Waste Policy Act of 1982 (NWPA), Public Law 97-425, January 7, 1983, 42 USC 10101 et seq.

3. Roy F. Weston, Inc., Cost Estimating Methods for the 1988 Total-System Life-Cycle Cost Analysis, draft (to be published).

4. U.S. Department of Energy, Draft 1988 Mission Plan Amendment, DOE/RW-0187, Washington, D.C., June 1988 .

5. U.S. Department of Energy, Office of Civilian Radioactive Waste Management, Analysis of the Total System Life Cycle Cost for the Civilian Radioactive Waste Management Program, DOE/RW-0047, Washington, D.C., June 1987.

6. U.S. Department of Energy, Office of Civilian Radioactive Waste Management, Office of Geologic Repositories Work Breakdown Structure Dictionary-Development and Evaluation Phase, OGR/B-4, Washington, D.C., November 1984.

7. U.S. Department of Energy, Office of Civilian Radioactive Waste Management, Monitored Retrievable Storage Submission to Congress, DOE/RW-0035/1-Rev 1, Washington, D.C., March 1987.

8. U.S. Department of Energy, Office of Civilian Radioactive Waste Management, MRS System Study Summary Report, (to be published).

9. U.S. Department of Energy, Office of Civilian Radioactive Waste Management, Consultation Draft Site Characterization Plan Overview, DOE/RW-0161, Washington, D.C., January 1988.

10 U.S. Department of Energy, Office of Civilian Radioactive Waste Management, Site Characterization Plan, DOE/RW-0199, Washington, D.C., December 1988 . 
In accordance with the requirements of the Nuclear Waste Policy Act ${ }^{1}$ (the Act) as amended, the Department of Energy (DOE) is developing the transportation capability necessary to support the waste-management system. This chapter summarizes the methods and the key assumptions used to estimate the costs of waste transportation, presents the estimated costs, and compares the estimated costs with those of previous TSLCC analyses. A more detailed discussion of the methods used to estimate transportation costs is given in the notebook on TSLCC estimating methods. 2

The transportation-cost estimates were structured to reflect the most recent TSLCC definition of the transportation system. This definition is refined annually in order to incorporate the best available information on the waste-management system. However, though significant progress has been made in the definition and planning of the transportation system, there are areas where the scope has not been sufficiently defined for costing purposes (e.g., support facilities). Subsequent TSLCC analyses will incorporate these additional elements as they become sufficiently defined.

\subsection{GENERAL DESCRIPTION}

The transportation system as defined for TSLCC purposes will transport spent fuel from the sites of U.S. commercial reactors and defense high-level waste from defense sites; the system will also transport wastes from the MRS facility to the repository.*

The transportation-cost category covers the capital costs of purchasing the transportation casks (and conveyances) and the operating costs of accepting the waste and providing all the transportation services needed to support the DOE's waste-management system, including the construction, operation, and decommissioning of a cask-maintenance facility. The costs of developing the transportation system are not included in the transportationcost estimates; they are included in the development-and-evaluation (D\&E) cost category (see Chapter 3 ).

*Until the appropriate contractual agreements are completed, the current program plans do not include the transportation of civilian high-level waste from the West Valley Demonstration Project, and therefore the costs of transporting this waste are not included in the TSLCC analysis. 
The various types of waste may be transported by various modes, depending on where the shipment begins and the type of waste being transported. The following shipment types were assumed in the TSLCC analysis:

Point of origin

Reactor site

Defense-waste site MRS facility
Waste type

Spent fuel

Defense high-1evel waste

Intact spent fuel

Consolidated spent fuel

Non-fue1-bearing hardware
Shipment type

Truck (legal weight)

Rai1 (unrestricted)

Rail (unrestricted)

Rail (high capacity)

Rail (high capacity)

Rail (high capacity)

The shipment types 1isted above are for TSLCC purposes only. The DOE may elect to ship some wastes by overweight truck or by barge.

It was assumed that truck shipments would be used only for reactors that do not at present have the capability to ship by rail. These shipments would be made in legal-weight tractor trailers hauling 28-ton transportation casks. From-reactor shipments by rail and defense-waste shipments were assumed to use unrestricted interchange trains with 100-ton transportation casks, whereas rail shipments from the MRS facility were assumed to be made in high-capacity 150-ton casks. For TSLCC purposes only, all loaded rail shipments were assumed to be made in dedicated trains; this assumption does not reflect DOE policy; it was made to ensure conservative cost estimates for determining the adequacy of the fee for the Nuclear Waste Fund.

\subsection{METHOD OF ANALYSIS}

The method used to estimate transportation costs for this year's TSLCC analysis was very similar to that used in the previous analysis ${ }^{3}$. The most important change was the use of the Waste Package Logistics (WPLOG) mode 14 for the logistics of transportation from the MRS facility. The WPLOG model was used to quantify the shipments of waste from the MRS facility to the first repository. The WPLOG model was also used to account for the wastepreparation activities and the characteristics of the spent fuel at the MRS facility and the repository or repositories. The key advantages of the WPLOG model are that it integrates the cost estimates for the transportation system, the MRS facility, and the first repository and that it approximates the operational and cost impacts of the spent-fuel characteristics on the waste-management system. The WPLOG model is also discussed in Chapters 5 and 6 (repository and MRS cost estimates, respectively).

Another important change was the use of the WASTES mode ${ }^{5}$ for calculating the costs of "from-reactor" transportation. The June 1987 TSLCC analysis used the spent-fue1 logistics from the WASTES mode1, but calculated the transporta- 
tion costs separately. An additional important change involves the use of improved data to estimate security costs for truck shipments through urban areas. The assumption that dedicated trains would be used for loaded from-reactor shipments and defense-waste shipments is probably the most significant change in assumptions about transportation operations.

The most significant change in terms of the transportation costs, however, was the updating of a great number of transportation data elements. These data changes affected the transportation-cost estimates more than a11 of the above-mentioned method changes combined.

\subsubsection{Transportation logistics}

The TSLCC transportation-cost estimates began with the formulation of "aggregate facility logistics," which define how much spent fuel each DOE waste-management facility (MRS facility, first repository, and second repository) would accept and ship in a given year. The aggregate facility logistics that formed the basis of the TSLCC analysis were presented in Chapter 2.

The WASTES mode1 was then used to develop from-reactor logistics that showed how much fuel would be shipped from specific reactor sites each year to meet the specified aggregate logistics. The model used a reactor-specific data base that was based on World Nuclear Fuel Cycle Requirements 1988.6 The reactor-specific data base uses data collected by the Energy Information Administration (EIA) to (1) keep track of spent fuel discharged from existing reactors through December 31, 1987, and (2) project the future spent-fuel discharges of each reactor (existing and future) from January 1, 1988, through the year 2037 (2020 in the upper reference case). The WASTES model was then used to generate the schedule of reactor-specific spent-fuel shipments, assuming that the oldest spent fuel was picked up first (in integer cask loads). The result of the simulation with WASTES was a "shipment list" that designated when each spent-fuel assembly discharged between 1960 and 2020 was to be picked up and to which waste-management facility that assembly should go. This list is referred to as the "from-reactor logistics" because it accounts for all shipments from reactors to any number of DOE facilities. The from-reactor logistics were supplemented by WPLOG logistics that accounted for shipments from the MRS facility and by logistics that accounted for shipments of defense high-level waste.

The logistics for the defense high-level waste were calculated by the DHLWLOG model, which accounts for defense-waste shipments from three defensewaste facilities to a repository or repositories. For the TSLCC analysis, the defense waste was assumed to be shipped on the basis of "the oldest canister first."

These three sets (from-reactor, from-MRS, and from-defense) of logistics information constitute a complete set of "total-system logistics." Once the total-system logistics were available, the transportation costs could be calculated. The waste-management system logistics were discussed in greater detail in Chapter 2. 


\subsubsection{Approach to calculating transportation costs}

The transportation costs can be divided into three groups: (1) the costs of shipping and security, (2) the costs of purchasing and maintaining the transportation casks, and (3) other costs. The costs of shipping and security and the costs of cask purchase and maintenance were calculated separately for each mode of transportation. The "other costs" were calculated for the transportation system as a whole.

\subsubsection{Shipping and security}

Shipping-and-security costs account for carrier shipping charges, the inspection-and-acceptance charges incurred when the waste is picked up, the equipment-detention charges that are incurred while the waste is picked up, and the costs of providing physical protection (security). These costs were calculated as unit costs for transporting a given unit of waste between two points in the waste-management system. Basically, the unit cost is simply the shipping-and-security cost of a single shipment divided by the quantity of waste (e.g., assemblies) that can be transported in a single shipment. The various unit costs are then applied to the quantities of waste moving between the various points in the system to calculate the annual and the total costs of shipping and security. The shipping rates (rail and truck) in the TSLCC analysis may be conservative; the actual shipping rates will be negotiated between the DOE and the carriers.

\subsubsection{Cask purchase and maintenance}

The cask costs account for the costs of purchasing and maintaining the transportation casks. These costs were calculated by determining how many casks would be needed to transport a given quantity of waste in any given year. The cask requirements were calculated by determining the following for a given year's shipments: the total round-trip transit days, the total loading days, and the total unloading days. This "total cask-days required" quantity was divided by the assumed number of days that an average cask could be used to obtain the size of the required cask fleet. The required cask fleet was then compared with the existing cask fleet; if necessary, additional casks were assumed to be purchased to meet the demand. To account for the maintenance of the casks, an annual maintenance cost was assessed as a fixed cost for every cask in the fleet. Therefore, the cask-maintenance costs vary with the size of the fleet.

\subsubsection{Other costs}

In addition to the costs described above, the TSLCC estimates include the costs of a cask-maintenance facility and contingency costs. The caskmaintenance facility is intended to be used for routine servicing, preventive maintenance, performing requalification license compliance tests and inspections, minor repairs, and decontamination of the transportation casks

$$
4-4
$$


and their railcars or tractor trailers. It was assumed that the construction and the decommissioning of this facility will cost $\$ 50$ million and $\$ 5$ million, respectively. The fixed operating costs of the cask-maintenance facility were assumed to be $\$ 10$ million per year.

An across-the-board contingency factor of 20 percent was included in the estimates to help cover the cost uncertainties that are inherent in estimates for a conceptual system and to accommodate future refinements in the scope of the transportation system. As the system becomes better defined, the contingency factor will be modified as appropriate.

\subsubsection{Calculation of the principal charges for each mode of transportation}

This section briefly describes how the costs of shipping, security, cask purchase, and cask maintenance were calculated for transportation by truck and by rail.

\subsubsection{Transportation by truck}

The truck shipping rates used in the TSLCC analysis are an average of the tariffs charged by three different truck carriers. $7-9$ The tariffs are stated in dollars per hundred-weight (pounds) of cargo and vary with the distance, and they include the services of one driver. Costs for a second driver were added to enable the shipment to travel 24 hours a day.

Two different costs would be incurred when the waste is accepted at the reactor site. The first is a detention charge for idle equipment and for the personnel time incurred as the spent fuel is loaded onto the truck. The second is a charge for the acceptance inspection, which is made to verify the shipment contents and to ensure that the shipping cask and conveyance meet all applicable regulatory requirements.

The final component of the truck shipping-and-security cost is the security cost. The security costs include the costs of providing constant surveillance, a 2-hour call-in, and special equipment; these costs are taken from the cited tariffs and are applicable only to the loaded portion of the shipment. An additional security measure is provided in every urban area, where the shipment is accompanied by two separate escort vehicles with armed escorts. The urbanized areas are identified in the HIGHWAY 10 model.

The shipping-and-security costs were expressed as unit costs for each pathway and were then applied to all the annual truck shipments along each

specific pathway. To obtain the total cost of truck transportation, the costs of cask purchase and maintenance (see Section 4.2.2.2) were added to the shipping-and-security costs. 


\subsubsection{Transportation by rail}

Transportation by rail was assumed to be used to the extent practicable to minimize the total number of shipments. Therefore, rail transportation was assumed to be used for all shipments from the MRS facility, all shipments of defense high-level waste, and all shipments from reactors that are currently capable of shipping by rail. These assumptions do not preclude a later decision to use trucks or barges on any of these transportation pathways.

The rail shipping rates were also expressed in dollars per hundredweight. The analysis used a general-freight "class 9" rail rate to reflect recent directives from the Interstate Commerce Commission. This rate was approximated by scaling down the class 40 shipping rate from the report Truck and Rail Charges for Shipping Spent Fuel and Nuclear Waste. 11

The rail costs for spent-fuel shipments from reactor sites and defensewaste shipments also include an acceptance-inspection charge that is incurred while the waste is loaded. The purpose of the acceptance inspection is to verify the shipment contents and to ensure that the cask and the conveyance meet all app1icable regulatory requirements.

Security charges for rail transportation reflect the costs of supplying two armed escorts to provide 24-hour surveillance for each shipment, including the travel costs and wages for each escort. The escorts were assumed to be paid a fixed wage per day; the transit time (in days) for each shipment was assumed to depend on the rail routing distance and the speed of travel.

As in the truck-transportation calculation, the shipping-and-security charges for rail shipments were first calculated for each shipment pathway. These were then converted to unit charges and applied to the amount of waste transported along each pathway to obtain the annual cost.

An additional shipping surcharge was assessed on the following shipments assumed to be made in dedicated trains: shipments from the MRS facility (round trip), defense-waste shipments (round trip), and loaded shipments from reactor sites (one-way only). The surcharge cost was assessed as a charge in dollars per train-mile, and therefore, this cost was applied to discrete train shipments as opposed to a unit cost. Though assumed for this analysis, the DOE does not believe that dedicated trains are necessary for spent-fuel transportation.

Finally, the annual costs for each pathway were summed to calculate the total annua1 shipping-and-security costs for spent-fuel transportation by rail. The last component in the estimated rail-transportation cost was the cost of purchasing and maintaining the rail cask fleet. These costs were calculated as described in Section 4.2.2.2.

\subsection{RESULTS}

The summarized transportation-cost estimates for the five TSLCC cases are presented in Table 4-1. The costs are divided into three categories: shipments from reactor sites, shipments from the MRS facility, and shipments of defense waste. The from-reactor costs cover the costs of spent-fuel transportation to the MRS facility and to the second repository, if included. $4-6$ 
The from-MRS costs cover the costs of transporting spent fuel and non-fuel-bearing hardware (in the consolidation cases) from the MRS facility to the first repository. The defense-waste costs cover the costs for transporting defense high-level waste from the three defense-waste sites to the repository or repositories.

Table 4-1. Summary of transportation cost est imates (Millions of 1988 dollars)

\begin{tabular}{|c|c|c|c|c|c|}
\hline \multirow[b]{2}{*}{ Cost category } & \multicolumn{2}{|c|}{ single repository } & \multicolumn{3}{|c|}{ Two repositories } \\
\hline & $\begin{array}{c}\text { Intact fuel } \\
\text { basic } \\
\text { MRS }\end{array}$ & $\begin{array}{c}\text { Consol idate } \\
\text { into canisters } \\
\text { at MRS }\end{array}$ & $\begin{array}{l}\text { Intact fuel } \\
\text { besic } \\
\text { MRS }\end{array}$ & $\begin{array}{l}\text { Consol idate } \\
\text { into canisters } \\
\text { at MRS }\end{array}$ & $\begin{array}{l}\text { Consolidate into } \\
\text { canisters at MRS } \\
\text { upper reference }\end{array}$ \\
\hline & \multicolumn{5}{|c|}{ Spent-fuel transportation } \\
\hline From reactors & 925 & 954 & 901 & 905 & 967 \\
\hline From MRS facility & 810 & 834 & 577 & 570 & 574 \\
\hline Cask-maintenance facility & 529 & 499 & 484 & 454 & 476 \\
\hline \multirow[t]{2}{*}{ Total spent-fuel costs } & 2264 & 2287 & 1962 & 1929 & 2017 \\
\hline & \multicolumn{5}{|c|}{ DHLW transportation } \\
\hline Defense waste & 297 & 297 & 307 & 307 & 307 \\
\hline Cask-maintenance facility & 53 & 47 & 56 & 50 & 53 \\
\hline & - & - & - & - & - \\
\hline Total DHLH costs & 351 & 344 & 363 & 357 & 359 \\
\hline Total transportation costs ${ }^{a}$ & 2614 & 2634 & 2325 & 2287 & 2377 \\
\hline
\end{tabular}

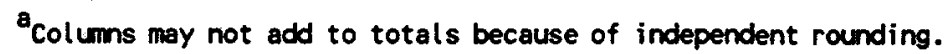

The most significant results of the analysis are as follows:

- The total transportation costs range from $\$ 2.3$ to $\$ 2.6$ billion and account for 6 to 11 percent of the total-system life-cycle costs.

- The transportation costs in the one-repository system are the highest because of the distances assumed in the TSLCC analysis; that is, it would be less costly to ship spent fuel from reactor sites to a centrally located second repository than to ship the spent fuel to a centrally located MRS facility and then to the Yucca Mountain repository in the western United States.

$$
4-7
$$


- The costs for defense-waste transportation range from $\$ 340$ to $\$ 360$ million and account for 13 to 16 percent of the total transportation costs.

- Transportation costs vary only slightly with the total quantity of waste. The extended period of operations in the no-new-orders, end-of-reactor-life case negates most of the cost impacts of transporting the additional 11,000 MTHM in the upper reference case.

The most important factors affecting transportation costs are the travel distance, cask capacity, and travel speed. Transportation costs increase with the distance traveled. Specifically, the shipping rates and special-equipment fees increase directly with distance. In addition, long distances lead to long in-transit times, which in turn lead to higher security costs and increases in the size of the cask fleet. At the same time, transportation costs decrease with increases in payload efficiency and travel speed. This decrease is attributable to the inverse relationship of capacity and speed to unit shipping rates, security costs, and cask-fleet size.

In this analysis, for a given waste quantity and distance, the shipment by rail of consolidated spent fuel (and the non-fuel-bearing hardware from consolidation) from the MRS facility was the most economical mode of transportation; rail shipment of unconsolidated spent fuel from the MRS facility was second, rail shipment of spent fuel from reactor sites was third, and truck shipment was the most expensive mode for spent-fuel transportation. Basically, this indicates that the payload differences in this analysis are more important than the assumed speed of trave1. That is, the high payload and the low speed of rail travel resulted in lower costs than the low payload and higher speed of truck transportation. The transportation of defense waste by rail is the most expensive mode of transportation (in dollars per MTHM-mile--that is, the cost to move 1 MTHM $1 \mathrm{mile}$ ) because the payload in MTHM equivalents is much lower than that of spent-fuel rail casks. The various cask payloads and travel speeds assumed in the analysis are given in Appendix B.

It is interesting to examine the transportation costs by component. of the cost components for waste transportation, shipping (shipping, surcharge, inspection, and detention) accounts for about 42 percent of the total, and security costs account for about 7 percent. Cask capital costs account for 13 percent of the total, maintenance costs add up to about 16 percent, and the cask-maintenance facility contributes 22 percent. Figure 4-1 shows how the transportation costs are distributed by component.

Another practical way of examining transportation costs is by mode of travel. Figure 4-2 shows how the relative magnitude of the transportation costs vary by travel mode. In the intact-fuel single-repository case, the "from-MRS" costs are high because all spent fuel passes through the MRS facility and because the MRS facility is shipping intact-fuel assemblies to the repository. Figure 4-3 shows the two-repository case with consolidation where the from-reactor costs are relatively high. This is because some of the fuel is now being moved from reactors to the second repository and the absolute costs of the from-MRS transportation have declined because of a lower flowthrough and the improved payload of consolidated spent fuel. 


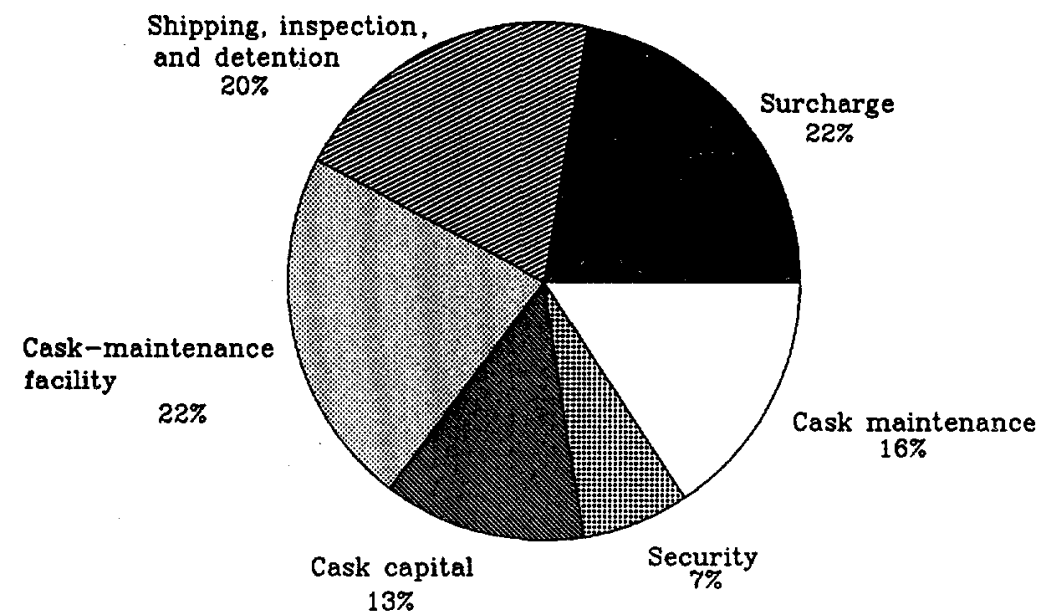

Figure 4-1. Total transportation costs by major component

for a one-repository system with intact-fuel disposal.

\subsection{COMPARISON WITH PREVIOUS COST ESTIMATES}

The TSLCC analysis tracks changes in the program cost and refinements in the estimating methods from year to year. This year's analysis reflects the changes in the program caused by the Amendments Act, and the analysis incorporates a number of refinements in the method of costing. Table 4-2 and Figure 4-4 illustrate the program impacts of the Amendments Act as well as the impacts caused by method changes. The 1987 case in Table 4-2 is taken directly from the 1987 TSLCC report ${ }^{3}$ and is based on the EIA's upperreference-case forecast with the first repository in tuff, the second repository in salt, and an MRS facility. The comparable case in this year's analysis is based on the no-new-orders, end-of-reactor-life case with a first repository in tuff, a generic second repository, and an MRS facility that consolidates spent fuel into canisters.

The transportation cost-estimating method was not significantly changed for this year's TSLCC analysis. However, there were significant changes in the input data and the assumptions used for the transportation-cost estimates, and these changes had some major impacts on the estimated costs, though the impacts were largely offsetting. Overal1, the changes in data and methods are 


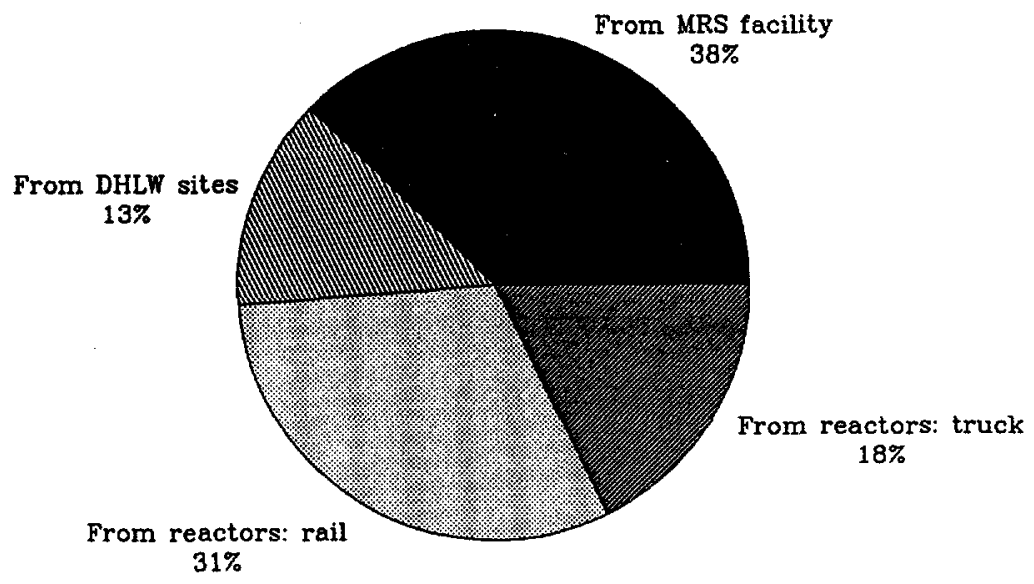

Figure 4-2. Total transportation costs by type of shipment for a one-repository system with intact-fuel disposal.

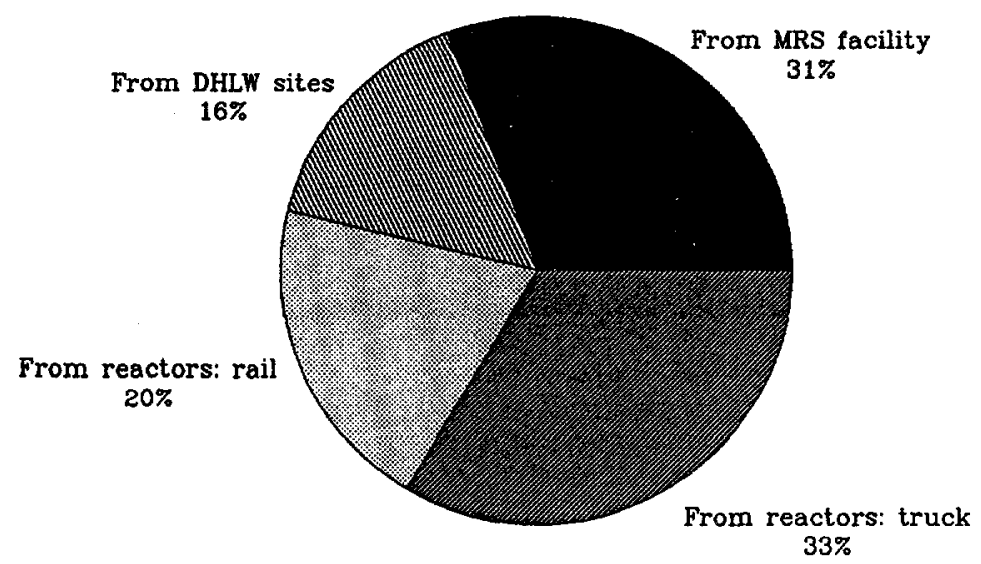

Figure 4-3. Total transportation costs by type of shipment for a two-repository system with consolidated-fuel disposal. 


\begin{tabular}{ccc} 
& \multicolumn{2}{c}{ Changes } \\
$\begin{array}{c}\text { June } 1987 \\
\text { TSLCC May } 1989\end{array}$ & TSLCC & $\begin{array}{c}\text { Due to } \\
\text { Dute to } \\
\text { ('86 dollars) ('88 dollars) }\end{array}$
\end{tabular}

Shippiro and security

Shipping
Surcharge
inspection
Detention
Security

Total shipping and security

Casks

Cask capital

Cask maiptenance

Facility

Total casks

Total transportation costs

\begin{tabular}{rr}
989 & 42 \\
61 & 442 \\
113 & 40 \\
55 & 29 \\
202 & 182 \\
\hline
\end{tabular}

1420

1114

\begin{tabular}{rr}
422 & 373 \\
244 & 295 \\
66 & 504 \\
- & \\
732 & 1172 \\
\hline & \\
\hline 2152 & 2286
\end{tabular}

$\begin{array}{r}-564 \\ +394 \\ -73 \\ -27 \\ -19 \\ \hline\end{array}$

$-288$

$-65$

$+104$

$+540$

+16
-54

$-102$

\begin{tabular}{rr}
-5 & -568 \\
-13 & +389 \\
0 & -73 \\
0 & -27 \\
-1 & -20 \\
- & - \\
\hline-19 & -306
\end{tabular}

$-306$

- -

$+579$

$-140$

${ }^{\text {I The }} 1987$ costs are in constant 1986 dollars, the 1988 estimates are in constant 1988 dollars.

The cask facility was not shown as a separate item in the 1987 version of this table.

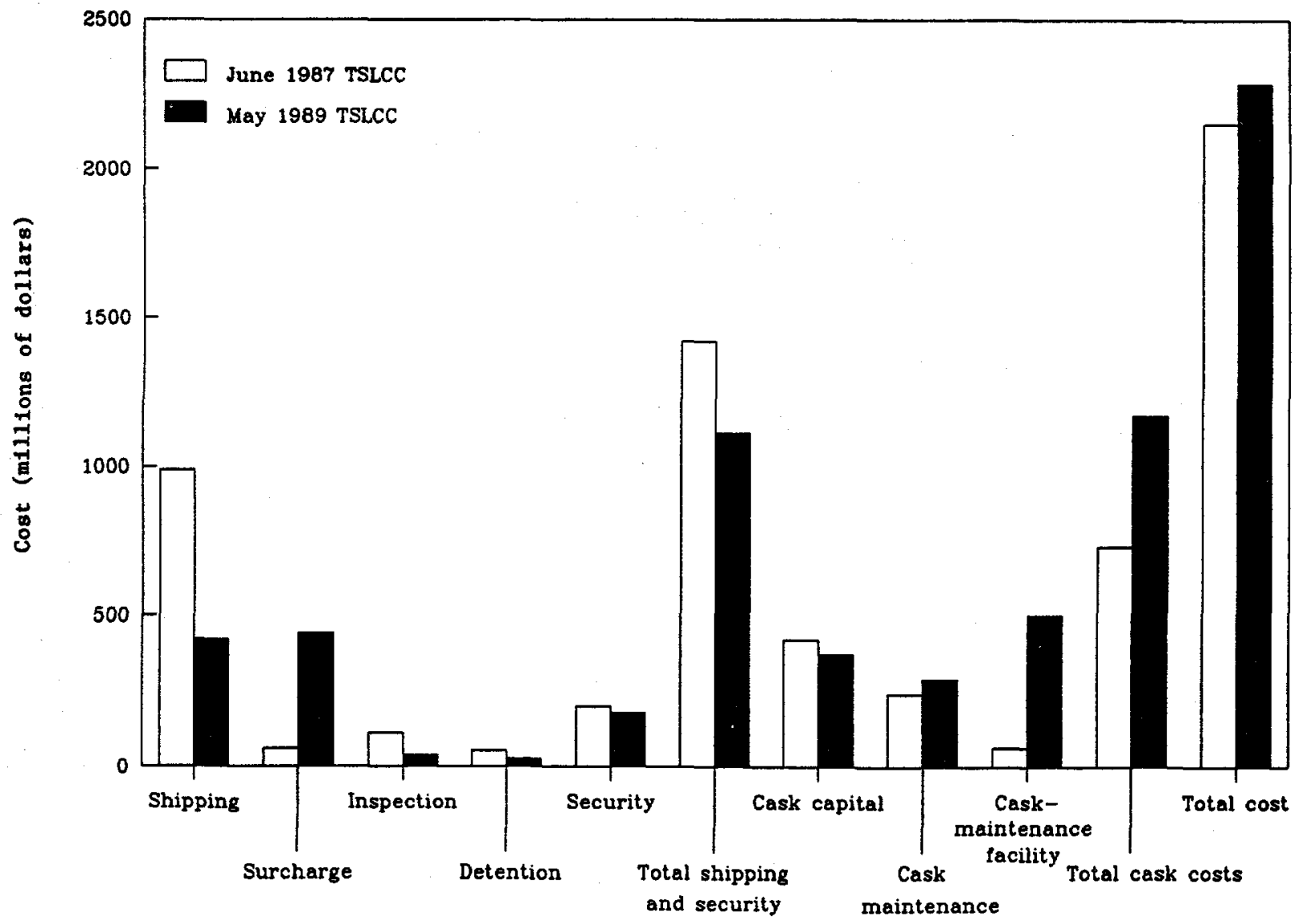

Figure 4-4. Comparison of Transportation costs to previous estimates. 
responsible for an increase of nearly 14 percent in the estimated transportation costs. One change that impacts virtually all of the cost components is the routing distance. This TSLCC is based upon generic routing distances to a hypothetical MRS facility while last year's analysis was based on an MRS at the $\mathrm{clinch}$ River site. The generic routing distances were developed as a part of the MRS systems studies, and are slightly higher for both from-reactor and from-MRS shipments. The following points are arranged by cost component to explain the reasons for the cost changes in the individual components:

- Shipping costs were significantly reduced because of a reduction in rail rates, an increase in cask capacities, an increase in rail speeds, and a decrease in the quantity of spent fuel.

- Surcharge costs were dramatically increased because of the use of dedicated trains for shipments from reactors and defense-waste sites and a modification in the dedicated-train costs for shipments from the MRS facility.

- Inspection and detention charges were reduced because the high cask capacities and reduced waste quantities reduced the number of shipments and because the cost algorithm was adjusted slightly.

- Security costs decreased slightly because the dedicated trains significantly reduced the rail-security requirements. The truck-security costs increased significantly because of an enhanced costing method and additional cost elements, but the reductions in rail-security costs were large enough to cause a total reduction of over 9 percent.

- Tota1 shipping and security costs were reduced by about 20 percent because the decreases in shipping, inspection, detention, and security overshadowed the increases in the dedicated-train surcharge.

- The cask capital costs were reduced because of higher capacities, a smaller quantity of spent fuel, and the longer life of the fromreactor cask fleet. In addition, the casks themselves are much less expensive. The reductions in the from-reactor fleet were more significant than the increases in the costs of casks for shipments from the MRS facility and shipments from defense-waste sites. The costs of from-MRS casks were increased because the WPLOG model estimated an increase in the number of canisters (and thus shipments) produced at the MRS facility. The shipments of the non-fuel-bearing hardware were also increased because of a reduction in hardware payload. The costs of defense-waste casks were increased, mainly because of the increased quantity of waste and the purchase of five-car lots in order to make up dedicated trains.

- The total cask-maintenance costs were increased because the decreases in the maintenance of from-reactor casks are overshadowed by the increases in the maintenance of from-MRS casks and defense-waste casks. 
- The cask-maintenance facility includes a fixed operating cost of $\$ 10$ million per year (including contingency) in the current estimates. When this cost is applied over the assumed 45-year 1ife of the facility, the costs are increased by $\$ 540$ million. In the previous analysis, the fixed maintenance cost per cask per year was assumed to cover the operating costs of the cask-maintenance facility.

- The total cask purchase and maintenance costs were increased by over 82 percent. This is almost entirely attributable to the operating costs of the cask-maintenance facility.

The impact of the Amendments Act caused no major changes in the costs of individual components. However, the total transportation costs were decreased by over 6 percent.

The major impact of the Amendments Act on transportation costs was due to assumptions about the rescheduling of the program (the start of MRS operations was assumed to be delayed from 1998 to 2003, and the second repository was assumed to be deferred until 2023). The assumed 5-year delay in the startup of the MRS facility results in the facility's accepting older spent fuel from reactors. This reduces the number of canisters that would be produced and subsequently shipped by the MRS facility, causing a sma11 decrease in the from-MRS shipping and surcharge costs.

However, the major impacts of the Amendments Act are found in the costs of cask maintenance. In the no-new-orders, end-of-reactor-life case, the system was assumed to run to the year 2042 in order not to accept spent fuel that is less than 5 years old. The Amendments Act generates significant savings in the cost of casks because of the deferral of the second repository. Substantial savings in cask-maintenance costs are realized because of a 9-year reduction in the operation period for the second repository. On the other hand, the cost savings at the cask-maintenance facility are directly attributable to the 5-year delay in the start of transportation operations, which shortens the operating life of the cask-maintenance facility by 5 years.

In summary, the TSLCC transportation costs have increased slightly from the previous estimates. These slight increases are the net result of many offsetting factors. When the 14-percent transportation-cost increase due to changes in data and methods is combined with the 6-percent decrease due to the Amendments Act, the total change of 6 percent in transportation costs between the 1987 analysis and the current analysis is explained. On average, the estimated overall cost of moving a metric ton of heavy metal (or the equivalent) has increased by about 5 percent. 
1. Nuclear Waste Policy Amendments Act of 1987, Public Law 100-203, December $22,1987,42$ USC 10101 et seq.

2. Roy F. Weston, Inc., Cost Estimating Methods for the May 1989 Tota1System Life-Cycle Cost Analysis, draft (to be pub1ished).

3. U.S. Department of Energy, Office of Civilian Radioactive Waste Management, Analysis of the Total System Life Cycle Cost for the Civilian Radioactive Waste Management Program, DOE/RW-0047, Washington, D.C., June 1987 .

4. Roy F. Weston, Inc., WPLOG, Waste Package Logistics Model User's Manual, draft, Washington, D.C., March 1988.

5. Pacific Northwest Laboratory, WASTES: Waste System Transportation and Economic Simulation--Release 24 User's Guide, PNL-5714-1, Richland, Wash., December 1988.

6. U.S. Department of Energy, Energy Information Administration, World Nuclear Fuel Cycle Requirements 1988, DOE/EIA-0436(88), Washington, D.C., September 1988 .

7. Tri-State Motor Transit Company, Radioactive Materials, Related Articles Classified or Declared Sensitive by the United States Government, and Empty Radioactive Material Containers, Docket No. MC-109397, November 1985.

8. McGil Specialized Carriers, Inc., Truckload Shipments of Radioactive Materials and Containers Thereof, ICC MGLS 287, February 1986.

9. A.J. Metler Hauling and Rigging, Inc., Naming Rules and Regulations Governing Motor Freight Traffic in Interstate or Foreign Commerce also Charges for Terminal and Other Special Services and Commodity Lists, MC-108676, May 1986.

10. Joy, D. S., P. E. Johnson, and S. M. Gibson, HIGHWAY, A Transportation Routing Mode1: Program Description and User's Manual, ORNL/TM-8149, Oak Ridge National Laboratory, Oak Ridge, Tenn., 1982.

11. Pacific Northwest Laboratory, Truck and Rail Charges for Shipping Spent Fuel and Nuclear Waste, PNL-5797, Richland, Wash., June 1986. 
Chapter 5

REPOSITORY COSTS

In the total-system life-cycle cost (TSLCC) analysis, repository costs cover the engineering, construction, operation, and closure and decommissioning costs for the repositories. This chapter explains how the requirements of the Nuclear Waste Policy Amendments Act of $1987^{1}$ (the Amendments Act) have affected the estimated repository costs, briefly describes the design and operation of geologic repositories, discusses the method of analysis used to estimate the costs, presents and discusses the estimated costs, and compares the costs with those calculated in previous TSLCC analyses.

\subsection{PERTINENT PROVISIONS OF THE AMENDMENTS ACT}

The repository-cost estimates have been significantly affected by the provisions of the Amendments Act for the first and the second repository. For the first repository, the Amendments Act has directed the Department of Energy (DOE) to limit site characterization to the Yucca Mountain site in Nevada. For the second repository, the Amendments Act has prohibited site-specific activities unless they are specifically authorized by the Congress and requires the Secretary of Energy to report between 2007 and 2010 on the need for a second repository.

Thus, to account for the possibility that a second repository may be needed and to evaluate the full range of repository life-cycle costs, two system configurations were considered for the TSLCC analysis--a one-repository system and a two-repository system.* In both configurations, the first repository was assumed to be developed in tuff at the Yucca Mountain site. For the two-repository system, neither the location nor the host rock is known for the second repository, and, therefore, a generic second repository with average mining conditions and operating productivities was assumed for the analysis. Additional repository impacts are introduced by the DOE's reevaluation of the desirability of spent-fuel consolidation and the functions of the facility for monitored retrievable storage (MRS). As discussed in Chapter 2 and below, these assumptions about consolidation and the MRS facility affected the TSLCC assumptions about the functions and design of the repositories.

*This chapter discusses, as appropriate, two repositories, but the second repository is not included in all cases. Furthermore, the second repository has not been authorized by the Congress and is not at present included in the DOE's waste-management system. 


\subsection{ASSUMPTIONS ABOUT THE DESIGN AND OPERATION OF THE REPOSITORIES}

This section summarizes the principal assumptions of the TSLCC analysis about the design and operation of the repositories. The tuff-repository design was based on the OGR Repository-Specific Rod Consolidation Study: Effect on Costs, Schedules, and Operations at the Yucca Mountain Repository, dated December, 1988. ${ }^{2}$ The tuff-repository design for the cases with intact-fuel disposal was based on the Case 2 design (repository design for intact-fuel disposal) described in the consolidation report; the design for the cases with consolidation was based on the Case 3 design (repository design for consolidated-fuel disposal with an MRS facility in the system). Additional design and cost data were taken from the latest Site Characterization Plan--Conceptual Design Report (SCP-CDR), dated November $1987,{ }^{3}$ and the Sandia report MRS System Study for the Repository, dated December, $1988^{4}$ which supported Task B of the MRS System Study.

The costs of the generic second repository are based on design information contained in the last SCP-CDRs that were prepared prior to the Amendments Act for the basalt and salt projects, along with additional pertinent information as appropriate.

The repositories consist of both surface and underground facilities. The principal surface facility is the waste-handling building, which is designed to receive, package, and transfer wastes underground. In all of the five TSLCC cases, the repositories have only one waste-handling building. In the cases with intact-fuel disposal, the waste-handling building receives spent fuel and high-level waste, encapsulates the waste into the disposal containers, and then prepares the containers for transfer to the underground repository. In the consolidation cases, the waste-handling functions of the first repository do not change significantly since the consolidation function is performed at the MRS facility. In these cases, the facility receives canisters of consolidated spent fuel from the MRS facility instead of the bare intact assemblies. In the case of the second repository, however, the waste-handling building must perform the consolidation in the cases with consolidated-fuel disposal because of the assumption that the MRS facility services only the first repository.

The underground facilities consist of access tunnels, support facilities, and disposal rooms in which the waste is emplaced. Access to the underground areas is provided through shafts and ramps or shafts only, depending on the host rock and site geology.

In order to meet the regulatory requirements of the Nuclear Regulatory Commission (NRC) in $10 \mathrm{CFR}$ Part 60,5 the waste emplaced in the repository must be retrievable for 50 years after the start of waste emplacement. Thus, after all the waste has been emplaced in the repository, a "caretaker" period will begin. If, at the end of this period, the NRC is satisfied that the repository is performing as expected, the repository will be prepared for permanent closure by backfilling the underground repository with previously excavated rock and permanently sealing the shafts and ramps. The surface facilities will be decontaminated and decommissioned, and permanent markers will be erected at the site to alert future generations to the presence of a repository. 
For the two-repository system, the waste-emplacement period of the first repository lasts 25 years, in accordance with the preliminary waste-acceptance schedule in the Draft 1988 Mission Plan Amendment, 5 and, therefore, the caretaker period is assumed to last an additional 25 years. For the second repository, the duration of the waste-emplacement period depends on the quantity of spent fuel to be emplaced and on how long spent fuel continues to be discharged from reactors. For the Energy Information Administration's (EIA's) no-new-orders, end-of-reactor-1ife case (discharges through 2037), the waste-emplacement period for the second repository was assumed to last 11 years, with the caretaker period lasting 39 years. For the EIA upper reference case (discharges through 2020), the waste-emplacement period for the second repository was assumed to last 13 years, with the caretaker period lasting 37 years. For the one-repository system and the EIA no-new-orders, end-of-reactor-1ife case, waste emplacement was assumed to take 40 years, with the caretaker period covering the remaining 10 years of the retrievability period.

The first repository begins operation in 2003 by receiving spent fuel from the MRS facility at an initial rate of 400 metric tons of heavy metal (MTHM). This annual rate increases to 900 MTHM in 2006 and 1800 MTHM in 2007. Starting in 2008 , the repository reaches its design waste-acceptance rate, receiving 3000 MTHM of spent fuel from the MRS facility and 400 MTHM of high-level waste.

In the cases with intact-fuel disposal, the repository accepts bare spent-fuel assemblies from the MRS facility and encapsulates them in containers for underground disposal. The vitrified high-level waste (defense and civilian) is accepted directly at the repository and is encapsulated in a specially designed container for underground disposal.

In the cases with consolidated-fuel disposal, 95 percent of the spent fuel is accepted from the MRS facility as consolidated fuel in canisters; the remainder ( 5 percent) is accepted as intact spent-fuel assemblies in canisters. (This 5 percent of the fuel was assumed to be unsuitable for consolidation.) The non-fuel-bearing hardware remaining after consolidation arrives at the repository in 55-gallon drums that are stacked in groups of five drums and held together by a frame; these frames are placed into a disposal container at the repository. The vitrified high-level waste is accepted directly at the repository and encapsulated in the disposal container. The high-leve1 waste is treated identically in the intact- and consolidated-fuel cases.

In the one-repository system, the first repository continues to operate until all of the waste has been accepted. The receipt of high-level waste in this case lasts for 24 years, for a total of 9515 MTHM. Spent fuel is accepted over a 40-year period ending in 2042. The total quantity of waste accepted at the repository is 96,272 MTHM.

In the two-repository system, the first repository is assumed to accept a total of 70,000 MTHM. This total includes defense high-level waste, which is divided proportionally between the first and the second repositories. In addition, commercial high-level waste from the West Valley Demonstration Project was assumed to be accepted at the first repository. Thus, for the 
no-new-orders, end-of-reactor-1ife case, the receipt of high-level waste lasts for 18 years (until 2025) at the first repository, with a total of 7093 MTHM being accepted; for the upper reference case, the first repository accepts high-level waste for 17 years (until 2024), for a total of 6478 MTHM.

The second repository was assumed to begin operations 20 to 25 years after the resumption of the second-repository program. It receives the remaining waste, and its annual acceptance rate is equivalent to $3400 \mathrm{MTHM}$, which includes 400 MTHM of high-level waste. It has one large waste-handling building designed to receive spent fuel from reactors and high-level waste from the high-level waste sites. In the cases with intact-fuel disposal, the bare spent-fuel assemblies are encapsulated directly in the disposal containers. In the consolidated-fuel cases, 95 percent of the spent fuel is consolidated, and the consolidated rods are then encapsulated in the disposal containers. Five percent of the fuel is encapsulated in the disposal containers as intact assemblies. The non-fuel-bearing hardware is placed in stacks of 55-gallon drums, and these stacks are then placed into the disposal containers. In both cases, the canisters of vitrified defense high-level waste from the defense sites are encapsulated in the disposal containers at the repository.

The logistics analysis is discussed in more detail in Chapter 2, and the waste-acceptance schedules for a11 five TSLCC cases are shown in Appendix A.

\subsection{SCOPE OF REPOSITORY-COST ESTIMATES}

\subsubsection{Engineering costs}

For the TSLCC analysis, the repository engineering costs cover the license-application design (LAD), the final procurement and construction design (FPC), and the Title III design. The LAD costs for the first repository are incurred between 1992 and 1994. The FPC design costs are incurred between 1994 and the receipt of a construction authorization from the NRC (in 1998), at which time construction begins.

\subsubsection{Construction costs}

Construction costs include site preparation, the construction of surface facilities, the installation of utility networks, the construction and outfitting of shafts and ramps, the excavation and construction of underground support areas, and a limited amount of excavation for waste emplacement. Construction and Title III design costs are incurred until all repository facilities are in operation. Included in these costs is the functional testing of the waste-handling building. 


\section{3 .3 Operating costs}

Operating costs cover all staffing, maintenance, supplies, and utilities during the waste-emplacement and the caretaker phases. Included in this category is the cost of the waste packages, which include the waste, the disposal container, shielding, packing, and other absorbent materials immediately surrounding an individual disposal container in the waste-emplacement hole. The costliest component of the waste package is the disposal container, which accounts for a significant portion of the repository costs. The disposal container is a large high-quality metal vessel that must be fabricated to exacting specifications. The unit costs for these containers are on the order of $\$ 31,000$ per container for the repository in tuff and $\$ 70,000$ per container for the generic second repository. (The exact cost depends on the design of the container.)

\subsubsection{The costs of closure and decommissioning}

The last component of the repository-cost analysis is the cost of closure and decommissioning, which covers all activities associated with backfilling and permanently sealing the underground repository and decommissioning the surface facilities.

\subsection{METHOD OF ANALYSIS}

The method of cost estimation draws on the most recent site-specific engineering design and cost data in order to establish the most accurate and comprehensive cost estimates. For the first repository, the cost estimates are based on the data developed for the MRS system studies (see Chapter 1) for the repository in tuff at Yucca Mountain. The second repository was assumed to represent a generic host rock with average mining conditions and productivities. Costs for this facility were derived from cost estimates that were prepared before the Amendments Act while other host rocks were still being evaluated. The cost data used in the TSLCC analysis were modified to account for current TSLCC assumptions and placed in standardized cost accounts that are time phased. This provides a consistent procedure for the estimation of repository costs.

The repository costs were estimated with the REPCOST spreadsheet, which was developed for the 1985 TSLCC analysis and has since undergone several modifications. REPCOST uses the waste-package logistics developed by the Waste Package Logistics (WPLOG) model 7 and the underground-repository costs developed by the URCOST spreadsheet. The matrix format of the spreadsheet provides the costs for specific repository facilities or activities, including surface facilities, shafts and ramps, underground development, underground support, and waste-package preparation. A more detailed discussion of the models and spreadsheets can be found in the TSLCC notebook. 8 


\subsubsection{Site and surface facilities}

For the first repository, the costs of surface facilities (waste-handling building, site, support facilities, and utilities) were estimated with REPCOST from cost estimates developed by the Yucca Mountain project. The costs for the second repository were adapted from estimates for a repository in a generic host rock, using additional pertinent information as appropriate.

The costs of the surface facilities for the first repository were estimated by baselining the surface-facility design in the REPCOST spreadsheet to the most recent cost estimate available from the repository project. These estimated costs were then adjusted to reflect the requirements of the Amendments Act and the TSLCC assumptions, particularly those related to the length of the operations period and waste-acceptance schedules. In addition, baseline estimates were revised to account for the ISLCC assumption that the total quantities of defense and civilian high-level wastes are split proportionally between the first and the second repositories.

The REPCOST input data were generally entered as requirements for labor, materials, equipment, and utilities. Separate cost estimates were developed for each phase of the repository life cycle, using construction costs as the basis for estimating the costs of the other phases.

As discussed in more detail in the cost-estimating notebook, 8 the estimate of construction costs began with the direct cost of construction labor, which was obtained by multiplying the average labor rate, adjusted as appropriate to account for such indirect costs as the contractors' overhead, by the total hours of construction labor. The labor costs were then added to the costs of materials, the capital equipment costs, and indirect costs (markups). Sales taxes were added to the estimated costs of materials and construction equipment, and construction-management and contingency costs were added to complete the estimate of construction costs. Where appropriate, the costs of quality assurance were applied as an additional contingency.

Engineering costs were calculated from the construction costs. This was done by taking a fixed percentage of the materials, labor, capital equipment, and markup subtotal as the base engineering cost. Contingency was applied to the costs of engineering at the percentage used for the line-item construction cost.

The annual operating costs for the surface facilities were derived from the construction costs as well as estimates of the necessary staffing and utilities. The staffing levels were combined with labor rates, developed for the average staff member, to produce annual operating-labor costs. The cost of operating materials was taken to be a fixed percentage of the operatinglabor cost. These materials include such things as decontamination materials, fue1s, and personne1-protection equipment. In addition to the costs of the plant maintenance staff, maintenance supplies and outside maintenance support were included annually at a fixed percent of the surface construction cost. 
For the first repository, the annual costs of utilities were calculated from the site-specific estimate by the architect-engineers of the tuff repository project. Also included in the operating costs were the costs of subsidized employee transportation, if required. These were treated as a cost per man-year. The utility costs for the second repository were derived from cost estimates prepared by the salt and basalt projects before the enactment of the Amendments Act.

The labor, materials, maintenance, utility, and transportation costs were summed by the spreadsheet. Management and integration costs were then added, such as support-contractor costs during construction and the costs of offsite performance-confirmation activities during operation. Finally, fees and contingency were added to complete each cost item.

The costs of closure and decommissioning were also calculated from the construction costs by taking a fixed percentage of the materials, labor, capital equipment, and markup subtotal as the base cost of closure and decommissioning. Finally, a cost for contingency was added at the same percentage as that used for the same line item in construction.

\section{4 .2 Shafts and ramps}

The costs of shafts and ramps for the first repository were taken directly from the cost estimate prepared by the Yucca Mountain project. Differences in shaft costs between TSLCC cases are attributable to differences in the length of the operating period. The costs of shafts are also driven by requirements for lining and depth. The second-repository cost estimates for shafts were derived from cost estimates prepared for other host rocks before the Amendments Act. The second-repository shafts are intended to reflect a generic host rock with "average" conditions. The estimated shaft costs were directly input to REPCOST.

\subsubsection{Underground development and operation}

The estimated costs of underground development and operation reflect al1 the construction, waste-emplacement, caretaker, and backfill activities that occur in the underground repository. They include all development, operation, and closure costs for the underground repository after the shafts and ramps are constructed.

The underground-repository costs for all TSLCC cases were calculated with the Underground Repository Cost (URCOST) spreadsheet. Once the spreadsheet was baselined to the first-repository-project estimates and the derived second-repository estimate, the variations required for the TSLCC cases were accommodated by changes to the input data for URCOST. 
The TSLCC assumptions about the characteristics of the spent fuel and the quantities of defense high-level waste differed somewhat from those used in the project estimates. The project estimates were based on spent fuel of constant burnup and fixed age. This assumption allows the underground wasteemplacement rooms to be standardized (e.g., fixed room spacing and distance between waste-emplacement boreholes). The quantity of waste that is received annually is also fixed in the project estimates.

In the TSLCC estimates, the quantity of spent fuel received at the repositories is based on one of two spent-fuel-discharge projections--either the no-new-orders, end-of-reactor-life case or the upper reference case. In addition, the TSLCC incorporates variations in fuel type (fuel from pressurized-water reactors or boiling-water reactors), burnup level, age, and heat output. As previously discussed, the WPLOG model accommodates these variations on an annual basis and translates them into a variable number of disposal containers to be emplaced, also on an annual basis. Thus, the cost estimates for underground construction and operation are based on a constantly changing number of disposal containers and spent-fuel characteristics. The URCOST spreadsheet has been designed to accommodate these changes.

The URCOST method accepts the WPLOG disposal-container quantities and characteristics (on an annual basis) and uses design specifications and recommendations by the repository project to simulate modifications to the reference underground designs. For the Yucca Mountain site, the distance between waste-emplacement boreholes was held constant, and the spacing of the disposal rooms was varied to maintain both the areal power density and the areal energy deposition at the reference values (values used in the SCP$\left.C^{2}{ }^{3}\right)$. For the second repository, the spacing of the disposal rooms was held constant, and the distance between waste-emplacement boreholes was varied in order to balance the heat load. The constraints imposed by the repository reference designs were set as the upper limit for al1 URCOST analyses. In other words, in no case will the total heat load (or, additionally, the total energy deposition for the tuff site) per emplacement room exceed the values specified in the designs developed by the repository project.

The URCOST spreadsheet conducts a sequence of analytical tasks to estimate the costs of the underground repository. It calculates the following on an annual basis:

1. Total excavation requirements (in tons of rock excavated) based on the number and the type of disposal containers (i.e., spent fuel, defense high-level waste, non-fuel-bearing hardware from consolidation, etc.) as we11 as the characteristics of the waste.

2. The total excavation costs for the excavation requirements identified in step 1.

3. The costs of handling the excavated rock for the excavation requirements and the repository phase (i.e., construction, emplacement, caretaker, and closure).

4. The general maintenance costs for each phase of the repository. 
5. The cost of drilling waste-emplacement boreholes for a given number and type of waste packages for each phase of the repository.

6. The costs of transferring underground and emplacing a given number of disposal containers and the costs of retrieving disposal containers for performance confirmation for each phase of the repository.

7. The costs of underground service systems--including support-system facilities, utilities, and monitoring--for each phase of the project.

8. Backfill requirements based on the initial excavation and factors to account for the compaction of backfill for each rock type.

9. Total costs for construction through the waste-emplacement, caretaker, and closure (backfil1) phases.

10. Staffing requirements for each unit operation conducted underground.

The costs estimated by the repository project provided the necessary unit costs and productivity values for each URCOST spreadsheet. The project designs also identify other direct inputs to URCOST in terms of common area tonnage, development schedules, and excavation requirements for wasteemplacement rooms and other required drifts. The results of the URCOST calculations were used as input to the REPCOST spreadsheet for calculating the total repository costs.

\subsubsection{Waste packages}

Design specifications and unit costs for the disposal containers were derived from estimates prepared for the MRS System Study. ${ }^{4}$ The REPCOST spreadsheet combines the predicted quantities of disposal containers with the unit costs to arrive at the waste-package costs. The disposal-container quantities are calculated in the following sequence by the Waste Package Logistics (WPLOG) ${ }^{7}$ model:

1. Waste-package design constraints (maximum heat and number of spent-fuel assemblies) for each waste type and host rock are input.

2. The rate at which non-fue1-bearing hardware is generated in spent-fue1 consolidation (if included in the system) is entered.

3. Data for each shipment of spent fuel (i.e., metric tons of heavy metal; number of assemblies; fuel type, age, burnup; and the heat-generation rate per metric ton of heavy metal) are read from the shipment file generated by the WASTES mode1.9

4. The WPLOG model calculates for each waste type in each year of operation the total number of disposal containers required. The number of spent-fuel assemblies in the container is reduced if heat constraints are exceeded. 
5. The factors that specify the annual heat emission per disposal container (the ratio of the actual heat to the design heat 1imit) along with the annual average burnup and age for each spent-fuel type are calculated by the WPLOG model for use in the URCOST spreadsheet to adjust the waste-package spacing in the underground repository as appropriate.

The number of canisters of defense and civilian high-level waste that is received annually is calculated externally, and the number for defense waste is entered in REPCOST for calculating the cost allocation for defense waste. In addition, the number of waste packages requiring repackaging in disposal containers after performance-confirmation testing is also entered directly into REPCOST.

\subsubsection{Tota1 costs}

The preceding sections discussed the individual components of the repository costs. The REPCOST spreadsheet sums all of these costs, calculates annual costs, and estimates the portion of repository costs to be allocated to defense waste. These calculations can be summarized as follows:

1. Annual costs of operation are calculated for a standard year of operation during the waste-emplacement phase and during the caretaker phase. These costs are then applied to each year of operation by annual cost factors.

2. Waste-package costs are obtained by multiplying quantities (input from the WPLOG mode1) by unit costs (extracted from design data).

3. URCOST summary and annual costs are input.

4. Cost factors for each engineering phase (1icense-application design, final procurement and construction design, and Title III design), as well as the construction and closure-and-decommissioning phases are used to annualize the costs of design and surface-facility construction as well as the costs of shaft-and-ramp closure and decommissioning.

5. The costs to be allocated to defense waste are calculated for each account by the method described in Chapter 8.

6. Sumnary (by account and by phase) and annual cost tables are produced for both total and defense-waste costs.

\subsection{RESULTS}

A summary of the repository-cost estimates for the TSLCC cases is presented in Table 5-1. 


\begin{tabular}{|c|c|c|c|c|c|}
\hline \multirow[b]{2}{*}{ Cost category } & \multicolumn{2}{|c|}{ Single repository } & \multicolumn{3}{|c|}{ Two repositories } \\
\hline & $\begin{array}{c}\text { Intact fuel } \\
\text { basic } \\
\text { MRS }\end{array}$ & $\begin{array}{c}\text { Consolidate } \\
\text { into canisters } \\
\text { at MRS }\end{array}$ & $\begin{array}{c}\text { Intact fuel } \\
\text { basic } \\
\text { MRS }\end{array}$ & $\begin{array}{c}\text { Consolidate } \\
\text { into Canisters } \\
\text { at MRS }\end{array}$ & $\begin{array}{l}\text { Consolidate into } \\
\text { canisters at mRs, } \\
\text { upper reference }\end{array}$ \\
\hline & \multicolumn{5}{|c|}{ First repository } \\
\hline Construction & 1177 & 1061 & 1,118 & 1,002 & 1,003 \\
\hline Operation & 7388 & 7196 & 5,461 & 5,276 & 5,240 \\
\hline Closure and decomissioning & 498 & 477 & 427 & 399 & 399 \\
\hline \multirow[t]{2}{*}{ Total first repository costs } & 9063 & 8734 & 7,006 & 6,677 & 6,642 \\
\hline & \multicolumn{5}{|c|}{ Second repository } \\
\hline Construction & $N A^{a}$ & NA & 2,245 & 2,699 & 2,697 \\
\hline Operation & NA & NA & 3,985 & 3,687 & 4,348 \\
\hline \multirow[t]{2}{*}{ Closure and decormissioning } & NA & NA & 352 & 377 & 384 \\
\hline & - & - & - & $\longrightarrow$ & - \\
\hline Total DHLW costs & NA & NA & 6,582 & 6,763 & 7,429 \\
\hline Total repository costs & 9063 & 8734 & 13,588 & 13,440 & 14,071 \\
\hline
\end{tabular}

\footnotetext{
Not applicable.
}

The one-repository case with intact-fuel disposal has a repository cost of $\$ 9.1$ billion. Compared to the two-repository cases, the cost estimates for the one-repository cases include additional costs for the following: an additional ventilation shaft at the south end of the mining drifts, ventilation support equipment and facilities, additional drift tonnage, additional emplacement panels in the northern block, and extended panels to the southeast. The one-repository estimates are based on the assumption that these additional areas of the underground are found to be usable; this premise would have to be verified by additional site characterization. It should be emphasized that the one-repository cost estimates are primarily based on engineering judgment; the estimates do not reflect any design study.

Figures 5-1 and 5-2 present the costs for the single repository in tuff by phase (engineering and construction, emplacement operations, caretakeroperations, and closure and decommissioning) and by account (management and integration, site preparation, surface facilities, shafts and ramps, underground excavations, underground service systems, and waste package), respectively.

The one-repository case with consolidated-fuel disposal has a repository cost of $\$ 8.7$ billion. This was $\$ 0.4$ billion lower than the cost of intactfuel disposal, mainly because a different design for the waste-handling building was used in each case. The design of the waste-handling building used in the one-repository case with intact-fuel disposal was based on the Case 2 design in the recent rod-consolidation study. ${ }^{2}$ In this design, the waste-handling building has 10 cask-receiving bays. For the one-repository case with consolidated disposal, the waste-handling building was based on the 


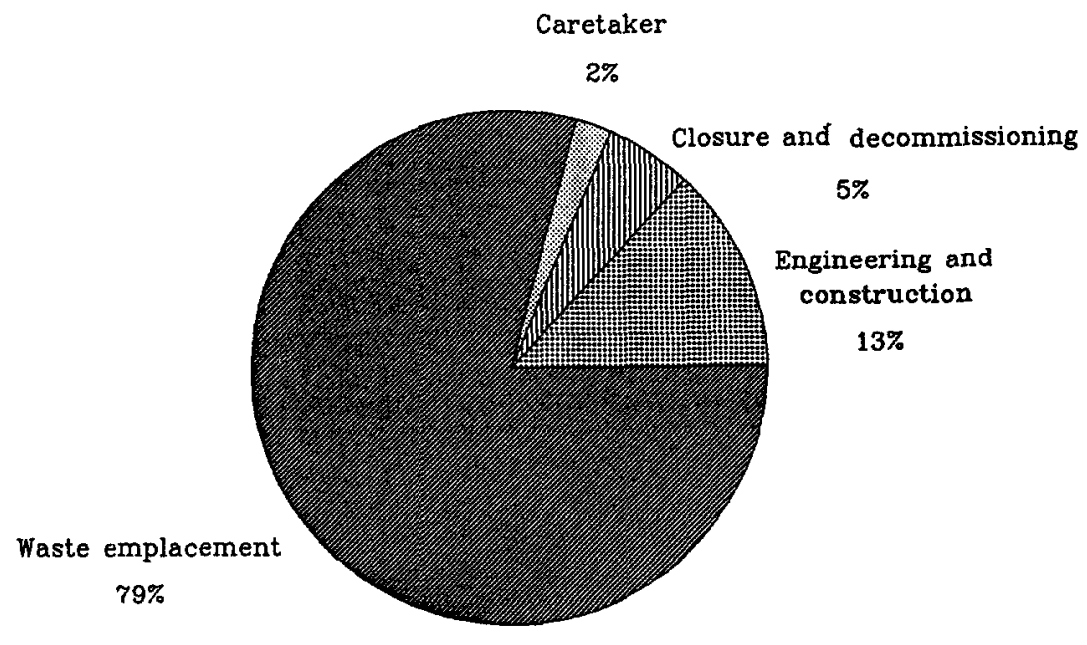

Figure 5-1. Repository costs by phase for a single repository in tuff.

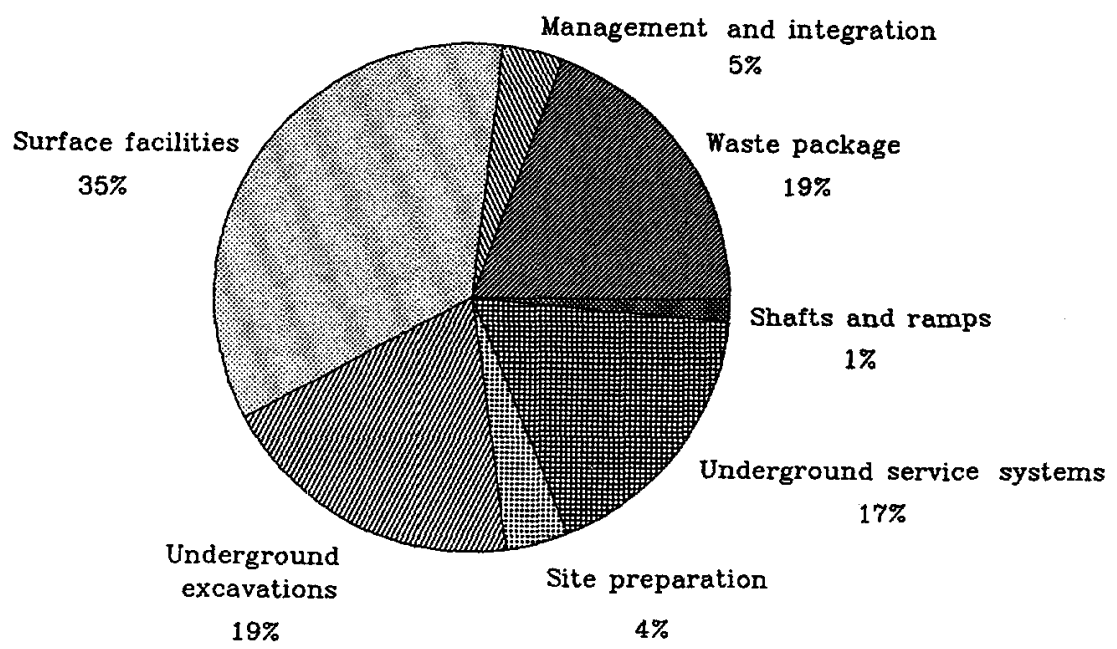

Figure 5-2. Repository costs by account for a single repository in tuff. 
Case 3 design of the rod consolidation study. The design of the wastehandling building for this case has a single pass-through cask-receiving bay. In addition, the waste-handling building is considerably smaller and simpler, primarily because most of the waste is received prepackaged in decontaminated canisters, which simplifies the waste-handling operation and contributes to a relatively uncomplicated facility design.

For the two-repository case with intact-fuel disposal, the total repository cost is $\$ 13.6$ billion, or $\$ 4.5$ billion higher than the cost of the comparable one-repository case with intact-fuel disposal. The first repository has a cost of $\$ 7.0$ billion, and the generic second repository had a cost of $\$ 6.6$ billion. This higher repository cost for the two-repository system can be attributed to the additional cost for a second repository ( $\$ 6.6$ billion), which is partially offset by a $\$ 2.1$-billion reduction in the cost of the first repository, whose capacity is now 1 imited to 70,000 MTHM. This reduction in the first-repository cost reflects a facility with a smaller capacity (70,000 versus 96,272 MTHM) and a shorter waste-emplacement period (25 versus 40 years). The reader may note that the second repository costs are relatively close to the first repository costs ( $\$ 6.6$ billion to $\$ 7.0$ billion) in this case; but the second repository capacity is only 26,272 MTHM whereas the first repository capacity is 70,000 MTHM. The similarity in the costs is caused by the assumed average mining conditions for the generic rock second repository versus the relatively inexpensive conditions for a repository at Yucca Mountain. The second repository cost estimates appear high because the tuff repository is at a relatively shallow excavation horizon and the repository zone is much drier than average. Also, because of these conditions, the tuff repository is able to utilize ramp entries versus shaft entries. The reader is reminded that the generic second repository estimates are derived from previous TSLCC estimates prepared for salt, basalt and crystalline rock repositories (prior to the Amendments Act), and that these repository costs were significantly more costly than a comparable repository in tuff. Finally, the second repository costs are high because of the substantial fixed costs associated with a repository. The fixed costs include the costs of construction and the costs of maintaining retrievability for 50 years.

For the two-repository cases with consolidated-fuel disposal, the total repository cost is $\$ 13.4$ billion. In this case, the first repository has a cost of $\$ 6.7$ billion, and the generic second repository has a cost of $\$ 6.8$ billion. The total repository cost for this case is $\$ 4.7$ billion higher than that of the comparable one-repository case with consolidated-fuel disposal. Again, this higher cost can be attributed to the additional cost for the second repository, partially offset by a reduction in the cost of the first repository, which has a smaller capacity and a shorter waste-emplacement period.

The total repository cost for the two-repository case with intact-fuel disposal is less than $\$ 0.2$ billion higher than the total repository cost for the comparable case with consolidation. This cost savings from consolidation is due to a savings of about $\$ 0.3$ billion at the first repository and a cost increase of about $\$ 0.2$ billion for consolidation at the second repository. The savings realized at the first repository is due primarily to a reduction in the capital and operating costs of the waste-handling building, which has a 
simpler design when the MRS facility consolidates spent fuel into canisters, as discussed previously for the one-repository cases. The second-repository cost increase for consolidation results from the additional costs for equipment, materials, staffing, etc., and the like for the consolidation process ( $\$ 0.8$ billion). Offsetting this increase somewhat is a reduction in the costs of waste-package fabrication ( $\$ 0.6$ billion), which comes from using fewer disposal containers with consolidated fuel.

For the upper reference case, the total repository cost for the two repositories is $\$ 14.1$ billion. This is $\$ 0.7$ billion higher than the $\$ 13.4$ billion estimate for the comparable no-new-orders, end-of-reactor-1ife case. The $\$ 0.7$ billion total-repository increase is due to the increase at the generic second repository because the second repository was assumed to accept all of the additional waste included in the upper reference case. The second repository accepts a total of $36,400 \mathrm{MTHM}$ in the upper reference case, which represents a capacity increase of nearly 39 percent over the no-new-orders, end-of-reactor-life case.

Included in the repository costs were the costs for the waste packages (i.e., disposal containers). The waste-package costs are given in Table 5-2.

Table 5.2. Waste-package costs

(Millions of 1988 dollars)

\begin{tabular}{lccc}
\hline & $\begin{array}{c}\text { First } \\
\text { repository }\end{array}$ & $\begin{array}{c}\text { Second } \\
\text { repository }\end{array}$ & Total \\
\hline $\begin{array}{l}\text { One repository, intact fue1, } \\
\text { storage-only MRS facility }\end{array}$ & 1698 & Not applicable & 1698 \\
$\begin{array}{l}\text { One repository, MRS facility } \\
\text { consolidates into canisters }\end{array}$ & $1678^{\mathrm{a}}$ & Not applicable & 1678 \\
$\begin{array}{l}\text { Two repositories, intact fuel, } \\
\text { Storage only MRS facility }\end{array}$ & 1220 & 1398 & 2618 \\
$\begin{array}{l}\text { Two repositories, MRS facility } \\
\text { consolidates into canisters }\end{array}$ & $1205^{\mathrm{a}}$ & $\mathbf{8 1 4}$ & 2019 \\
$\begin{array}{l}\text { Two repository, MRS facility } \\
\text { consolidates into canisters, } \\
\text { upper reference case }\end{array}$ & $1185^{\mathrm{a}}$ & 1026 & 2211 \\
\hline
\end{tabular}

apoes not include the cost of the canisters used at the MRS facility. 


\subsection{COMPARISON WITH PREVIOUS RESULTS}

Table 5-3 and Figure 5-3 compare this year's cost estimate for a first repository in tuff in the two-repository system with the comparable case from the 1987 analysis. 10 In both cases the spent fuel was assumed to be consolidated at the MRS facility, and the spent-fuel quantities were based on the no-new-orders, end-of-reactor-1ife case. The cost impacts are divided into those due to changes in data and methods, and those due to the Amendments Act.

of the total cost increase of $\$ 1.2$ billion, less than $\$ 0.1$ billion is due to the Amendments Act. The small impact of the Amendments Act can be attributed to the assumed 2003 startup date for the MRS facility rather than the 1998 startup assumed in the 1987 analysis. Because of the later startup of the MRS facility, there is a small effect on the characteristics of the spent fuel in the canisters being shipped from the MRS facility to the repository.

Changes in data and methods since the 1987 TSLCC analysis result in a $\$ 1.2-b i l 1 i o n$ increase. Included in this change is the escalation from 1986 to 1988 dollars. Specific impacts are as follows:

- Construction costs increased by $\$ 0.2$ billion, and most of the increase occurred in the management-and-integration account because of an accounting change made in this year's TSLCC analysis. In previous years, the license-application design (LAD) costs for the three sites characterized had been included in the development-and-evaluation component of the TSLCC analysis. This year, the LAD costs are included in the repository component because only one site is incurring LAD costs.

- The costs of underground excavation increased by $\$ 0.1$ billion because of an increase in the number of waste packages, a revised method for determining the underground-excavation requirements, and a modification in the underground layout. The revised method was based on the areal energy deposition of the waste emplaced in the tuff. The reader is referred to the TSLCC notebook for a detailed explanation of this method. 8 The different underground layout was used in order to remain consistent with the rod-consolidation study ${ }^{2}$ and the MRS system study. 4

- The costs of underground service systems increased by $\$ 0.2$ billion because of the modification in the underground layout discussed above and updated information.

- The costs of waste-package fabrication increased by $\$ 0.8$ billion because of an increase in the unit waste-package cost and a new method for calculating the number of disposal containers. The revised unit waste-package cost results from the analysis performed for the MRS system study. ${ }^{4}$ The unit costs of the spent-fuel waste packages increased by almost a factor of 2 to $\$ 31,000$ per container. The new method of calculating the number of disposal containers takes into account the heat rate of each spent-fuel assembly as it is processed at an MRS facility or a repository, whereas the previous 


\begin{tabular}{|c|c|c|c|c|c|}
\hline \multirow[b]{2}{*}{ Cost category } & \multirow[b]{2}{*}{$\begin{array}{c}\text { June } 1987 \\
\text { TSLCC } \\
\text { ('86 dollars) }\end{array}$} & \multirow[b]{2}{*}{$\begin{array}{c}\text { May } 1989 \\
\text { TSLCC } \\
\text { ('88 dollars) }\end{array}$} & \multicolumn{3}{|c|}{ Changes } \\
\hline & & & $\begin{array}{l}\text { Due to } \\
\text { data/ } \\
\text { assumptions }\end{array}$ & $\begin{array}{l}\text { Due to } \\
\text { legislation }\end{array}$ & Total change \\
\hline $\begin{array}{l}\text { Construction } \\
\text { Management and integration } \\
\text { Other }\end{array}$ & $\begin{array}{l}127 \\
716\end{array}$ & $\begin{array}{l}235 \\
763\end{array}$ & $\begin{array}{r}+108 \\
+47\end{array}$ & - & $\begin{array}{r}+108 \\
+47\end{array}$ \\
\hline Total construction & 843 & 998 & +155 & - & +155 \\
\hline $\begin{array}{l}\text { Operation } \\
\text { Surface facility } \\
\text { Subsurface excavation } \\
\text { Underground service system } \\
\text { Waste package fabrication } \\
\text { Other }\end{array}$ & $\begin{array}{r}1847 \\
993 \\
759 \\
492 \\
190\end{array}$ & $\begin{array}{r}1836 \\
1067 \\
911 \\
1271 \\
189\end{array}$ & $\begin{array}{r}-11 \\
+103 \\
+152 \\
+808 \\
-\end{array}$ & $\begin{array}{l}- \\
-29 \\
-30 \\
-1\end{array}$ & $\begin{array}{r}-11 \\
+74 \\
+152 \\
+778 \\
-1\end{array}$ \\
\hline Total operation & 4281 & 5274 & +1053 & -60 & +993 \\
\hline Closure and decommissioning & 363 & 399 & +40 & -4 & +36 \\
\hline Total first repository costs & 5487 & 6671 & +1248 & -63 & +1184 \\
\hline
\end{tabular}

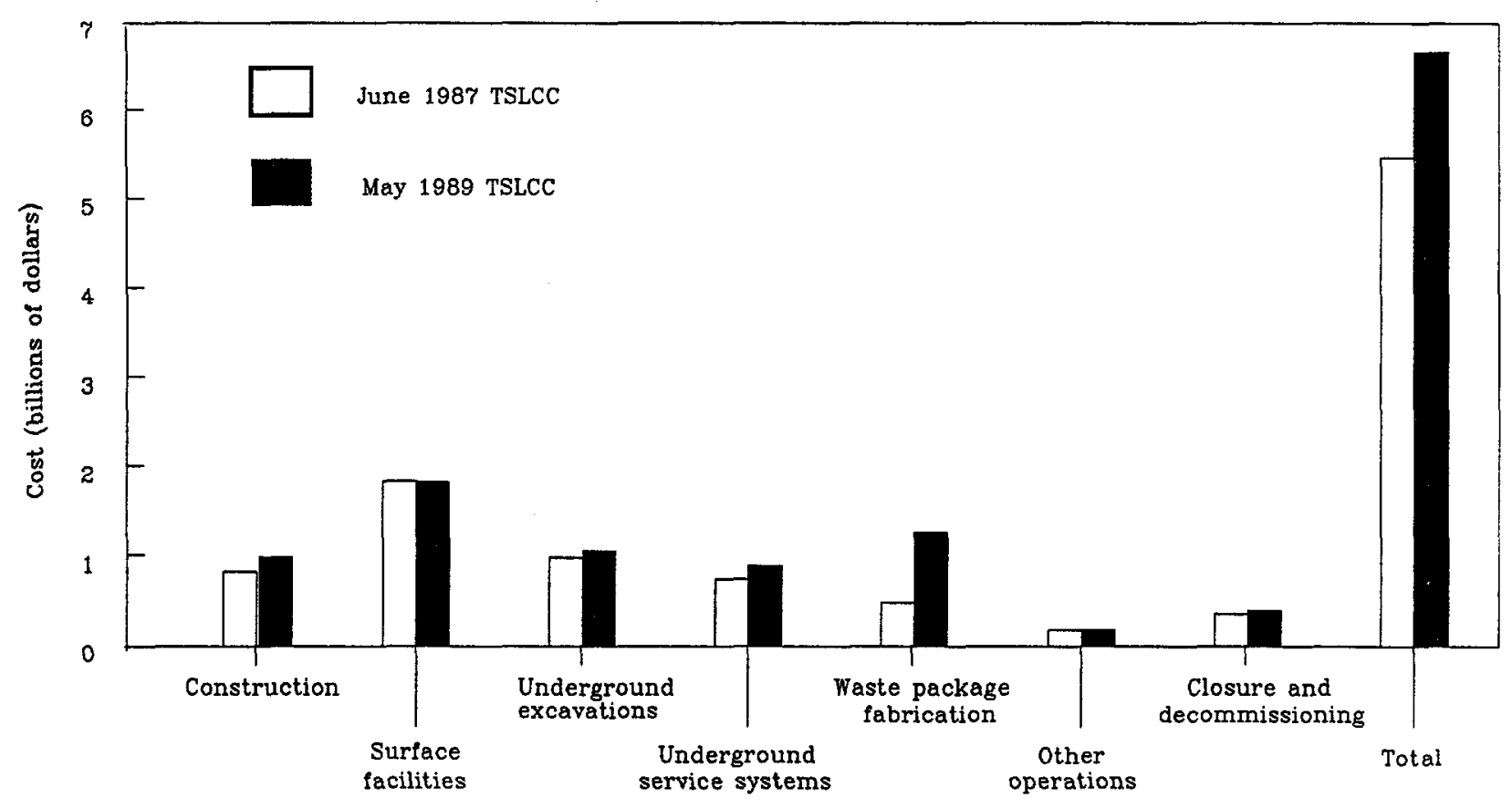

Figure 5-3. Comparison of Tuff first repository costs to previous estimates. 
method used an average annual heat rate for all assemblies. Again, the reader is referred to the notebook 8 for a detailed discussion of this method.

- The costs of operating the surface facilities decreased slightly because in this year's estimate, the waste-emplacement operations last one year less. The duration is shorter because less spent fuel is emplaced (last year's estimate was based on the EIA's upper reference case, whereas this year's estimate was based on the no-new-orders, end-of-1ife case). 
1. Nuclear Waste Policy Amendments Act of 1987, Public Law 100-203, December 22, 1987, 42 USC 10101 et seq.

2. O'Brien, P., OGR Repository-Specific Rod Consolidation Study: Effect on Costs, Schedules, and Operations at the Yucca Mountain Repository, SAND86-2357, Sandia National Laboratories, Albuquerque, N. Mex., December 1988.

3. Site Characterization - P1an Conceptual Design Report, SAND84-2641, Sandia National Laboratories, Albuquerque, N. Mex., September 1987.

4. MRS System Study for the Repository, SLTR88-7022, Sandia National Laboratories, Albuquerque, N. Mex., December 1988.

5. U.S. Nuclear Regulatory Commission, "Disposal of High-Leve1 Radioactive Wastes in Geologic Repositories," Code of Federal Regulations, "Energy", Title 10, Part 60, Washington, D.C., January 1986.

6. U.S. Department of Energy, Draft 1988 Mission Plan Amendment, DOE/RW-0187, Washington, D.C., June 1988 .

7. Roy F. Weston, Inc., WPLOG, Waste Package Logistics Model User's Manual, draft, Washington, D.C., March 1988.

8. Roy F. Weston, Inc., Cost Estimating Methods for the May 1989 Total-System Life-Cycle Cost Analysis, draft (to be published).

9. Pacific Northwest Laboratory, WASTES: Waste System Transportation and Economic Simulation--Release 24 User's Guide, PNL-5714-1, Rich1and, Wash., December 1988.

10. U.S. Department of Energy, Office of Civilian Radioactive Waste Management, Analysis of the Total System Life Cycle Cost for the Civilian Radioactive Waste Management Program, DOE/RW-0047, Washington, D.C., June 1987. 
The Nuclear Waste Policy Amendments Act of $1987^{1}$ (the Amendments Act) authorizes the Department of Energy (DOE) to site, construct, and operate a facility for monitored retrievable storage (MRS), subject to certain conditions. As a result, the DOE is including an MRS facility as an integral part of the authorized waste-management system, and the assumptions used in the TSLCC analysis are based on an integral MRS facility. In last year's TSLCC analysis, the MRS facility was not part of the authorized system; it was, however, included in the TSLCC analysis as part of a proposed "improvedperformance" system. This chapter presents some background information on the MRS facility and on the applicable provisions of the Amendments Act, describes the method used to estimate the costs of the MRS facility, presents the estimated costs, and compares the estimated costs with those of last year's TSLCC analysis.

\subsection{THE MRS FACILITY AND THE PROVISIONS OF THE AMENDMENTS ACT}

The Nuclear Waste Policy Act of $1982^{2}$ required the DOE to complete a study of the need for, and the feasibility of, an MRS facility and to submit to the Congress a proposal for the construction of one or more MRS facilities. In response to these requirements, the $\mathrm{DOE}$ completed, in the spring of 1985, a preliminary need-and-feasibility analysis ${ }^{3}$ and in March 1987 submitted to the Congress a proposal to construct and operate an MRS facility at a site on the Clinch River in the Roane County portion of Oak Ridge, Tennessee. ${ }^{4}$ The proposed MRS facility was to be fully integrated into the waste-management system, its principal functions being the preparation of spent fuel for disposal in a repository and serving as a hub for spent-fuel transportation.

The Amendments Act annulled and revoked the DOE's proposal. However, it authorized the DOE to site, construct, and operate an MRS facility as part of the Federal waste-management system subject to several conditions. An independent MRS Review Commission, appointed by the Congress, is to report to the Congress by November 1989 on the need for an MRS facility. After the Commission's report has been submitted, the DOE may survey, evaluate, and identify potentially suitable sites. However, the selection of the MRS site cannot take place until site characterization for the repository site has been completed and the Secretary of Energy has recommended to the President the approval of the repository site. The MRS site selected by the DOE must be approved by the Congress, and, as in the case of the repository site, the State or the affected Indian Tribe may submit a notice of disapproval that can be overridden only by a joint resolution of the Congress.

Once the selection of the MRS site is effective, the Secretary may submit an application to the Nuclear Regulatory Commission (NRC) for a 1icense to construct and operate the facility. The Amendments Act specifies several 
licensing conditions for the MRS facility. These conditions establish a connection between the MRS facility and the repository. First, the construction of the MRS facility cannot begin until the NRC has issued a construction authorization for the repository. Second, if the construction authorization for the repository is revoked or if the construction of the repository ceases, then the construction of, or waste acceptance by, the MRS facility must cease. The Amendments Act also specifies that no more than 10,000 metric tons of heavy metal (MTHM) can be stored at the MRS facility until the repository begins receiving waste; the quantity of waste present at the MRS site at any one time thereafter may not exceed 15,000 MTHM.

The Amendments Act permits another approach to the siting of an MRS facility. An MRS facility may be sited through the office of the Nuclear Waste Negotiator, who would attempt to find a State or an Indian Tribe willing to host an MRS facility at a technically qualified site on reasonable terms. This office would also negotiate a proposed agreement specifying the terms and conditions under which the State or the Indian Tribe would agree to host the MRS facility. In coordination with the Negotiator, the DOE is to make grants available to requesting States, Indian Tribes, or affected units of local government to assess the feasibility of siting an MRS facility within their jurisdictions.

\subsection{THE DESIGN AND OPERATIONS OF AN MRS FACILITY}

The DOE's MRS proposal of $1987^{4}$ included a conceptual design for an MRS facility whose principal function was to serve as a centralized facility for receiving commercial spent fuel and preparing it for disposal, including the consolidation of spent-fuel rods into more-compact arrays. In addition, the MRS facility was designed to provide temporary storage for up to 15,000 MTHM of spent fuel. However, in order to maximize the efficiency and performance of the total waste-management system, the DOE has recently re-evaluated both the desirability of consolidation in the waste-management system and the functions of the MRS facility. 5

The results of the DOE's studies indicate that intact spent fuel as received from reactors should be the waste form used as the basis for the advanced conceptual designs for the repository and the waste package. The DOE will not presume at this point that the spent fuel will be subjected to any operations like consolidation because there is no clear incentive for such operations. However, the desirability of such operations will be evaluated during the advanced conceptual design of the repository and the waste package.

Thus, the exact functions of the MRS facility have not yet been defined. The TSLCC analysis examined two cases from the MRS system study ${ }^{5}$ with different MRS design and operation characteristics. When consolidation is included in the system, the MRS facility performs the consolidation function, and the MRS design is based on the 1987 proposal to the Congress 4 and the accompanying conceptual design report. 6 When intact-fuel disposal is assumed, the MRS facility is mainly a "basic" MRS facility. The design of this 
assumed basic MRS facility is based on new design information developed as a variation from the design with consolidation.

\subsubsection{MRS facility that consolidates spent fuel}

The MRS facility that consolidates spent fuel consists of a receiving-and-handling building (the principal structure); an area for monitored storage; a plant for manufacturing concrete casks in which the spent fuel would be stored; and various support facilities, including an administration building, visitors center, maintenance shops, supply warehouse, fire station, and the water-treatment facility.

After arriving by truck or rail, the spent fuel would be unloaded into the receiving-and-handling building, where it would be prepared for subsequent emplacement in the repository. Many of the operations in this building would be performed by remote control inside shielded "hot cells" to protect the workers from exposure to radiation.

The waste-preparation operations include the consolidation of spent fuel. The objective of consolidation is to optimize transportation and waste-emplacement operations by reducing the volume of waste that must be handled. Consolidation would be accomplished by removing the spent-fuel rods from the hardware that holds them together in square assemblies and rearranging them in a tighter array. The non-fuel-bearing hardware of the fuel assemblies would be compacted and loaded into containers for shipment to the repository. After consolidation, the spent-fuel rods would be loaded and sealed into clean metal canisters for temporary storage at the MRS facility or for shipment to the repository. After loading, the outside surfaces of the canisters would be cleaned to remove any radioactive contamination. It was assumed that 5 percent of the spent fuel would be sealed in canisters as intact assemblies because of special circumstances, such as damaged rods, distorted assemb1ies, or unusual fuel characteristics (dimensions, burnup, or age). The secondary radioactive wastes resulting from the consolidation process (e.g., ventilation filters, trash) would be treated and packaged in 55-gallon drums for shipment to an offsite facility for the disposal of low-leve1 waste.

Three types of storage would be provided at the MRS facility: lag storage for incoming fue1, monitored retrievable storage in a storage yard, and vault storage for fuel that could be shipped to the repository after consolidation, without storage in the storage yard. Lag storage would be provided in the consolidation "hot" cells of the receiving-and-handling building with enough capacity for process surges and emergencies. Most of the spent-fuel storage capacity (up to 14,000 MTHM, if necessary) would be provided in the storage yard, where the waste canisters would be stored in sealed concrete casks on the surface. These dry-storage casks would provide radiation shielding, and each cask would be monitored for the release of radioactive material. The number of spent-fuel canisters stored in each cask would depend on the heat output and size of the canisters. The canisters stored in concrete casks would be retrievable at any time for examination, repair, or shipment to the 
repository. In addition to the yard storage, vault storage would be provided in the receiving-and-handling building; it would accommodate 1000 MTHM of spent fuel ready for shipment to the repository.

\subsubsection{MRS facility with intact-fuel disposal}

The MRS facility assumed in the cases with intact-fuel disposal is a "basic" facility. Its primary difference from the MRS described above is that it does not consolidate spent fuel or load spent fuel into canisters. The basic MRS facility was assumed to receive spent-fuel shipments from reactors, unload the spent fuel, and transfer the intact assemblies to transportation casks or storage casks, as necessary. This functional difference is largely confined to the receiving-and-handling building; the various support facilities, the administration building, the visitors center, the maintenance shops, the supply warehouse, the fire station, and the water-treatment facility are unaffected by this change. The removal of consolidation from the functions of the receiving-and-handling building simplifies the design and construction of the building. The operations of consolidation and loading into canisters are complex because the radioactivity of the spent-fuel necessitates massive shielding for the workers and remote operations inside the hot cells during the process of spent-fuel disassembly. The vault storage for up to 1000 MTHM was also removed from the receiving-and-handling building. In addition, the removal of consolidation reduces the secondary-waste quantities produced by the MRS facility.

Because of the aforementioned simplifications to the receiving-andhandling of the MRS facility, it was assumed that a basic MRS facility could begin operations much earlier than an MRS facility that consolidates spent fuel into canisters. This analysis has assumed that a basic MRS would start operations in the year 2000, whereas the MRS facility that consolidates would start operations in 2003. These start dates were assumed solely for cost-analysis purposes and are the same as the start dates assumed in Task J of the MRS system study ${ }^{5}$.

\subsubsection{MRS waste logistics and schedule}

As presented in Chapter 2, the MRS facility is assumed to have a maximum receipt or shipment rate of 3000 MTHM for both facility designs. The rates at which the facility achieves these maximum rates are identical for both consolidated- and intact-fuel disposal, although the basic MRS was assumed to start in 2000, and the MRS facility that consolidates into canisters was 
assumed to start in 2003. The ramp-up rates and storage inventories are as follows :

\begin{tabular}{|c|c|c|c|c|}
\hline \multirow[b]{2}{*}{ Year } & \multicolumn{2}{|c|}{ Basic MRS } & \multicolumn{2}{|c|}{ Consolidating MRS } \\
\hline & Receipts & Inventory & Receipts & Inventory \\
\hline 2000 & 1200 & 1200 & & \\
\hline 2001 & 1200 & 2400 & & \\
\hline 2002 & 2000 & 4400 & & \\
\hline 2003 & 2000 & 6000 & 1200 & 800 \\
\hline 2004 & 2700 & 8300 & 1200 & 1600 \\
\hline 2005 & 3000 & 10900 & 2000 & 3200 \\
\hline 2006 & 3000 & 13000 & 2000 & 4300 \\
\hline 2007 & 3000 & 14200 & 2700 & 5200 \\
\hline 2008 & 3000 & 14200 & 3000 & 5200 \\
\hline
\end{tabular}

As these data indicate, the MRS storage inventory climbs in both cases until 2008, when the repository reaches its design spent-fuel acceptance level of 3000 MTHM. Therefore, because the MRS is accepting 3000 MTHM per year from reactors and shipping 3000 MTHM per year to the repository, the MRS storage inventory will remain stable at the specified levels until the annual from-reactor receipts begin to differ from the shipments to the repository. In the single-repository cases, the MRS operates through 2042 in both cases. In the two-repository cases, the MRS facility was assumed to service only the first repository. In these cases the MRS operates through 2027. In all cases, decommissioning begins in the year before the last year of operations. For the basic MRS, decommissioning takes five years, which results in closure dates of 2045 and 2030 for the single-repository and two-repository cases, respectively. For the consolidate and canister MRS, decommissioning takes seven years, which results in closure dates of 2047 and 2032 for the single-repository and two-repository cases, respectively.

These data follow the provisions of the Amendments Act. Specifically no more than 10,000 MTHM can be stored at the MRS facility until the repository begins receiving waste and the quantity of waste present at the MRS site at any one time may not exceed 15,000 MTHM.

\subsection{METHOD OF ANALYSIS}

The MRS costs for the TSLCC analysis were estimated by the methods developed for the MRS system studies. 5 Operating costs were calculated from data developed for the MRS system studies by the MRS architect/engineer, including staffing levels by functional activity, maintenance and replacement costs, consumable-materials costs, and labor rates. These data were then used in conjunction with the waste logistics and characteristics developed specifically for each TSLCC case (see Chapter 2). 
To facilitate the development of the ISLCC cost estimates, the spreadsheet MRSCOST was modified. This spreadsheet was originally developed for the June 1987 TSLCC analysis and was baselined to the MRS 1ife-cycle cost analysis ${ }^{7}$ of the MRS conceptual design.6 The spreadsheet was modified to calculate MRS construction, operating, and decommissioning costs in a manner consistent with the approach followed in the MRS system studies. An example of the MRSCOST spreadsheet is presented in the notebook on cost-estimating methods. ${ }^{8}$

The design-and-construction costs include the costs of the MRS design and design support, construction and construction management, and training and testing. The costs for training and testing are included because these activities are associated with the startup of the MRS facility. The operations costs include the costs of the waste canisters, the concrete storage casks, and the concrete pads on which the casks are kept in the storage yard, labor and materials, utilities, and various consumable materials (e.g., drums and filters). The decommissioning costs include the costs of site decontamination and restoration to unrestricted use. Decommissioning costs were estimated for each building of the facility as well as the storage casks. The MRS facility was not assumed to be demolished.

Two factors that exert a significant effect on MRS costs are the requirements (derived from the system logistics) for waste canisters and the requirements for the concrete dry-storage casks. The number of waste canisters needed at the MRS facility is affected by the cumulative quantity of spent fuel to be received. The number of dry-storage casks depends on the number and the heat output of the waste canisters.

To calculate the required number of storage casks, the maximum number of canisters that would be stored in casks was estimated by subtracting the number of canisters shipped annually to the repository from the number of canisters annually loaded at the MRS facility; the latter was based on spentfuel receipts. The number of canisters requiring dry storage was then divided by the number of canisters that can be stored in each cask, which depends on the total heat generation and volume constraints. It was assumed that heat generation in the storage casks and radiation exposure must remain at or below the values given in the conceptual design.6 To calculate the annual number of canisters and the maximum number of storage casks needed, the MRS-torepository shipment data from the WASTES mode $1^{9}$ was used as input to the WPLOG model. 10

\subsection{RESULTS}

The estimated costs for MRS construction, operation, and decommissioning are summarized in Table 6-1 for each of the TSLCC cases described in Chapter 2. The MRS facility costs range from a low of $\$ 1.4$ billion to a high of $\$ 3.1$ billion. The most important variables are the spent-fuel total throughput and the MRS design. Within each design, all construction and decommissioning costs are the same. The only costs that differ are the operating costs, which vary with the number of years of operation, the 


\begin{tabular}{|c|c|c|c|c|c|}
\hline \multirow[b]{2}{*}{ Cost category } & \multicolumn{2}{|c|}{ Single repository } & \multicolumn{3}{|c|}{ Two repositories } \\
\hline & $\begin{array}{l}\text { Intact fuel } \\
\text { basic } \\
\text { MRS }\end{array}$ & $\begin{array}{l}\text { Consolidate } \\
\text { into canisters } \\
\text { at MRS }\end{array}$ & $\begin{array}{c}\text { Intact fuel } \\
\text { basic } \\
\text { MRS }\end{array}$ & $\begin{array}{l}\text { Consolidate } \\
\text { into canisters } \\
\text { ot MRS }\end{array}$ & $\begin{array}{l}\text { Consol idate into } \\
\text { canisters at MRS, } \\
\text { upper reference }\end{array}$ \\
\hline Construction & 343 & 837 & 343 & 837 & 837 \\
\hline Operation & 1442 & 2159 & 1020 & 1445 & 1444 \\
\hline Deconmissioning & 24 & 63 & 24 & 63 & 63 \\
\hline Total MRS facility costs & 1809 & 3059 & 1387 & 2345 & 2344 \\
\hline
\end{tabular}

spent-fuel throughput, and the storage inventory. In the single-repository cases, the MRS facility handles nearly 86,800 MTHM of spent-fuel and operates for over 40 years. The basic MRS costs $\$ 1.8$ billion in this case, and the consolidating MRS facility costs $\$ 3.1$ billion. In the two-repository cases, the MRS total throughput drops to just over 62,900 MTHM (a drop of about 27 percent) and the operations period decreases to between 25 and 28 years. As a result, the comparable MRS costs decline to $\$ 1.4$ billion for the basic facility and $\$ 2.3$ billion for the consolidating facility. This represents a 25-percent cost decrease in both cases.

Figures 6-1 and 6-2 depict the relative shares of the MRS cost by phase of operation for the single repository, basic MRS and the consolidate and canister MRS respectively.

\subsection{COMPARISON WITH PREVIOUS ESTIMATES}

Table 6-2 and Figure 6-3 compare the current MRS costs with the June $1987^{11}$ estimates for a two-repository system. The comparison shows the impacts of changes in TSLCC assumptions, data, and methods as well as the effects of the Amendments Act. The June 1987 costs are based on the upper-reference-case forecast, a first repository in tuff, a second repository in salt, and an integrated MRS facility. The current estimate is based on the no-new-orders forecast, a first repository in tuff, a generic second repository, and an MRS facility that consolidates spent fuel into canisters.

The cost differences attributable to changes in data and methods are due to inflation adjustments and a change in the routing logistics. The routing logistics were changed to eliminate direct shipments of spent fuel from the reactors to the repository. This increases the spent-fuel annual receipt rate at the MRS facility from 2700 MTHM to 3000 MTHM. 


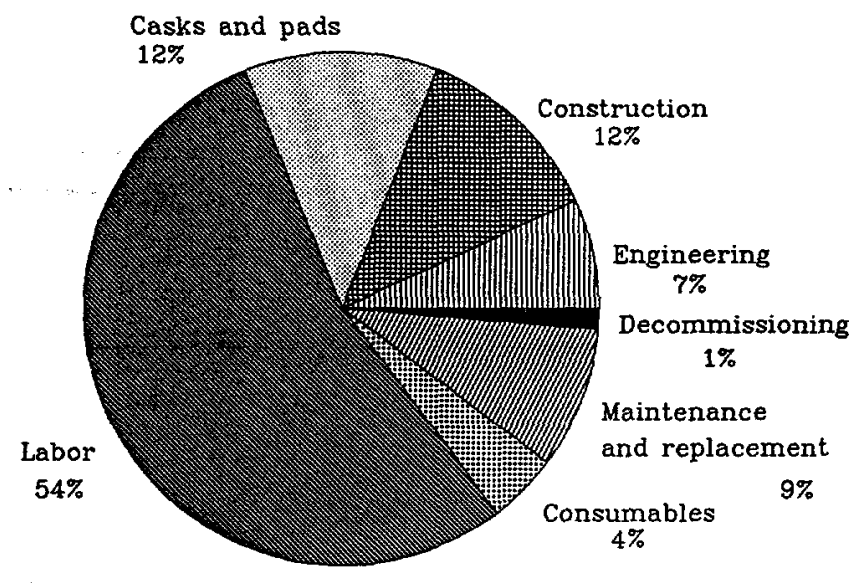

Figure 6-1. MRS costs by account for a one-repository system basic MRS facility.

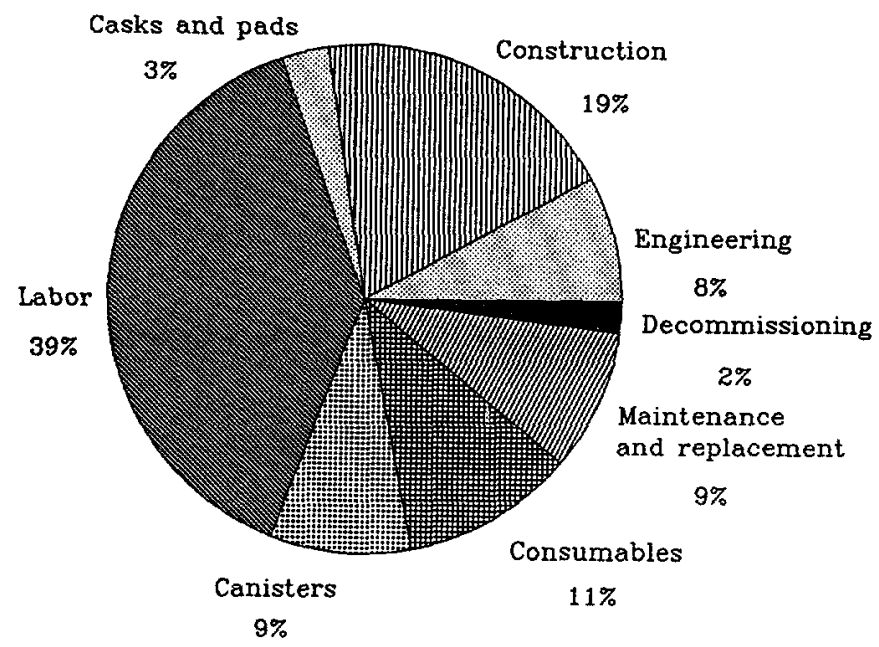

Figure 6-2. MRS costs by account for a one-repository system with an MRS facility that consolidates into canisters. 
Table 6-2. Comparison of MRS costs to previous estimates (Millions of constant dollars)

Changes

\begin{tabular}{|c|c|c|c|c|c|}
\hline \multirow[b]{2}{*}{ Cost category } & \multirow[b]{2}{*}{$\begin{array}{c}\text { June } 1987 \\
\text { TSLCC } \\
\text { ('86 dollars) }\end{array}$} & \multirow[b]{2}{*}{$\begin{array}{c}\text { May } 1989 \\
\text { TSLCC } \\
\text { ('88 dollars) }\end{array}$} & \\
\hline & & & $\begin{array}{l}\text { Due to } \\
\text { dataf } \\
\text { essumptions }\end{array}$ & $\begin{array}{l}\text { Due to } \\
\text { legislation }\end{array}$ & Total change \\
\hline $\begin{array}{l}\text { Operation } \\
\text { Storage casks and pads } \\
\text { Labor } \\
\text { Spent-fuel canisters } \\
\text { Consumables and ut il ities } \\
\text { Maintenance/replacement } \\
\text { Regulatory compl iance }\end{array}$ & $\begin{array}{r}336 \\
768 \\
113 \\
350 \\
229 \\
13\end{array}$ & $\begin{array}{r}90 \\
759 \\
190 \\
210 \\
196 \\
0\end{array}$ & $\begin{array}{r}-83 \\
+109 \\
+84 \\
-101 \\
-19 \\
-13\end{array}$ & $\begin{array}{r}-163 \\
-118 \\
-7 \\
-39 \\
-14 \\
-\end{array}$ & $\begin{array}{r}-246 \\
-9 \\
+77 \\
-140 \\
-33 \\
-13\end{array}$ \\
\hline Total operation & 1809 & 1445 & -23 & -341 & -364 \\
\hline $\begin{array}{l}\text { Engineering and construction } \\
\text { Decomissioning }\end{array}$ & $\begin{array}{r}817 \\
87\end{array}$ & $\begin{array}{r}837 \\
63\end{array}$ & $\begin{array}{l}+20 \\
-16\end{array}$ & -8 & $\begin{array}{l}+20 \\
-24\end{array}$ \\
\hline Total MRS facility costs & 2713 & 2345 & -19 & -349 & -368 \\
\hline
\end{tabular}

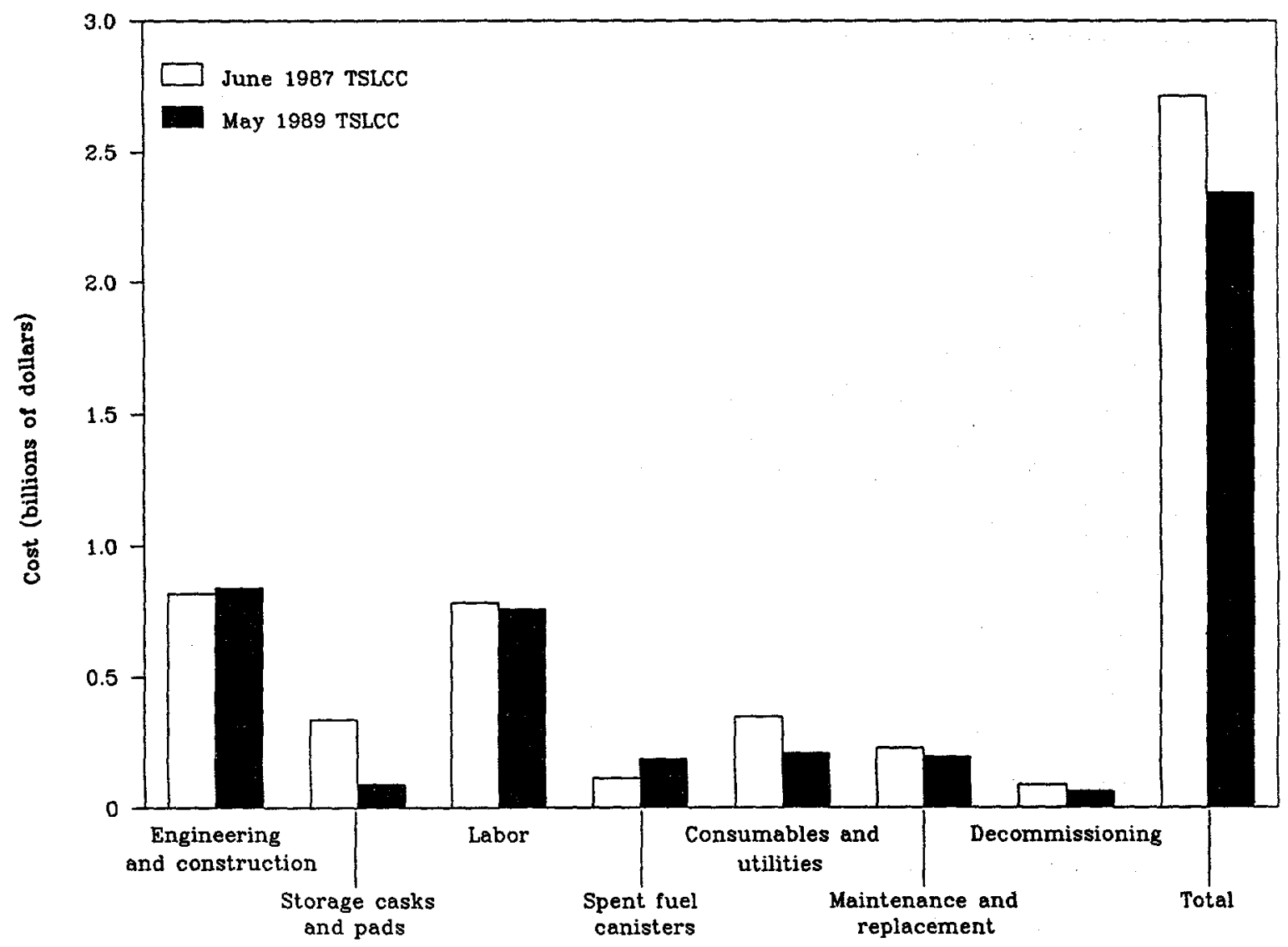

Figure 6-3. Comparison of MRS costs to previous estimates. 
One of the differences seen in Table $6-2$ is the higher cost of waste canisters in this year's analysis. This increase is due to the higher number of waste canisters calculated by the WPLOG model. For the current analysis, the WPLOG model calculated the number of canisters from the heat generated by the incoming spent-fuel assemblies and the heat limit imposed by the waste-package constraints. The heat calculation was based on spent-fuel age and burnup. For each canister, the model calculated the number of spent-fuel assemblies that could be accommodated while staying within the waste-package heat limit. The June 1987 TSLCC analysis, on the other hand, was based on an annual average heat output per canister, which allowed more spent-fuel assemblies to be loaded into canisters.

One of the effects of the Amendments Act is a large decrease in the costs of operation and decommissioning. These cost differences are due to the older age of the spent fuel accepted at the MRS facility because of the 5-year delay in startup (from 1998 to 2003) and a lower peak inventory of spent fuel in the MRS storage yard (from 14900 to 5200 MTHM), both of which not only decrease requirements for concrete storage casks and pads but also decrease the operating period for the MRS facility. The largest decrease is in the costs of the storage casks. 
1. Nuclear Waste Policy Amendments Act of 1987, Public Law 100-203, December 22, 1987, 42 USC 10101 et seq.

2. Nuclear Waste Policy Act of 1982 (NWPA), Public Law 97-425, January 7 , 1983, 42 USC 10101 et seq.

3. U.S. Department of Energy, Need for and Feasibility of Monitored Retrievable Storage--A Preliminary Analysis, DOE/RW-0022, Washington, D.C., 1985.

4. U.S. Department of Energy, Monitored Retrievable Storage Submission to Congress, DOE/RW-0035, three volumes, Washington, D.C., 1987.

5. U.S. Department of Energy, Office of Civilian Radioactive Waste Management, MRS System Study Summary Report (to be published).

6. Ralph M. Parsons Company, Integral Monitored Retrievable Storage (MRS) Facility, Conceptual Design Report, MRS-11, 1985.

7. Pacific Northwest Laboratory, Analysis of the Life-Cycle Cost for the Monitored Retrievable Storage Program, PNL-5952, draft, Richland, Wash., July 1986.

8. Roy F. Weston, Inc., Cost Estimating Methods for the May 1989 Total-System Life-Cycle Cost Analysis, draft (to be published).

9. Pacific Northwest Laboratory, WASTES: Waste System Transportation and Economic Simulation-Release 24 User's Guide, PNL-5714-1, Richland, Wash., December 1988.

10. Roy F. Weston, Inc., WPLOG, Waste Package Logistics Model User's Manual, draft, Washington, D.C., March 1988.

11. U.S. Department of Energy, Office of Civilian Radioactive Waste Management, Analysis of the Total System Life Cycle Cost for the Civilian Radioactive Waste Management Program, DOE/RW-0047, Washington, D.C., June 1987. 


\section{BENEFITS PAYMENTS}

The Nuclear Waste Policy Amendments Act of $1987^{1}$ (the Amendments Act) allows the Secretary of Energy to enter into benefits agreements with the State of Nevada concerning a repository and a State or Indian Tribe concerning a facility for monitored retrievable storage (MRS). As a result, a benefits component has been added to the total-system life-cycle cost (TSLCC) analysis. This chapter brief $1 \mathrm{y}$ discusses the provisions of the Amendments Act for benefits agreements, the method used to estimate the potential costs of these agreements, and the estimated costs of the agreements over the life of the Civilian Radioactive Waste Management Program.

\subsection{THE BENEFITS PROVISIONS OF THE AMENDMENTS ACT}

The Amendments Act specifies that a benefits agreement is to provide for the following:

1. The State or Indian Tribe is to receive annual payments for the life of the repository or the MRS facility.

2. The State or Indian Tribe may nominate members to the MRS or repository review pane1, as discussed in Section 4.2.3 of the Draft 1988 Mission P1an Amendment. 2

3. Parties to the agreement are to share information relevant to the licensing of the repository or the MRS facility.

4. The State or Indian Tribe may participate in the design of the repository or the MRS facility and in the preparation of documents relating to effects of the facility on health and safety.

In return for these benefits, the State or Indian Tribe waives its rights to disapprove the recommendation of a site for a repository or an MRS facility and its rights for funding for impact assistance as provided for by the Nuclear Waste Policy Act ${ }^{3}$, although some impacts may be mitigated by the Federal Government.

Any benefits agreement that is concluded with a state is to be negotiated in consultation with the affected units of local government in that State.* Furthermore, any state that is party to a benefits agreement is to transfer not less than one-third of the payment to affected units of local government in accordance with a plan that is to be included in the benefits agreement. Should there be a dispute about such a plan, the secretary of Energy is to resolve it consistent with the Amendments Act and applicable State law. Only one benefits agreement may be in effect at one time for a repository and only one for an MRS facility. 
The annual payment to the State of Nevada under a benefits agreement would be $\$ 10$ million upon execution of the agreement. It would remain at that level for each year until the start of waste acceptance at the repository. At that time, the annual payment would increase to $\$ 20$ million and remain at that level until the closure and decommissioning of the repository is complete.

For the MRS facility, the annual payment to the host state or Indian Tribe would be $\$ 5$ million upon execution of the agreement and until waste acceptance starts at the MRS facility. The annual payment would then increase to $\$ 10$ million and remain the same until the decommissioning of the MRS facility is complete.

The Amendments Act also provided that no benefits payments were to be made before January 1, 1989. In addition, the Amendments Act allows the Secretary of Energy to terminate a benefits agreement if the site under consideration fails to comply with the guidelines and technical requirements established in accordance with the Amendments Act or if the Secretary determines that a license for the facility cannot be obtained within a reasonable amount of time.

The DOE has offered to work with the State of Nevada to negotiate a benefits agreement, but the Governor of Nevada by a letter dated May 20, 1988, has declined the offer. Eventually, if an MRS facility is sited through the survey-and-evaluation process, the DOE will also be prepared to enter into negotiations for a benefits agreement with the State or Indian Tribe that has jurisdiction over the site.

\subsection{METHOD OF ANALYSIS}

In estimating the costs associated with the benefits agreements, the sums specified in the schedule of payments in Section 5031 of the Amendments Act were assumed to be in "year-of-expenditure" dollars. Thus, to be consistent with the other TSICC cost components, these costs were deflated in order to express them in constant 1988 dollars. The discussion of the annual payments schedules is expressed in year-of-expenditure dollars. The total benefits payments are expressed in constant 1988 dollars.

*An affected unit of local government is defined in the Amendments Act as the unit of local government with jurisdiction over the site of a repository or an MRS facility. At the discretion of the Secretary of Energy, units of local government that are contiguous with an affected unit may also be considered affected. In the State of Nevada, the affected units of local government are Nye County, which is an affected unit by definition because it contains the Yucca Mountain site, Clark County, and Lincoln County. The latter two counties have applied for, and have been granted, the status of affected unit of local government. 
For a repository, benefits payments to the State of Nevada were assumed to begin in 1990 at a rate of $\$ 10$ million (in year-of-expenditure dollars) per year. The acceptance of waste at the repository was assumed to start in 2003, at which time the payments to the State of Nevada increase to $\$ 20$ million per year. The annual payments remain at $\$ 20$ million until the closure and the decommissioning of the repository are completed.

Benefits payments for the MRS facility were also assumed to begin in 1990. These payments would start at $\$ 5$ million (year-of-expenditure do1lars) and would increase to $\$ 10$ million when the MRS facility begins accepting shipments of spent fuel. The basic MRS facility was assumed to open in the year 2000 in the case with intact-fuel disposal and 2003 in the consolidated-fuel cases. The payments would remain at $\$ 10$ million per year until the decommissioning of the facility is completed.

In the two-repository cases the benefits payments begin at $\$ 10$ million (year-of-expenditure dollars) per year. Using the rationale applied for the first repository, the benefits payments for the second repository were assumed to remain at $\$ 10$ million for an equivalent number of years preceding waste acceptance. The payments increase to $\$ 20$ million with the assumed start of waste acceptance and continue at this rate through closure and decommissioning.

\subsection{RESULTS}

Table 7-1 summarizes the results of the benefits payments analysis for the five TSLCC cases. Generally, the benefits payments for the TSLCC cases fall into two categories. The benefits in the one-repository cases total about $\$ 700$ million (constant 1988 dollars) for the repository and the MRS facility. The benefits in the two-repository cases total about $\$ 850$ million for the first repository, the MRS facility, and the second repository.

The benefits payments were slightly higher in the cases with intact-fuel disposal than in the consolidation cases because the MRS facility was assumed to start 3 years earlier. The benefits payments were identical in the comparable discharge-projection cases (the no-new-orders, end-of-1ife cases or the upper reference case). This reflects the fact that the operating life times for the first-repository, the MRS facility, and the second repository are identical in each case.

The benefits agreements require that the State or Indian Tribe waive its rights to additional funding for the mitigation of socioeconomic impacts. Therefore, the benefits costs are somewhat offset by the elimination of the costs for the mitigation of these impacts over the life cycle of the waste-management system. These costs were included in the development-andevaluation category of last year's TSLCC analysis and were estimated at $\$ 660$ million. 
Table 7-1. Summary of total benefits payments (Millions of 1988 dollars)

\begin{tabular}{|c|c|c|c|c|c|}
\hline \multirow[b]{2}{*}{ Cost category } & \multicolumn{2}{|c|}{ Single repository } & \multicolumn{3}{|c|}{ Two repositories } \\
\hline & $\begin{array}{l}\text { Intact fuel } \\
\text { basic } \\
\text { MRS }\end{array}$ & $\begin{array}{c}\text { Consolidate } \\
\text { into canisters } \\
\text { ot MRS }\end{array}$ & $\begin{array}{c}\text { Intact fuel } \\
\text { basic } \\
\text { MRS }\end{array}$ & $\begin{array}{c}\text { Consolidate } \\
\text { into canisters } \\
\text { at MRS }\end{array}$ & $\begin{array}{l}\text { Consolidate into } \\
\text { canisters at MRS, } \\
\text { upper reference }\end{array}$ \\
\hline First repository & 480 & 480 & 476 & 476 & 476 \\
\hline Second repository & 0 & 0 & 193 & 193 & 193 \\
\hline MRS facility & 221 & 214 & 187 & 182 & 182 \\
\hline Total benefits payments & 701 & 694 & 856 & 851 & 851 \\
\hline
\end{tabular}




\section{REFERENCES}

1. Nuclear Waste Policy Amendments Act of 1987, Public Law 100-203, December 22, 1987, 42 USC 10101 et seq.

2. U.S. Department of Energy, Draft 1988 OCRWM Mission P1an Amendment, DOE/RW-0187, Washington, D.C., June 1988.

3. Nuclear Waste Policy Act of 1982 (NWPA), Public Law 97-425, January 7, 1983, 42 USC 10101 et seq. 
Chapter 8

COSTS FOR THE DISPOSAL OF DEFENSE WASTE

As explained in the 1985 Mission $\mathrm{P} 1 \mathrm{an}^{1}$ and in subsequent Mission Plan amendments, 2,3 defense high-level waste (DHLW) will be accepted for disposal in the geologic repository being developed by the office of Civilian Radioactive Waste Management (OCRWM) of the Department of Energy (DOE). The defense high-level waste will be accepted by the OCRWM at its storage locations and transported directly to the repository in transportation casks that will be developed by the Civilian Radioactive Waste Management program and whose design will be certified by the Nuclear Regulatory Commission (NRC). The full cost for the transportation and the disposal of this waste, including interest, will be paid by the DOE's office of Defense Programs. This chapter begins with background information on the defense high-level waste and the method that will be used to determine the defense-waste share of the costs of the waste-management program. It then discusses the method in some detail and concludes with estimates of the costs.

\subsection{BACKGROUND INFORMATION}

\subsubsection{Description of the waste}

The defense high-level waste will be processed and solidified into a borosilicate glass or ceramic waste-form. The solidified waste will be packaged in thin-walled canisters prior to shipment. Estimates of the quantities of defense high-level waste that will be available for disposal are updated periodically, and the updated estimates are published every year in the DOE's Integrated Data Base Report. According to the Integrated Data Base for 1988,4 about 17,750 canisters (approximately 8875 metric tons of heavy metal (MTHM)) of defense high-level waste will be available for geologic disposal by the year 2030. This quantity is slightly greater than that reported in the 1985 Mission Plan and the 1987 Mission P1an Amendment ${ }^{2}$ $(16,000$ canisters, or about 8000 MTHM $)$.

\subsubsection{Current plans for the transportation and disposal of defense high-1eve1 waste}

Defense high-level waste will be shipped directly to the repository for disposal. In the TSLCC analysis it was assumed that in the two-repository system the defense waste would be divided between the two repositories in the same proportion as the spent fuel; that is, the first repository would accept equal proportions of spent fuel and defense high-level waste in relation to the total quantities of these wastes. At the repository, the canisters of high-level waste would be encapsulated in disposal containers and emplaced in the underground disposal rooms. According to current plans, none of the defense waste will be shipped to the MRS facility. 
The transportation of the defense high-level waste may require a cask configuration different from that for spent fuel because the physical dimensions of the high-level-waste canisters are different from those of spent-fuel assemblies and because the waste form is very different from spent-fuel rods. Work on casks for shipping high-level waste will be initiated after developing a strategy for transporting this waste. The DOE will determine whether it will be necessary to develop new casks or to modify existing "from-reactor" casks. It is assumed that the high-level waste will be shipped by rail.

\subsubsection{Payment for the transportation and disposal of defense high-level waste}

The Nuclear Waste Policy Act ${ }^{5}$ specifies that no waste, including defense waste, is to be accepted for disposal unless disposal fees have been paid and the DOE deposits, in the Nuclear Waste Fund, an amount of money equivalent to the fees paid by the civilian generators of the spent fuel. The method to be used in estimating the fee to be paid for defense-waste disposal was published in the Federal Register ${ }^{6}$ in August 1987. This approach, which is a modification of the preferred approach outlined in the notice of inquiry published in the Federal Register in December 1986,7 provided the basis for estimating the defense-waste share of costs for each case studied in this year's TSLCC analysis. According to this method, the costs of activities carried out solely for the disposal of a specific type of waste-civilian or defense--are directly assigned to the generators of the waste. A large portion of the program cost is to be shared by the utilities and the Federal Government on the basis of the numbers of disposal containers that are handled, the portion of the repository used for civilian or defense waste, and the use of various facilities at the repository. Costs that cannot be easily assigned to either type of waste are to be shared on the basis of the assignable costs.

It is important to note that the defense-waste fee will be based on cost estimates that will be refined annually as the program evolves. If the estimates of the quantities of defense high-level waste increase in the future, greater portions of fixed program costs will be assigned to the defense waste, thus reducing the costs assigned to civilian waste. It is also important to note that in the fee-adequacy analysis, which is performed to determine the adequacy of the fee collected from the owners and generators of civilian radioactive waste for the Nuclear Waste Fund, it is assumed that the DOE will pay the defense-waste cost share, with interest, and the adequacy of the civilian-waste fee is determined from the civilian-waste cost share only.

The cost estimates for defense high-level waste consist of both annual and total defense-waste costs for development and evaluation, transportation, repository, and benefits. Since the analysis was based on the assumption that no defense high-level waste is sent through the MRS facility, no MRS costs were allocated to defense high-level waste. 


\subsection{COST-ALLOCATION METHOD FOR DEFENSE HIGH-LEVEL WASTE}

The estimation of defense-waste costs is based on the concept of full cost recovery, with sharing formulas applied to all applicable system cost components. The costs of facilities and activities carried out solely for defense-waste disposal, such as defense-waste transportation and the fabrication of disposal containers for the defense waste, are directly allocated (100 percent) to defense high-level waste. Common costs for facilities and activities used for both defense and civilian waste are apportioned between the two types of waste. The portion of costs allocated to defense-waste disposal from a shared cost account is a fraction of the total cost, indicated by a "cost factor." A variety of cost-sharing factors are used, depending on the cost category to which the factor is applied.

The first step in the analysis is the definition of the basis for cost allocation. Each cost account, either for components or subsystems of components, is grouped into one of three cost categories:

1. Direct costs. These costs are incurred solely for the disposal of either defense or civilian wastes.

2. Common variable costs. The common variable costs are allocated to both defense and civilian wastes by applying one of two types of cost-sharing factors: sharing based on the number of disposal containers (defense waste or spent fuel) accepted (i.e., the "piece count") and sharing based on the mined volume (i.e., the "areal dispersion") for the disposal of defense waste or spent fuel. The cost-sharing factors are based on parameters that vary with the quantity of waste that is to be disposed of.

3. Common unassigned costs. These costs cannot be directly assigned or allocated on the basis of the above cost-sharing factors. Instead, factors that are derived by comparing the appropriate assignable costs of defense waste to the appropriate total assignable costs are applied to the costs in this category.

A summary of the allocation of cost accounts for this year's TSLCC analysis is given in Table 8-1.

The "piece-count" factor is defined as the ratio of defense-waste containers to the total number of disposal containers (defense high-level waste, civilian high-level waste, spent fuel, and the non-fuel-bearing hardware left after spent-fuel consolidation). Case-specific waste logistics and information on disposal-container designs were used to calculate the piece-count factors for each repository in each TSLCC case. The "arealdispersion" factor is the ratio of the volume of rock excavated in the underground repository for the disposal of defense waste to the total volume excavated for all wastes. This factor was used to allocate costs that vary more closely with the quantity of excavated rock than with the number of waste packages. Data on the design of the repository, such as the distance between 
waste-emplacement boreholes and excavation requirements, combined with the waste logistics, were used to compute the areal-dispersion factor for each repository. The cost factors used for each case are summarized in Appendix $F$.

The allocation of development-and-evaluation (D\&E) costs (see Chapter 3 ) as based on the specific D\&E cost accounts (Table 8-1). The MRS facility and waste-package $D \& E$ costs were directly assigned as civilian-waste costs. The allocation of D\&E costs in the transportation category was based on the proportion of defense-waste transportation costs to the total transportation costs. The defense-waste allocation of the other repository D\&E costs (non-waste-package costs) was based on the proportion of the assignable defense-waste repository costs to the total assignable repository costs. The defense-waste allocation of costs for administration by the Federal Government was based on the proportion of the total defense-waste assignable costs to the total-system assignable costs.

For the transportation of defense high-level waste, the costs of shipping and security, cask purchase, and cask maintenance were calculated separately, using the methods described in Chapter 4. The result of these calculations is a discrete (direct) cost for defense-waste transportation. The allocation for the last component in the transportation category, the cost of the cask-maintenance facility, was based on the proportion of the cask-miles traveled for defense waste to the total cask-miles traveled for the transportation of all wastes.

The defense-waste share of the repository costs (see Chapter 5) was annualized differently for the various phases of the repository life cycle. For the engineering-and-construction phase, the annual total engineering and construction costs were multiplied by the ratio of the engineering-andconstruction costs for defense waste (calculated by applying factors to each cost account) to the total engineering-and-construction costs to produce the annual defense-waste share of the costs. For the waste-emplacement phase, the total defense-waste cost was allocated on a "unit basis" (i.e., dollars per container) according to the acceptance schedule for defense waste. Therefore, no costs for defense-waste emplacement appear in years where no defense waste is emplaced. For the caretaker phase and the closure-anddecommissioning phase, the areal-dispersion factor was applied directly to the total annual cost to produce the annual defense-waste cost for each year. The annual defense-waste shares for each of the cost components were then summed to calculate the total defense-waste costs for each case. These defense-waste costs were then used in the fee-adequacy calculations. 
Table 8-1. Cost-allocation basis for defense high-level waste

Cost component

Development and evaluation (D\&E)

Repository

Cost account

Sharing basis

MRS facility

Waste package

Transportation and Systems

integration

Other repository $D \& E$ costs

Government administration

Management and integration

Site preparation

Waste-handling building

Other waste handling

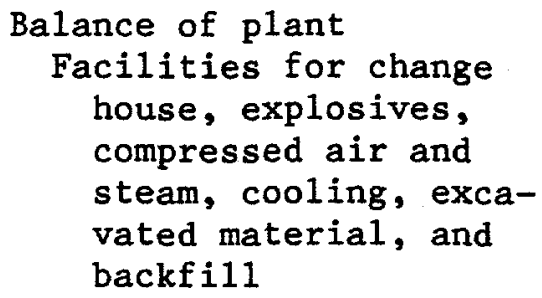

A11 other
Surface shaft facilities Waste facility
A11 other

Shafts and ramps

Underground waste handling

All other
Direct cost (civilian)

Direct cost (civilian)

Common unassigned cost (based on assignable transportation cost)

Common unassigned cost (based on assignable repository cost)

Common unassigned cost (based on total assignable cost)

Common unassigned cost (based on assignable repository cost)

Common unassigned cost (based on assignable repository cost)

Common variable cost (piece count)

Common variable cost (piece count)

Common variable cost (areal dispersion)

Common unassigned cost (based on assignable repository cost)

Common variable cost (piece count)

Common variable costs (area1 dispersion)

Common variable cost (piece count)

Common variable cost (area1 dispersion) 
Table 8-1. Cost-allocation basis for defense high-level waste

Cost component

Cost account

Sharing basis

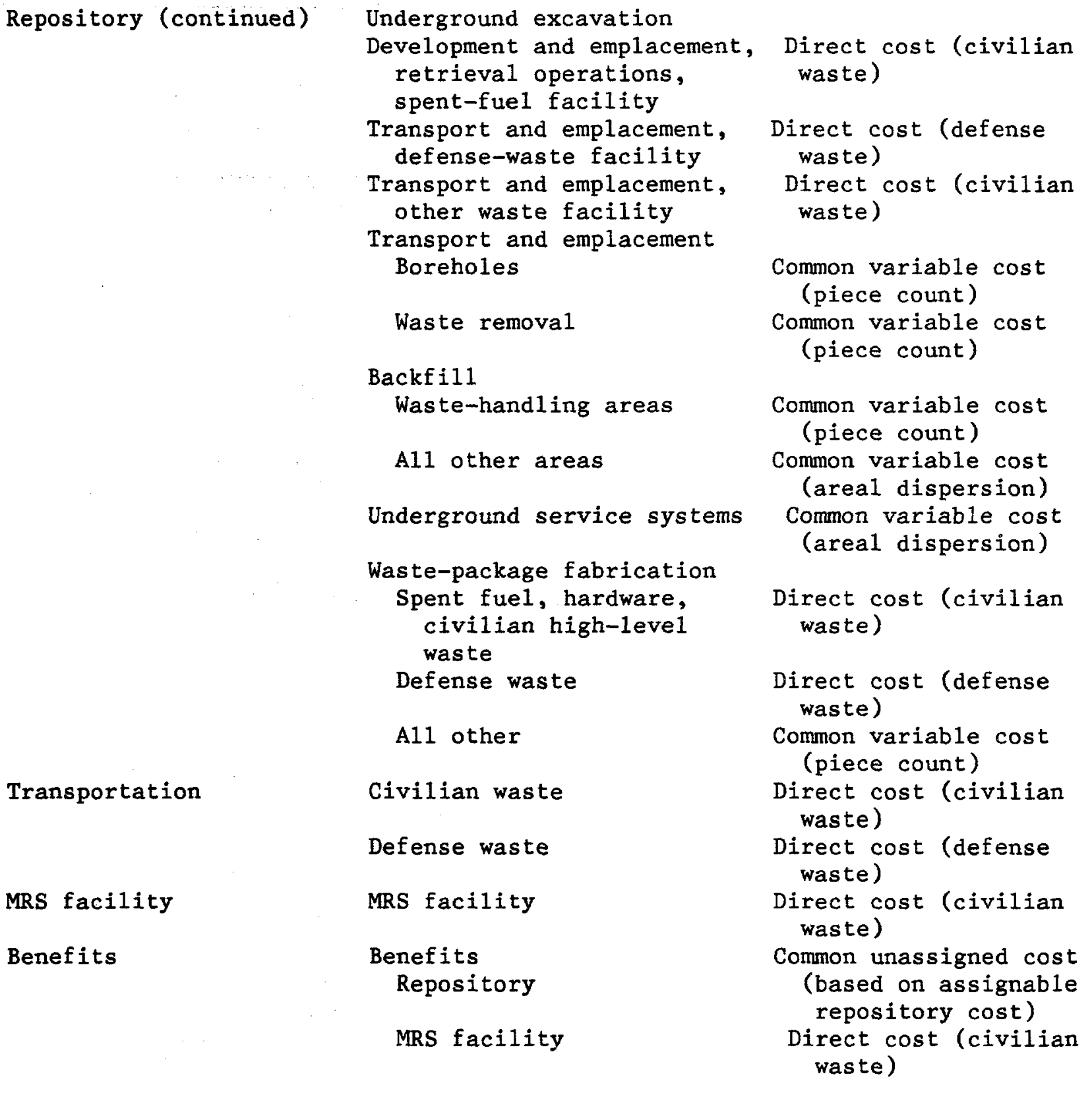




\subsection{RESULTS}

The defense-waste share of the total-system costs, calculated with the costing method described in the preceding section, are presented for all five TSLCC cases in Table 8-2 and Figure 8-1. Annual cost streams are provided in Appendix C. A11 estimates are based on a defense-waste quantity of 17,750 canisters, which was assumed to be equivalent to 8875 MTHM. As already mentioned, for the two-repository system, the defense waste was assumed to be divided between the two repositories, with the quantity sent to each repository depending on the proportion of the first-repository capacity (in metric tons of heavy metal) to the total quantity of wastes (spent fuel, civilian high-level waste, and defense high-level waste). In the no-new-orders, end-of-life case with two repositories, the first repository accepts approximately 73 percent of the total waste (civilian and defense). In the upper reference case with two repositories, the first repository accepts about 66 percent of the total waste.

The results indicate that the allocation of costs for the defense high-level waste was virtually unaffected by an increase in the projected quantity of civilian spent fuel. This can be attributed to the fact that an increase in the total quantity of waste to be disposed of results in changes to the quantity of defense waste to be accepted at each repository. As a result, there was a decrease in the quantity of defense waste to be emplaced in the first repository and a corresponding increase in the defense waste to be emplaced in the more-expensive second repository. The final result was an offsetting cost impact on the defense-waste share of the total-system cost.

\subsection{COMPARISON WITH PREVIOUS ESTIMATES}

Table 8-3 and Figure 8-2 compare the current defense-waste cost estimates with the June $1987^{8}$ estimates. This cost comparison reflects the changes due to assumptions, data, and methods as well as the effects of the Amendments Act. The June 1987 case was based on the upper reference case forecast with an integrated MRS facility and repositories in tuff and salt. The current case was based on the no-new-orders, end-of-life forecast with an "integrated" MRS facility and repositories in tuff and generic rock.

The table shows that the changes in assumptions, data, and methods created cost increases of nearly $\$ 2.9$ billion. These cost increases were somewhat offset by cost decreases of nearly $\$ 0.8$ billion that can be attributed to the passage of the Amendments Act. The net difference between the two sets of estimates was a cost increase for disposal of defense waste of nearly $\$ 2.1$ billion.

As was previously mentioned, the defense-waste allocation methodology currently used was based on the methodology described in a Federal Register notice published in August of 1987. The June 1987 TSLCC analysis was based on a Federal Register notice published in December of 1986 . Although the later methodology was basically a refinement of the earlier methodology, the refinement caused a cost increase for Defense Program waste. In addition to the changes in the defense waste allocation method, the defense waste costs were indirectly affected by cost increases to categories where the costs were 
Table 8-2. Sumary of defense waste and total-systen cost estimates (Millions of 1988 dollars)

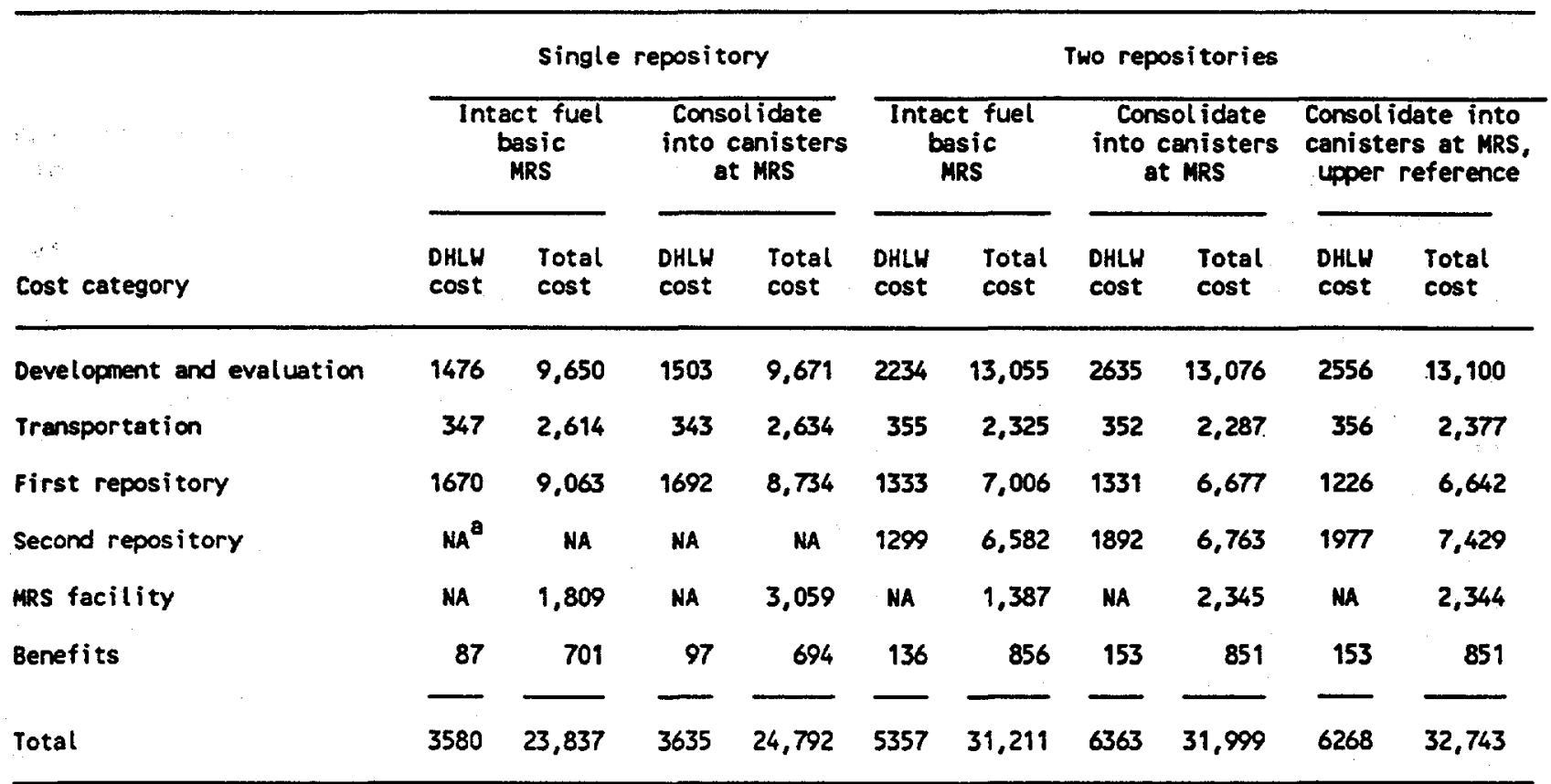

a Not applicable.

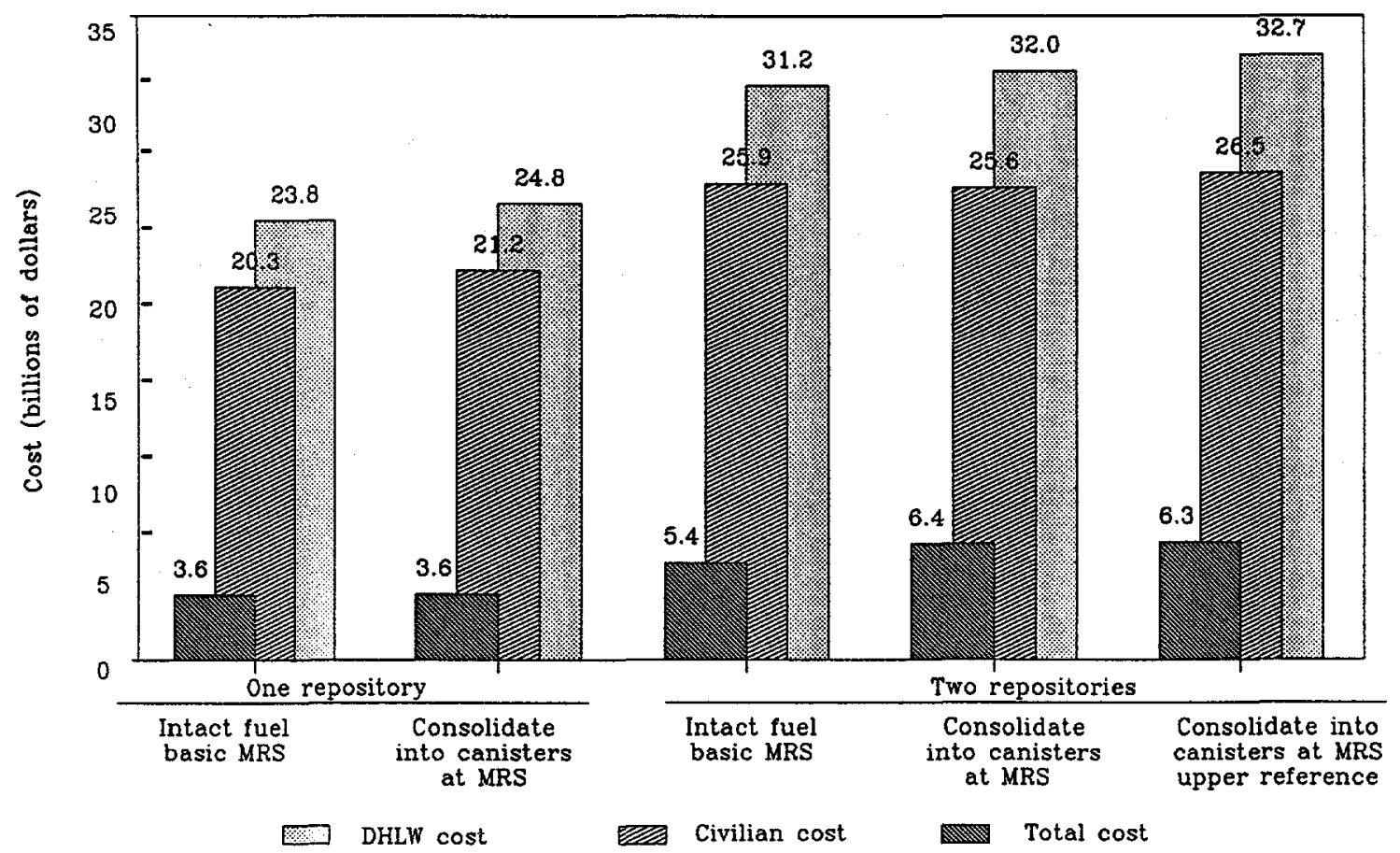

Figure 8-1. Summary of defense, civilian, and total life-cycle costs. 
shared (e.g. D\&E costs). Finally, the defense waste quantities assumed for the 1988 TSLCC represent an increase of about 11 percent over the quantity assumed in 1987.

The data, methods, and assumptions cost increases in the D\&E category were a result of cost increases in the total D\&E cost and the increased level of detail in allocating "unassigned" costs. Although the costs of defense transportation have changed for a number of reasons, the most important was the increase (approximately $\$ 500$ million) in the cask maintenance facility costs; the defense waste costs for this facility were allocated based on the total cask-miles travelled. The increased quantity of defense waste also increasesd transportation costs. The first repository costs increased by about 65 percent. This cost increase was largely caused by the proportional sharing of the repository capacity between civilian and defense waste. That is, the first repository was assumed to emplace an equal percentage of the total civilian and the total defense waste; in this case the first repository emplaces about 73 percent of the total civilian and defense waste, and its share of defense waste is 6453 MTHM. In last year's analysis, it was assumed that the two repositories each emplaced 4000 MTHM ( 8000 canisters). The proportional sharing therefore, results in an increase of about 60 percent in the quantity of defense waste in the first repository. The second-repository defense-waste costs have increased by about 20 percent. This is caused by changes in the second-repository estimates and to minor changes in the way defense-waste costs were allocated. (The defense wastes represent about 9 percent of the second-repository capacity in both the June 1987 and the May 1989 analyses because of the proportional sharing, an increased quantity of defense waste, and a much lower spent-fuel forecast.) These cost increases combined to create an increase of nearly 70 percent in the total-system defense-waste cost on account of changes in data, methods, and assumptions.

The incorporation of the Amendments Act into the TSLCC analysis resulted in a defense-waste cost decrease of $\$ 0.8$ billion. The decrease was virtually entirely attributable to the cost decreases to the total cost components which result in a decrease in the "amount" of the defense-waste share as opposed to a decrease in the share (percentage) itself. Specifically, cost decreases were found in the D\&E category because of the cost reductions cited in Chapter 3 and, in particular, the reduction of the number of sites to be characterized. Finally, the defense-waste costs were increased slightly by the inclusion of benefits payments. However, in the June 1987 analysis, the defense waste would have paid a share of the impact-mitigation costs, which have been replaced by the benefits payments.

The net impact of these changes was an increase of $\$ 2.1$ billion in the defense-waste cost share. It should be reiterated that the defense-waste quantities and cost estimates will be modified annually. 
Table 8-3. Comparison of defense waste costs to previous estimates (Millions of constant dollars)

\begin{tabular}{|c|c|c|c|c|c|}
\hline \multirow[b]{2}{*}{ Cost category } & \multirow[b]{2}{*}{$\begin{array}{c}\text { June } 1987 \\
\text { TSLCC } \\
\text { (' } 86 \text { dollars) }\end{array}$} & \multirow[b]{2}{*}{$\begin{array}{c}\text { May } 1989 \\
\text { TSLCC } \\
\text { ('88 dollars) }\end{array}$} & \multicolumn{3}{|c|}{ Changes } \\
\hline & & & $\begin{array}{l}\text { Due to } \\
\text { data/ } \\
\text { assumptions }\end{array}$ & $\begin{array}{l}\text { Due to } \\
\text { legislation }\end{array}$ & Total change \\
\hline Development and evaluation & 1655 & 2635 & +2005 & -1025 & +980 \\
\hline Transportation & 279 & 352 & +82 & -9 & +73 \\
\hline First repository & 780 & 1331 & +520 & +31 & +551 \\
\hline Second repository & 1564 & 1892 & +293 & +35 & +328 \\
\hline Benefits ${ }^{a}$ & $N A^{b}$ & 153 & - & +153 & +153 \\
\hline Total defense waste costs & 4278 & 6363 & +2900 & -815 & +2085 \\
\hline
\end{tabular}

Benefits were not included in the June 1987 TSLCC, but costs for impact mitigation were included in the develgpment and evaluation est imate.

Not appl icable.

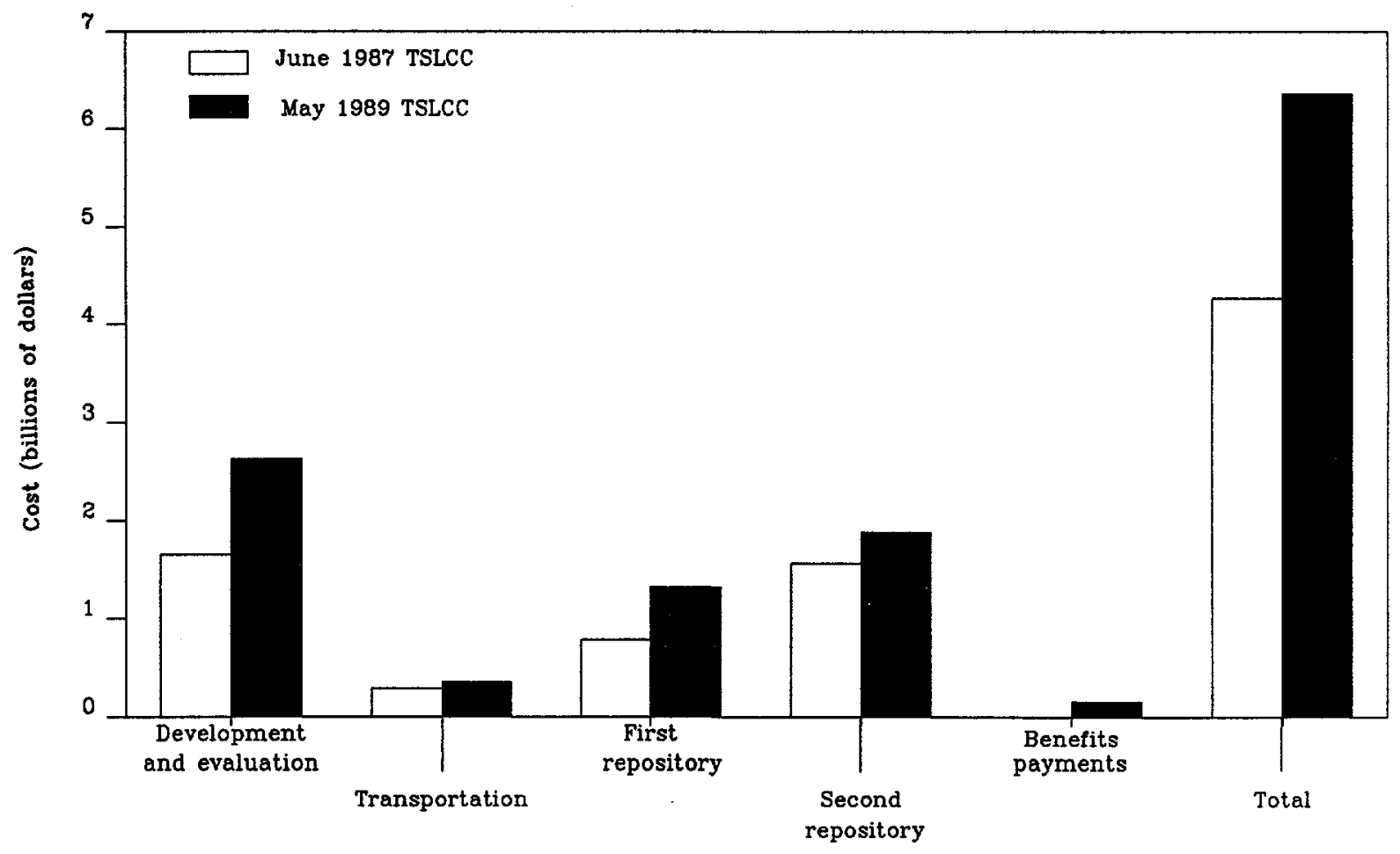

Figure 8-2. Comparison of defense cost allocation to previous estimates. 


\section{REFERENCES}

1. U.S. Department of Energy, Mission Plan for the Civilian Radioactive Waste Management Program, DOE/RW-0005, Washington, D.C., 1985.

2. U.S. Department of Energy, OCRWM Mission Plan Amendment, DOE/RW-0128, Washington, D.C., 1987.

3. U.S. Department of Energy, Draft 1988 Mission P1an Amendment, DOE/RW-0187, Washington, D.C., June 1988.

4. U.S. Department of Energy, Integrated Data Base for 1988: Spent Fuel and Radioactive Waste Inventories, Projections, and Characteristics, DOE/RW-0006, Rev. 4, Washington, D.C., 1988 .

5. Nuclear Waste Policy Act of 1982 (NWPA), Public Law 97-425, January 7 , 1983 , 42 USC 10101 et seq.

6. U.S. Department of Energy, "Civilian Radioactive Waste Management: Calculating Nuclear Waste Fund Disposal Fees for Department of Energy Defense Program Waste," Federal Register, Vol. 52, No. 161, August 20, 1987.

7. U.S. Department of Energy, office of Civilian Radioactive Waste Management, "Calculating Nuclear Waste Final Disposal Fees for DOE Defense Program Waste; Inquiry and Request for Public Comment," Docket No. OCRWM/NOI 86-101, Federal Register, Vol. 51, No. 231, December 2, 1986.

8. U.S. Department of Energy, office of Civilian Radioactive Waste Management, Analysis of the Total System Life Cycle Cost for the Civilian Radioactive Waste Management Program, DOE/RW-0047, Washington, D.C., June 1987. 
Chapter 9

RESULTS OF THE TSLCC ANALYSIS

Total-system costs were obtained by summing the estimated costs for each of the cost categories presented in the preceding chapters. For this year's analysis, a new cost category, benefits payments, is included in the estimates of total-system costs. This category is a direct result of the Nuclear Waste Policy Amendments Act. 1 The total-system costs range from $\$ 23.8$ billion for a single-repository system to $\$ 32.7$ billion for a two-repository system. The results for the cases studied in this analysis are summarized in Table 9-1 and discussed in this chapter.

\subsection{SINGLE REPOSITORY WITH INTACT-FUEL DISPOSAL}

The single-repository case with intact-fuel disposal and a basic MRS facility has a total-system cost of $\$ 23.8$ billion. The development-andevaluation component and the repository component account for more than 78 percent ( 40 and 38 percent, respectively) of the costs for the case. The transportation costs account for less than 11 percent, the MRS costs are about 8 percent, and the benefits payments add up to 3 percent. Figure 9-1 shows the costs by major cost component for this case.

\subsection{SINGLE REPOSITORY WITH CONSOLIDATION}

In the single-repository case with consolidation, the total-system cost is $\$ 24.8$ billion, or $\$ 1.0$ billion higher than in the case of intact-fuel disposal. Spent-fuel consolidation reduces repository costs by $\$ 0.3$ billion, but it increases MRS costs by about $\$ 1.3$ billion; the development-andevaluation costs and the benefits costs are essentially unchanged. The transportation costs are slightly increased because a combination of factors reduce the from-MRS efficiency of the transportation of consolidated spent fuel and hardware to a level that is about the same as the transportation efficiency of the large from-MRS cask specifically designed for intact spent fuel. The repository costs are reduced because consolidation reduces the number of waste packages and the required underground volume. The MRS costs are increased dramatically because the MRS facility that consolidates is much larger and more complicated than the basic MRS facility. In addition, in this case it was assumed that all the fuel is loaded into canisters at the MRS facility; the MRS cost includes the cost of this loading operation and the cost of the canisters themselves. Figure 9-2 shows the costs by major component for this case. Figure 9-3 shows the annual cost stream for the two single-repository cases. 
Table 9-1. Summary of total-system life-cycle cost estimates (Millions of 1988 dollars)

\begin{tabular}{|c|c|c|c|c|c|}
\hline \multirow[b]{2}{*}{ Cost category } & \multicolumn{2}{|c|}{ single repository } & \multicolumn{3}{|c|}{ Two repositories } \\
\hline & $\begin{array}{c}\text { Intact fuel } \\
\text { bas ic } \\
\text { MRS }\end{array}$ & $\begin{array}{c}\text { Consolidate } \\
\text { into canisters } \\
\text { at MRS }\end{array}$ & $\begin{array}{c}\text { Intact fuel } \\
\text { basic } \\
\text { MRs }\end{array}$ & $\begin{array}{c}\text { Consolidate } \\
\text { into canisters } \\
\text { at MRS }\end{array}$ & $\begin{array}{l}\text { Consolidate into } \\
\text { canisters at MRS, } \\
\text { upper reference }\end{array}$ \\
\hline Development and evaluation & 9,650 & 9,671 & 13,055 & 13,076 & 13,100 \\
\hline Transportation & 2,614 & 2,634 & 2,325 & 2,287 & 2,377 \\
\hline First repository & 9,063 & 8,734 & 7,006 & 6,677 & 6,642 \\
\hline Second repository & $\mathrm{NA}^{\mathrm{a}}$ & NA & 6,582 & 6,763 & 7,429 \\
\hline MRS facility & 1,809 & 3,059 & 1,387 & 2,345 & 2,344 \\
\hline Benefits & 701 & 694 & 856 & 851 & 851 \\
\hline Total system costs & 23,837 & 24,792 & 31,211 & 31,999 & 32,743 \\
\hline
\end{tabular}

$a_{\text {Not applicable. }}$

\subsection{TWO REPOSITORIES WITH INTACT-FUEL DISPOSAL}

The total-system cost for the two-repository case with intact-fuel disposal is $\$ 31.2$ billion, or $\$ 7.4$ billion higher than that for the comparable single-repository case. The development-and-evaluation costs are increased by $\$ 3.4$ billion because of the resumption of the second-repository program (site characterization, etc.). The transportation costs are decreased by $\$ 0.3$ billion because direct shipments from reactors to the centrally located second repository are less expensive than shipments to an MRS facility followed by shipments of unconsolidated spent fuel to a repository in Nevada. The firstrepository costs are decreased by $\$ 2.1$ billion because the facility was assumed to emplace only 70,000 metric tons of heavy metal (MTHM) which is about 26,000 MTHM less than in the single-repository case. The second repository, which was assumed to dispose of more than 26,000 MTHM in this case, costs $\$ 6.6$ billion. The second-repository costs are relatively high for two reasons: (1) the fixed repository costs (e.g., construction) are incurred regardless of the quantity of waste to be disposed of, and (2) the costs of the second repository are based on average mining conditions and costs; these appear high in relation to the relatively low mining costs for the tuff repository. The MRS costs are decreased by $\$ 0.4$ billion because the throughput is reduced by 26,000 MTHM and the operating 1 ife is reduced by 15 years. Finally, the benefits costs are increased by $\$ 0.2$ billion because of the inclusion of an assumed benefits agreement for the second repository. Figure 9-4 shows the cost for this case by component. 


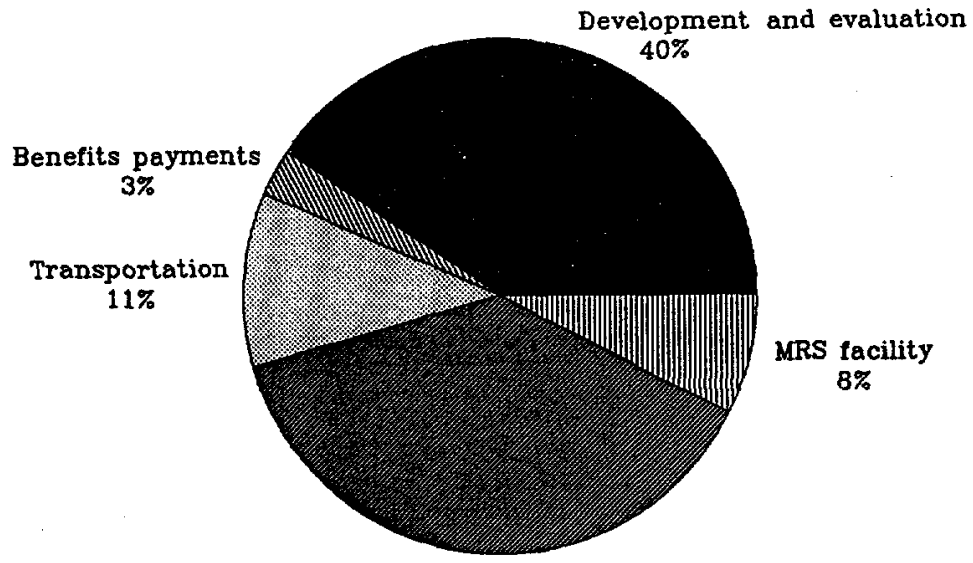

Single repository

$38 \%$

Figure 9-1. Total system costs by major cost component for a one-repository system with intact-fuel disposal and a basic MRS.

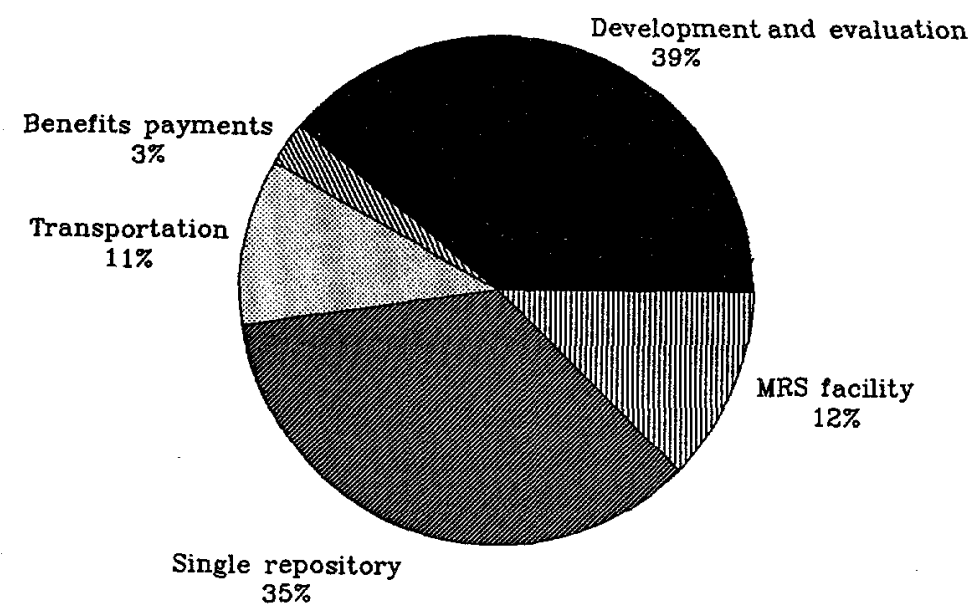

Figure 9-2. Total-system cost by major cost component for a one-repository system, with an MRS facility that consolidates into canisters. 


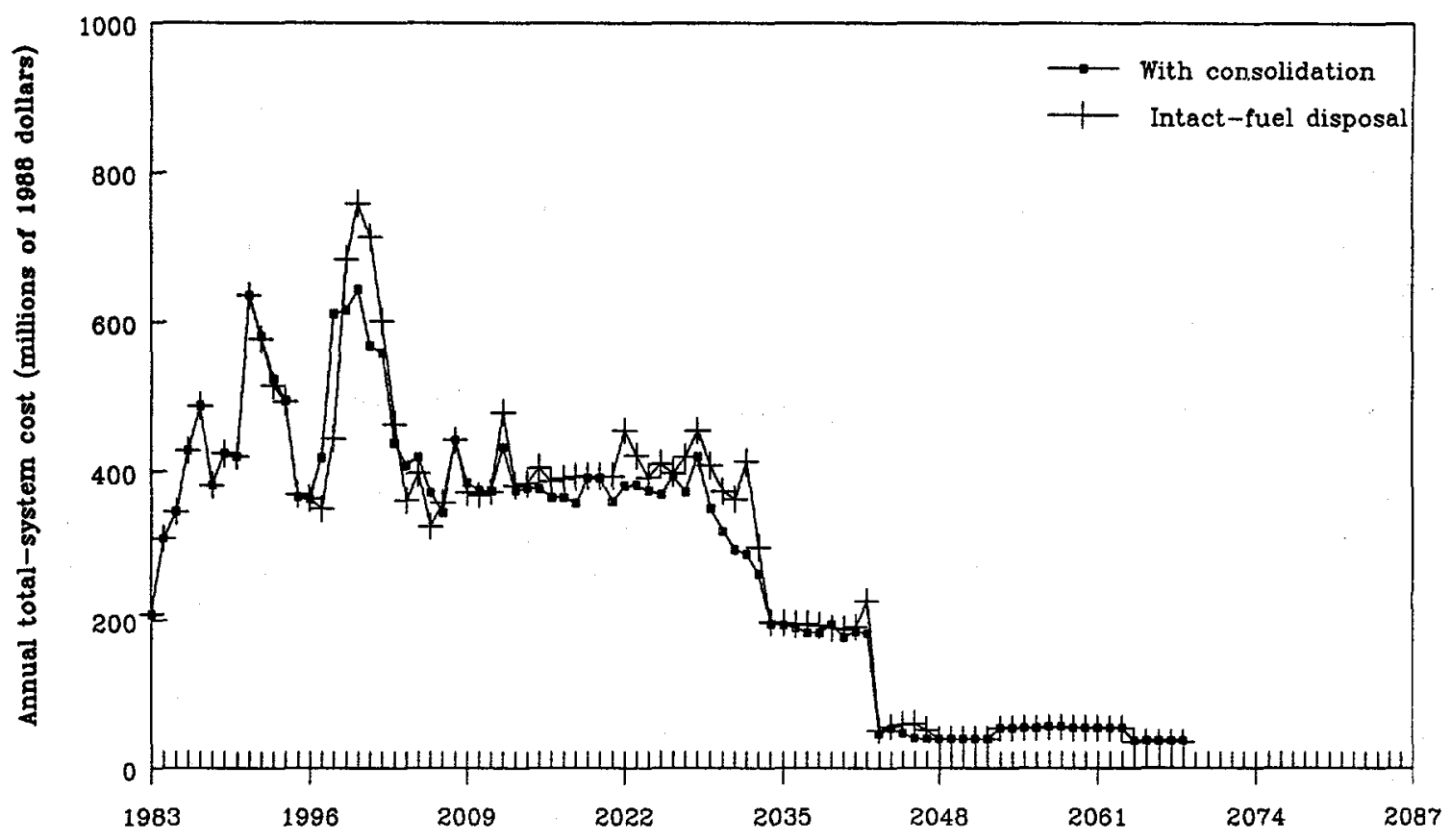

Figure 9-3. Annual total system costs for one-repository cases.

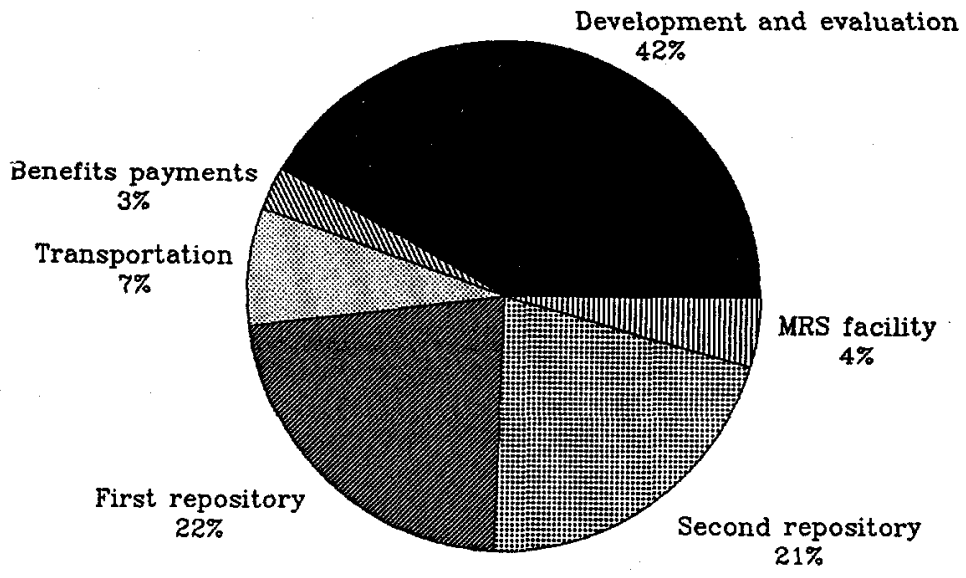

Figure 9-4. Total-system costs by major cost component for a two-repository system, with intact fuel and a basic MRS facility. 


\subsection{TWO REPOSITORIES WITH CONSOLIDATION}

The two-repository case with consolidation costs $\$ 32.0$ billion. This case costs $\$ 7.2$ billion more than the comparable single-repository case. The magnitude of the cost increase and the reasons for the cost increase are very similar to those explained for the two-repository case with intact-fuel disposal. Therefore, the differences with the single-repository case will not be discussed further.

This case indicates that the inclusion of consolidation in the wastemanagement system increases costs by about $\$ 0.8$ billion. This cost increase is similar to the increase found when consolidation was added to the single-repository case, and the reasons for the cost increase are also very similar. Costs for the first repository decrease and the costs for the second repository increase when consolidation is added to the system. The first-repository costs are decreased because the number of waste packages and the underground volume are decreased. The second-repository costs are also decreased by the smaller number of waste packages and the decrease in the mined volume, but the second repository cost decreases are more than offset by the cost increases of adding consolidation at the second repository. The first repository shows cost decreases in the consolidation cases because the spent fuel for the first repository is consolidated at the MRS facility, and for this reason MRS costs are increased by about $\$ 1.0$ billion. The MRS cost increase includes the construction and operations costs of the consolidation facilities and the costs for the packaging canisters.

\subsection{TWO REPOSITORIES WITH CONSOLIDATION--UPPER REFERENCE PROJECTION}

The final TSLCC case is based on the EIA upper reference case spent fuel discharge forecast, 2 which projects 96,900 MTHM of spent fuel versus the 86,800 MTHM of the no-new-orders, end-of-reactor-life case. The upper reference case was included in the TSLCC analysis to examine the cost impacts of increases in spent-fuel discharges. The TSLCC for this case is $\$ 32.7$ billion, or about $\$ 0.7$ billion higher than that for the comparable no-neworders, end-of-reactor-1ife case. Generally, the component costs for the two cases are similar, except that the transportation costs do increase slightly (by less than $\$ 0.1$ billion) because more waste is transported. Almost all of the cost impact in this case is at the second repository. The secondrepository costs are increased by nearly $\$ 0.7$ billion (or nearly 10 percent) because of the disposal of more waste.

While a $\$ 0.7$ billion cost increase seems relatively large, it represents an increase of less than 3 percent for an increase of nearly 12 percent in the total quantity of waste. This relatively small cost impact helps to point out the high fixed costs of the waste-management program. Figure 9-5 shows the annual cost streams for the three two-repository cases. 


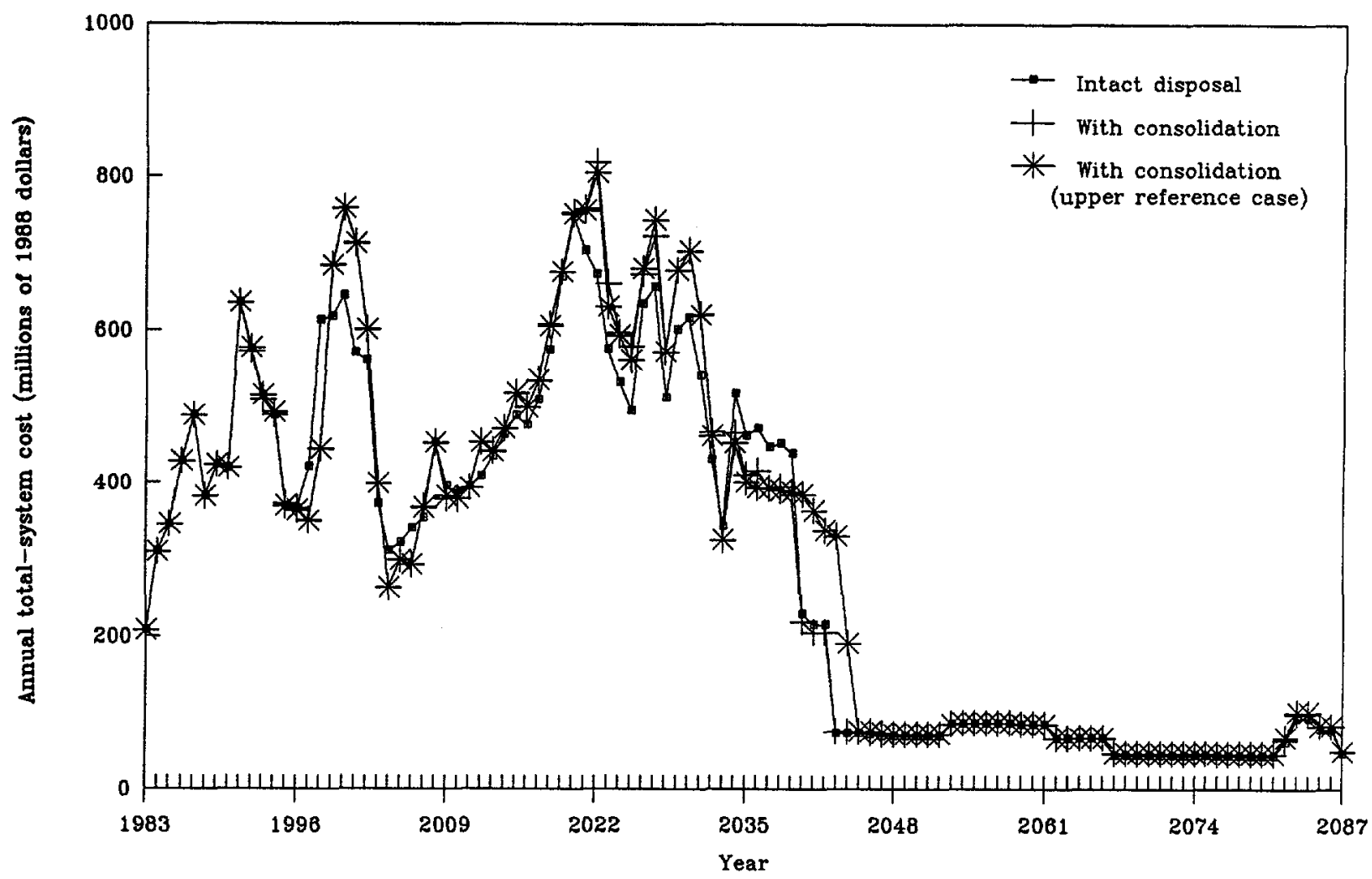

Figure 9-5. Annual total-system costs for two-repository cases.

\subsection{SUMMARY}

The total-system life-cycle costs range from $\$ 23.8$ to $\$ 32.8$ billion. For comparable cases (two-repository system with the reference spent-fuel forecast and spent-fuel consolidation), the cost is only slightly lower ( $\$ 0.1$ bilion) than last year's analysis despite numerous programmatic and design-data changes (see Chapter 1). This TSLCC analysis does indicate that program costs can be significantly reduced if a single repository is a feasible waste-management alternative. 


\section{REFERENCES}

1. Nuclear Waste Policy Amendments Act of 1987, Public Law 100-203, December $22,1987,4210101$ et seq.

2. U.S. Department of Energy, Energy Information Administration, World Nuclear Fuel Cycle Requirements 1988, DOE/EIA-0436(88), Washington, D.C., September 1988. 
Appendix A

WASTE ACCEPTANCE TABLES 
Table A-1. Waste-acceptance schedule for the single-repository system: no-new-orders, end-of-reactor-1 ife case, intact-fuel disposal

(Metric tons of heavy metal)

\begin{tabular}{|c|c|c|c|c|c|c|}
\hline \multirow[b]{2}{*}{ Year } & \multicolumn{2}{|c|}{ MRS facility } & \multicolumn{2}{|c|}{ Single repository } & \multicolumn{2}{|c|}{$\begin{array}{c}\text { Total annual } \\
\text { system acceptance }\end{array}$} \\
\hline & $\begin{array}{l}\text { Spent fuel } \\
\text { received }\end{array}$ & $\begin{array}{l}\text { Stored } \\
\text { at MRS }\end{array}$ & $\begin{array}{l}\text { Spent fuel } \\
\text { from MRS }\end{array}$ & $\begin{array}{l}\text { High-level } \\
\text { waste }\end{array}$ & $\begin{array}{l}\text { Spent } \\
\text { fuel }\end{array}$ & $\begin{array}{l}\text { Spent fuel } \\
\text { and high- } \\
\text { level waste }\end{array}$ \\
\hline $\begin{array}{l}2000 \\
2001 \\
2002 \\
2003 \\
2004 \\
2005 \\
2006 \\
2007 \\
2008 \\
2009 \\
2010 \\
2011 \\
2012 \\
2013 \\
2014 \\
2015 \\
2016 \\
2017 \\
2018 \\
2019 \\
2020 \\
2021 \\
2022 \\
2023 \\
2024 \\
2025 \\
2026 \\
2027 \\
2028 \\
2029 \\
2030 \\
2031 \\
2032 \\
2033 \\
2034 \\
2035 \\
2036 \\
2037 \\
2038 \\
2039 \\
2040 \\
2041 \\
2042\end{array}$ & $\begin{array}{r}1,200 \\
1,200 \\
2,000 \\
2,000 \\
2,700 \\
3,000 \\
3,000 \\
3,000 \\
3,000 \\
3,000 \\
3,000 \\
3,000 \\
3,000 \\
3,000 \\
3,000 \\
3,000 \\
3,000 \\
3,000 \\
3,000 \\
3,000 \\
3,000 \\
3,000 \\
3,000 \\
3,000 \\
3,000 \\
3,000 \\
3,000 \\
3,000 \\
3,000 \\
425 \\
425 \\
425 \\
425 \\
425 \\
425 \\
425 \\
425 \\
425 \\
425 \\
425 \\
425 \\
425 \\
132\end{array}$ & $\begin{array}{r}1,200 \\
2,400 \\
4,400 \\
6,000 \\
8,300 \\
10,900 \\
13,000 \\
14,200 \\
14,200 \\
14,200 \\
14,200 \\
14,200 \\
14,200 \\
14,200 \\
14,200 \\
14,200 \\
14,200 \\
14,200 \\
14,200 \\
14,200 \\
14,200 \\
14,200 \\
14,200 \\
14,200 \\
14,200 \\
14,200 \\
14,200 \\
14,200 \\
14,200 \\
11,625 \\
9,050 \\
6,475 \\
3,900 \\
1,325 \\
1,200 \\
1,075 \\
950 \\
825 \\
700 \\
500 \\
400 \\
450 \\
325 \\
140\end{array}$ & $\begin{array}{r}400 \\
400 \\
400 \\
900 \\
1,800 \\
3,000 \\
3,000 \\
3,000 \\
3,000 \\
3,000 \\
3,000 \\
3,000 \\
3,000 \\
3,000 \\
3,000 \\
3,000 \\
3,000 \\
3,000 \\
3,000 \\
3,000 \\
3,000 \\
3,000 \\
3,000 \\
3,000 \\
3,000 \\
3,000 \\
3,000 \\
3,000 \\
3,000 \\
3,000 \\
3,000 \\
550 \\
550 \\
550 \\
550 \\
550 \\
550 \\
550 \\
550 \\
457\end{array}$ & $\begin{array}{l}400 \\
400 \\
400 \\
400 \\
400 \\
400 \\
400 \\
400 \\
400 \\
400 \\
400 \\
400 \\
400 \\
400 \\
400 \\
400 \\
400 \\
400 \\
400 \\
400 \\
400 \\
400 \\
400 \\
315\end{array}$ & $\begin{array}{r}1,200 \\
1,200 \\
2,000 \\
2,000 \\
2,700 \\
3,000 \\
3,000 \\
3,000 \\
3,000 \\
3,000 \\
3,000 \\
3,000 \\
3,000 \\
3,000 \\
3,000 \\
3,000 \\
3,000 \\
3,000 \\
3,000 \\
3,000 \\
3,000 \\
3,000 \\
3,000 \\
3,000 \\
3,000 \\
3,000 \\
3,000 \\
3,000 \\
3,000 \\
425 \\
425 \\
425 \\
425 \\
425 \\
425 \\
425 \\
425 \\
425 \\
425 \\
425 \\
425 \\
425 \\
132\end{array}$ & $\begin{array}{r}1,200 \\
1,200 \\
2,000 \\
2,000 \\
2,700 \\
3,000 \\
3,000 \\
3,000 \\
3,400 \\
3,400 \\
3,400 \\
3,400 \\
3,400 \\
3,400 \\
3,400 \\
3,400 \\
3,400 \\
3,400 \\
3,400 \\
3,400 \\
3,400 \\
3,400 \\
3,400 \\
3,400 \\
3,400 \\
3,400 \\
3,400 \\
3,400 \\
3,400 \\
825 \\
825 \\
740 \\
425 \\
425 \\
425 \\
425 \\
425 \\
425 \\
425 \\
425 \\
425 \\
425 \\
132\end{array}$ \\
\hline Totals & 86,757 & & 86,757 & 9515 & 86,757 & 96,272 \\
\hline
\end{tabular}


Table A-2. Waste-acceptance schedule for the single-repository system: no-new-orders, end-of-1 ife case, consolidated-fuel disposal

(Metric tons of heavy metal)

\begin{tabular}{|c|c|c|c|c|c|c|}
\hline \multirow[b]{2}{*}{ Year } & \multicolumn{2}{|c|}{ MRS facility } & \multicolumn{2}{|c|}{ Single Repository } & \multicolumn{2}{|c|}{$\begin{array}{c}\text { Total annual } \\
\text { system acceptance }\end{array}$} \\
\hline & $\begin{array}{l}\text { Spent fuel } \\
\text { received }\end{array}$ & $\begin{array}{l}\text { Stored } \\
\text { at MRS }\end{array}$ & $\begin{array}{l}\text { Spent fuel } \\
\text { from MRS }\end{array}$ & $\begin{array}{c}\text { High-level } \\
\text { waste }\end{array}$ & $\begin{array}{l}\text { Spent } \\
\text { fuel }\end{array}$ & $\begin{array}{l}\text { Spent fuel } \\
\text { and high- } \\
\text { level waste }\end{array}$ \\
\hline $\begin{array}{l}2003 \\
2004 \\
2005 \\
2006 \\
2007 \\
2008 \\
2009 \\
2010 \\
2011 \\
2012 \\
2013 \\
2014 \\
2015 \\
2016 \\
2017 \\
2018 \\
2019 \\
2020 \\
2021 \\
2022 \\
2023 \\
2024 \\
2025 \\
2026 \\
2027 \\
2028 \\
2029 \\
2030 \\
2031 \\
2032 \\
2033 \\
2034 \\
2035 \\
2036 \\
2037 \\
2038 \\
2039 \\
2040 \\
2041 \\
2042\end{array}$ & $\begin{array}{r}1,200 \\
1,200 \\
2,000 \\
2,000 \\
2,700 \\
3,000 \\
3,000 \\
3,000 \\
3,000 \\
3,000 \\
3,000 \\
3,000 \\
3,000 \\
3,000 \\
3,000 \\
3,000 \\
3,000 \\
3,000 \\
3,000 \\
3,000 \\
3,000 \\
3,000 \\
3,000 \\
3,000 \\
3,000 \\
3,000 \\
3,000 \\
3,000 \\
3,000 \\
3,000 \\
275 \\
275 \\
275 \\
275 \\
275 \\
275 \\
275 \\
275 \\
275 \\
182\end{array}$ & $\begin{array}{r}800 \\
1,600 \\
3,200 \\
4,300 \\
5,200 \\
5,200 \\
5,200 \\
5,200 \\
5,200 \\
5,200 \\
5,200 \\
5,200 \\
5,200 \\
5,200 \\
5,200 \\
5,200 \\
5,200 \\
5,200 \\
5,200 \\
5,200 \\
5,200 \\
5,200 \\
5,200 \\
5,200 \\
5,200 \\
5,200 \\
5,200 \\
5,200 \\
5,200 \\
5,200 \\
2,475 \\
2,200 \\
1,925 \\
1,650 \\
1,375 \\
1,100 \\
825 \\
550 \\
275 \\
0\end{array}$ & $\begin{array}{r}400 \\
400 \\
400 \\
900 \\
1,800 \\
3,000 \\
3,000 \\
3,000 \\
3,000 \\
3,000 \\
3,000 \\
3,000 \\
3,000 \\
3,000 \\
3,000 \\
3,000 \\
3,000 \\
3,000 \\
3,000 \\
3,000 \\
3,000 \\
3,000 \\
3,000 \\
3,000 \\
3,000 \\
3,000 \\
3,000 \\
3,000 \\
3,000 \\
3,000 \\
3,000 \\
550 \\
550 \\
550 \\
550 \\
550 \\
550 \\
550 \\
550 \\
457\end{array}$ & $\begin{array}{l}400 \\
400 \\
400 \\
400 \\
400 \\
400 \\
400 \\
400 \\
400 \\
400 \\
400 \\
400 \\
400 \\
400 \\
400 \\
400 \\
400 \\
400 \\
400 \\
400 \\
400 \\
400 \\
400 \\
315\end{array}$ & $\begin{array}{r}1,200 \\
1,200 \\
2,000 \\
2,000 \\
2,700 \\
3,000 \\
3,000 \\
3,000 \\
3,000 \\
3,000 \\
3,000 \\
3,000 \\
3,000 \\
3,000 \\
3,000 \\
3,000 \\
3,000 \\
3,000 \\
3,000 \\
3,000 \\
3,000 \\
3,000 \\
3,000 \\
3,000 \\
3,000 \\
3,000 \\
3,000 \\
3,000 \\
3,000 \\
3,000 \\
275 \\
275 \\
275 \\
275 \\
275 \\
275 \\
275 \\
275 \\
275 \\
182\end{array}$ & $\begin{array}{r}1,200 \\
1,200 \\
2,000 \\
2,000 \\
2,700 \\
3,400 \\
3,400 \\
3,400 \\
3,400 \\
3,400 \\
3,400 \\
3,400 \\
3,400 \\
3,400 \\
3,400 \\
3,400 \\
3,400 \\
3,400 \\
3,400 \\
3,400 \\
3,400 \\
3,400 \\
3,400 \\
3,400 \\
3,400 \\
3,400 \\
3,400 \\
3,400 \\
3,315 \\
3,000 \\
275 \\
275 \\
275 \\
275 \\
275 \\
275 \\
275 \\
275 \\
275 \\
182\end{array}$ \\
\hline Totals & 86,757 & & 86,757 & 9515 & 86,757 & 96,272 \\
\hline
\end{tabular}


Table A-3. Waste-acceptance schedule for the two-repository system: no-new-orders, end-of-reactor-life case, intact-fuel disposal

(Metric tons of heavy metal)

\begin{tabular}{|c|c|c|c|c|c|c|c|c|}
\hline \multirow[b]{2}{*}{ Year } & \multicolumn{2}{|c|}{ MRS facility } & \multicolumn{2}{|c|}{ First repository } & \multicolumn{2}{|c|}{ Second repository } & \multicolumn{2}{|c|}{$\begin{array}{c}\text { Total annual } \\
\text { system acceptance }\end{array}$} \\
\hline & $\begin{array}{l}\text { Spent fuel } \\
\text { received }\end{array}$ & $\begin{array}{l}\text { Stored } \\
\text { at MRS }\end{array}$ & $\begin{array}{l}\text { Spent fuel } \\
\text { from MRS }\end{array}$ & $\begin{array}{l}\text { High-level } \\
\text { waste }\end{array}$ & $\begin{array}{l}\text { Spent } \\
\text { fuel }\end{array}$ & $\begin{array}{c}\text { High-1 evel } \\
\text { waste }\end{array}$ & $\begin{array}{l}\text { Spent } \\
\text { fuel }\end{array}$ & $\begin{array}{l}\text { Spent fuel } \\
\text { and high- } \\
\text { level waste }\end{array}$ \\
\hline $\begin{array}{l}2000 \\
2001 \\
2002 \\
2003 \\
2004 \\
2005 \\
2006 \\
2007 \\
2008 \\
2009 \\
2010 \\
2011 \\
2012 \\
2013 \\
2014 \\
2015 \\
2016 \\
2017 \\
2018 \\
2019 \\
2020 \\
2021 \\
2022 \\
2023 \\
2024 \\
2025 \\
2026 \\
2027 \\
2028 \\
2029 \\
2030 \\
2031 \\
2032 \\
2033 \\
2034 \\
2035 \\
2036 \\
2037 \\
2038 \\
2039 \\
2040 \\
2041 \\
2042\end{array}$ & $\begin{array}{l}1,200 \\
1,200 \\
2,000 \\
2,000 \\
2,700 \\
3,000 \\
3,000 \\
3,000 \\
3,000 \\
3,000 \\
3,000 \\
3,000 \\
3,000 \\
3,000 \\
3,000 \\
3,000 \\
3,000 \\
3,000 \\
3,000 \\
3,000 \\
3,000 \\
3,000 \\
2,807\end{array}$ & $\begin{array}{r}1,200 \\
2,400 \\
4,400 \\
6,000 \\
8,300 \\
10,900 \\
13,000 \\
14,200 \\
14,200 \\
14,200 \\
14,200 \\
14,200 \\
14,200 \\
14,200 \\
14,200 \\
14,200 \\
14,200 \\
14,200 \\
14,200 \\
14,200 \\
14,200 \\
14,200 \\
14,007 \\
11,007 \\
8,007 \\
5,007 \\
2,007 \\
0\end{array}$ & $\begin{array}{r}400 \\
400 \\
400 \\
900 \\
1,800 \\
3,000 \\
3,000 \\
3,000 \\
3,000 \\
3,000 \\
3,000 \\
3,000 \\
3,000 \\
3,000 \\
3,000 \\
3,000 \\
3,000 \\
3,000 \\
3,000 \\
3,000 \\
3,000 \\
3,000 \\
3,000 \\
3,000 \\
2,007\end{array}$ & $\begin{array}{l}400 \\
400 \\
400 \\
400 \\
400 \\
400 \\
400 \\
400 \\
400 \\
400 \\
400 \\
400 \\
400 \\
400 \\
400 \\
400 \\
400 \\
293\end{array}$ & $\begin{array}{r}900 \\
1,800 \\
3,000 \\
3,000 \\
3,000 \\
3,000 \\
3,000 \\
3,000 \\
1,050 \\
1,050 \\
1,050\end{array}$ & 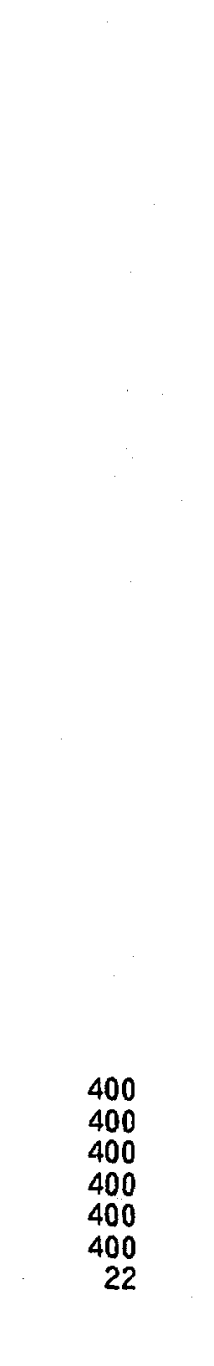 & $\begin{array}{r}1,200 \\
1,200 \\
2,000 \\
2,000 \\
2,700 \\
3,000 \\
3,000 \\
3,000 \\
3,000 \\
3,000 \\
3,000 \\
3,000 \\
3,000 \\
3,000 \\
3,000 \\
3,000 \\
3,000 \\
3,000 \\
3,000 \\
3,000 \\
3,000 \\
3,000 \\
2,807 \\
0 \\
0 \\
0 \\
1,800 \\
3,000 \\
3,000 \\
3,000 \\
3,000 \\
3,000 \\
3,000 \\
1,050 \\
1,050 \\
1,050 \\
00 \\
0\end{array}$ & $\begin{array}{r}1,200 \\
1,200 \\
2,000 \\
2,000 \\
2,700 \\
3,000 \\
3,000 \\
3,000 \\
3,400 \\
3,400 \\
3,400 \\
3,400 \\
3,400 \\
3,400 \\
3,400 \\
3,400 \\
3,400 \\
3,400 \\
3,400 \\
3,400 \\
3,400 \\
3,400 \\
3,207 \\
400 \\
400 \\
293 \\
3, \\
3,400 \\
3,400 \\
3,400 \\
3,400 \\
3,400 \\
1,072 \\
1,050 \\
1,050 \\
00 \\
0 \\
0 \\
0\end{array}$ \\
\hline Totals & 62,907 & & 62,907 & 7093 & 23,850 & 2422 & 86,757 & 96,272 \\
\hline
\end{tabular}


Table A-4. Waste-acceptance schedule for the two-repository system: no-new-orders, end-of-reactor-life case, consolidated-fuel disposal

(Metric tons of heavy metal)

\begin{tabular}{|c|c|c|c|c|c|c|c|c|}
\hline \multirow[b]{2}{*}{ Year } & \multicolumn{2}{|c|}{ MRS facility } & \multicolumn{2}{|c|}{ First repository } & \multicolumn{2}{|c|}{ Second repository } & \multicolumn{2}{|c|}{$\begin{array}{c}\text { Total annual } \\
\text { system acceptance }\end{array}$} \\
\hline & $\begin{array}{l}\text { Spent fuel } \\
\text { received }\end{array}$ & $\begin{array}{l}\text { Stored } \\
\text { at MRS }\end{array}$ & $\begin{array}{l}\text { Spent fuel } \\
\text { from MRS }\end{array}$ & $\begin{array}{l}\text { High-l evel } \\
\text { waste }\end{array}$ & $\begin{array}{l}\text { Spent } \\
\text { fuel }\end{array}$ & $\begin{array}{l}\text { High-level } \\
\text { waste }\end{array}$ & $\begin{array}{l}\text { Spent } \\
\text { fuel }\end{array}$ & $\begin{array}{l}\text { Spent fuel } \\
\text { and high- } \\
\text { level waste }\end{array}$ \\
\hline $\begin{array}{l}2003 \\
2004 \\
2005 \\
2006 \\
2007 \\
2008 \\
2009 \\
2010 \\
2011 \\
2012 \\
2013 \\
2014 \\
2015 \\
2016 \\
2017 \\
2018 \\
2019 \\
2020 \\
2021 \\
2022 \\
2023 \\
2024 \\
2025 \\
2026 \\
2027 \\
2028 \\
2029 \\
2030 \\
2031 \\
2032 \\
2033 \\
2034 \\
2035 \\
2036 \\
2037 \\
2038 \\
2039 \\
2040 \\
2041 \\
2042\end{array}$ & $\begin{array}{l}1,200 \\
1,200 \\
2,000 \\
2,000 \\
2,700 \\
3,000 \\
3,000 \\
3,000 \\
3,000 \\
3,000 \\
3,000 \\
3,000 \\
3,000 \\
3,000 \\
3,000 \\
3,000 \\
3,000 \\
3,000 \\
3,000 \\
3,000 \\
3,000 \\
3,000 \\
2,807\end{array}$ & $\begin{array}{r}800 \\
1600 \\
3200 \\
4300 \\
5200 \\
5200 \\
5200 \\
5200 \\
5200 \\
5200 \\
5200 \\
5200 \\
5200 \\
5200 \\
5200 \\
5200 \\
5200 \\
5200 \\
5200 \\
5200 \\
5200 \\
5200 \\
5007 \\
2007 \\
0\end{array}$ & $\begin{array}{r}400 \\
400 \\
400 \\
900 \\
1,800 \\
3,000 \\
3,000 \\
3,000 \\
3,000 \\
3,000 \\
3,000 \\
3,000 \\
3,000 \\
3,000 \\
3,000 \\
3,000 \\
3,000 \\
3,000 \\
3,000 \\
3,000 \\
3,000 \\
3,000 \\
3,000 \\
3,000 \\
2,007\end{array}$ & $\begin{array}{l}400 \\
400 \\
400 \\
400 \\
400 \\
400 \\
400 \\
400 \\
400 \\
400 \\
400 \\
400 \\
400 \\
400 \\
400 \\
400 \\
400 \\
293\end{array}$ & $\begin{array}{r}900 \\
1,800 \\
3,000 \\
3,000 \\
3,000 \\
3,000 \\
3,000 \\
3,000 \\
1,050 \\
1,050 \\
1,050\end{array}$ & (⿸丆口 & $\begin{array}{r}1,200 \\
1,200 \\
2,000 \\
2,000 \\
2,700 \\
3,000 \\
3,000 \\
3,000 \\
3,000 \\
3,000 \\
3,000 \\
3,000 \\
3,000 \\
3,000 \\
3,000 \\
3,000 \\
3,000 \\
3,000 \\
3,000 \\
3,000 \\
3,000 \\
3,000 \\
2,807 \\
0 \\
0 \\
3,00 \\
3,000 \\
3,000 \\
1,050 \\
1,050 \\
1,050\end{array}$ & $\begin{array}{r}1,200 \\
1,200 \\
2,000 \\
2,000 \\
2,700 \\
3,400 \\
3,400 \\
3,400 \\
3,400 \\
3,400 \\
3,400 \\
3,400 \\
3,400 \\
3,400 \\
3,400 \\
3,400 \\
3,400 \\
3,400 \\
3,400 \\
3,400 \\
3,400 \\
3,400 \\
3,100 \\
0 \\
0 \\
3,400 \\
3,400 \\
1,072 \\
1,050 \\
1,050 \\
3,400 \\
3,400 \\
0 \\
0 \\
0 \\
0 \\
3,400 \\
3\end{array}$ \\
\hline Totals & 62,907 & & 62,907 & 7093 & 23,850 & 2422 & 86,757 & 96,272 \\
\hline
\end{tabular}


Table A-5. Waste-acceptance schedule for the two-repository system: upper reference case, consolidated-fuel disposal

(Metric tons of heavy metal)

\begin{tabular}{|c|c|c|c|c|c|c|c|c|}
\hline \multirow[b]{2}{*}{ Year } & \multicolumn{2}{|c|}{ MRS facility } & \multicolumn{2}{|c|}{ First repository } & \multicolumn{2}{|c|}{ Second repository } & \multicolumn{2}{|c|}{$\begin{array}{l}\text { Total annual } \\
\text { system acceptance }\end{array}$} \\
\hline & $\begin{array}{l}\text { Spent fuel } \\
\text { received }\end{array}$ & $\begin{array}{l}\text { Stored } \\
\text { at MRS }\end{array}$ & $\begin{array}{l}\text { Spent fuel } \\
\text { from MRS }\end{array}$ & $\begin{array}{l}\text { High-level } \\
\text { waste }\end{array}$ & $\begin{array}{l}\text { Spent } \\
\text { fuel }\end{array}$ & $\begin{array}{l}\text { High-level } \\
\text { waste }\end{array}$ & $\begin{array}{l}\text { Spent } \\
\text { fuel }\end{array}$ & $\begin{array}{l}\text { Spent fuel } \\
\text { and high- } \\
\text { level waste }\end{array}$ \\
\hline $\begin{array}{l}2003 \\
2004 \\
2005 \\
2006 \\
2007 \\
2008 \\
2009 \\
2010 \\
2011 \\
2012 \\
2013 \\
2014 \\
2015 \\
2016 \\
2017 \\
2018 \\
2019 \\
2020 \\
2021 \\
2022 \\
2023 \\
2024 \\
2025 \\
2026 \\
2027 \\
2028 \\
2029 \\
2030 \\
2031 \\
2032 \\
2033 \\
2034 \\
2035 \\
2036 \\
2037 \\
2038 \\
2039 \\
2040 \\
2041 \\
2042 \\
2043 \\
2044\end{array}$ & $\begin{array}{r}1,200 \\
1,200 \\
2,000 \\
2,000 \\
2,700 \\
3,000 \\
3,000 \\
3,000 \\
3,000 \\
3,000 \\
3,000 \\
3,000 \\
3,000 \\
3,000 \\
3,000 \\
3,000 \\
3,000 \\
3,000 \\
3,000 \\
3,000 \\
3,000 \\
3,000 \\
3,000 \\
422\end{array}$ & $\begin{array}{r}800 \\
1,600 \\
3,200 \\
4,300 \\
5,200 \\
5,200 \\
5,200 \\
5,200 \\
5,200 \\
5,200 \\
5,200 \\
5,200 \\
5,200 \\
5,200 \\
5,200 \\
5,200 \\
5,200 \\
5,200 \\
5,200 \\
5,200 \\
5,200 \\
5,200 \\
5,200 \\
2,622 \\
0\end{array}$ & $\begin{array}{r}400 \\
400 \\
400 \\
900 \\
1,800 \\
3,000 \\
3,000 \\
3,000 \\
3,000 \\
3,000 \\
3,000 \\
3,000 \\
3,000 \\
3,000 \\
3,000 \\
3,000 \\
3,000 \\
3,000 \\
3,000 \\
3,000 \\
3,000 \\
3,000 \\
3,000 \\
3,000 \\
2,622\end{array}$ & $\begin{array}{r}400 \\
400 \\
400 \\
400 \\
400 \\
400 \\
400 \\
400 \\
400 \\
400 \\
400 \\
400 \\
400 \\
400 \\
400 \\
400 \\
78\end{array}$ & $\begin{array}{r}900 \\
1,800 \\
3,000 \\
3,000 \\
3,000 \\
3,000 \\
3,000 \\
3,000 \\
3,000 \\
3,000 \\
3,000 \\
3,000 \\
677\end{array}$ & $\begin{array}{l}400 \\
400 \\
400 \\
400 \\
400 \\
400 \\
400 \\
237\end{array}$ & $\begin{array}{r}1,200 \\
1,200 \\
2,000 \\
2,000 \\
2,700 \\
3,000 \\
3,000 \\
3,000 \\
3,000 \\
3,000 \\
3,000 \\
3,000 \\
3,000 \\
3,000 \\
3,000 \\
3,000 \\
3,000 \\
3,000 \\
3,000 \\
3,000 \\
3,000 \\
3,000 \\
3,000 \\
422 \\
0 \\
0 \\
0 \\
3,000 \\
3,000 \\
3,000 \\
3,000 \\
3,000 \\
3,000 \\
3,000 \\
670 \\
3,000 \\
1,800 \\
000 \\
0 \\
3,000 \\
3,000 \\
3,\end{array}$ & $\begin{array}{r}1,200 \\
1,200 \\
2,000 \\
2,000 \\
2,700 \\
3,400 \\
3,400 \\
3,400 \\
3,400 \\
3,400 \\
3,400 \\
3,400 \\
3,400 \\
3,400 \\
3,400 \\
3,400 \\
3,400 \\
3,400 \\
3,400 \\
3,400 \\
3,400 \\
3,078 \\
3,000 \\
422 \\
0 \\
0 \\
0 \\
3,400 \\
3,400 \\
3,400 \\
3,400 \\
3,237 \\
3,000 \\
3,000 \\
670 \\
3,400 \\
1,800 \\
00 \\
0 \\
3,400 \\
3\end{array}$ \\
\hline Totals & 63,522 & & 63,522 & 6478 & 33,377 & 3037 & 96,899 & 106,414 \\
\hline
\end{tabular}


Appendix B

ASSUMPTIONS FOR THE MAY 1989

ANALYSIS OF THE TOTAL-SYSTEM LIFE-CYCLE COSTS

$$
\text { B-1 }
$$


Note To The Reader:

This document refers to the Waste Management System which includes an MRS Facility as the "Authorized System." 


\section{ASSUMPTIONS ABOUT THE WASTE}

\section{A. Waste Type}

1. Spent fuel generated by commercial nuclear reactors will be the dominant waste form emplaced in the repository.

2. Spent fuel disassembly hardware will be emplaced in the repository in waste packages that meet the requirements of $10 \mathrm{CFR} .60$. Spent fue 1 disassemb1y hardware is defined as the pieces of a fuel assembly left after the fuel rods have been removed. Spent fuel disassembly hardware includes but is not limited to: guide tubes, instrument tubes, nozzles, grid spacers, hold-down springs, and attachment components.

3. Low-leve1 waste (LLW) generated at DOE/OCRWM facilities is assumed to be packaged and then shipped off-site for disposal.

4. Canisters of defense high-level waste (DHLW) will be emplaced in the repository in waste-packages which meet the requirements of 10 CFR. 60 .

5. Canisters of high-level waste from the West Valley Demonstration Project will be emplaced in the repository in waste packages which meet the requirements of 10 CFR. 60 .

6. Other types of potential high-level wastes have not been included in the TSLCC analysis.

\section{B. Quantities of Spent Fuel}

1. The quantities of spent fuel in the TSLCC analysis were based on the Wor1d Nuclear Fuel Cycle Requirements 1988, DOE/EIA-0436(88), September 1988. The spent discharges reported in this document are compiled by the Energy Information Administration (EIA) and are based on historical data and commercial nuclear forecasts prepared by the EIA.

2. The TSLCC analysis is based on the EIA "no-new-orders, end-ofreactor-1ife" case with a total generation of 86,757 MTHM with the last discharge occurring in the year 2037, the analysis includes an examination of the EIA "upper reference case" forecast with 96,899 MTHM through 2020.

\section{Characteristics of Spent Fue1}

The characteristics of the spent fuel assemblies (burnup, age, type, MTHM) were based on the projections in the 1988 EIA reactor-specific database. The annual spent fuel receipts at the MRS and repository(ies) were categorized by fuel type, burnup, age, and calculated heat output. 
1. The annual spent fuel mix by reactor type changes from year to year, but in total the mix was approximately $2 / 3$ by weight (MTHM) from PWR's and $1 / 3$ from BWR's.

2. The TSLCC analysis is based on projections which assume a 30 percent increase in spent fuel burnup through the year 2000 .

3. Spent fuel burnups were assumed to reach peak levels of up to 50,000 MWD/MTHM for boiling-water reactors (BWR's) and up to 60,000 MWD/MTHM for pressurized-water reactors (PWR's).

4. The TSLCC logistics analysis utilized data on the MTHM quantities contained in individual assemblies. This data may be found in the reactor specific database. For the reader's information, the average content of the PWR assemblies was 0.43 MTHM and the average content of the BWR assemblies was 0.18 MTHM, but there were considerable variations in the assembly heavy metal weights.

5. It is expected that some reactors may consolidate some of their spent fuel for storage efficiency. However, for costing purposes only, the TSLCC analysis treated all fuel from reactors as if it was intact. As the amount of future at-reactor consolidation becomes more apparent, this assumption ( $100 \%$ intact fuel) may be modified.

\section{Quantity and Characteristics of High-Leve1 Waste}

1. The high-level waste (HLW) quantities and characteristics were based on the Integrated Data Base for 1988: Spent Fuel and Radioactive Waste Inventories, Projections, and Characteristics, DOE/RW-0006, Rev. 3, September 1988 .

2. The total defense high-level waste (DHLW) quantity was 17,750 canisters (about $8875 \mathrm{MTHM}$ ). This consisted of: 6050 canisters from the Savannah River Plant (SRP) in South Carolina; 10,500 canisters from the Idaho National Engineering Laboratory (INEL) in Idaho; and 1200 canisters from the Hanford facility in Washington.

3. For the purposes of the TSLCC analysis only, it was assumed that each canister of DHLW was equivalent to 0.5 MTHM. This "equivalence factor" is current1y under review. The DHLW quantities and equivalence factors are interrelated, and they will be revised as appropriate in the future.

4. The total quantity of West Valley high-level waste (WVHLW) was 300 canisters which represents the waste resulting from the reprocessing of 640 MTHM of spent nuclear fuel.

\section{E. Waste Acceptance}

1. The allocation of spent fuel acceptance rights was based on the "oldest-fue1-first" concept. In addition, for the purposes of the

$$
\text { B-4 }
$$


cost analysis only, the TSLCC analysis assumed that the spent fuel delivery schedule was also based on the oldest-fuel-first concept. However, whenever possible, the spent fuel was accepted in full transportation cask loads (integer casking) to avoid excessive movements of partially filled transportation casks. The actual delivery schedule employed in the waste-management system will be established via the process outlined in the Annual Capacity Report dated June 1988 (DOE/RW-0191).

2. Defense High-Level Waste (DHLW) acceptance was assumed to be prioritized in order of "oldest-canister-first." That is, in any given year priorities for DHLW acceptance were awarded to the sites with the oldest available canisters of DHLW. DHLW was also assumed to be accepted in integer cask loads. These assumptions were made solely for the purposes of the TSLCC analysis. The actual acceptance priority logic that will be employed for DHLW acceptance will be negotiated by the Office of Civilian Radioactive Waste Management and the Office of Defense Programs.

3. It was assumed, for the purposes of the TSLCC analysis only, that West Valley high-level waste is accepted at the first repository following the acceptance of defense high-level waste. The actual acceptance-timing of West Valley high-level waste will be negotiated by the owners of the waste and the office of Civilian Radioactive Waste Management following the execution of a contract for disposal of this high-1evel waste.

4. It was assumed that spent fuel will be at least 5 years of age (out of reactor core) before it is accepted by the DOE. 


\section{ASSUMPTIONS ABOUT TRANSPORTATION}

\section{A. Waste Locations}

1. Spent Fue1

The spent fuel was assumed to be picked up from the reactors and storage pools listed in the reactor-specific database maintained by Pacific Northwest Laboratory (PNL); this database includes the locations of these sites.

2. High-Leve1 Waste*

Idaho National Engineering Laboratory, Idaho; Savannah River Plant, South Carolina; and Hanford Reservation, Washington.

note: * The transportation costs of West Valley HLW are not included in the TSLCC analysis because the West Valley Demonstration Act and the cooperative agreement between the owner's of the fuel (NYSERDA) and DOE indicate that The office of Civilian Radioactive Waste Management is not responsible for West Valley Waste transportation.

\section{B. Routing Distances}

1. Rail routing distances were generated by the Oak Ridge National Laboratory (ORNL) using the computer mode1 INTERLINE.

2. Highway routing distances were generated by ORNL using the computer mode1 HIGHWAY.

\section{Transportation Modes}

1. Reactor facility data from the EIA Form RW-859 and infrastructure data from ORNL were used to determine the transportation mode capabilities for individual reactors.

2. All reactors that can presently ship by rail were assumed to do so.

3. Shipments from any projected "generic reactors" (reactors that are ordered in the future in EIA nuclear growth scenarios) were assumed to be made by rail.

4. Shipments from an MRS were assumed to be made by rail.

5. Defense high-1evel waste (DHLW) shipments were assumed to be made by rail.

6. Al1 loaded rail shipments were assumed to be made by dedicated trains. 


\section{Train Configuration}

\section{From-Reactor}

The trains transporting spent fuel from reactors will vary in length (number of cars). It was assumed solely for the purposes of the TSLCC analysis that each reactor will ship all the fuel that is supposed to be shipped each year in one dedicated train shipment. The actual pick-up schedule will be determined by the process outlined in the Annual Capacity Report of June 1988, DOE/RW-0146. Additionally, reactor site limitations could limit the number of cars that could be shipped in a single train. However, this was not included in the TSLCC analysis. The empty casks were assumed to travel from DOE facilities to the reactors in sequential single cask shipments in "genera1 freight" trains.

\section{From-MRS}

The MRS dedicated trains consisted of 5 cars of spent fuel (consolidated and/or intact) plus car(s) for the canisters of hardware generated during rod consolidation (for cases which include consolidation). The dedicated train will be "made-up" at the MRS, shipped to the repository, unloaded, reassembled at the repository, and returned to the MRS.

3. From-DHLW Sites

The DHLW dedicated trains were assumed to be made-up of 5 cars of DHLW. These cars will be loaded at a defense facility, shipped to the repository, unloaded, and then the dedicated train of empty casks will return to a defense facility.

\section{E. Transportation Speed}

1. Truck: 900 miles per day.

2. Rail:

The rail speed varied as a function of travel distance; the average speed, which includes both travel and idle time, was higher for longer distances. The empty shipments to reactors were dispatched singly and moved at general freight speeds. A11 other rail travel is by dedicated trains which were assumed to be $50 \%$ faster than general freight. The assumed minimum general freight rail speed was 40 miles per day (mpd). (A general freight rail shipment of 2,000 miles was assumed to have an average speed of about $170 \mathrm{mpd}$. )

\section{F. Transportation-Cask Capacities}

$\underline{\text { PWR }}$

1. Truck (from reactors)

2. Rail (from reactors)
3 assemblies

21 assemblies
BWR 
3. Rail (from MRS Facility)

a. Cases with Intact Disposal

\section{$\underline{\text { PWR }}$}

Intact assemblies

Consolidated

Hardware

b. Cases with Consolidation

$\begin{array}{ll}34 & 80 \\ \text { NA } & \text { NA } \\ \text { NA } & \text { NA }\end{array}$

$\underline{\text { PWR }} \quad \underline{B W R}$

Intact

28

61

56

Consolidated ${ }^{a}$

140

80

NA

Hardware ${ }^{b}$

4 canisters

$\underline{B W R}$

notes: (a) The "from-MRS" transportation cask capacities were based on transportating "canisters" of spent fuel. The transport cask capacities shown here were based on fully loaded canisters. If the canisters are not fully loaded (due to MRS or repository heat constraints) the transportation cask would transport a lower number of spent nuclear fuel (SNF) assemblies even though the cask would still contain the same number of canisters.

(b) The spent fuel disassembly hardware "canisters" consisted of a stack of five 55 gallon drums bound together by an external frame or cage.

4. Rai1 (from DHLW sites)

G. Cask Capital Cost

1. Truck (from reactors)

2. Rail (from reactors)

3. Rail (From MRS facility)

a. Cases with Intact Disposa1

b. Cases with Consolidation

Consolidated spent fuel

Intact spent fuel

SNF hardware

4. Rail (from DHLW sites)
5 canisters

$$
\begin{array}{r}
\$ 800,000 \\
\$ 2,000,000 \\
\$ 2,750,000 \\
\$ 2,750,000 \\
\$ 2,750,000 \\
\$ 2,750,000 \\
\$ 1,800,000
\end{array}
$$


H. Cask Weights

Empty (1b) Loaded (1b)

1. Truck (from reactors)

2. Rail (from reactors)

3. Rail (from MRS Facility

a. Cases with Intact Disposal

b. Cases with

Consolidation

Consolidated spent fuel

Intact spent fuel

SNF hardware

4. Rail (from DHLW sites)

51,500

56,000

168,000

200,000

250,000

300,000

215,000

300,000

215,000

267,000

190,000

225,000

177,400

200,000

I. Annua1 Cask Maintenance Costs

1. Truck (from reactors)

$\$ 75,000$

2. Rai1 (from reactors)

3. Rai1 (from MRS Facility

$\$ 125,000$

a. Cases with Intact

$$
\text { Disposa1 }
$$

b. Cases with Consolidation

Consolidated spent fuel

Intact spent fuel

SNF hardware

4. Rail (from DHLW sites)

$\$ 125,000$

$\$ 125,000$

$\$ 125,000$

$\$ 125,000$

$\$ 90,000$

J. Average Cask Life:

20 years

\section{K. Security}

1. Truck: There were two levels of truck security.

a. There was one escort with the driver in the truck cab for the entire shipment.

b. In addition, two separate escort vehicles would accompany the loaded shipment through each "heavily populated area" encountered on the shipment route.

2. Rail: Two armed escorts per train for the entire shipment. 
L. Peak Cask-Utilization Rate ${ }^{a}$

1. Truck:

2. Rail: from-reactor from-MRS

from-defense sites
310 days/year

280 days/year

310 days/year

310 days/year

a

The peak cask-utilization rate was the cask availability rate minus a number of days for assumed inefficiencies. The values shown here were used in calculating the cask-fleet sizes.

\section{Cask Maintenance Facility}

The Cask Maintenance Facility (CMF) is intended to be used for routine servicing, preventive maintenance, performing requalification license compliance tests and inspections, minor repairs, and decontamination of the transportation casks and their associated railcars or tractor-trailors. The facility was assumed to be collocated with the MRS. The costs associated with the facility were as follows:

1. CMF Capital Cost

2. Annua1 Operating Cost

3. Decommissioning Cost
$\$ 50,000,000$

$\$ 10,000,000$

$\$ 5,000,000$

\section{N. Shipping Rates}

1. The truck shipping rates were based on tariffs provided by 3 different highway carriers.

2. The rail shipping rates reflected recent Interstate Commerce Commission (ICC) rulings directing that the railroads use a "Class-9 tariff" for shipments of spent fuel (the Class-40 tariff used in the June 1987 TSLCC was higher by better than a factor of 4). An additional charge per train-mile was also included to account for dedicated rail service.

3. It must be stressed that the shipping rates that will be applied to OCRWM shipments will be decided on through negotiations between the DOE and the appropriate carriers (truck and rail). 


\section{A. Materia1}

First Repository in Tuff:

Generic Second Repository:

Stainless Stee1

Carbon Steel

\section{B. Disposal Container Capacities}

Each disposal container holds the following number of waste formsa:

Waste Form

Spent Fuel

1. First Repository in Tuff:

a. Cases with Intact Disposal:

Hybrid ${ }^{b}$

PWR-On1y

BWR-On1y

3 PWR and 4 BWR assemblies

4 PWR assemblies

10 BWR assemblies

b. Cases with Consolidation:

Consolidated spent fuel: $c$

Intact spent fuel:

Hardware: $d$

8 PWR or 20 BWR assemblies

4 PWR or 9 BWR assemblies

1 canister

2. Generic Second Repository:

a. Cases with Intact Disposal:

4 PWR or 9 BWR assemblies

b. Cases with Consolidation:

Consolidated spent fuel:

Intact Spent Fuel

Hardware ${ }^{e}$

12 PWR or 30 BWR assemblies

4 PWR or 9 BWR assemblies

1 canister

High-Leve1 Waste:

1 canister

Notes: (a) The disposal container capacities shown here are based on fully loaded containers. If these containers are not fully loaded (due to heat constraints applied), these container capacities would be reduced.

(b) For the intact disposal cases, the spent fuel is optimally packaged in the hybrid container in which PWR and BWR fuel is mixed. Any assemb1ies which cannot be optimized for this configuration are placed in PWR-only or BWR-only containers.

(c) These capacities based on a waste container containing 4 square canisters of consolidated spent fuel.

(d) The tuff hardware canister consisted of a stack of five drums of compacted hardware bound together by a stainless steel cage or frame.

(e) The second repository hardware canisters consisted of four drums of compacted hardware bound together by a carbon steel cage or frame. 


\section{Disposal Container Description}

1. Tuff Repository Disposal Container

a. The tuff spent-fuel disposal container designs are based on the OGR Repository-Specific Rod Consolidation Study: Effect on Costs, Schedules, and Operations at the Yucca Mountain Repository, (RCS) SAND 86-2357, December 1988. For the system with intact disposal, the design is based on that used for RCS Case 2, and the system with consolidation utilizes the RCS Case 3 design. In both cases, the disposal container is assumed to be fabricated from $3 / 8$ inch stainless steel and have a diameter of approximately 28 inches. The tuff spent-fuel disposal containers are between 15 and 16 feet long.

b. For cases which include consolidation, the spent-fuel hardware processed at the MRS is packaged in separate drums. These drums are bound together in a stack of five by a stainless steel cage or frame. At the repository, the stacked drums are placed into stainless steel thin-walled containers that meet the requirements of 10 CFR 60 .

\section{Second Repository Disposal Container}

a. The second repository disposal container is based on design information used for the draft of the Site Characterization Plan-Conceptual Design Reports prepared for the basalt and salt sites prior to the passage of the 1987 Amendments Act. The disposal container is a cylindrical thick-walled carbon steel container over a thin-walled carbon steel canister. The consolidated spent fuel pins are placed in six wedge-shaped compartments in the cylindrical canister. The intact spent fuel assemblies are placed directly into the canister. The containers consisting of intact fuel have an outside diameter of about 37 inches and those consisting of consolidated spent fuel have an $0 . D$. of about 35 inches. These waste containers are close to 16 feet in length.

b. The spent fuel hardware from consolidation activities at the second repository would be compacted and placed into 55 gallon drums. The drums are bound together into "canisters" which are actually stacks of four drums held together by a carbon steel external cage or frame. These "canisters" are then placed into carbon steel thick-walled waste containers that meet the requirements of $10 \mathrm{CFR} .60$ for emplacement in the repository boreholes. 


\section{HLW Disposa1 Container}

The DHLW is placed in stainless-steel canisters at the defense site before shipment to the repository. The West Valley Waste is placed in a similar canister prior to shipment from the West Valley site. At the tuff repository, a thin-walled stainless-steel container is applied to the high-level waste canisters prior to emplacement. It was assumed that the canister has a diameter of 24 inches. The container for the tuff repository was assumed to have a diameter of 26 inches and a length of about 10.5 feet. At the second repository the high-level waste canisters are enclosed in a thick-walled carbon steel container.

\section{E. Low-Leve1 Waste}

Low-level wastes generated at the MRS facility or the repository are compacted or solidified and packaged in 55-gallon drums or 100-cubic-foot boxes. These wastes are then transported off-site to the nearest DOE facility with disposal requirements equivalent to those required under 10 CFR.61 for low-level waste disposal. F. Spent Fuel Consolidation Assumptions (for cases which include

1. The MRS facility reflects the assumption that 5 percent of spent fuel assemblies would not be consolidated. Therefore, the MRS would package and ship 95 percent of its spent fuel "flow-through" as consolidated spent fuel; the remaining 5 percent of the MRS flow-through will be packaged and shipped as intact assemblies.

2. The second repository (when included) has a single waste handling building that handles all of the spent fuel accepted at the facility. This facility was assumed to consolidate 95 percent of the spent fuel received at the second repository.

3. The TSLCC analysis has treated all fuel shipped from reactors as intact fuel. As at-reactor consolidation efforts move forward, this assumption may be modified.

\section{G. Disposal Container Derating Assumptions}

The disposal containers were assumed to be loaded so that the site-specific thermal constraints were not violated. It was also assumed that all of the rods from a consolidated assembly were placed in the same waste container (integer-assembly waste packing). The waste package capacity derating was modeled by examining the thermal energy output of each batch of assemblies as they are received at DOE packaging facilities (MRS or repository). The assemblies were assumed to be processed and placed in specific "bins." Each bin was associated with a specific package capacity 
stated in assemblies. For example, bin 非1 would be filled with assemblies that would not exceed the package thermal constraint when the package is loaded to the design capacity. Similarly, bin $\left.\right|^{2}$ would be loaded with assemblies that will not exceed the container thermal constraint when it is loaded to the first derating step. (The first derating step is generally the package design capacity minus 1 or 2 assemblies). This methodology allowed for continuous, efficient packaging of spent fuel while minimizing lag storage requirements and repetitive handling operations.

1. The tuff repository thermal constraint was 3.5 kilowatts per container for a11 spent fuel packages.

2. The second repository assumed thermal constraints were specified for each type of package. The consolidated PWR package constraint is 6.6 kilowatts per package, the consolidated BWR package constraint is 5.4 kilowatts per package, the intact PWR package constraint is 2.2 kilowatts per package, and the intact BWR package constraint is 1.8 kilowatts per package.

3. The high-leve1 waste is cold enough to negate the need for waste-container thermal constraints. 


\section{ASSUMPTIONS ABOUT THE REPOSITORIES}

\section{A. Number of Repositories}

The TSLCC analysis has included cases which assume a system with a single repository and a system with two repositories to ensure thoroughness.

\section{B. Number of Repository Sites Characterized}

It was assumed that only one site will be characterized for each repository that is developed. Site Characterization costs are included in the Development and Evaluation (D\&E) cost category of the TSLCC.

\section{Capacity of the Repositories}

For the single repository cases, the single repository was assumed to accept a11 of the waste included in the case. These cases were included for cost analysis purposes only. These cases cannot be construed to imply that the tuff repository has adequate capacity for disposal of greater than 70,000 MTHM. Furthermore, since there were no engineering designs for a single repository to dispose of more than 70,000 MTHM, the single repository estimates were based on a number of simplifying assumptions. Finally, a single repository would require explicit Congressional authorization to accommodate more than 70,000 MTHM.

The capacity for the first repository is assumed to be 70,000 MTHM in the cases which include a second repository. In these "two repository" cases, the second repository is assumed to accommodate the remaining waste in each case (i.e. the total quantity of waste minus 70,000 MTHM).

\section{Repository Startup Dates}

The first repository will start in 2003 .

The second repository (where applicable) would start in 2032.

E. Repository Ramp-Up

1. The first repository will ramp-up waste acceptance as follows (all values are expressed in MTHM or MTHM equivalent):

\begin{tabular}{lcrr} 
YEAR & $\begin{array}{l}\text { Spent Fue } \\
\text { FROM-MRS }\end{array}$ & HIW & TOTAL \\
\cline { 2 - 4 } 2003 & 400 & 0 & 400 \\
2004 & 400 & 0 & 400 \\
2005 & 400 & 0 & 400 \\
2006 & 900 & 0 & 900 \\
2007 & 1800 & 0 & 1800 \\
2008 & $\underline{3000}$ & $\underline{400}$ & $\underline{3400}$
\end{tabular}


2. The second repository would ramp-up waste acceptance as follows:

$\begin{array}{lrrr}\text { Year } & \text { Spent Fuel } & \text { HLW } & \text { Total } \\ 2032 & 900 & & 900 \\ 2033 & 1800 & & 1800 \\ \underline{2034} & \underline{3000} & \underline{400} & \underline{3400}\end{array}$

\section{F. Repository Design Sources}

The repository designs were based on the OGR Repository-Specific Rod Consolidation Study: Effect on Costs, Schedules, and 0perations at the Yucca Mountain Repository (SAND86-2357) dated December, 1988. The tuff repository design for the cases with intact disposal is based on the Case 2 design described in this report. The design for the cases with consolidation is based on the Case 3 design described in this report. Additional design and cost data were taken from the latest site Characterization Plan -- Conceptual Design Report (SCP-CDR) and the Sandia report MRS System Study for the Repository (SLTR88-7022) dated December, 1988.

The generic second repository costs are based on design information contained in the latest SCP-CDR's for the basalt and salt projects, along with additional pertinent information as appropriate.

\section{G. Underground Description}

1. The spent fuel spacing constraints assumed for this study were based on the referenced designs for the repository.

2. For the tuff repository the wastes are all emplaced vertically. The wastes are placed in lined boreholes in "emplacement drifts." The emplacement drifts are driven perpendicular to the panel access drifts.

System with intact disposal:

a. The spent fuel boreholes are about 25 feet deep and the pitch (center to center spacing) is fixed at 15 feet.

b. The spent fuel borehole spacing at the tuff repository was based on the "integrated" (cumulative long-term) heat output of the wastes in the repository. The emplacement room spacing in tuff was adjusted based on the burnup and the age of the spent fuel. When the average annual fuel burnup level was above the reference value or the average annual fuel age was below the reference level, the room spacing was increased above the reference level on an annual basis to accommodate the increased heat output of the 
"hotter" spent fuel. When the burnup level was low or the age was high the room spacing was decreased below the reference level to accommodate the relatively cool spent fuel.

c. The high-level wastes and hardware are emplaced with the spent fuel in the spent fuel drifts (commingling). These waste packages are placed in 20 foot deep boreholes in between spent fuel boreholes; the borehole pitch for this waste was fixed at 7.5 feet.

System with consolidation:

a. The consolidated spent fuel boreholes are about 25 feet deep and the pitch (center to center spacing) is fixed at 16 feet.

b. The intact spent fuel boreholes are also about 25 feet deep, and the pitch is fixed at 8 feet. (The intact spent fuel is emplaced in separate drifts).

c. The spent fuel borehole spacing at the tuff repository was based on the "integrated" (cumulative long-term) heat output of the wastes in the repository. The emplacement room spacing was adjusted based on the burnup of the spent fuel and the age of the spent fuel. When the average annual fuel burnup level was above the reference value or the average annual fuel age was below the reference level, the room spacing was increased above the reference level on an annual basis to accommodate the increased heat output of the "hotter" spent fuel. When the burnup level was low or the age was high the room spacing was decreased below the reference level to accommodate the relatively cool spent fuel.

d. The high-level wastes and hardware are emplaced with the spent fuel in the consolidated spent fuel drifts (commingling). These waste packages are placed in 20 foot deep boreholes in between consolidated spent fuel boreholes; the borehole pitch for this waste was fixed at 8 feet.

3. The second repository also utilizes vertical emplacement. The emplacement panels are perpendicular to the submains (the submains provide access to the emplacement panels). This approach results in the emplacement panels being paralle1 to the main entries.

a. The spent fuel disposal containers will be emplaced in dedicated panels.

b. The spent fuel boreholes (including a top-section counterbore of 6.6 feet) are between 21 and 23 feet deep depending upon the type of spent fuel (PWR vs BWR; consolidated vs intact) to be emplaced.

c. The reference average borehole pitch ranges from 10.4 feet for intact spent fuel to 42.3 feet for consolidated spent fuel, depending on fuel type. 
d. The spent fuel borehole spacing at the second repository was based on the "power density" (kilowatts per acre) constraint. For the TSLCC analysis the second repository pitch spacing was adjusted to maintain an annual average level of $40 \mathrm{~kW} /$ acre upon waste emplacement, but minimum spacings of 8.7 feet were not violated.

e. The "low-heat waste" (HLW and hardware) will be emplaced in panels that are separate from the spent fuel panels.

f. The low-heat waste boreholes are between 20 and 24 feet deep (including a 6.6 foot deep counterbore top-section) depending on the type of waste.

g. The borehole pitch for low-heat waste was limited by structural constraints rather than heat (thermal) constraints. The borehole pitch is assumed to be 8.7 feet which is about twice the diameter of the counterbore.

\section{H. Surface Facility Description}

1. Surface facility designs were based on the information referenced in section IV.F.

a. The waste-management system takes information as appropriate from the Rod Consolidation Study, the MRS System Study for the Repository, and SCP-CDR designs.

b. For the system with intact disposal, the repository design is based on the RCS Case 2 facility design. This consists of a single waste handling building with a throughput capacity of 3000 MTHM/year of spent fuel and 400 MTHM/year of DHLW and WVHLW. No spent fuel is consolidated at the repository.

c. For the system with consolidation, the repository design is based on the RCS Case 3 facility design. Again, this consists of a single waste handling building with a throughput capacity of 3000 MTHM/year of spent fuel and $400 \mathrm{MTHM} /$ year of DHLW and WVHLW. No spent fuel is consolidated at the repository. The consolidation is performed at the MRS facility.

d. The second repository design reflects a "single-phase" facility. The second repository is assumed to perform all waste-package operations on-site without utilizing the MRS facility.

2. Based on preliminary operations data prepared for the tuff repository design during the 1985 MRS/Repository Interface Task Force, there was a potential impact on the waste handling building's canistering, containerizing, and loadout facilities due to the increased annual quantity of waste packages required by high burnup spent fuel. An increase in quantity (20\% to $25 \%$ ) could require additional welding and 
load-out equipment. However, recognizing the preliminary nature of the design data and the capability to increase the operating time (2 to 3 shifts or 5 to 7 days), it was not considered necessary to make any facility construction cost adjustments in this respect at this time. Operating cost adjustments will be made to account for the increased annual welding and loadout activities required.

\section{Repository Operations Description}

\section{First Repository}

a. For the system with intact disposal, the repository surface facility layout includes a single waste handling building which received intact spent fuel assemblies from the MRS facility and HLW from defense sites. All waste receipts are by rail. The facility would not consolidate any fuel, but it would package the intact assemblies and HLW canisters onto disposal container.

b. For the system with consolidation, the MRS facility relieves the repository of many of its waste preparation activities. Therefore, the repository waste-handling building layout is somewhat less complicated. This building would receive waste from the MRS and the HLW sites. The facility would not consolidate any fuel, but it would place the wastes received into disposal containers.

2. The second repository utilizes a single waste handling building that receives, processes (including consolidation if included in the system), and packages all of the wastes that are to be emplaced in the second repository. The facility was assumed to open in 2032 receiving 900 MTHM and be fully operational receiving 3,000 MTHM of SNF and 400 MTHM HLW by 2034.

3. Receipt and Emplacement Rates

For costing purposes, it was assumed that repository receipt rates and emplacement rates are identical.

\section{J. Other Repository Design Assumptions}

1. The surface storage (or lag storage) capacity of the repository will be 850 MTHM.

2. The second repository also has 850 MTHM of lag storage.

3. The repository designs include the ability to initiate waste retrieval for as long as 50 years from the date of the emplacement of the first waste package. Therefore, the emplacement period is followed by a caretaker period, together these two periods cover 50 years. 
Retrieval costs were not included in the estimates, but costs were included for removing a small number of waste packages for performance confirmation testing.

4. "Hot-fuel" caused by a combination of high burnup and relatively young age may increase the required number of waste packages and boreholes. This was also discussed in the Waste Package Derating Section (III. J).

a. Waste emplacement unit operating costs were increased if the annual number of waste packages handled exceeds the design limit for 2 shift per day operations.

b. The waste emplacement ramp utilization rate was low enough to preclude the need for an additional ramp.

\section{K. Shaft and Ramp Requirements}

The shaft and ramp requirements and dimensions are as follows:

Number of

Shafts or Ramps

$\underline{\text { Tuff }}$

Second Repository

Exploratory Shafts

Repository Shafts

Ramps

\begin{tabular}{ll}
2 & 2 \\
2 & 4 \\
2 & 0 \\
\hline 6 & 6
\end{tabular}

Finished Shaft

Diameters ( $\mathrm{ft}$ )

$\begin{array}{lll}\text { Exploratory Shafts } & 12^{\prime} & 12^{\prime} \\ \text { Repository Shafts } & 20^{\prime} & 2 \text { @ } 18^{\prime} \\ & 1 \text { @ } 23^{\prime} & 2 \text { @ } 2^{\prime} \\ \text { Ramps } & 1 @ 25^{\prime} & \text { NA }\end{array}$

These tuff shaft requirements and dimensions are for a repository with a design capacity of 70,000 MTHM. When the tuff repository capacity was expanded, an additional ventilation shaft was included in the single repository cases. 


\section{Repository Costing Assumptions}

\section{Engineering and Construction Phase}

a. The TSLCC analysis includes the cost of Architect-Engineering (A-E) services for the Advanced Conceptual Design (ACD) in the Development and Evaluation (D\&E) cost category. The repository cost estimates include the $A-E$ costs for license application design ( $L A D$ ), the final procurement and construction (FP\&C) design, and the A-E services during construction (Title III). These post ACD engineering cost data are provided by the NNWSI project and are assumed (for TSLCC purposes) to be split as follows: $63 \% \mathrm{LAD}, 32 \% \mathrm{FP} \& \mathrm{C}$, and $5 \% \mathrm{AE}$ during construction.

b. Repository construction proceeds immediately following the receipt of construction authorization in 1998 and terminates for the surface facilities in 2002 with facility turnover for operations. The underground facility construction period ends upon receipt of the first waste shipment. The necessary additional mine development work, which will continue throughout the emplacement period, was categorized as an annual operating cost.

c. Costs for exploratory shafts were included in the D\&E costs; however, costs for shaft conversion or refitting for repository usage were included in the repository construction estimate.

\section{Operations Phase}

a. Costs associated with repository operations have been divided into two phases, emplacement and caretaker, with a total duration of 50 years. Therefore, the total operations period was constant. The emplacement phase is the period during which wastes are being received and emplaced in the repository, while the caretaker phase follows and is necessary to satisfy the 50-year retrievability criterion.

b. Continuous closure costs were included in the operations for the second repository. Final closure of shafts and open drifts was included in the second repository closure/decommissioning phase similar to the costs for the first repository in tuff.

c. Employee transportation subsidies during operations were included in each estimate.

d. During the caretaker phase, a small maintenance and monitoring staff is on hand to control the site and monitor the repository. Ongoing maintenance of underground systems is provided. 
e. The contractor responsible for repository operation requires no home office support. All administrative staff is found onsite. The underground development work during operations is subcontracted to the same contractor employed for underground development work during repository construction.

f. DOE administration and oversight costs were not included in the repository life-cycle costs, but were included in the D\&E costs.

g. Additional consultants have been included with repository operations costs. These consultants will supplement the staff with special skills on an as-needed basis.

h. Starting in the sixth year of the emplacement period, one waste container per month will be removed, shipped off-site, examined, returned to the site, repackaged, and emplaced underground. Though these operations are scheduled to begin in the sixth year, this confirmation capability will be available in the first year of operations. Costs were also included for the offsite laboratory analysis. Costs for additional performance confirmation activities in the operations phase, such as seal testing and geological examinations, were also included.

\section{Closure and Decommissioning Phase}

a. The repository closure and decommissioning phase begins at the end of the operating period. During this time, underground facilities and shafts are backfilled and sealed. Site decommissioning was assumed to be completed following closure.

b. Costs were accrued in closure accounts for subsurface closure (shafts and development areas) activities or support. The closure phase covers 9 years for the tuff repository with a capacity of 70,000 MTHM. Continuous closure (i.e. backfilling emplacement areas immediately following completion of the waste emplacement activities for that area) during the operations phase was assumed for the second repository, thus only 3 additional years of closure are required following the operating period.

c. Costs were included in decommissioning for surface facility demolition, site restoration, and erection of permanent repository markings. Decommissioning covers a 5 year period following closure for both the first and second repository. 
A. Design Concepts

1. Two distinct MRS facility design concepts were evaluated for the 1988 TSLCC analysis: a) an MRS facility that only receives and stores spent fuel from reactors as intact bare assemblies before shipment to the repository (referred to as the "basic MRS design"), and b) an MRS facility that receives, consolidates and canisters spent fuel from reactors before shipment to the repository as presented in the MRS proposal to Congress in March 1987 (referred to as the "MRS proposal design").

a) In the basic MRS design, the receiving and hand1ing building consists of two transfer cells to unload shipping casks, transfer spent fuel to storage and to transfer stored spent fuel into rail shipping casks for transport to the repository. Each cell has two unloading/loading ports and one loadout port to storage. The four unloading ports can support the maximum throughput rates as dictated by the waste acceptance schedules. The balance of plant configuration is identical to that in the MRS proposal design. This design concept is detailed in the PNL/Parsons Task B Report completed as part of the MRS Systems Studies.

b) In the MRS proposal design, the receiving and handling building consists of four unloading bays (with two unloading ports each), four hot cells, and two canyon cells. The facility would unload shipping casks, consolidate spent fuel, canister spent fuel, package fuel assembly hardware, transfer spent fuel to storage, and retrieve spent fuel from storage for transport to the repository. The facility includes all infrastructure, and support facilities for administrative, operational and maintenance functions; vehicle maintenance; warehousing; security and fire protection facilities; standby emergency power generator; and other miscellaneous utilization structures to make the MRS a self sufficient installation.

\section{B. Logistics}

1. The MRS facility proposal design startup date was 2003, with a 4 year ramp-up to full-scale operations. For the basic MRS design the startup date was 2000 , with a 4 year ramp up to full scale operations.

2. The MRS annual receiving, processing, and shipping rates are based on the waste-acceptance schedule discussed in the Draft 1988 Mission Plan Amendment.

3. The waste management system modeled in the TSLCC analysis assumed that all of the spent fuel shipped from reactors goes directly to the MRS before shipment to the repository. 
4. After the repository has ramped up to full annual acceptance capacity, the MRS was assumed to have a discharge rate equal to its acceptance rate of $3000 \mathrm{MTHM} /$ year.

5. Low-leve1 wastes generated on site are packaged and shipped to the nearest available DOE operated low-level waste site for disposal. The costs for these activities were not included in the MRS facility cost estimate.

\section{Design Basis}

1. The MRS proposal design data were from the Monitored Retrievable Storage Submission to Congress, DOE/RW-0035/1-Rev 1, March 1987. The design data for the basic MRS are from the PNL/Parsons MRS Action Plan Task B Report, PNL-6770, December 1988, completed for the MRS Systems Studies.

2. MRS facility costs in the TSLCC did not include the following, which were included in the TSLCC Development \& Evaluation (D\&E) cost estimates:
a. Environmental evaluations
b. Regulatory compliance through start of MRS operations
c. Institutional interaction
d. Program management through start of MRS operations
e. Site selection and investigation
f. Proof-of-principal tests
g. Advanced conceptual design

3. The MRS facility was assumed to package consolidated spent fuel and intact PWR spent fuel in 9.1 inch square canisters. The intact BWR assemblies are packed in 6.0 inch square canisters. In the basic MRS design, spent fuel is stored as bare jntact assemblies.

\section{Waste Forms}

\section{Spent Fue1}

a. In the intact disposal cases the spent-fuel waste form is left as bare intact assemblies.

b. In the consolidation cases, $95 \%$ of spent-fuel assemblies that are processed by the MRS are consolidated and placed in canisters.

c. In the consolidation cases, $5 \%$ of spent fuel assemblies that are processed by the MRS are not consolidated and are placed into canisters as intact assemblies. 
2. Spent fuel disassemb1y hardware from consolidated spent fuel.

a. Spent fuel disassembly hardware is compacted and placed in 55 ga1lon drums.

b. The hardware from seven assemblies was assumed to create one drum of compacted hardware; this is true for PWR and BWR fuel elements.

c. Five 55 gallon drums of hardware are bound together by a stainless steel "cage" for storage or shipment.

3. On-site generated waste

a. On-site generated waste is compacted or solidified and placed in 55 gallon drums before shipment off-site.

b. Remote-handled waste quantities (e.g., HEPA filters) are proportional to hot cell operating periods.

c. Contact-handled waste quantities are proportional to Receiving and Handling ( $R \& H)$ building operating man-hours.

\section{E. Waste Storage}

1. The peak waste storage capacity of the MRS facility is 15,000 MTHM of spent fuel and the associated hardware. Following the NWPAA, the MRS will not be allowed to store more than 10,000 MTHM before the start of repository operations.

2. The total number of concrete storage casks produced was governed by the peak quantity of spent fuel in the waste storage yard.

3. The storage cask manufacturing plant and equipment costs were treated as MRS facility construction costs. The storage cask costs (labor and materials) were treated as operating costs.

\section{F.}

1. Decommissioning costs were included for decontamination of the spent fuel receiving and handing building. These costs include removal and disposal of contaminated materials and equipment. No demolition charges are included. Decommissioning takes place over a 5-year period for the store-only MRS and over a 7-year period for the MRS that consolidates.

2. A11 costs were adjusted to constant 1988 dollars. 
Appendix C

ANNUAL TOTAL-SYSTEM COSTS BY MAJOR COST COMPONENT 
Table C-1

ANNUAL TOTAL-SYSTEM COSTS FOR THE SINGLE-REPOSITORY SYSTEM

NO-NEW-ORDERS, END-OF-REACTOR-LIFE CASE WITH INTACT DISPOSAL

(MILLIONS OF 1988 DOLLARS)

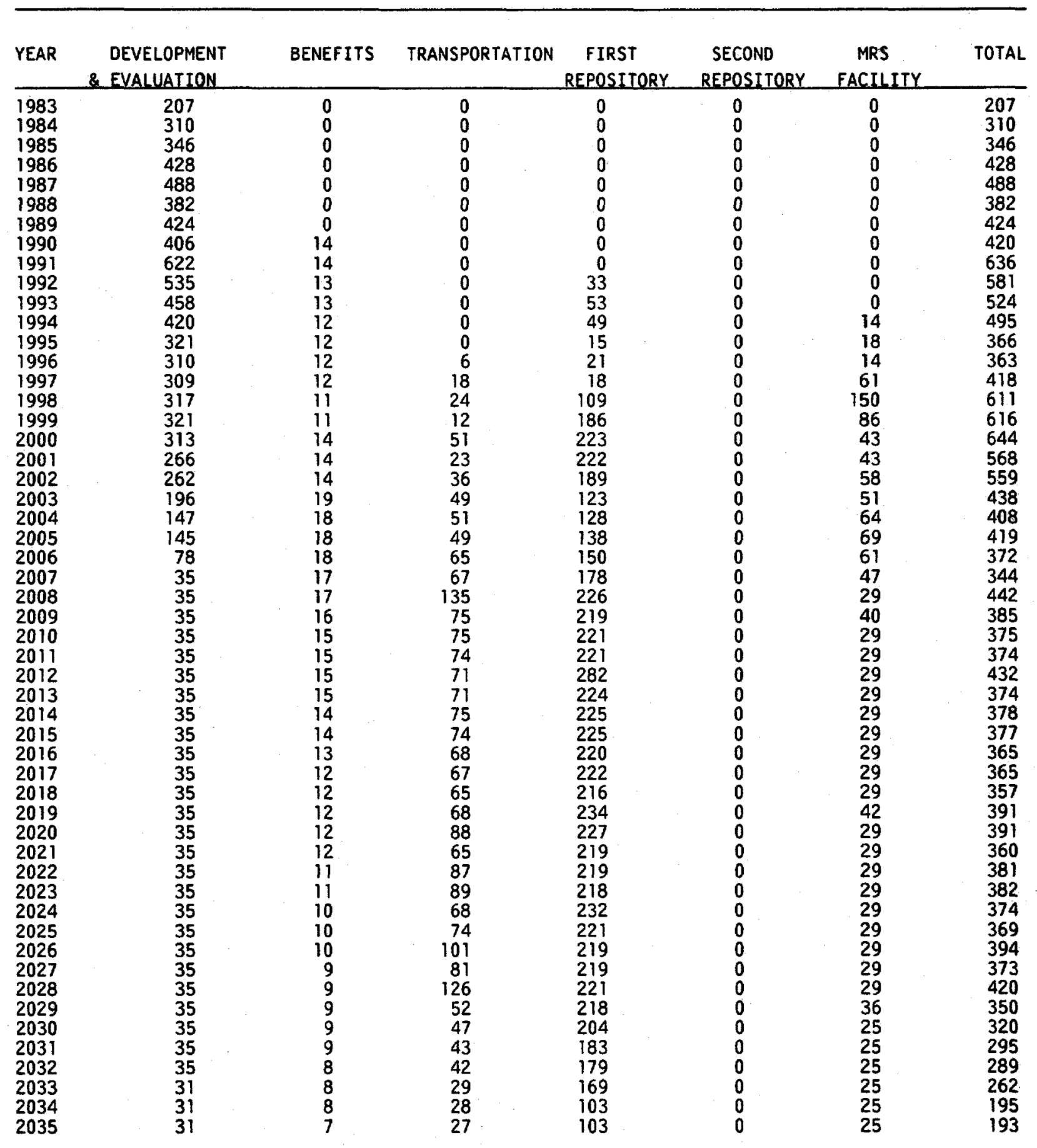


Table $C-1$ (continued)

ANNUAL TOTAL-SYSTEM COSTS FOR THE SINGLE-REPOSITORY SYSTEM

NO-NEW-ORDERS, END-OF-REACTOR-LIFE CASE WITH INTACT DISPOSAL

(MILLIONS OF 1988 DOLLARS)

\begin{tabular}{|c|c|c|c|c|c|c|c|}
\hline YEAR & $\begin{array}{l}\text { DEVELOPMENT } \\
\text { \& EVALUATION }\end{array}$ & BENEFITS & TRANSPORTATION & $\begin{array}{c}\text { FIRST } \\
\text { REPOSITORY } \\
\end{array}$ & $\begin{array}{c}\text { SECOND } \\
\text { REPOSITORY }\end{array}$ & $\begin{array}{c}\text { MRS } \\
\text { FACILITY }\end{array}$ & TOTAL \\
\hline $\begin{array}{l}2036 \\
2037 \\
2038 \\
2039 \\
2040 \\
2041 \\
2042 \\
2043 \\
2044 \\
2045 \\
2046 \\
2047 \\
2048 \\
2049 \\
2050 \\
2051 \\
2052 \\
2053 \\
2054 \\
2055 \\
2056 \\
2057 \\
2058 \\
2059 \\
2060 \\
2061 \\
2062 \\
2063 \\
2064 \\
2065 \\
2066 \\
2067 \\
2068 \\
\text { T0TAL }\end{array}$ & $\begin{array}{c}31 \\
31 \\
31 \\
31 \\
31 \\
31 \\
31 \\
17 \\
17 \\
17 \\
16 \\
16 \\
16 \\
16 \\
16 \\
16 \\
16 \\
16 \\
16 \\
16 \\
16 \\
16 \\
16 \\
16 \\
16 \\
16 \\
16 \\
16 \\
16 \\
16 \\
16 \\
16 \\
16 \\
9650\end{array}$ & $\begin{array}{r}7 \\
7 \\
7 \\
6 \\
6 \\
6 \\
6 \\
6 \\
6 \\
6 \\
4 \\
3 \\
3 \\
3 \\
3 \\
3 \\
3 \\
3 \\
3 \\
3 \\
3 \\
3 \\
3 \\
2 \\
2 \\
2 \\
2 \\
2 \\
2 \\
2 \\
2 \\
2 \\
2 \\
701\end{array}$ & $\begin{array}{r}29 \\
27 \\
27 \\
28 \\
26 \\
27 \\
28 \\
2 \\
2 \\
2 \\
0 \\
0 \\
0 \\
0 \\
0 \\
0 \\
0 \\
0 \\
0 \\
0 \\
0 \\
0 \\
0 \\
0 \\
0 \\
0 \\
0 \\
0 \\
0 \\
0 \\
0 \\
0 \\
0 \\
2614\end{array}$ & $\begin{array}{l}98 \\
93 \\
93 \\
92 \\
89 \\
89 \\
87 \\
20 \\
20 \\
20 \\
20 \\
20 \\
20 \\
20 \\
20 \\
20 \\
20 \\
36 \\
36 \\
36 \\
36 \\
37 \\
37 \\
37 \\
37 \\
37 \\
37 \\
37 \\
19 \\
19 \\
19 \\
19 \\
19 \\
9063\end{array}$ & $\begin{array}{l}0 \\
0 \\
0 \\
0 \\
0 \\
0 \\
0 \\
0 \\
0 \\
0 \\
0 \\
0 \\
0 \\
0 \\
0 \\
0 \\
0 \\
0 \\
0 \\
0 \\
0 \\
0 \\
0 \\
0 \\
0 \\
0 \\
0 \\
0 \\
0 \\
0 \\
0 \\
0 \\
0 \\
0\end{array}$ & $\begin{array}{r}25 \\
25 \\
25 \\
37 \\
25 \\
32 \\
30 \\
1 \\
9 \\
2 \\
0 \\
0 \\
0 \\
0 \\
0 \\
0 \\
0 \\
0 \\
0 \\
0 \\
0 \\
0 \\
0 \\
0 \\
0 \\
0 \\
0 \\
0 \\
0 \\
0 \\
0 \\
0 \\
0 \\
1809\end{array}$ & $\begin{array}{r}190 \\
183 \\
183 \\
194 \\
177 \\
185 \\
182 \\
46 \\
54 \\
47 \\
40 \\
39 \\
39 \\
39 \\
39 \\
39 \\
39 \\
55 \\
55 \\
55 \\
55 \\
56 \\
56 \\
55 \\
55 \\
55 \\
55 \\
55 \\
37 \\
37 \\
37 \\
37 \\
37 \\
23837\end{array}$ \\
\hline
\end{tabular}


Table $C-2$

ANNUAL TOTAL-SYSTEM COSTS FOR THE SINGLE-REPOSITORY SYSTEM

NO-NEW-ORDERS, END-OF-REACTOR-LIFE CASE WITH CONSOLIDATION

(MILLIONS OF 1988 DOLLARS)

\begin{tabular}{|c|c|c|c|c|c|c|c|}
\hline YEAR & $\begin{array}{l}\text { DEVELOPMENT } \\
\text { \& EVALUATION } \\
\end{array}$ & BENEFITS & TRANSPORTATION & $\begin{array}{c}\text { FIRST } \\
\text { REPOSITORY }\end{array}$ & $\begin{array}{l}\text { SECOND } \\
\text { REPOSITORY }\end{array}$ & $\begin{array}{c}\text { MRS } \\
\text { FACILITY } \\
\end{array}$ & TOTAL \\
\hline $\begin{array}{l}1983 \\
1984 \\
1985 \\
1986 \\
1987 \\
1988 \\
1989 \\
1990 \\
1991 \\
1992 \\
1993 \\
1994 \\
1995 \\
1996 \\
1997 \\
1998 \\
1999 \\
2000 \\
2001 \\
2002 \\
2003 \\
2004 \\
2005 \\
2006 \\
2007 \\
2008 \\
2009 \\
2010 \\
2011 \\
2012 \\
2013 \\
2014 \\
2015 \\
2016 \\
2017 \\
2018 \\
2019 \\
2020 \\
2021 \\
2022 \\
2023 \\
2024 \\
2025 \\
2026 \\
2027 \\
2028 \\
2029 \\
2030 \\
2031 \\
2032 \\
2033 \\
2034 \\
2035\end{array}$ & $\begin{array}{l}207 \\
310 \\
346 \\
428 \\
488 \\
382 \\
424 \\
406 \\
622 \\
535 \\
455 \\
420 \\
321 \\
310 \\
309 \\
317 \\
321 \\
313 \\
276 \\
269 \\
201 \\
147 \\
145 \\
78 \\
35 \\
35 \\
35 \\
35 \\
35 \\
35 \\
35 \\
35 \\
35 \\
35 \\
35 \\
35 \\
35 \\
35 \\
35 \\
35 \\
35 \\
35 \\
35 \\
35 \\
35 \\
35 \\
35 \\
35 \\
35 \\
35 \\
31 \\
31 \\
31 \\
35\end{array}$ & $\begin{array}{l}0 \\
0 \\
0 \\
0 \\
0 \\
0 \\
0 \\
14 \\
14 \\
13 \\
13 \\
12 \\
12 \\
12 \\
12 \\
11 \\
11 \\
11 \\
10 \\
10 \\
19 \\
18 \\
18 \\
18 \\
17 \\
17 \\
16 \\
15 \\
15 \\
15 \\
15 \\
14 \\
14 \\
13 \\
12 \\
12 \\
12 \\
12 \\
12 \\
11 \\
11 \\
10 \\
10 \\
10 \\
9 \\
9 \\
9 \\
9 \\
9 \\
8 \\
8 \\
8 \\
7\end{array}$ & $\begin{array}{r}0 \\
0 \\
0 \\
0 \\
0 \\
0 \\
0 \\
0 \\
0 \\
0 \\
0 \\
0 \\
0 \\
0 \\
0 \\
0 \\
6 \\
18 \\
24 \\
12 \\
77 \\
26 \\
39 \\
34 \\
84 \\
144 \\
74 \\
69 \\
70 \\
68 \\
69 \\
71 \\
87 \\
67 \\
68 \\
69 \\
68 \\
68 \\
67 \\
90 \\
95 \\
67 \\
87 \\
74 \\
96 \\
130 \\
87 \\
64 \\
74 \\
85 \\
47 \\
29 \\
28\end{array}$ & $\begin{array}{r}0 \\
0 \\
0 \\
0 \\
0 \\
0 \\
0 \\
0 \\
0 \\
29 \\
46 \\
43 \\
13 \\
18 \\
16 \\
99 \\
167 \\
200 \\
200 \\
170 \\
113 \\
117 \\
124 \\
133 \\
157 \\
196 \\
197 \\
199 \\
202 \\
266 \\
210 \\
212 \\
216 \\
219 \\
222 \\
224 \\
225 \\
225 \\
226 \\
227 \\
226 \\
226 \\
225 \\
226 \\
226 \\
227 \\
223 \\
212 \\
191 \\
188 \\
175 \\
92 \\
93\end{array}$ & $\begin{array}{l}0 \\
0 \\
0 \\
0 \\
0 \\
0 \\
0 \\
0 \\
0 \\
0 \\
0 \\
0 \\
0 \\
0 \\
0 \\
0 \\
0 \\
0 \\
0 \\
0 \\
0 \\
0 \\
0 \\
0 \\
0 \\
0 \\
0 \\
0 \\
0 \\
0 \\
0 \\
0 \\
0 \\
0 \\
0 \\
0 \\
0 \\
0 \\
0 \\
0 \\
0 \\
0 \\
0 \\
0 \\
0 \\
0 \\
0 \\
0 \\
0 \\
0 \\
0 \\
0 \\
0 \\
0 \\
0 \\
0 \\
0 \\
0 \\
0\end{array}$ & 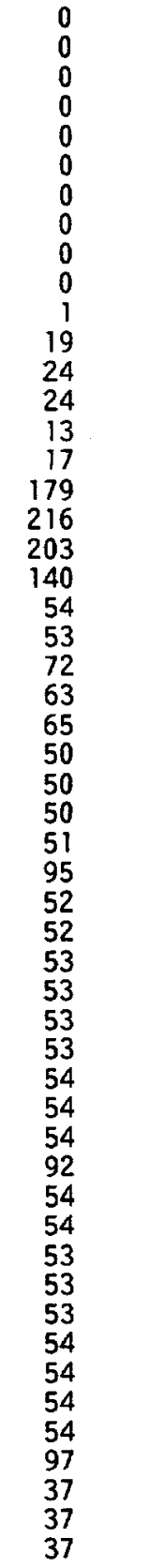 & $\begin{array}{l}207 \\
310 \\
346 \\
428 \\
488 \\
382 \\
424 \\
420 \\
636 \\
577 \\
515 \\
494 \\
370 \\
364 \\
350 \\
444 \\
684 \\
758 \\
713 \\
601 \\
464 \\
361 \\
398 \\
326 \\
358 \\
442 \\
372 \\
368 \\
373 \\
479 \\
381 \\
384 \\
405 \\
387 \\
390 \\
393 \\
394 \\
394 \\
394 \\
455 \\
421 \\
392 \\
410 \\
398 \\
419 \\
455 \\
408 \\
374 \\
363 \\
413 \\
298 \\
197 \\
196\end{array}$ \\
\hline
\end{tabular}


Table C-2 (continued)

ANNUAL TOTAL-SYSTEM COSTS FOR THE SINGLE-REPOSITORY SYSTEM NO-NEW-ORDERS, END-OF-REACTOR-LIFE CASE WITH CONSOLIDATION (MILLIONS OF 1988 DOLLARS)

\begin{tabular}{|c|c|c|c|c|c|c|c|}
\hline YEAR & $\begin{array}{l}\text { DEVELOPMENT } \\
\text { \& EVALUATION } \\
\end{array}$ & BENEFITS & TRANSPORTATION & $\begin{array}{c}\text { FIRST } \\
\text { REPOSITORY }\end{array}$ & $\begin{array}{l}\text { SECOND } \\
\text { REPOSITORY }\end{array}$ & $\begin{array}{c}\text { MRS } \\
\text { FACILITY }\end{array}$ & TOTAL \\
\hline $\begin{array}{l}2036 \\
2037 \\
2038 \\
2039 \\
2040 \\
2041 \\
2042 \\
2043 \\
2044 \\
2045 \\
2046 \\
2047 \\
2048 \\
2049 \\
2050 \\
2051 \\
2052 \\
2053 \\
2054 \\
2055 \\
2056 \\
2057 \\
2058 \\
2059 \\
2060 \\
2061 \\
2062 \\
2063 \\
2064 \\
2065 \\
2066 \\
2067 \\
2068 \\
\text { TOTAL }\end{array}$ & $\begin{array}{r}31 \\
31 \\
31 \\
31 \\
31 \\
31 \\
31 \\
17 \\
17 \\
17 \\
17 \\
17 \\
16 \\
16 \\
16 \\
16 \\
16 \\
16 \\
16 \\
16 \\
16 \\
16 \\
16 \\
16 \\
16 \\
16 \\
16 \\
16 \\
16 \\
16 \\
16 \\
16 \\
16 \\
9671\end{array}$ & $\begin{array}{l}7 \\
7 \\
7 \\
6 \\
6 \\
6 \\
6 \\
6 \\
6 \\
6 \\
6 \\
5 \\
3 \\
3 \\
3 \\
3 \\
3 \\
3 \\
3 \\
3 \\
3 \\
3 \\
3 \\
2 \\
2 \\
2 \\
2 \\
2 \\
2 \\
2 \\
2 \\
2 \\
2 \\
694\end{array}$ & $\begin{array}{r}27 \\
28 \\
28 \\
28 \\
28 \\
29 \\
28 \\
2 \\
2 \\
2 \\
0 \\
0 \\
0 \\
0 \\
0 \\
0 \\
0 \\
0 \\
0 \\
0 \\
0 \\
0 \\
0 \\
0 \\
0 \\
0 \\
0 \\
0 \\
0 \\
0 \\
0 \\
0 \\
0 \\
2634\end{array}$ & $\begin{array}{r}92 \\
92 \\
90 \\
88 \\
86 \\
85 \\
83 \\
20 \\
20 \\
20 \\
20 \\
20 \\
20 \\
20 \\
20 \\
20 \\
20 \\
35 \\
35 \\
35 \\
35 \\
36 \\
36 \\
36 \\
36 \\
36 \\
36 \\
36 \\
17 \\
17 \\
17 \\
17 \\
17 \\
8734\end{array}$ & $\begin{array}{l}0 \\
0 \\
0 \\
0 \\
0 \\
0 \\
0 \\
0 \\
0 \\
0 \\
0 \\
0 \\
0 \\
0 \\
0 \\
0 \\
0 \\
0 \\
0 \\
0 \\
0 \\
0 \\
0 \\
0 \\
0 \\
0 \\
0 \\
0 \\
0 \\
0 \\
0 \\
0 \\
0 \\
0\end{array}$ & $\begin{array}{r}37 \\
37 \\
37 \\
36 \\
37 \\
40 \\
77 \\
6 \\
11 \\
14 \\
17 \\
10 \\
0 \\
0 \\
0 \\
0 \\
0 \\
0 \\
0 \\
0 \\
0 \\
0 \\
0 \\
0 \\
0 \\
0 \\
0 \\
0 \\
0 \\
0 \\
0 \\
0 \\
0 \\
3059\end{array}$ & $\begin{array}{r}194 \\
195 \\
193 \\
189 \\
188 \\
191 \\
225 \\
51 \\
56 \\
59 \\
60 \\
52 \\
39 \\
39 \\
39 \\
39 \\
39 \\
54 \\
54 \\
54 \\
54 \\
55 \\
55 \\
54 \\
54 \\
54 \\
54 \\
54 \\
35 \\
35 \\
35 \\
35 \\
35 \\
24792\end{array}$ \\
\hline
\end{tabular}


Table $\mathrm{C}-3$

ANNUAL TOTAL-SYSTEM COSTS FOR THE TWO-REPOSITORY SYSTEM

NO-NEW-ORDERS, END-OF-REACTOR-LIFE CASE WITH INTACT DISPOSAL

(MILLIONS OF 1988 DOLLARS)

\begin{tabular}{|c|c|c|c|c|c|c|c|}
\hline YEAR & $\begin{aligned} \text { DEVELOPMENT } \\
\text { \& EVALUATION } \\
\end{aligned}$ & BENEFITS & TRANSPORTATION & $\begin{array}{c}\text { FIRST } \\
\text { REPOSITORY } \\
\end{array}$ & $\begin{array}{c}\text { SECOND } \\
\text { REPOSITORY } \\
\end{array}$ & $\begin{array}{c}\text { MRS } \\
\text { FACILITY }\end{array}$ & TOTAL \\
\hline $\begin{array}{l}1983 \\
1984 \\
1985 \\
1986 \\
1987 \\
1988 \\
1989 \\
1990 \\
1991 \\
1992 \\
1993 \\
1994 \\
1995 \\
1996 \\
1997 \\
1998 \\
1999 \\
2000 \\
2001 \\
2002 \\
2003 \\
2004 \\
2005 \\
2006 \\
2007 \\
2008 \\
2009 \\
2010 \\
2011 \\
2012 \\
2013 \\
2014 \\
2015 \\
2016 \\
2017 \\
2018 \\
2019 \\
2020 \\
2021 \\
2022 \\
2023 \\
2024 \\
2025 \\
2026 \\
2027 \\
2028 \\
2029 \\
2030 \\
2031 \\
2032 \\
2033 \\
2034 \\
2035\end{array}$ & $\begin{array}{r}207 \\
310 \\
346 \\
428 \\
488 \\
382 \\
424 \\
406 \\
622 \\
535 \\
458 \\
420 \\
321 \\
310 \\
309 \\
317 \\
321 \\
313 \\
266 \\
262 \\
131 \\
50 \\
48 \\
46 \\
46 \\
46 \\
46 \\
46 \\
56 \\
71 \\
96 \\
121 \\
146 \\
146 \\
177 \\
253 \\
317 \\
367 \\
294 \\
250 \\
223 \\
202 \\
194 \\
195 \\
187 \\
187 \\
187 \\
178 \\
179 \\
91 \\
29 \\
29 \\
29\end{array}$ & $\begin{array}{l}0 \\
0 \\
0 \\
0 \\
0 \\
0 \\
0 \\
14 \\
14 \\
13 \\
13 \\
12 \\
12 \\
12 \\
12 \\
11 \\
11 \\
14 \\
14 \\
14 \\
19 \\
18 \\
18 \\
18 \\
17 \\
17 \\
16 \\
15 \\
15 \\
15 \\
15 \\
14 \\
14 \\
13 \\
12 \\
12 \\
16 \\
16 \\
16 \\
15 \\
15 \\
13 \\
13 \\
13 \\
12 \\
12 \\
12 \\
12 \\
9 \\
10 \\
10 \\
10 \\
10\end{array}$ & $\begin{array}{r}0 \\
0 \\
0 \\
0 \\
0 \\
0 \\
0 \\
0 \\
0 \\
0 \\
0 \\
0 \\
0 \\
6 \\
18 \\
24 \\
12 \\
51 \\
23 \\
36 \\
49 \\
51 \\
49 \\
65 \\
67 \\
135 \\
75 \\
75 \\
74 \\
71 \\
71 \\
75 \\
74 \\
68 \\
67 \\
65 \\
68 \\
88 \\
65 \\
79 \\
58 \\
37 \\
35 \\
51 \\
27 \\
4 \\
2 \\
2 \\
2 \\
17 \\
36 \\
111 \\
53\end{array}$ & $\begin{array}{r}0 \\
0 \\
0 \\
0 \\
0 \\
0 \\
0 \\
0 \\
0 \\
28 \\
44 \\
42 \\
18 \\
24 \\
21 \\
111 \\
188 \\
225 \\
225 \\
192 \\
123 \\
128 \\
138 \\
151 \\
178 \\
226 \\
219 \\
221 \\
221 \\
223 \\
224 \\
225 \\
225 \\
220 \\
224 \\
216 \\
216 \\
227 \\
219 \\
219 \\
214 \\
207 \\
180 \\
172 \\
145 \\
20 \\
20 \\
20 \\
20 \\
20 \\
20 \\
20 \\
20 \\
17 \\
19\end{array}$ & 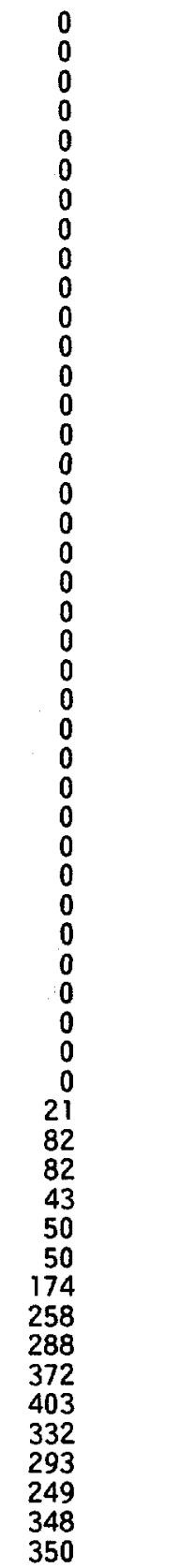 & $\begin{array}{l}0 \\
0 \\
0 \\
0 \\
0 \\
0 \\
0 \\
0 \\
0 \\
0 \\
0 \\
14 \\
18 \\
14 \\
61 \\
150 \\
86 \\
43 \\
43 \\
57 \\
51 \\
64 \\
69 \\
61 \\
47 \\
29 \\
40 \\
29 \\
29 \\
29 \\
29 \\
29 \\
29 \\
29 \\
29 \\
29 \\
53 \\
29 \\
29 \\
29 \\
23 \\
23 \\
23 \\
30 \\
28 \\
1 \\
9 \\
2 \\
0 \\
0 \\
0 \\
0 \\
0\end{array}$ & $\begin{array}{l}207 \\
310 \\
346 \\
428 \\
488 \\
382 \\
424 \\
420 \\
636 \\
576 \\
515 \\
488 \\
369 \\
366 \\
421 \\
613 \\
618 \\
646 \\
571 \\
561 \\
373 \\
311 \\
322 \\
341 \\
355 \\
453 \\
396 \\
386 \\
395 \\
409 \\
435 \\
464 \\
488 \\
476 \\
509 \\
575 \\
670 \\
748 \\
705 \\
674 \\
576 \\
532 \\
495 \\
635 \\
657 \\
512 \\
602 \\
617 \\
542 \\
431 \\
344 \\
518 \\
462\end{array}$ \\
\hline
\end{tabular}


TabTe C-3 (continued)

ANNUAL TOTAL-SYSTEM COSTS FOR THE TWO-REPOSITORY SYSTEM

NO-NEW-ORDERS, END-OF-REACTOR-LIFE CASE WITH INTACT DISPOSAL

(MILLIONS OF 1988 DOLLARS)

\begin{tabular}{|c|c|c|c|c|c|c|c|}
\hline YEAR & $\begin{array}{l}\text { DEVELOPMENT } \\
\text { \& EVALUATION } \\
\end{array}$ & BENEF ITS & TRANSPORTATION & $\begin{array}{c}\text { FIRST } \\
\text { REPOSITORY }\end{array}$ & $\begin{array}{l}\text { SECOND } \\
\text { REPOSITORY }\end{array}$ & $\begin{array}{c}\text { MRS } \\
\text { FACILITY }\end{array}$ & TOTAL \\
\hline $\begin{array}{l}2036 \\
2037 \\
2038 \\
2039 \\
2040 \\
2041 \\
2042 \\
2043 \\
2044 \\
2045 \\
2046 \\
2047 \\
2048 \\
2049 \\
2050 \\
2051 \\
2052 \\
2053 \\
2054 \\
2055 \\
2056 \\
2057 \\
2058 \\
2059 \\
2060 \\
2061 \\
2062 \\
2063 \\
2064 \\
2065 \\
2066 \\
2067 \\
2068 \\
2069 \\
2070 \\
2071 \\
2072 \\
2073 \\
2074 \\
2075 \\
2076 \\
2077 \\
2078 \\
2079 \\
2080 \\
2081 \\
2082 \\
2083 \\
2084 \\
2085 \\
2086 \\
2087 \\
T 0 T A L\end{array}$ & $\begin{array}{l}29 \\
29 \\
29 \\
29 \\
29 \\
29 \\
29 \\
17 \\
17 \\
17 \\
17 \\
17 \\
17 \\
17 \\
17 \\
17 \\
17 \\
17 \\
17 \\
17 \\
17 \\
17 \\
17 \\
17 \\
17 \\
17 \\
17 \\
17 \\
17 \\
17 \\
17 \\
16 \\
16 \\
16 \\
16 \\
16 \\
16 \\
16 \\
16 \\
16 \\
16 \\
16 \\
16 \\
16 \\
16 \\
16 \\
16 \\
16 \\
16 \\
16 \\
16 \\
16 \\
13055\end{array}$ & $\begin{array}{r}10 \\
10 \\
10 \\
8 \\
8 \\
8 \\
8 \\
8 \\
8 \\
8 \\
8 \\
6 \\
6 \\
6 \\
6 \\
6 \\
6 \\
6 \\
6 \\
6 \\
6 \\
6 \\
6 \\
4 \\
4 \\
4 \\
4 \\
4 \\
4 \\
4 \\
4 \\
2 \\
2 \\
2 \\
2 \\
2 \\
2 \\
2 \\
2 \\
2 \\
1 \\
1 \\
1 \\
1 \\
1 \\
1 \\
1 \\
1 \\
1 \\
1 \\
1 \\
1 \\
856\end{array}$ & 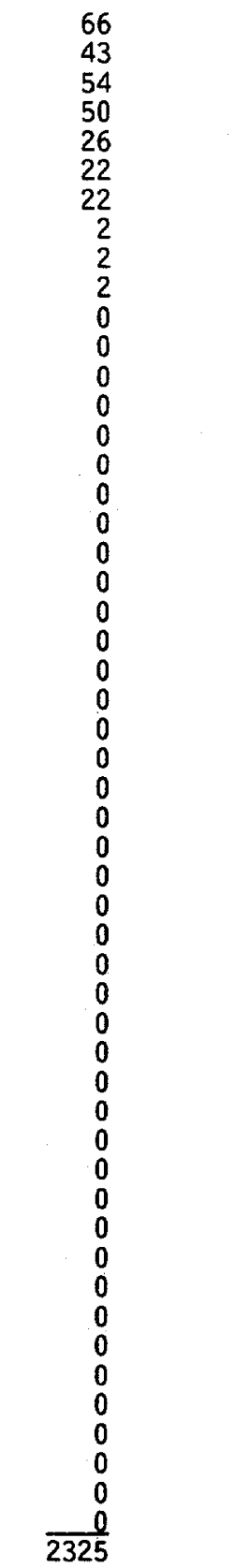 & $\begin{array}{l}20 \\
20 \\
20 \\
20 \\
20 \\
20 \\
20 \\
20 \\
20 \\
20 \\
20 \\
20 \\
20 \\
20 \\
20 \\
20 \\
20 \\
36 \\
37 \\
37 \\
37 \\
37 \\
37 \\
37 \\
37 \\
37 \\
19 \\
19 \\
19 \\
19 \\
19 \\
0 \\
0 \\
0 \\
0 \\
0 \\
0 \\
0 \\
0 \\
0 \\
0 \\
0 \\
0 \\
0 \\
0 \\
0 \\
0 \\
0 \\
0 \\
0 \\
0 \\
0 \\
7006 \\
\\
\\
\\
\\
\\
\end{array}$ & 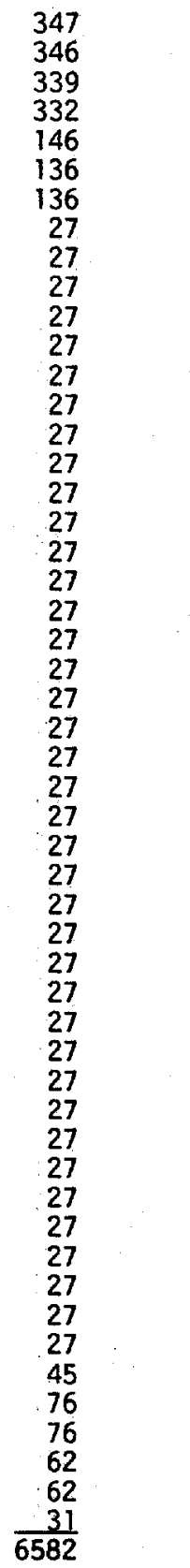 & $\begin{array}{l}0 \\
0 \\
0 \\
0 \\
0 \\
0 \\
0 \\
0 \\
0 \\
0 \\
0 \\
0 \\
0 \\
0 \\
0 \\
0 \\
0 \\
0 \\
0 \\
0 \\
0 \\
0 \\
0 \\
0 \\
0 \\
0 \\
0 \\
0 \\
0 \\
0 \\
0 \\
0 \\
0 \\
0 \\
0 \\
0 \\
0 \\
0 \\
0 \\
0 \\
0 \\
0 \\
0 \\
0 \\
0 \\
0 \\
0 \\
0 \\
0 \\
0 \\
0 \\
0 \\
0 \\
0 \\
0 \\
0 \\
0 \\
0 \\
0 \\
0 \\
0 \\
0 \\
0 \\
0 \\
0\end{array}$ & $\begin{array}{r}472 \\
448 \\
452 \\
439 \\
229 \\
215 \\
215 \\
74 \\
74 \\
74 \\
72 \\
70 \\
70 \\
70 \\
70 \\
70 \\
70 \\
86 \\
87 \\
87 \\
87 \\
87 \\
87 \\
85 \\
85 \\
85 \\
67 \\
67 \\
67 \\
67 \\
67 \\
45 \\
45 \\
45 \\
45 \\
45 \\
45 \\
45 \\
45 \\
45 \\
44 \\
44 \\
44 \\
44 \\
44 \\
44 \\
62 \\
93 \\
93 \\
79 \\
79 \\
48 \\
31217\end{array}$ \\
\hline
\end{tabular}


Table $\mathrm{C}-4$

ANNUAL TOTAL-SYSTEM COSTS FOR THE TWO-REPOSITORY SYSTEM

NO-NEW-ORDERS, END-OF-REACTOR-LIFE CASE WITH CONSOLIDATION

(MILLIONS OF 1988 DOLLARS)

\begin{tabular}{|c|c|c|c|c|c|c|c|}
\hline YEAR & $\begin{aligned} \text { OEVELOPMENT } \\
\text { \& EVALUATION } \\
\end{aligned}$ & BENEFITS & TRANSPORTATION & $\begin{array}{c}\text { FIRST } \\
\text { REPOSITORY } \\
\end{array}$ & $\begin{array}{c}\text { SECOND } \\
\text { REPOSITORY }\end{array}$ & $\begin{array}{c}\text { MRS } \\
\text { FACILITY }\end{array}$ & TOTAL \\
\hline 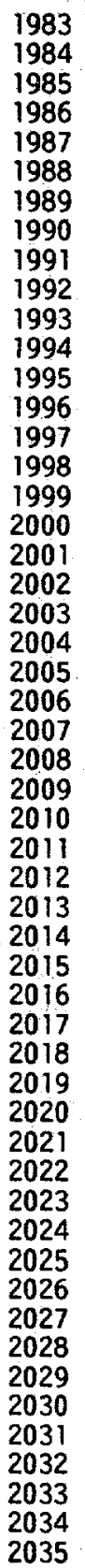 & 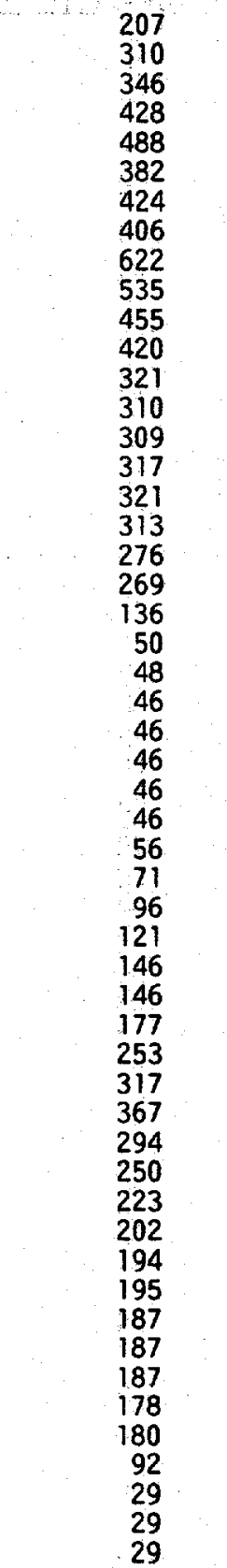 & $\begin{array}{l}0 \\
0 \\
0 \\
0 \\
0 \\
0 \\
0 \\
14 \\
14 \\
13 \\
13 \\
12 \\
12 \\
12 \\
12 \\
11 \\
11 \\
11 \\
10 \\
10 \\
19 \\
18 \\
18 \\
18 \\
17 \\
17 \\
16 \\
15 \\
15 \\
15 \\
15 \\
14 \\
14 \\
13 \\
12 \\
12 \\
16 \\
16 \\
16 \\
15 \\
15 \\
13 \\
13 \\
13 \\
12 \\
12 \\
12 \\
12 \\
12 \\
13 \\
10 \\
10 \\
10\end{array}$ & $\begin{array}{r}0 \\
0 \\
0 \\
0 \\
0 \\
0 \\
0 \\
0 \\
0 \\
0 \\
0 \\
0 \\
0 \\
0 \\
0 \\
0 \\
6 \\
18 \\
24 \\
12 \\
77 \\
26 \\
39 \\
34 \\
84 \\
144 \\
74 \\
69 \\
70 \\
68 \\
69 \\
71 \\
87 \\
67 \\
68 \\
69 \\
68 \\
68 \\
67 \\
90 \\
95 \\
63 \\
72 \\
36 \\
32 \\
4 \\
2 \\
2 \\
2 \\
17 \\
36 \\
111 \\
53\end{array}$ & $\begin{array}{r}0 \\
0 \\
0 \\
0 \\
0 \\
0 \\
0 \\
0 \\
0 \\
25 \\
40 \\
38 \\
16 \\
21 \\
18 \\
100 \\
169 \\
202 \\
202 \\
171 \\
113 \\
117 \\
123 \\
132 \\
157 \\
195 \\
193 \\
199 \\
202 \\
205 \\
210 \\
214 \\
218 \\
221 \\
224 \\
221 \\
222 \\
223 \\
224 \\
224 \\
221 \\
204 \\
187 \\
182 \\
145 \\
20 \\
20 \\
20 \\
20 \\
20 \\
20 \\
20 \\
20 \\
19\end{array}$ & 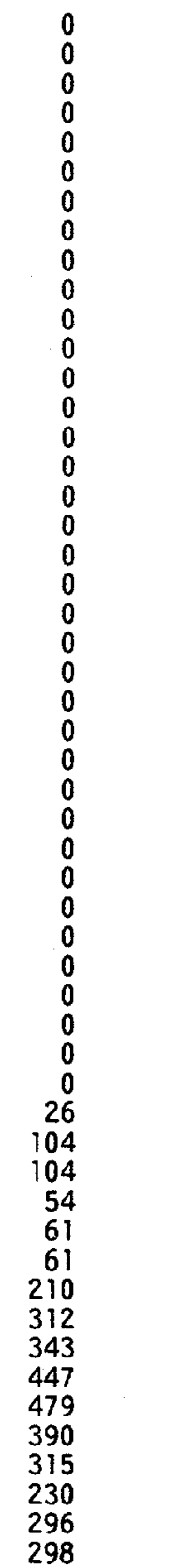 & 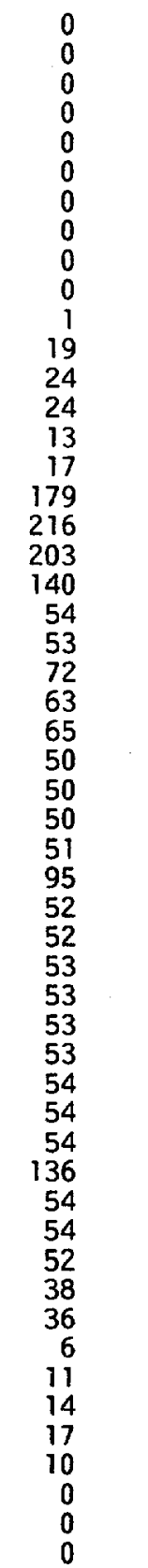 & $\begin{array}{l}207 \\
310 \\
346 \\
428 \\
488 \\
382 \\
424 \\
420 \\
636 \\
573 \\
509 \\
489 \\
373 \\
367 \\
352 \\
445 \\
686 \\
760 \\
715 \\
602 \\
399 \\
264 \\
300 \\
293 \\
369 \\
452 \\
379 \\
379 \\
394 \\
454 \\
442 \\
472 \\
518 \\
500 \\
534 \\
608 \\
677 \\
754 \\
759 \\
819 \\
662 \\
597 \\
579 \\
674 \\
724 \\
572 \\
679 \\
705 \\
621 \\
467 \\
325 \\
466 \\
410\end{array}$ \\
\hline
\end{tabular}


Table C-4 (continued)

ANNUAL TOTAL-SYSTEM COSTS FOR THE TWO-REPOSITORY SYSTEM

NO-NEW-ORDERS, END-OF-REACTOR-LIFE CASE WITH CONSOLIDATION

(MILLIONS OF 1988 DOLLARS)

\begin{tabular}{|c|c|c|c|c|c|c|c|}
\hline YEAR & $\begin{array}{l}\text { DEVELOPMENT } \\
\text { \& EVALUATION } \\
\end{array}$ & BENEFITS & TRANSPORTATION & $\begin{array}{c}\text { FIRST } \\
\text { REPOSITORY } \\
\end{array}$ & $\begin{array}{l}\text { SECOND } \\
\text { REPOSITORY }\end{array}$ & $\begin{array}{c}\text { MRS } \\
\text { FACILITY }\end{array}$ & TOTAL \\
\hline $\begin{array}{l}2036 \\
2037 \\
2038 \\
2039 \\
2040 \\
2041 \\
2042 \\
2043 \\
2044 \\
2045 \\
2046 \\
2047 \\
2048 \\
2049 \\
2050 \\
2051 \\
2052 \\
2053 \\
2054 \\
2055 \\
2056 \\
2057 \\
2058 \\
2059 \\
2060 \\
2061 \\
2062 \\
2063 \\
2064 \\
2065 \\
2066 \\
2067 \\
2068 \\
2069 \\
2070 \\
2071 \\
2072 \\
2073 \\
2074 \\
2075 \\
2076 \\
2077 \\
2078 \\
2079 \\
2080 \\
2081 \\
2082 \\
2083 \\
2084 \\
2085 \\
2086 \\
2087 \\
T 0 T A L\end{array}$ & $\begin{array}{l}29 \\
29 \\
29 \\
29 \\
29 \\
29 \\
29 \\
17 \\
17 \\
17 \\
17 \\
17 \\
17 \\
17 \\
17 \\
17 \\
17 \\
17 \\
17 \\
17 \\
17 \\
17 \\
17 \\
17 \\
17 \\
17 \\
17 \\
17 \\
17 \\
17 \\
17 \\
16 \\
16 \\
16 \\
16 \\
16 \\
16 \\
16 \\
16 \\
16 \\
16 \\
16 \\
16 \\
16 \\
16 \\
16 \\
16 \\
16 \\
16 \\
16 \\
16 \\
16 \\
13076 \\
17\end{array}$ & $\begin{array}{r}10 \\
10 \\
10 \\
8 \\
8 \\
8 \\
8 \\
8 \\
8 \\
8 \\
8 \\
6 \\
6 \\
6 \\
6 \\
6 \\
6 \\
6 \\
6 \\
6 \\
6 \\
6 \\
6 \\
4 \\
4 \\
4 \\
4 \\
4 \\
4 \\
4 \\
4 \\
2 \\
2 \\
2 \\
2 \\
2 \\
2 \\
2 \\
2 \\
2 \\
1 \\
1 \\
1 \\
1 \\
1 \\
1 \\
1 \\
1 \\
1 \\
1 \\
1 \\
1 \\
851\end{array}$ & $\begin{array}{l}66 \\
43 \\
54 \\
50 \\
28 \\
23 \\
23 \\
2 \\
2 \\
2 \\
0 \\
0 \\
0 \\
0 \\
0 \\
0 \\
0 \\
0 \\
0 \\
0 \\
0 \\
0 \\
0 \\
0 \\
0 \\
0 \\
0 \\
0 \\
0 \\
0 \\
0 \\
0 \\
0 \\
0 \\
0 \\
0 \\
0 \\
0 \\
0 \\
0 \\
0 \\
0 \\
0 \\
0 \\
0 \\
0 \\
0 \\
0 \\
0 \\
0 \\
0 \\
0 \\
2287\end{array}$ & 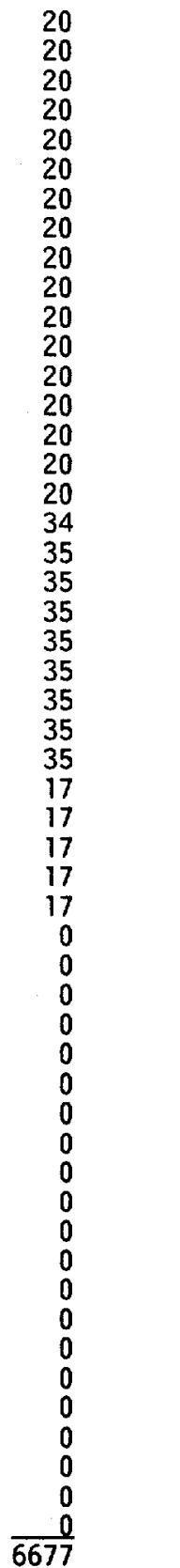 & $\begin{array}{r}297 \\
291 \\
282 \\
277 \\
134 \\
125 \\
125 \\
29 \\
29 \\
29 \\
29 \\
29 \\
29 \\
29 \\
29 \\
29 \\
29 \\
29 \\
29 \\
29 \\
29 \\
29 \\
29 \\
29 \\
29 \\
29 \\
29 \\
29 \\
29 \\
29 \\
29 \\
29 \\
29 \\
29 \\
29 \\
29 \\
29 \\
29 \\
29 \\
29 \\
29 \\
29 \\
29 \\
29 \\
29 \\
29 \\
29 \\
48 \\
82 \\
6 \\
29 \\
29 \\
29\end{array}$ & 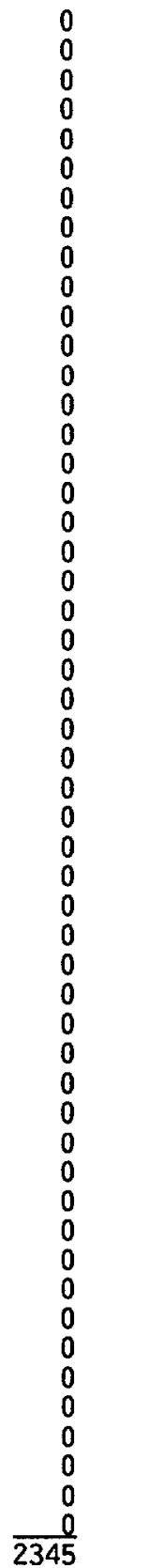 & $\begin{array}{r}416 \\
393 \\
395 \\
384 \\
219 \\
205 \\
205 \\
76 \\
76 \\
76 \\
74 \\
72 \\
72 \\
72 \\
72 \\
72 \\
72 \\
86 \\
87 \\
87 \\
87 \\
87 \\
87 \\
85 \\
85 \\
85 \\
67 \\
67 \\
67 \\
67 \\
67 \\
47 \\
47 \\
47 \\
47 \\
47 \\
47 \\
47 \\
47 \\
47 \\
46 \\
46 \\
46 \\
46 \\
46 \\
46 \\
65 \\
99 \\
99 \\
83 \\
83 \\
50 \\
31999\end{array}$ \\
\hline
\end{tabular}


Table C-5

ANNUAL TOTAL-SYSTEM COSTS FOR THE TWO-REPOSITORY SYSTEM

UPPER REFERENCE CASE WITH CONSOLIDATION

(MILLIONS OF 1988 DOLLARS)

\begin{tabular}{|c|c|c|c|c|c|c|c|}
\hline YEAR & $\begin{array}{l}\text { DEVELOPMENT } \\
\& \text { EVALUATION } \\
\end{array}$ & BENEF ITS & TRANSPORTATION & $\begin{array}{c}\text { FIRST } \\
\text { REPOSITORY } \\
\end{array}$ & $\begin{array}{l}\text { SECOND } \\
\text { REPOSITORY }\end{array}$ & $\begin{array}{c}\text { MRS } \\
\text { FACILITY }\end{array}$ & TOTAL \\
\hline $\begin{array}{l}1983 \\
1984 \\
1985 \\
1986 \\
1987 \\
1988 \\
1989 \\
1990 \\
1991 \\
1992 \\
1993 \\
1994 \\
1995 \\
1996 \\
1997 \\
1998 \\
1999 \\
2000 \\
2001 \\
2002 \\
2003 \\
2004 \\
2005 \\
2006 \\
2007 \\
2008 \\
2009 \\
2010 \\
2011 \\
2012 \\
2013 \\
2014 \\
2015 \\
2016 \\
2017 \\
2018 \\
2019 \\
2020 \\
2021 \\
2022 \\
2023 \\
2024 \\
2025 \\
2026 \\
2027 \\
2028 \\
2029 \\
2030 \\
2031 \\
2032 \\
2033 \\
2034 \\
2035\end{array}$ & $\begin{array}{r}207 \\
310 \\
346 \\
428 \\
488 \\
382 \\
424 \\
406 \\
622 \\
535 \\
455 \\
420 \\
321 \\
310 \\
309 \\
317 \\
321 \\
313 \\
276 \\
269 \\
136 \\
50 \\
48 \\
46 \\
46 \\
46 \\
46 \\
46 \\
56 \\
71 \\
96 \\
121 \\
146 \\
146 \\
177 \\
253 \\
317 \\
367 \\
294 \\
250 \\
223 \\
202 \\
194 \\
195 \\
187 \\
187 \\
187 \\
178 \\
180 \\
92 \\
29 \\
29 \\
29\end{array}$ & 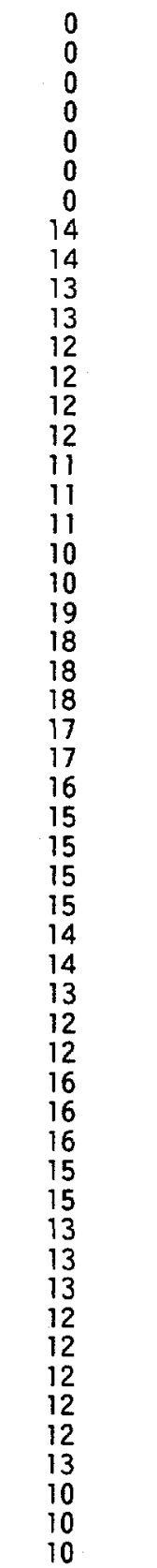 & $\begin{array}{r}0 \\
0 \\
0 \\
0 \\
0 \\
0 \\
0 \\
0 \\
0 \\
0 \\
0 \\
0 \\
0 \\
0 \\
0 \\
0 \\
6 \\
18 \\
24 \\
12 \\
77 \\
26 \\
39 \\
34 \\
84 \\
144 \\
74 \\
69 \\
70 \\
68 \\
69 \\
70 \\
89 \\
67 \\
68 \\
67 \\
68 \\
67 \\
67 \\
89 \\
84 \\
65 \\
60 \\
45 \\
39 \\
4 \\
2 \\
2 \\
2 \\
17 \\
42 \\
106 \\
52 \\
\\
\\
\\
\\
\\
\\
\\
\end{array}$ & $\begin{array}{l}0 \\
0 \\
0 \\
0 \\
0 \\
0 \\
0 \\
0 \\
0 \\
29 \\
46 \\
42 \\
13 \\
18 \\
16 \\
99 \\
168 \\
201 \\
201 \\
170 \\
113 \\
117 \\
123 \\
133 \\
157 \\
196 \\
197 \\
199 \\
202 \\
205 \\
209 \\
214 \\
217 \\
220 \\
224 \\
221 \\
222 \\
222 \\
221 \\
212 \\
202 \\
200 \\
180 \\
177 \\
157 \\
20 \\
20 \\
20 \\
20 \\
20 \\
20 \\
20 \\
20 \\
\\
\\
\\
\\
\\
\\
\end{array}$ & $\begin{array}{r}0 \\
0 \\
0 \\
0 \\
0 \\
0 \\
0 \\
0 \\
0 \\
0 \\
0 \\
0 \\
0 \\
0 \\
0 \\
0 \\
0 \\
0 \\
0 \\
0 \\
0 \\
0 \\
0 \\
0 \\
0 \\
0 \\
0 \\
0 \\
0 \\
0 \\
0 \\
0 \\
0 \\
0 \\
0 \\
0 \\
0 \\
26 \\
104 \\
104 \\
54 \\
61 \\
61 \\
210 \\
312 \\
343 \\
447 \\
478 \\
389 \\
310 \\
225 \\
288 \\
290 \\
\\
\\
\\
\\
\\
\\
\\
\\
\\
\\
\\
\\
\end{array}$ & 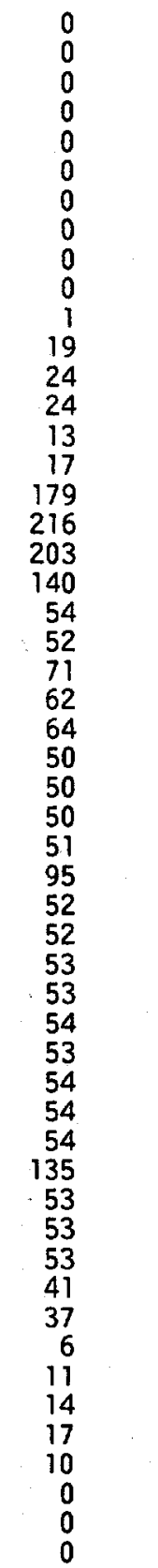 & $\begin{array}{l}207 \\
310 \\
346 \\
428 \\
488 \\
382 \\
424 \\
420 \\
636 \\
577 \\
515 \\
493 \\
370 \\
364 \\
350 \\
444 \\
685 \\
759 \\
714 \\
601 \\
399 \\
263 \\
299 \\
293 \\
368 \\
453 \\
383 \\
379 \\
394 \\
454 \\
441 \\
471 \\
519 \\
499 \\
535 \\
606 \\
677 \\
752 \\
756 \\
805 \\
631 \\
594 \\
561 \\
681 \\
744 \\
572 \\
679 \\
704 \\
620 \\
462 \\
326 \\
453 \\
401\end{array}$ \\
\hline
\end{tabular}


Table C-5 (continued)

ANNUAL TOTAL-SYSTEM COSTS FOR THE TWO-REPOSITORY SYSTEM

UPPER REFERENCE CASE WITH CONSOLIDATION

(MILLIONS OF 1988 DOLLARS)

\begin{tabular}{|c|c|c|c|c|c|c|c|}
\hline YEAR & $\begin{aligned} & \text { DEVELOPMENT } \\
& \text { \& EVALUATION } \\
&\end{aligned}$ & BENEFITS & TRANSPORTATION & $\begin{array}{c}\text { FIRST } \\
\text { REPOSITORY } \\
\end{array}$ & $\begin{array}{l}\text { SECOND } \\
\text { REPOSITORY }\end{array}$ & $\begin{array}{c}\text { MRS } \\
\text { FACILITY }\end{array}$ & TOTAL \\
\hline $\begin{array}{l}2036 \\
2037 \\
2038 \\
2039 \\
2040 \\
2041 \\
2042 \\
2043 \\
2044 \\
2045 \\
2046 \\
2047 \\
2048 \\
2049 \\
2050 \\
2051 \\
2052 \\
2053 \\
2054 \\
2055 \\
2056 \\
2057 \\
2058 \\
2059 \\
2060 \\
2061 \\
2062 \\
2063 \\
2064 \\
2065 \\
2066 \\
2067 \\
2068 \\
2069 \\
2070 \\
2071 \\
2072 \\
2073 \\
2074 \\
2075 \\
2076 \\
2077 \\
2078 \\
2079 \\
2080 \\
2081 \\
2082 \\
2083 \\
2084 \\
2085 \\
2086 \\
2087 \\
70 T A L\end{array}$ & $\begin{array}{l}29 \\
29 \\
29 \\
29 \\
29 \\
29 \\
29 \\
29 \\
29 \\
17 \\
17 \\
17 \\
17 \\
17 \\
17 \\
17 \\
17 \\
17 \\
17 \\
17 \\
17 \\
17 \\
17 \\
17 \\
17 \\
17 \\
17 \\
17 \\
17 \\
17 \\
17 \\
16 \\
16 \\
16 \\
16 \\
16 \\
16 \\
16 \\
16 \\
16 \\
16 \\
16 \\
16 \\
16 \\
16 \\
16 \\
16 \\
16 \\
16 \\
16 \\
16 \\
16 \\
13100 \\
17\end{array}$ & $\begin{array}{r}10 \\
10 \\
10 \\
8 \\
8 \\
8 \\
8 \\
8 \\
8 \\
8 \\
8 \\
6 \\
6 \\
6 \\
6 \\
6 \\
6 \\
6 \\
6 \\
6 \\
6 \\
6 \\
6 \\
4 \\
4 \\
4 \\
4 \\
4 \\
4 \\
4 \\
4 \\
2 \\
2 \\
2 \\
2 \\
2 \\
2 \\
2 \\
2 \\
2 \\
1 \\
1 \\
1 \\
1 \\
1 \\
1 \\
1 \\
1 \\
1 \\
1 \\
1 \\
85\end{array}$ & $\begin{array}{l}47 \\
46 \\
47 \\
46 \\
45 \\
40 \\
48 \\
45 \\
21 \\
2 \\
2 \\
2 \\
0 \\
0 \\
0 \\
0 \\
0 \\
0 \\
0 \\
0 \\
0 \\
0 \\
0 \\
0 \\
0 \\
0 \\
0 \\
0 \\
0 \\
0 \\
0 \\
0 \\
0 \\
0 \\
0 \\
0 \\
0 \\
0 \\
0 \\
0 \\
0 \\
0 \\
0 \\
0 \\
0 \\
0 \\
0 \\
0 \\
0 \\
0 \\
0 \\
0 \\
377\end{array}$ & 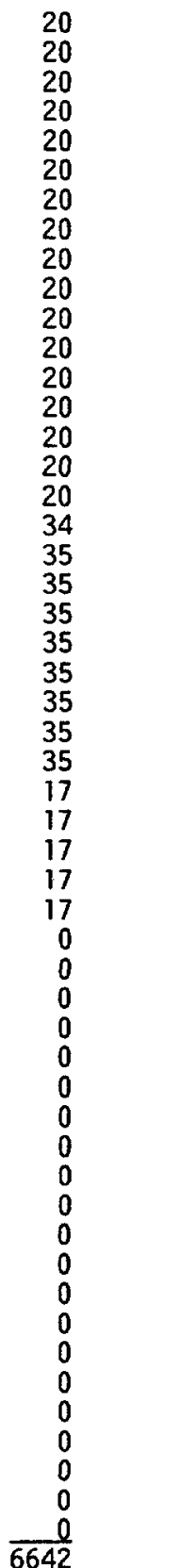 & $\begin{array}{l}288 \\
288 \\
284 \\
285 \\
283 \\
267 \\
233 \\
229 \\
113 \\
29 \\
29 \\
29 \\
29 \\
29 \\
29 \\
29 \\
29 \\
29 \\
29 \\
29 \\
29 \\
29 \\
29 \\
29 \\
29 \\
29 \\
29 \\
29 \\
29 \\
29 \\
29 \\
29 \\
29 \\
29 \\
29 \\
29 \\
29 \\
29 \\
29 \\
29 \\
29 \\
29 \\
29 \\
29 \\
29 \\
29 \\
29 \\
51 \\
84 \\
84 \\
29 \\
29 \\
29\end{array}$ & 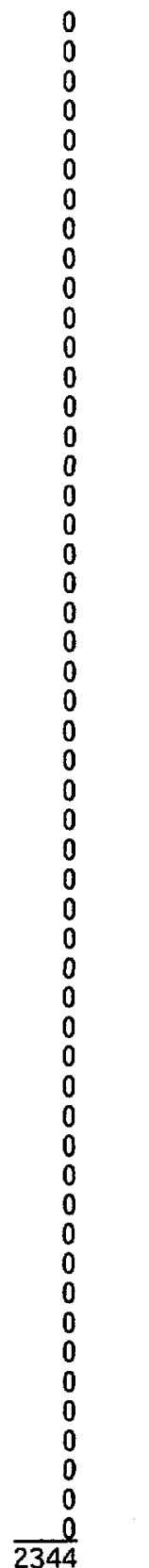 & $\begin{array}{r}394 \\
393 \\
390 \\
388 \\
385 \\
364 \\
338 \\
331 \\
191 \\
76 \\
76 \\
74 \\
72 \\
72 \\
72 \\
72 \\
72 \\
86 \\
87 \\
87 \\
87 \\
87 \\
87 \\
85 \\
85 \\
85 \\
67 \\
67 \\
67 \\
67 \\
67 \\
47 \\
47 \\
47 \\
47 \\
47 \\
47 \\
47 \\
47 \\
47 \\
46 \\
46 \\
46 \\
46 \\
46 \\
46 \\
68 \\
101 \\
101 \\
83 \\
83 \\
50 \\
32743\end{array}$ \\
\hline
\end{tabular}


Appendix D

ANNUAL DEFENSE COSTS BY MAJOR COST COMPONENT 
Table D-1

ANNUAL DEFENSE-WASTE COSTS FOR THE SINGLE-REPOSITORY SYSTEM

NO-NEW-ORDERS, END-OF-REACTOR-LIFE CASE WITH INTACT DISPOSAL

(MILLIONS OF 1988 DOLLARS)

\begin{tabular}{|c|c|c|c|c|c|c|}
\hline YEAR & $\begin{array}{l}\text { DEVELOPMENT } \\
\text { \& EVALUATION }\end{array}$ & BENEFITS & TRANSPORTATION & $\begin{array}{c}\text { FIRST } \\
\text { REPOSITORY }\end{array}$ & $\begin{array}{c}\text { SECOND } \\
\text { REPOSITORY }\end{array}$ & TOTAL \\
\hline 1983 & 34 & 0 & 0 & 0 & 0 & 34 \\
\hline 1984 & 49 & 0 & 0 & 0 & 0 & 49 \\
\hline 1985 & 53 & 0 & 0 & 0 & 0 & 53 \\
\hline 1986 & 68 & 0 & 0 & 0 & 0 & 68 \\
\hline 1987 & 78 & 0 & 0 & 0 & 0 & 78 \\
\hline 1988 & 64 & 0 & 0 & 0 & 0 & 64 \\
\hline 1989 & 68 & 0 & 0 & 0 & 0 & 68 \\
\hline 1990 & 63 & 2 & 0 & 0 & 0 & 65 \\
\hline $\begin{array}{l}1991 \\
1992\end{array}$ & $\begin{array}{l}96 \\
77\end{array}$ & 2 & 0 & 0 & 0 & $\begin{array}{l}98 \\
85\end{array}$ \\
\hline $\begin{array}{l}1992 \\
1993\end{array}$ & 66 & 2 & $\begin{array}{l}0 \\
0\end{array}$ & $\begin{array}{r}6 \\
10\end{array}$ & $\begin{array}{l}0 \\
0\end{array}$ & $\begin{array}{l}85 \\
78\end{array}$ \\
\hline 1994 & 61 & $i$ & 0 & 9 & 0 & 71 \\
\hline 1995 & 50 & $i$ & 0 & 3 & 0 & 54 \\
\hline 1996 & 48 & i & 1 & 4 & 0 & 54 \\
\hline 1997 & 48 & 1 & 2 & 3 & 0 & 54 \\
\hline 1998 & 50 & $i$ & 2 & 20 & 0 & 73 \\
\hline 1999 & 50 & i & $i$ & 34 & 0 & 86 \\
\hline 2000 & 50 & 1 & $i$ & 41 & 0 & 93 \\
\hline 2001 & 45 & 1 & 1 & 41 & 0 & 88 \\
\hline 2002 & 44 & 1 & 1 & 35 & 0 & 81 \\
\hline 2003 & 32 & 2 & 1 & 47 & 0 & 82 \\
\hline 2004 & 24 & 2 & 1 & 47 & 0 & 74 \\
\hline 2005 & 24 & 2 & 1 & 47 & 0 & 74 \\
\hline 2006 & 12 & 2 & 1 & 47 & 0 & 62 \\
\hline 2007 & 5 & 2 & 1 & 47 & 0 & 55 \\
\hline 2008 & 5 & 2 & 60 & 47 & 0 & 114 \\
\hline 2009 & 5 & 2 & 17 & 47 & 0 & 71 \\
\hline 2010 & 5 & 2 & 17 & 47 & 0 & 71 \\
\hline 2011 & 5 & 2 & 17 & 47 & 0 & 71 \\
\hline 2012 & 5 & 2 & 14 & 58 & 0 & 79 \\
\hline 2013 & 5 & 2 & 15 & 47 & 0 & 69 \\
\hline 2014 & 5 & 2 & 14 & 47 & 0 & 68 \\
\hline 2015 & 5 & 2 & 15 & 47 & 0 & 69 \\
\hline 2016 & 5 & 2 & 10 & 47 & 0 & 64 \\
\hline 2017 & 5 & 1 & 8 & 47 & 0 & 61 \\
\hline 2018 & 5 & $i$ & 8 & 47 & 0 & 61 \\
\hline 2019 & 5 & $i$ & 8 & 47 & 0 & 61 \\
\hline 2020 & 5 & $i$ & 8 & 47 & 0 & 61 \\
\hline 2021 & 5 & 1 & 8 & 47 & 0 & 61 \\
\hline 2022 & 5 & $i$ & 8 & 47 & 0 & 61 \\
\hline 2023 & 5 & $i$ & 8 & 47 & 0 & 61 \\
\hline 2024 & 5 & $i$ & 8 & 47 & 0 & 61 \\
\hline 2025 & 5 & 1 & 8 & 47 & 0 & $6 !$ \\
\hline 2026 & 5 & 1 & 8 & 47 & 0 & 61 \\
\hline 2027 & 5 & 1 & 8 & 47 & 0 & 61 \\
\hline 2028 & 5 & $i$ & 40 & 47 & 0 & 93 \\
\hline 2029 & 5 & 1 & 9 & 47 & 0 & 62 \\
\hline 2030 & 5 & 1 & 5 & 47 & 0 & 58 \\
\hline 2031 & 5 & $i$ & 1 & 3 & 0 & 10 \\
\hline 2032 & 5 & $i$ & $i$ & 3 & 0 & 10 \\
\hline 2033 & 4 & 1 & 1 & 3 & 0 & 9 \\
\hline 203 & 4 & 1 & 1 & 3 & 0 & 9 \\
\hline 2035 & 4 & 1 & 1 & 3 & 0 & 9 \\
\hline
\end{tabular}


Table D-1 (continued)

ANNUAL OEFENSE-WASTE COSTS FOR THE SINGLE-REPOSITORY SYSTEM NO-NEW-ORDERS, END-OF-REACTOR-LIFE CASE WITH INTACT DISPOSAL

(MILLIONS OF 1988 DOLLARS)

\begin{tabular}{|c|c|c|c|c|c|c|}
\hline YEAR & $\begin{array}{l}\text { DEVELOPMENT } \\
\text { \& EVALUATION } \\
\end{array}$ & BENEFITS & TRANSPORTATION & $\begin{array}{c}\text { FIRST } \\
\text { REPOSITORY }\end{array}$ & $\begin{array}{c}\text { SECOND } \\
\text { REPOSITORY }\end{array}$ & TOTAL \\
\hline 2036 & 4 & 1 & 1 & 3 & 0 & $\overline{9}$ \\
\hline 2037 & 4 & $i$ & 1 & 3 & 0 & 9 \\
\hline 2038 & 4 & 1 & 1 & 3 & 0 & 9 \\
\hline 2039 & 4 & 1 & 1 & 3 & 0 & 9 \\
\hline 2040 & 4 & 1 & 1 & 3 & 0 & 9 \\
\hline 2041 & 4 & 1 & $i$ & 3 & 0 & 9 \\
\hline 2042 & 4 & 1 & 1 & 3 & 0 & 9 \\
\hline 2043 & 2 & 1 & 0 & 4 & 0 & 7 \\
\hline 2044 & 2 & $i$ & 0 & 4 & 0 & 7 \\
\hline 2045 & 2 & $i$ & 0 & 4 & 0 & 7 \\
\hline 2046 & 2 & 1 & 0 & 4 & 0 & 7 \\
\hline 2047 & 2 & 1 & 0 & 4 & 0 & 7 \\
\hline 2048 & 2 & 1 & 0 & 4 & 0 & 7 \\
\hline 2049 & 2 & 1 & 0 & 4 & 0 & 7 \\
\hline 2050 & 2 & 1 & 0 & 4 & 0 & 7 \\
\hline 2051 & 2 & $i$ & 0 & 4 & 0 & 7 \\
\hline 2052 & 2 & 1 & 0 & 4 & 0 & 7 \\
\hline 2053 & 2 & $i$ & 0 & 4 & 0 & 7 \\
\hline 2054 & 2 & 1 & 0 & 4 & 0 & 7 \\
\hline 2055 & 2 & 1 & 0 & 4 & 0 & 7 \\
\hline 2056 & 2 & 1 & 0 & 4 & 0 & 7 \\
\hline 2057 & 2 & $i$ & 0 & 5 & 0 & 8 \\
\hline 2058 & 2 & 1 & 0 & 5 & 0 & 8 \\
\hline 2059 & 2 & 0 & 0 & 5 & 0 & 7 \\
\hline 2060 & 2 & 0 & 0 & 5 & 0 & 7 \\
\hline 2061 & 2 & 0 & 0 & 5 & 0 & 7 \\
\hline 2062 & 2 & 0 & 0 & 5 & 0 & 7 \\
\hline 2063 & 2 & 0 & 0 & 5 & 0 & 7 \\
\hline 2064 & 2 & 0 & 0 & 2 & 0 & 4 \\
\hline 2065 & 2 & 0 & 0 & 2 & 0 & 4 \\
\hline 2066 & 2 & 0 & 0 & 2 & 0 & \\
\hline 2067 & 2 & 0 & 0 & 2 & 0 & 4 \\
\hline $\begin{array}{l}2068 \\
\text { TOTAL }\end{array}$ & $\frac{2}{1476}$ & $\frac{0}{87}$ & $\frac{0}{347}$ & $\frac{2}{1670}$ & $\frac{0}{0}$ & $\frac{4}{3580}$ \\
\hline
\end{tabular}


Table $0-2$

ANNUAL DEFENSE-WASTE COSTS FOR THE SINGLE-REPOSITORY SYSTEM NO-NEW-ORDERS, END-OF-REACTOR-LIFE CASE WITH CONSOLIDATION (MILLIONS OF 1988 DOLLARS)

\begin{tabular}{|c|c|c|c|c|c|c|}
\hline YEAR & $\begin{array}{l}\text { DEVELOPMENT } \\
\text { \& EVALUATION } \\
\end{array}$ & BENEF ITS & TRANSPORTATION & $\begin{array}{c}\text { FIRST } \\
\text { REPOSITORY } \\
\end{array}$ & $\begin{array}{c}\text { SECOND } \\
\text { REPOSITORY }\end{array}$ & TOTAL \\
\hline $\begin{array}{l}1983 \\
1984 \\
1985 \\
1986 \\
1987 \\
1988 \\
1989 \\
1990 \\
1991 \\
1992 \\
1993 \\
1994 \\
1995 \\
1996 \\
1997 \\
1998 \\
1999 \\
2000 \\
2001 \\
2002 \\
2003 \\
2004 \\
2005 \\
2006 \\
2007 \\
2008 \\
2009 \\
2010 \\
2011 \\
2012 \\
2013 \\
2014 \\
2015 \\
2016 \\
2017 \\
2018 \\
2019 \\
2020 \\
2021 \\
2022 \\
2023 \\
2024 \\
2025 \\
2026 \\
2027 \\
2028 \\
2029 \\
2030 \\
2031 \\
2032 \\
2033 \\
2034 \\
2035\end{array}$ & $\begin{array}{r}36 \\
51 \\
56 \\
71 \\
82 \\
67 \\
70 \\
66 \\
100 \\
80 \\
69 \\
63 \\
52 \\
50 \\
50 \\
52 \\
52 \\
51 \\
47 \\
46 \\
34 \\
25 \\
25 \\
12 \\
4 \\
4 \\
4 \\
4 \\
4 \\
4 \\
4 \\
4 \\
4 \\
4 \\
4 \\
4 \\
4 \\
4 \\
4 \\
4 \\
4 \\
4 \\
4 \\
4 \\
4 \\
4 \\
4 \\
4 \\
4 \\
4 \\
4 \\
4 \\
4 \\
\end{array}$ & $\begin{array}{l}0 \\
0 \\
0 \\
0 \\
0 \\
0 \\
0 \\
2 \\
2 \\
2 \\
2 \\
2 \\
2 \\
2 \\
2 \\
1 \\
1 \\
1 \\
1 \\
1 \\
3 \\
2 \\
2 \\
2 \\
2 \\
2 \\
2 \\
2 \\
2 \\
2 \\
2 \\
2 \\
2 \\
2 \\
2 \\
2 \\
2 \\
2 \\
2 \\
1 \\
1 \\
1 \\
1 \\
1 \\
1 \\
1 \\
1 \\
1 \\
1 \\
1 \\
1 \\
1 \\
1\end{array}$ & $\begin{array}{r}0 \\
0 \\
0 \\
0 \\
0 \\
0 \\
0 \\
0 \\
0 \\
0 \\
0 \\
0 \\
0 \\
0 \\
0 \\
0 \\
1 \\
2 \\
2 \\
1 \\
1 \\
1 \\
1 \\
1 \\
1 \\
60 \\
17 \\
17 \\
17 \\
14 \\
14 \\
14 \\
15 \\
10 \\
8 \\
8 \\
8 \\
8 \\
8 \\
8 \\
8 \\
8 \\
8 \\
8 \\
8 \\
40 \\
9 \\
5 \\
1 \\
1 \\
1 \\
1 \\
1\end{array}$ & 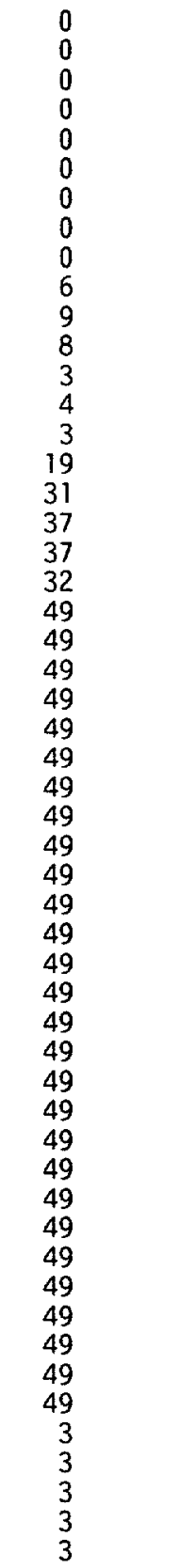 & $\begin{array}{l}0 \\
0 \\
0 \\
0 \\
0 \\
0 \\
0 \\
0 \\
0 \\
0 \\
0 \\
0 \\
0 \\
0 \\
0 \\
0 \\
0 \\
0 \\
0 \\
0 \\
0 \\
0 \\
0 \\
0 \\
0 \\
0 \\
0 \\
0 \\
0 \\
0 \\
0 \\
0 \\
0 \\
0 \\
0 \\
0 \\
0 \\
0 \\
0 \\
0 \\
0 \\
0 \\
0 \\
0 \\
0 \\
0 \\
0 \\
0 \\
0 \\
0 \\
0 \\
0 \\
0 \\
0 \\
0 \\
0 \\
0 \\
0 \\
0 \\
0 \\
0 \\
0 \\
0\end{array}$ & $\begin{array}{r}36 \\
51 \\
56 \\
71 \\
82 \\
67 \\
70 \\
68 \\
102 \\
88 \\
80 \\
73 \\
57 \\
56 \\
55 \\
72 \\
85 \\
91 \\
87 \\
80 \\
87 \\
77 \\
77 \\
64 \\
56 \\
115 \\
72 \\
72 \\
72 \\
69 \\
69 \\
69 \\
70 \\
65 \\
63 \\
63 \\
63 \\
63 \\
63 \\
62 \\
62 \\
62 \\
62 \\
62 \\
62 \\
94 \\
63 \\
59 \\
9 \\
9 \\
9 \\
9 \\
9\end{array}$ \\
\hline
\end{tabular}


Table D-2 (continued)

ANNUAL DEFENSE-WASTE COSTS FOR THE SINGLE-REPOSITORY SYSTEM

NO-NEW-ORDERS, END-OF-REACTOR-LIFE CASE WITH CONSOLIDATION

(MILLIONS OF 1988 DOLLARS)

\begin{tabular}{|c|c|c|c|c|c|c|}
\hline YEAR & $\begin{array}{l}\text { DEVELOPMENT } \\
\& \text { EVALUATION }\end{array}$ & BENEFITS & TRANSPORTATION & $\begin{array}{c}\text { FIRST } \\
\text { REPOSITORY }\end{array}$ & $\begin{array}{c}\text { SECOND } \\
\text { REPOSITORY }\end{array}$ & TOTAL \\
\hline $\begin{array}{l}2036 \\
2037 \\
2038 \\
2039 \\
2040 \\
2041 \\
2042 \\
2043 \\
2044 \\
2045 \\
2046 \\
2047 \\
2048 \\
2049 \\
2050 \\
2051 \\
2052 \\
2053 \\
2054 \\
2055 \\
2056 \\
2057 \\
2058 \\
2059 \\
2060 \\
2061 \\
2062 \\
2063 \\
2064 \\
2065 \\
2066 \\
2067 \\
2068 \\
\text { TOTAL }\end{array}$ & $\begin{array}{r}4 \\
4 \\
4 \\
4 \\
4 \\
4 \\
4 \\
2 \\
2 \\
2 \\
2 \\
2 \\
2 \\
2 \\
2 \\
2 \\
2 \\
2 \\
2 \\
2 \\
2 \\
2 \\
2 \\
2 \\
2 \\
2 \\
2 \\
2 \\
2 \\
2 \\
2 \\
2 \\
2 \\
1503\end{array}$ & $\begin{array}{r}1 \\
1 \\
1 \\
1 \\
1 \\
1 \\
1 \\
1 \\
1 \\
1 \\
1 \\
1 \\
1 \\
1 \\
1 \\
1 \\
1 \\
1 \\
1 \\
1 \\
1 \\
1 \\
1 \\
0 \\
0 \\
0 \\
0 \\
0 \\
0 \\
0 \\
0 \\
0 \\
0 \\
97\end{array}$ & $\begin{array}{r}1 \\
1 \\
1 \\
1 \\
1 \\
1 \\
0 \\
0 \\
0 \\
0 \\
0 \\
0 \\
0 \\
0 \\
0 \\
0 \\
0 \\
0 \\
0 \\
0 \\
0 \\
0 \\
0 \\
0 \\
0 \\
0 \\
0 \\
0 \\
0 \\
0 \\
0 \\
0 \\
343\end{array}$ & $\begin{aligned} 3 \\
3 \\
3 \\
3 \\
3 \\
3 \\
3 \\
3 \\
3 \\
3 \\
3 \\
3 \\
3 \\
3 \\
3 \\
3 \\
3 \\
5 \\
5 \\
5 \\
5 \\
5 \\
5 \\
5 \\
5 \\
5 \\
5 \\
5 \\
2 \\
2 \\
2 \\
2 \\
2 \\
1692\end{aligned}$ & $\begin{array}{l}0 \\
0 \\
0 \\
0 \\
0 \\
0 \\
0 \\
0 \\
0 \\
0 \\
0 \\
0 \\
0 \\
0 \\
0 \\
0 \\
0 \\
0 \\
0 \\
0 \\
0 \\
0 \\
0 \\
0 \\
0 \\
0 \\
0 \\
0 \\
0 \\
0 \\
0 \\
0 \\
0 \\
0\end{array}$ & $\begin{array}{r}9 \\
9 \\
9 \\
9 \\
9 \\
9 \\
9 \\
6 \\
6 \\
6 \\
6 \\
6 \\
6 \\
6 \\
6 \\
6 \\
6 \\
8 \\
8 \\
8 \\
8 \\
8 \\
8 \\
7 \\
7 \\
7 \\
7 \\
7 \\
4 \\
4 \\
4 \\
4 \\
4 \\
3635\end{array}$ \\
\hline
\end{tabular}


Table $D-3$

ANNUAL DEFENSE COSTS FOR THE TWO-REPOSITORY SYSTEM

NO-NEW-ORDERS, ENO-OF-REACTOR-LIFE CASE WITH INTACT DISPOSAL

(MILLIONS OF 1988 DOLLARS)

\begin{tabular}{|c|c|c|c|c|c|c|}
\hline YEAR & $\begin{array}{r}\text { DEVELOPMENT } \\
\text { \& EVALUATION }\end{array}$ & BENEFITS & TRANSPORTATION & $\begin{array}{c}\text { FIRST } \\
\text { REPOSITORY } \\
\end{array}$ & $\begin{array}{c}\text { SECOND } \\
\text { REPOSITORY } \\
\end{array}$ & TOTAL \\
\hline $\begin{array}{l}1983 \\
1984 \\
1985 \\
1986 \\
1987 \\
1988 \\
1989 \\
1990 \\
1999 \\
1992 \\
1993 \\
1994 \\
1995 \\
1996 \\
1997 \\
1998 \\
1999 \\
2000 \\
2001 \\
2002 \\
2003 \\
2004 \\
2005 \\
2006 \\
2007 \\
2008 \\
2009 \\
2010 \\
2011 \\
2012 \\
2013 \\
2014 \\
2015 \\
2016 \\
2017 \\
2018 \\
2019 \\
2020 \\
2021 \\
2022 \\
2023 \\
2024 \\
2025 \\
2026 \\
2027 \\
2028 \\
2029 \\
2030 \\
2031 \\
2032 \\
2033 \\
2034 \\
2035\end{array}$ & $\begin{array}{r}36 \\
52 \\
57 \\
72 \\
83 \\
68 \\
73 \\
68 \\
103 \\
83 \\
72 \\
67 \\
54 \\
52 \\
52 \\
54 \\
55 \\
54 \\
48 \\
48 \\
23 \\
8 \\
7 \\
7 \\
7 \\
7 \\
7 \\
7 \\
9 \\
12 \\
17 \\
22 \\
26 \\
26 \\
31 \\
44 \\
56 \\
64 \\
51 \\
44 \\
39 \\
36 \\
34 \\
34 \\
33 \\
33 \\
34 \\
32 \\
32 \\
16 \\
5 \\
5 \\
5 \\
5\end{array}$ & $\begin{array}{l}0 \\
0 \\
0 \\
0 \\
0 \\
0 \\
0 \\
2 \\
2 \\
2 \\
2 \\
2 \\
2 \\
2 \\
2 \\
1 \\
1 \\
1 \\
1 \\
1 \\
2 \\
2 \\
2 \\
2 \\
2 \\
2 \\
2 \\
2 \\
2 \\
2 \\
2 \\
2 \\
2 \\
2 \\
2 \\
2 \\
3 \\
3 \\
3 \\
2 \\
2 \\
2 \\
2 \\
2 \\
2 \\
2 \\
2 \\
2 \\
2 \\
2 \\
2 \\
2 \\
2\end{array}$ & $\begin{array}{l}0 \\
0 \\
0 \\
0 \\
0 \\
0 \\
0 \\
0 \\
0 \\
0 \\
0 \\
0 \\
0 \\
1 \\
2 \\
2 \\
1 \\
1 \\
1 \\
1 \\
1 \\
1 \\
1 \\
1 \\
1 \\
60 \\
17 \\
17 \\
17 \\
14 \\
15 \\
14 \\
15 \\
10 \\
8 \\
8 \\
8 \\
8 \\
8 \\
8 \\
8 \\
4 \\
1 \\
1 \\
1 \\
0 \\
0 \\
0 \\
0 \\
1 \\
1 \\
42 \\
10\end{array}$ & $\begin{array}{l}0 \\
0 \\
0 \\
0 \\
0 \\
0 \\
0 \\
0 \\
0 \\
5 \\
9 \\
8 \\
4 \\
5 \\
4 \\
23 \\
37 \\
44 \\
44 \\
38 \\
44 \\
44 \\
44 \\
44 \\
44 \\
44 \\
44 \\
44 \\
44 \\
44 \\
44 \\
44 \\
44 \\
44 \\
44 \\
44 \\
44 \\
44 \\
44 \\
44 \\
44 \\
3 \\
3 \\
3 \\
3 \\
3 \\
3 \\
3 \\
3 \\
3 \\
3 \\
3 \\
\\
\\
\\
\\
\\
\\
\\
\\
\\
\\
\end{array}$ & $\begin{array}{l}0 \\
0 \\
0 \\
0 \\
0 \\
0 \\
0 \\
0 \\
0 \\
0 \\
0 \\
0 \\
0 \\
0 \\
0 \\
0 \\
0 \\
0 \\
0 \\
0 \\
0 \\
0 \\
0 \\
0 \\
0 \\
0 \\
0 \\
0 \\
0 \\
0 \\
0 \\
0 \\
0 \\
0 \\
0 \\
0 \\
0 \\
4 \\
16 \\
16 \\
8 \\
10 \\
10 \\
37 \\
56 \\
63 \\
81 \\
87 \\
72 \\
75 \\
56 \\
56 \\
56 \\
\\
\\
\\
\\
\\
\\
\\
\\
\\
\\
\\
\\
\\
\end{array}$ & $\begin{array}{r}36 \\
52 \\
57 \\
72 \\
83 \\
68 \\
73 \\
70 \\
105 \\
90 \\
83 \\
77 \\
60 \\
60 \\
60 \\
80 \\
94 \\
100 \\
94 \\
88 \\
70 \\
55 \\
54 \\
54 \\
54 \\
113 \\
70 \\
70 \\
72 \\
72 \\
78 \\
82 \\
87 \\
82 \\
85 \\
98 \\
111 \\
123 \\
122 \\
114 \\
101 \\
96 \\
50 \\
77 \\
95 \\
101 \\
120 \\
124 \\
109 \\
97 \\
67 \\
108 \\
76\end{array}$ \\
\hline
\end{tabular}


Table D-3 (continued)

ANNUAL DEFENSE COSTS FOR THE TWO-REPOSITORY SYSTEM

NO-NEW-OROERS, END-OF-REACTOR-LIFE CASE WITH INTACT DISPOSAL

(MILLIONS OF 1988 DOLLARS)

\begin{tabular}{|c|c|c|c|c|c|c|}
\hline YEAR & $\begin{array}{l}\text { DEVELOPMENT } \\
\& \quad \text { EVALUATION } \\
\end{array}$ & BENEFITS & TRANSPORTATION & $\begin{array}{c}\text { FIRST } \\
\text { REPOSITORY } \\
\end{array}$ & $\begin{array}{c}\text { SECOND } \\
\text { REPOSITORY } \\
\end{array}$ & TOTAL \\
\hline $\begin{array}{l}2036 \\
2037 \\
2038 \\
2039 \\
2040 \\
2041 \\
2042 \\
2043 \\
2044 \\
2045 \\
2046 \\
2047 \\
2048 \\
2049 \\
2050 \\
2051 \\
2052 \\
2053 \\
2054 \\
2055 \\
2056 \\
2057 \\
2058 \\
2059 \\
2060 \\
2061 \\
2062 \\
2063 \\
2064 \\
2065 \\
2066 \\
2067 \\
2068 \\
2069 \\
2070 \\
2071 \\
2072 \\
2073 \\
2074 \\
2075 \\
2076 \\
2077 \\
2078 \\
2079 \\
2080 \\
2081 \\
2082 \\
2083 \\
2084 \\
2085 \\
2086 \\
2087 \\
T 07 A L\end{array}$ & 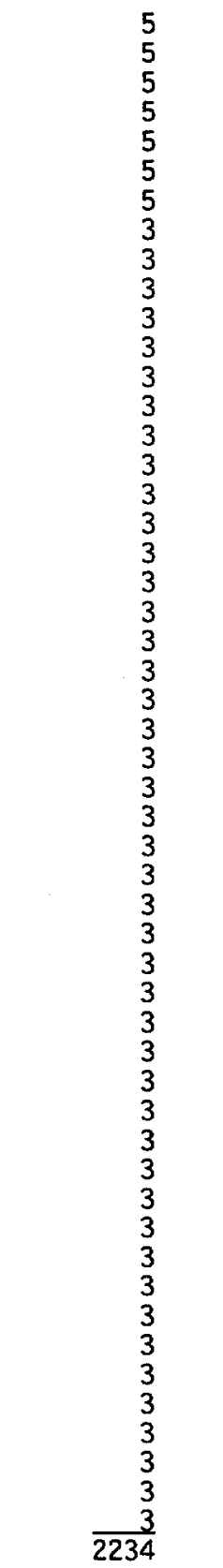 & $\begin{array}{l}2 \\
2 \\
2 \\
2 \\
2 \\
2 \\
2 \\
2 \\
2 \\
2 \\
2 \\
2 \\
2 \\
2 \\
2 \\
2 \\
2 \\
2 \\
2 \\
2 \\
2 \\
2 \\
2 \\
0 \\
0 \\
0 \\
0 \\
0 \\
0 \\
0 \\
0 \\
0 \\
0 \\
0 \\
0 \\
0 \\
0 \\
0 \\
0 \\
0 \\
0 \\
0 \\
0 \\
0 \\
0 \\
0 \\
0 \\
0 \\
0 \\
0 \\
0 \\
0 \\
136\end{array}$ & $\begin{array}{l}10 \\
10 \\
10 \\
10 \\
3 \\
1 \\
1 \\
0 \\
0 \\
0 \\
0 \\
0 \\
0 \\
0 \\
0 \\
0 \\
0 \\
0 \\
0 \\
0 \\
0 \\
0 \\
0 \\
0 \\
0 \\
0 \\
0 \\
0 \\
0 \\
0 \\
0 \\
0 \\
0 \\
0 \\
0 \\
0 \\
0 \\
0 \\
0 \\
0 \\
0 \\
0 \\
0 \\
0 \\
0 \\
0 \\
0 \\
0 \\
0 \\
0 \\
0 \\
0 \\
355\end{array}$ & $\begin{array}{l}3 \\
3 \\
3 \\
3 \\
3 \\
3 \\
3 \\
3 \\
3 \\
3 \\
3 \\
3 \\
3 \\
3 \\
3 \\
3 \\
3 \\
5 \\
5 \\
5 \\
5 \\
5 \\
5 \\
5 \\
5 \\
5 \\
3 \\
3 \\
3 \\
3 \\
3 \\
0 \\
0 \\
0 \\
0 \\
0 \\
0 \\
0 \\
0 \\
0 \\
0 \\
0 \\
0 \\
0 \\
0 \\
0 \\
0 \\
0 \\
0 \\
0 \\
0 \\
0 \\
1333 \\
\\
\\
\\
\\
\\
\\
\\
\\
\\
\\
\\
\\
\\
\\
\\
\\
\\
\end{array}$ & $\begin{array}{r}56 \\
56 \\
56 \\
56 \\
56 \\
6 \\
6 \\
6 \\
6 \\
6 \\
6 \\
6 \\
6 \\
6 \\
6 \\
6 \\
6 \\
6 \\
6 \\
6 \\
6 \\
6 \\
6 \\
6 \\
6 \\
6 \\
6 \\
6 \\
6 \\
6 \\
6 \\
6 \\
6 \\
6 \\
6 \\
6 \\
6 \\
6 \\
6 \\
6 \\
6 \\
6 \\
6 \\
5 \\
5 \\
5 \\
9 \\
16 \\
16 \\
13 \\
13 \\
6 \\
1299 \\
6 \\
6 \\
6 \\
6 \\
6 \\
6 \\
6 \\
6 \\
6 \\
6 \\
6 \\
6 \\
6\end{array}$ & $\begin{array}{r}76 \\
76 \\
76 \\
76 \\
69 \\
17 \\
17 \\
14 \\
14 \\
14 \\
14 \\
14 \\
14 \\
14 \\
14 \\
14 \\
14 \\
16 \\
16 \\
16 \\
16 \\
16 \\
16 \\
14 \\
14 \\
14 \\
12 \\
12 \\
12 \\
12 \\
12 \\
9 \\
9 \\
9 \\
9 \\
9 \\
9 \\
9 \\
9 \\
9 \\
9 \\
9 \\
9 \\
8 \\
8 \\
8 \\
12 \\
19 \\
19 \\
16 \\
16 \\
9 \\
5357\end{array}$ \\
\hline
\end{tabular}


Table $D-4$

ANNUAL DEFENSE COSTS FOR THE TWO-REPOSITORY SYSTEM

NO-NEW-ORDERS, END-OF-REACTOR-LIFE CASE WITH CONSOLIDATION

(MILLIONS OF 1988 DOLLARS)

\begin{tabular}{|c|c|c|c|c|c|c|}
\hline YEAR & $\begin{array}{r}\text { DEVELOPMENT } \\
\text { \& EVALUATION } \\
\end{array}$ & BENEFITS & TRANSPORTATION & $\begin{array}{c}\text { FIRST } \\
\text { REPOSITORY }\end{array}$ & $\begin{array}{c}\text { SECOND } \\
\text { REPOSITORY }\end{array}$ & TOTAL \\
\hline $\begin{array}{l}1983 \\
1984 \\
1985 \\
1986 \\
1987 \\
1988 \\
1989 \\
1990 \\
1991 \\
1992 \\
1993 \\
1994 \\
1995 \\
1996 \\
1997 \\
1998 \\
1999 \\
2000 \\
2001 \\
2002 \\
2003 \\
2004 \\
2005 \\
2006 \\
2007 \\
2008 \\
2009 \\
2010 \\
2011 \\
2012 \\
2013 \\
2014 \\
2015 \\
2016 \\
2017 \\
2018 \\
2019 \\
2020 \\
2021 \\
2022 \\
2023 \\
2024 \\
2025 \\
2026 \\
2027 \\
2028 \\
2029 \\
2030 \\
2031 \\
2032 \\
2033 \\
2034 \\
2035\end{array}$ & 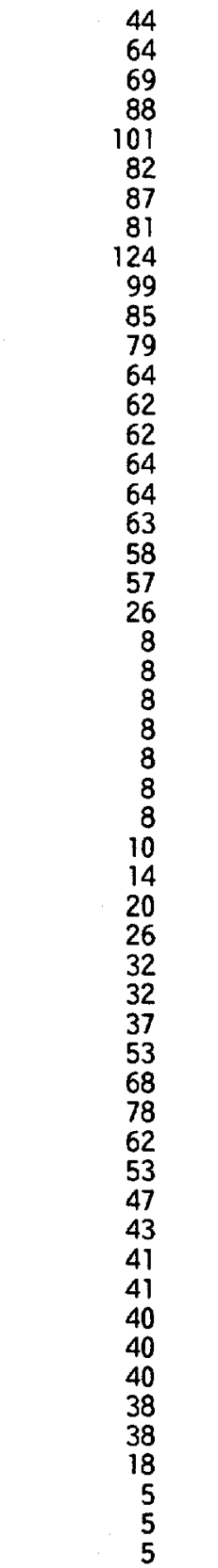 & $\begin{array}{l}0 \\
0 \\
0 \\
0 \\
0 \\
0 \\
0 \\
2 \\
2 \\
2 \\
2 \\
2 \\
2 \\
2 \\
2 \\
2 \\
2 \\
2 \\
2 \\
2 \\
3 \\
3 \\
3 \\
3 \\
3 \\
3 \\
3 \\
2 \\
2 \\
2 \\
2 \\
2 \\
2 \\
2 \\
2 \\
2 \\
3 \\
3 \\
3 \\
3 \\
3 \\
3 \\
3 \\
3 \\
2 \\
2 \\
2 \\
2 \\
2 \\
2 \\
2 \\
2 \\
2\end{array}$ & $\begin{array}{r}0 \\
0 \\
0 \\
0 \\
0 \\
0 \\
0 \\
0 \\
0 \\
0 \\
0 \\
0 \\
0 \\
0 \\
0 \\
0 \\
1 \\
2 \\
2 \\
1 \\
1 \\
1 \\
1 \\
1 \\
1 \\
60 \\
17 \\
17 \\
17 \\
14 \\
15 \\
14 \\
15 \\
10 \\
8 \\
8 \\
8 \\
8 \\
8 \\
8 \\
8 \\
4 \\
1 \\
1 \\
1 \\
0 \\
0 \\
0 \\
0 \\
1 \\
12 \\
10\end{array}$ & 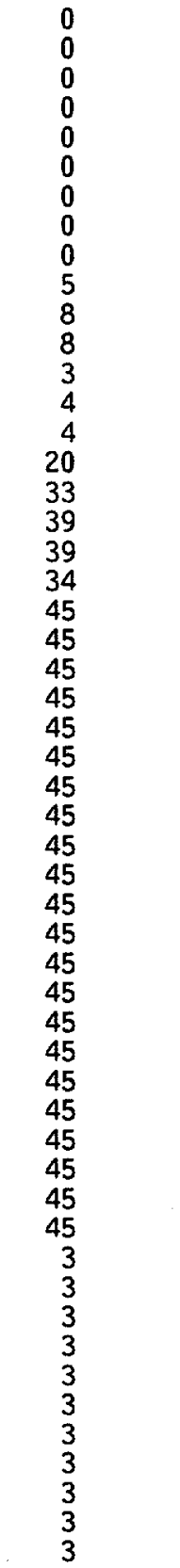 & 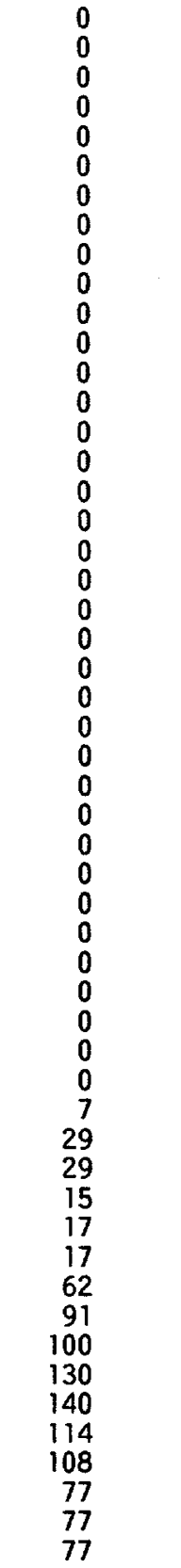 & $\begin{array}{r}44 \\
64 \\
69 \\
88 \\
101 \\
82 \\
87 \\
83 \\
126 \\
106 \\
95 \\
89 \\
69 \\
68 \\
68 \\
86 \\
100 \\
106 \\
101 \\
94 \\
75 \\
57 \\
57 \\
57 \\
57 \\
116 \\
73 \\
72 \\
74 \\
75 \\
82 \\
87 \\
94 \\
89 \\
92 \\
108 \\
124 \\
141 \\
147 \\
138 \\
118 \\
112 \\
65 \\
110 \\
137 \\
145 \\
175 \\
183 \\
157 \\
132 \\
88 \\
129 \\
97\end{array}$ \\
\hline
\end{tabular}


Table $0-4$ (continued)

ANNUAL DEFENSE COSTS FOR THE TWO-REPOSITORY SYSTEM

NO-NEW-ORDERS, END-OF-REACTOR-LIFE CASE WITH CONSOLIDATION

(MILLIONS OF 1988 DOLLARS)

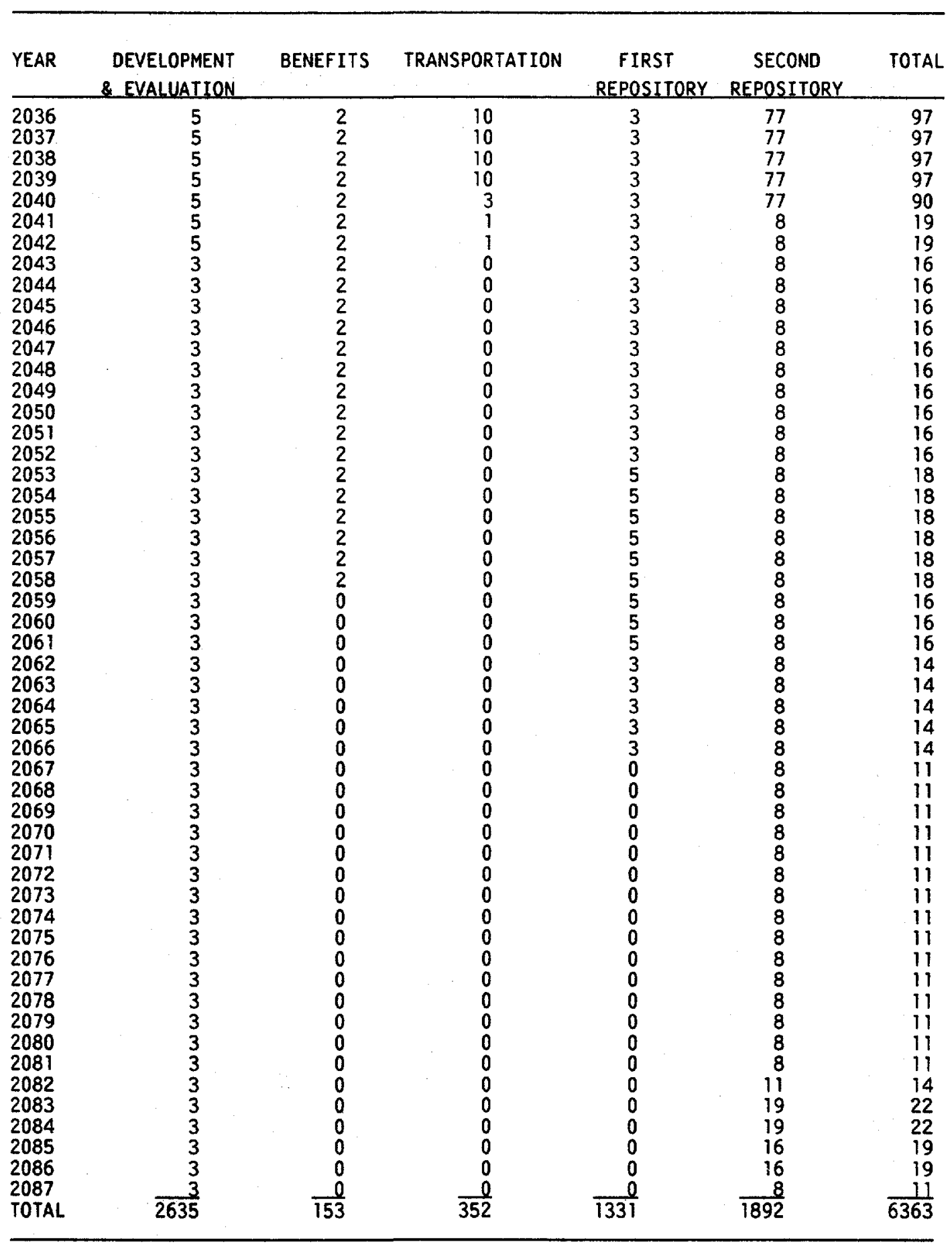


Table $D-5$

ANNUAL DEFENSE COSTS FOR THE TWO-REPOSITORY SYSTEM

UPPER REFERENCE CASE WITH CONSOLIDATION

(MILLIONS OF 1988 DOLLARS)

\begin{tabular}{|c|c|c|c|c|c|c|}
\hline YEAR & $\begin{array}{l}\text { DEVELOPMENT } \\
\text { \& EVALUATION } \\
\end{array}$ & BENEF ITS & TRANSPORTATION & $\begin{array}{c}\text { FIRST } \\
\text { REPOSITORY }\end{array}$ & $\begin{array}{c}\text { SECOND } \\
\text { REPOSITORY }\end{array}$ & TOTAL \\
\hline $\begin{array}{l}1983 \\
1984 \\
1985 \\
1986 \\
1987 \\
1988 \\
1989 \\
1990 \\
1991 \\
1992 \\
1993 \\
1994 \\
1995 \\
1996 \\
1997 \\
1998 \\
1999 \\
2000 \\
2001 \\
2002 \\
2003 \\
2004 \\
2005 \\
2006 \\
2007 \\
2008 \\
2009 \\
2010 \\
2011 \\
2012 \\
2013 \\
2014 \\
2015 \\
2016 \\
2017 \\
2018 \\
2019 \\
2020 \\
2021 \\
2022 \\
2023 \\
2024 \\
2025 \\
2026 \\
2027 \\
2028 \\
2029 \\
2030 \\
2031 \\
2032 \\
2033 \\
2034 \\
2035\end{array}$ & $\begin{array}{r}43 \\
61 \\
67 \\
85 \\
97 \\
80 \\
84 \\
79 \\
119 \\
96 \\
83 \\
76 \\
62 \\
60 \\
60 \\
62 \\
62 \\
61 \\
56 \\
55 \\
25 \\
8 \\
8 \\
8 \\
8 \\
8 \\
8 \\
8 \\
10 \\
13 \\
19 \\
25 \\
30 \\
30 \\
36 \\
51 \\
65 \\
75 \\
60 \\
51 \\
45 \\
41 \\
39 \\
40 \\
39 \\
38 \\
39 \\
37 \\
37 \\
18 \\
5 \\
5 \\
5\end{array}$ & $\begin{array}{l}0 \\
0 \\
0 \\
0 \\
0 \\
0 \\
0 \\
2 \\
2 \\
2 \\
2 \\
2 \\
2 \\
2 \\
2 \\
2 \\
2 \\
2 \\
2 \\
2 \\
3 \\
3 \\
3 \\
3 \\
3 \\
3 \\
3 \\
2 \\
2 \\
2 \\
2 \\
2 \\
2 \\
2 \\
2 \\
2 \\
3 \\
3 \\
3 \\
3 \\
3 \\
3 \\
3 \\
3 \\
2 \\
2 \\
2 \\
2 \\
2 \\
2 \\
2 \\
2 \\
2\end{array}$ & $\begin{array}{l}0 \\
0 \\
0 \\
0 \\
0 \\
0 \\
0 \\
0 \\
0 \\
0 \\
0 \\
0 \\
0 \\
0 \\
0 \\
0 \\
1 \\
2 \\
2 \\
1 \\
1 \\
1 \\
1 \\
1 \\
1 \\
60 \\
17 \\
17 \\
17 \\
14 \\
15 \\
14 \\
15 \\
10 \\
8 \\
8 \\
8 \\
8 \\
8 \\
6 \\
1 \\
1 \\
1 \\
1 \\
1 \\
0 \\
0 \\
0 \\
0 \\
1 \\
1 \\
10\end{array}$ & 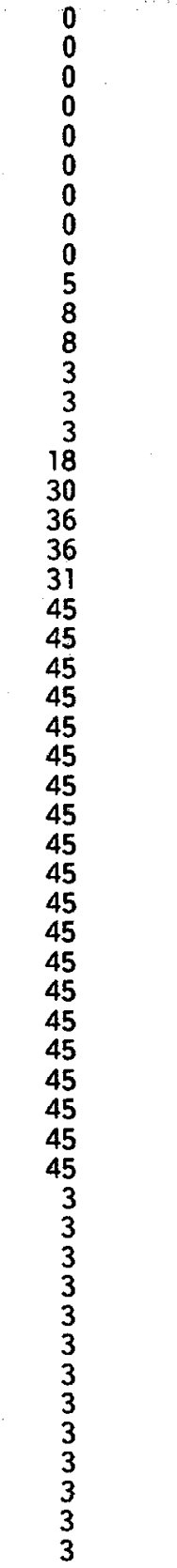 & 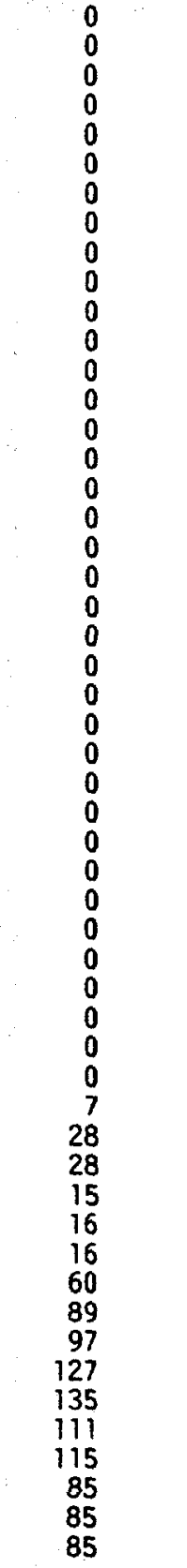 & $\begin{array}{r}43 \\
61 \\
67 \\
85 \\
97 \\
80 \\
84 \\
81 \\
121 \\
103 \\
93 \\
86 \\
67 \\
65 \\
65 \\
82 \\
95 \\
101 \\
96 \\
89 \\
74 \\
57 \\
57 \\
57 \\
57 \\
116 \\
73 \\
72 \\
74 \\
74 \\
81 \\
86 \\
92 \\
87 \\
91 \\
106 \\
121 \\
138 \\
144 \\
133 \\
67 \\
64 \\
62 \\
107 \\
134 \\
140 \\
171 \\
177 \\
153 \\
139 \\
96 \\
137 \\
105\end{array}$ \\
\hline
\end{tabular}


Table D-5 (continued)

ANNUAL DEFENSE COSTS FOR THE TWO-REPOSITORY SYSTEM UPPER REFERENCE CASE WITH CONSOLIDATION

(MILLIONS OF 1988 DOLLARS)

\begin{tabular}{|c|c|c|c|c|c|c|}
\hline YEAR & $\begin{array}{r}\text { DEVELOPMENT } \\
\text { \& EVALUATION }\end{array}$ & BENEFITS & TRANSPORTATION & $\begin{array}{c}\text { FIRST } \\
\text { REPOSITORY }\end{array}$ & $\begin{array}{c}\text { SECOND } \\
\text { REPOSITORY }\end{array}$ & TOTAL \\
\hline $\begin{array}{l}2036 \\
2037 \\
2038 \\
2039 \\
2040 \\
2041 \\
2042 \\
2043 \\
2044 \\
2045 \\
2046 \\
2047 \\
2048 \\
2049 \\
2050 \\
2051 \\
2052 \\
2053 \\
2054 \\
2055 \\
2056 \\
2057 \\
2058 \\
2059 \\
2060 \\
2061 \\
2062 \\
2063 \\
2064 \\
2065 \\
2066 \\
2067 \\
2068 \\
2069 \\
2070 \\
2071 \\
2072 \\
2073 \\
2074 \\
2075 \\
2076 \\
2077 \\
2078 \\
2079 \\
2080 \\
2081 \\
2082 \\
2083 \\
2084 \\
2085 \\
2086 \\
2087 \\
T 0 T A L\end{array}$ & $\begin{array}{l}5 \\
5 \\
5 \\
5 \\
5 \\
5 \\
5 \\
5 \\
5 \\
3 \\
3 \\
3 \\
3 \\
3 \\
3 \\
3 \\
3 \\
3 \\
3 \\
3 \\
3 \\
3 \\
3 \\
3 \\
3 \\
3 \\
3 \\
3 \\
3 \\
3 \\
3 \\
3 \\
3 \\
3 \\
3 \\
3 \\
3 \\
3 \\
3 \\
3 \\
3 \\
3 \\
3 \\
3 \\
3 \\
3 \\
3 \\
3 \\
3 \\
3 \\
3 \\
3 \\
2556\end{array}$ & $\begin{array}{l}2 \\
2 \\
2 \\
2 \\
2 \\
2 \\
2 \\
2 \\
2 \\
2 \\
2 \\
2 \\
2 \\
2 \\
2 \\
2 \\
2 \\
2 \\
2 \\
2 \\
2 \\
2 \\
2 \\
0 \\
0 \\
0 \\
0 \\
0 \\
0 \\
0 \\
0 \\
0 \\
0 \\
0 \\
0 \\
0 \\
0 \\
0 \\
0 \\
0 \\
0 \\
0 \\
0 \\
0 \\
0 \\
0 \\
0 \\
0 \\
0 \\
0 \\
153\end{array}$ & $\begin{array}{l}10 \\
10 \\
10 \\
10 \\
10 \\
8 \\
1 \\
1 \\
1 \\
0 \\
0 \\
0 \\
0 \\
0 \\
0 \\
0 \\
0 \\
0 \\
0 \\
0 \\
0 \\
0 \\
0 \\
0 \\
0 \\
0 \\
0 \\
0 \\
0 \\
0 \\
0 \\
0 \\
0 \\
0 \\
0 \\
0 \\
0 \\
0 \\
0 \\
0 \\
0 \\
0 \\
0 \\
0 \\
0 \\
0 \\
0 \\
0 \\
0 \\
0 \\
0 \\
0 \\
356\end{array}$ & 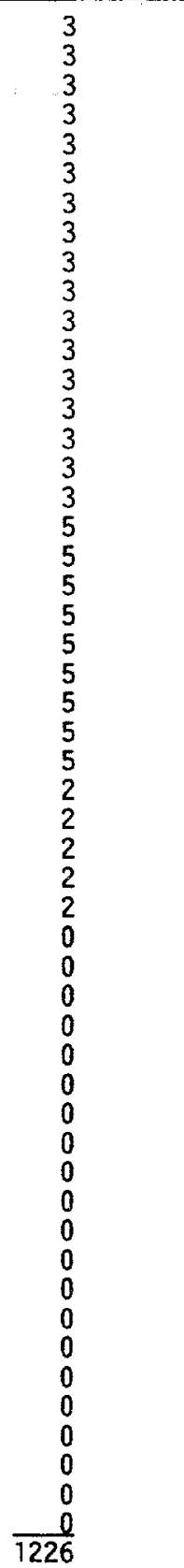 & 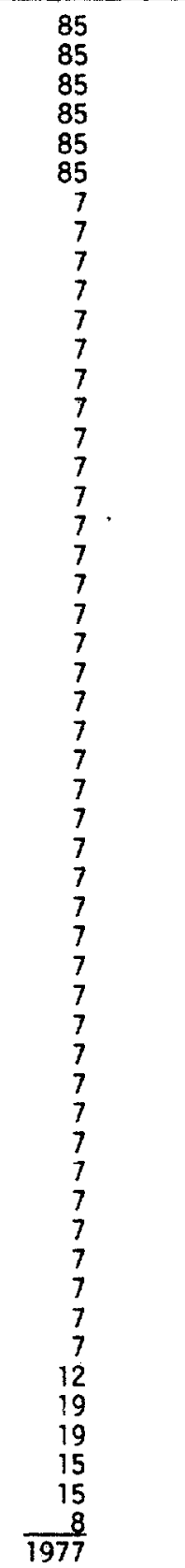 & $\begin{array}{l}105 \\
105 \\
105 \\
105 \\
105 \\
103 \\
18 \\
18 \\
18 \\
15 \\
15 \\
15 \\
15 \\
15 \\
15 \\
15 \\
15 \\
17 \\
17 \\
17 \\
17 \\
17 \\
17 \\
15 \\
15 \\
15 \\
12 \\
12 \\
12 \\
12 \\
12 \\
10 \\
10 \\
10 \\
10 \\
10 \\
10 \\
10 \\
10 \\
10 \\
10 \\
10 \\
10 \\
10 \\
10 \\
10 \\
15 \\
22 \\
22 \\
18 \\
18 \\
11 \\
6268\end{array}$ \\
\hline
\end{tabular}


Appendix E

SUMMARY OF TOTAL SYSTEM COSTS 
Table E-1

SUMMARY OF TOTAL ANNUAL COST FOR THE SINGLE REPOSITORY

SYSTEM NO-NEW-ORDERS, END-OF-REACTOR-LIFE

CASE WITH INTACT DISPOSAL

(MILLIONS OF 1988 DOLLARS)

\begin{tabular}{|c|c|c|c|}
\hline YEAR & $\begin{array}{c}\text { TOTAL DEFENSE } \\
\text { WASTE } \$\end{array}$ & $\begin{array}{c}\text { TOTAL CIVIL } \\
\text { WASTE } \$\end{array}$ & TOTAL \\
\hline $\begin{array}{l}1983 \\
1984 \\
1985 \\
1986 \\
1987 \\
1988 \\
1989 \\
1990 \\
1991 \\
1992 \\
1993 \\
1994 \\
1995 \\
1996 \\
1997 \\
1998 \\
1999 \\
2000 \\
2001 \\
2002 \\
2003 \\
2004 \\
2005 \\
2006 \\
2007 \\
2008 \\
2009 \\
2010 \\
2011 \\
2012 \\
2013 \\
2014 \\
2015 \\
2016 \\
2017 \\
2018 \\
2019 \\
2020 \\
2021 \\
2022 \\
2023 \\
2024 \\
2025 \\
2026 \\
2027 \\
2028 \\
2029 \\
2030 \\
2031 \\
2032 \\
2033 \\
2034 \\
2035\end{array}$ & 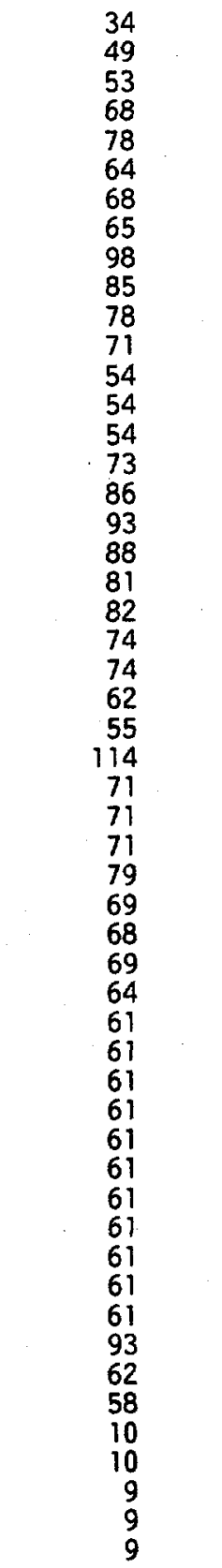 & 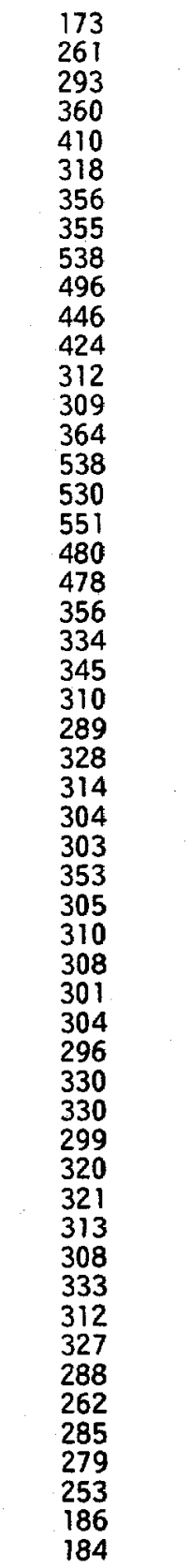 & $\begin{array}{l}207 \\
310 \\
346 \\
428 \\
488 \\
382 \\
424 \\
420 \\
636 \\
581 \\
524 \\
495 \\
366 \\
363 \\
418 \\
611 \\
616 \\
644 \\
568 \\
559 \\
438 \\
408 \\
419 \\
372 \\
344 \\
442 \\
385 \\
375 \\
374 \\
432 \\
374 \\
378 \\
377 \\
365 \\
365 \\
357 \\
391 \\
391 \\
360 \\
381 \\
382 \\
374 \\
369 \\
394 \\
373 \\
420 \\
350 \\
320 \\
295 \\
289 \\
262 \\
195 \\
193\end{array}$ \\
\hline
\end{tabular}


Table E-1 (continued)

SUMMARY OF TOTAL ANNUAL COST FOR THE SINGLE REPOSITORY SYSTEM NO-NEW-ORDERS, END-OF-REACTOR-LIFE CASE WITH INTACT DISPOSAL

(MILLIONS OF 1988 DOLLARS)

\begin{tabular}{|c|c|c|c|}
\hline YEAR & $\begin{array}{c}\text { TOTAL DEFENSE } \\
\text { WASTE } \$\end{array}$ & $\begin{array}{l}\text { TOTAL CIVIL } \\
\text { WASTE } \$\end{array}$ & TOTAL \\
\hline 2036 & 9 & 181 & 190 \\
\hline 2037 & 9 & 174 & 183 \\
\hline 2038 & 9 & 174 & 183 \\
\hline 2039 & 9 & 185 & 194 \\
\hline 2040 & 9 & 168 & 177 \\
\hline 2041 & 9 & 176 & 185 \\
\hline 2042 & 9 & 173 & 182 \\
\hline 2043 & 7 & 39 & 46 \\
\hline 2044 & 7 & 47 & 54 \\
\hline 2045 & 7 & 40 & 47 \\
\hline 2046 & 7 & 33 & 40 \\
\hline 2047 & 7 & 32 & 39 \\
\hline 2048 & 7 & 32 & 39 \\
\hline 2049 & 7 & 32 & 39 \\
\hline 2050 & 7 & 32 & 39 \\
\hline 2051 & 7 & 32 & 39 \\
\hline 2052 & 7 & 32 & 39 \\
\hline 2053 & 7 & 48 & 55 \\
\hline 2054 & 7 & 48 & 55 \\
\hline 2055 & 7 & 48 & 55 \\
\hline 2056 & 7 & 48 & 55 \\
\hline 2057 & 8 & 48 & 56 \\
\hline 2058 & 8 & 48 & 56 \\
\hline 2059 & 7 & 48 & 55 \\
\hline 2060 & 7 & 48 & 55 \\
\hline 2061 & 7 & 48 & 55 \\
\hline 2062 & 7 & 48 & 55 \\
\hline 2063 & 7 & 48 & 55 \\
\hline 2064 & 4 & 33 & 37 \\
\hline 2065 & 4 & 33 & 37 \\
\hline 2066 & 4 & 33 & 37 \\
\hline 2067 & 4 & 33 & 37 \\
\hline 2068 & 4 & 33 & 37 \\
\hline TOTAL & $\overline{3580}$ & 20257 & $\overline{23837}$ \\
\hline
\end{tabular}


Table E-2

SUMMARY OF TOTAL ANNUAL COST FOR THE SINGLE REPOSITORY

SYSTEM NO-NEW-ORDERS, END-OF-REACTOR-LIFE

CASE WITH CONSOLIDATION

(MILLIONS OF 1988 DOLLARS)

\begin{tabular}{|c|c|c|c|}
\hline YEAR & $\begin{array}{c}\text { TOTAL DEFENSE } \\
\text { WASTE } \$\end{array}$ & $\begin{array}{c}\text { TOTAL CIVIL } \\
\text { WASTE } \$\end{array}$ & TOTAL \\
\hline $\begin{array}{l}1983 \\
1984 \\
1985 \\
1986 \\
1987 \\
1988 \\
1989 \\
1990 \\
1991 \\
1992 \\
1993 \\
1994 \\
1995 \\
1996 \\
1997 \\
1998 \\
1999 \\
2000 \\
2001 \\
2002 \\
2003 \\
2004 \\
2005 \\
2006 \\
2007 \\
2008 \\
2009 \\
2010 \\
2011 \\
2012 \\
2013 \\
2014 \\
2015 \\
2016 \\
2017 \\
2018 \\
2019 \\
2020 \\
2021 \\
2022 \\
2023 \\
2024 \\
2025 \\
2026 \\
2027 \\
2028 \\
2029 \\
2030 \\
2031 \\
2032 \\
2033 \\
2034 \\
2035\end{array}$ & 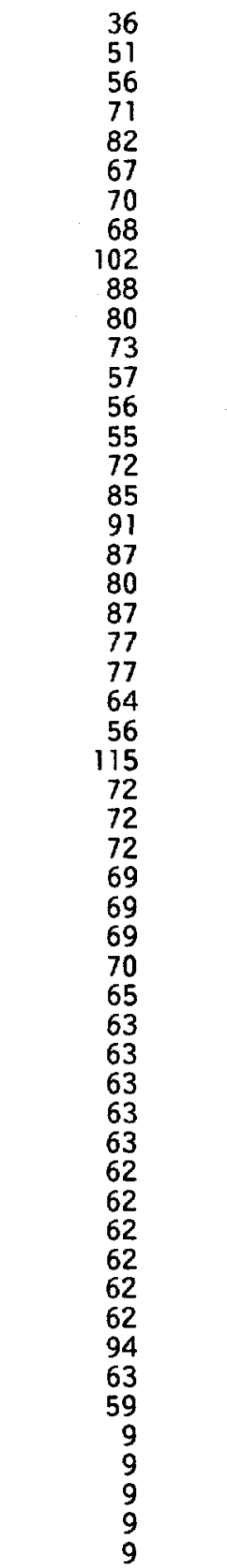 & 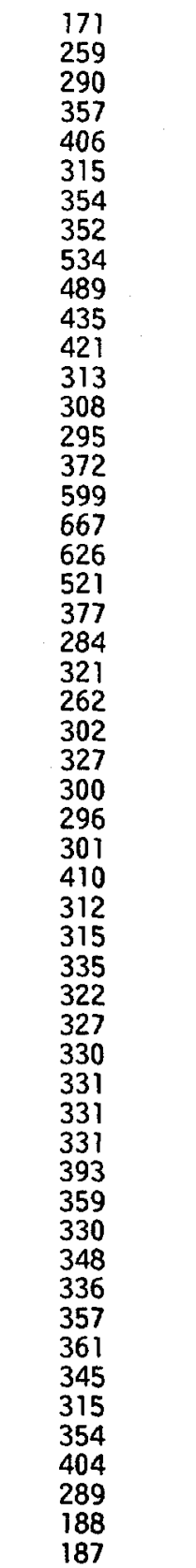 & $\begin{array}{l}207 \\
310 \\
346 \\
428 \\
488 \\
382 \\
424 \\
420 \\
636 \\
577 \\
515 \\
494 \\
370 \\
364 \\
350 \\
444 \\
684 \\
758 \\
713 \\
601 \\
464 \\
361 \\
398 \\
326 \\
358 \\
442 \\
372 \\
368 \\
373 \\
479 \\
381 \\
384 \\
405 \\
387 \\
390 \\
393 \\
394 \\
394 \\
394 \\
455 \\
421 \\
392 \\
410 \\
398 \\
419 \\
455 \\
408 \\
374 \\
363 \\
413 \\
298 \\
197 \\
196\end{array}$ \\
\hline
\end{tabular}


Table E-2 (continued)

SUMMARY OF TOTAL ANNUAL COST FOR THE SINGLE REPOSITORY SYSTEM NO-NEW-ORDERS, END-OF-REACTOR-LIFE

CASE WITH CONSOLIDATION

(MILLIONS OF 1988 DOLLARS)

\begin{tabular}{|c|c|c|c|}
\hline YEAR & $\begin{array}{c}\text { TOTAL DEFENSE } \\
\text { WASTE } \$ \\
\end{array}$ & $\begin{array}{c}\text { TOTAL CIVIL } \\
\text { WASTE } \$ \\
\end{array}$ & TOTAL \\
\hline $\begin{array}{l}2036 \\
2037 \\
2038 \\
2039 \\
2040 \\
2041 \\
2042 \\
2043 \\
2044 \\
2045 \\
2046 \\
2047 \\
2048 \\
2049 \\
2050 \\
2051 \\
2052 \\
2053 \\
2054 \\
2055 \\
2056 \\
2057 \\
2058 \\
2059 \\
2060 \\
2061 \\
2062 \\
2063 \\
2064 \\
2065 \\
2066 \\
2067 \\
2068 \\
\text { TOTAL }\end{array}$ & $\begin{array}{r}9 \\
9 \\
9 \\
9 \\
9 \\
9 \\
9 \\
9 \\
6 \\
6 \\
6 \\
6 \\
6 \\
6 \\
6 \\
6 \\
6 \\
6 \\
8 \\
8 \\
8 \\
8 \\
8 \\
8 \\
7 \\
7 \\
7 \\
7 \\
7 \\
4 \\
4 \\
4 \\
4 \\
4 \\
3635\end{array}$ & $\begin{array}{r}185 \\
186 \\
184 \\
180 \\
179 \\
182 \\
216 \\
45 \\
50 \\
53 \\
54 \\
46 \\
33 \\
33 \\
33 \\
33 \\
33 \\
46 \\
46 \\
46 \\
46 \\
47 \\
47 \\
47 \\
47 \\
47 \\
47 \\
47 \\
31 \\
31 \\
31 \\
31 \\
31 \\
21157\end{array}$ & $\begin{array}{r}194 \\
195 \\
193 \\
189 \\
188 \\
191 \\
225 \\
51 \\
56 \\
59 \\
60 \\
52 \\
39 \\
39 \\
39 \\
39 \\
39 \\
54 \\
54 \\
54 \\
54 \\
55 \\
55 \\
54 \\
54 \\
54 \\
54 \\
54 \\
35 \\
35 \\
35 \\
35 \\
35 \\
24792\end{array}$ \\
\hline
\end{tabular}


Table E-3

SUMMARY OF TOTAL ANNUAL COSTS FOR THE TWO-REPOSITORY

SYSTEM NO-NEW-ORDERS, END-OF-REACTOR-LIFE

CASE WITH INTACT DISPOSAL

(MILLIONS OF 1988 DOLLARS)

\begin{tabular}{|c|c|c|c|}
\hline YEAR & $\begin{array}{c}\text { TOTAL DEFENSE } \\
\text { WASTE } \$\end{array}$ & $\begin{array}{c}\text { TOTAL CIVIL } \\
\text { WASTE \$ }\end{array}$ & TOTAL \\
\hline $\begin{array}{l}1983 \\
1984 \\
1985 \\
1986 \\
1987 \\
1988 \\
1989 \\
1990 \\
1991 \\
1992 \\
1993 \\
1994 \\
1995 \\
1996 \\
1997 \\
1998 \\
1999 \\
2000 \\
2001 \\
2002 \\
2003 \\
2004 \\
2005 \\
2006 \\
2007 \\
2008 \\
2009 \\
2010 \\
2011 \\
2012 \\
2013 \\
2014 \\
2015 \\
2016 \\
2017 \\
2018 \\
2019 \\
2020 \\
2021 \\
2022 \\
2023 \\
2024 \\
2025 \\
2026 \\
2027 \\
2028 \\
2029 \\
2030 \\
2031 \\
2032 \\
2033 \\
2034 \\
2035\end{array}$ & 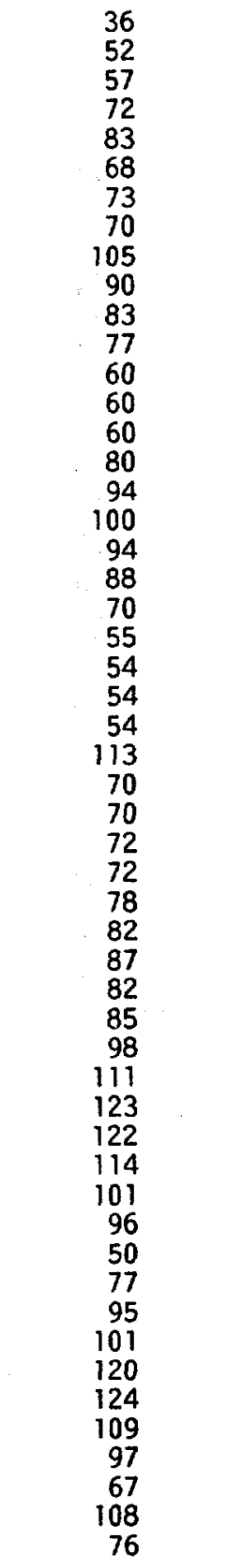 & 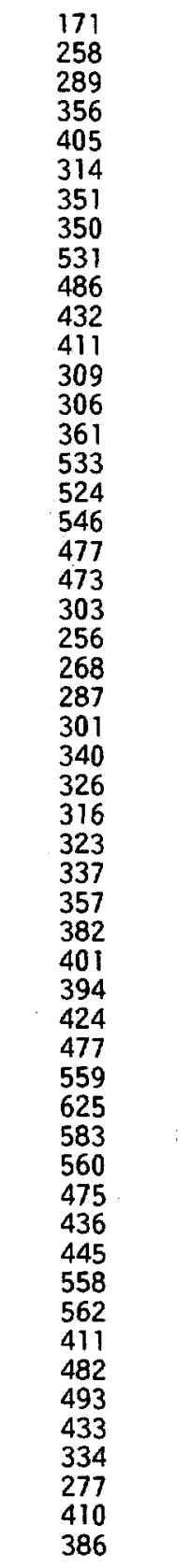 & $\begin{array}{l}207 \\
310 \\
346 \\
428 \\
488 \\
382 \\
424 \\
420 \\
636 \\
576 \\
515 \\
488 \\
369 \\
366 \\
421 \\
613 \\
618 \\
646 \\
571 \\
561 \\
373 \\
311 \\
322 \\
341 \\
355 \\
453 \\
396 \\
386 \\
395 \\
409 \\
435 \\
464 \\
488 \\
476 \\
509 \\
575 \\
670 \\
748 \\
705 \\
674 \\
576 \\
532 \\
495 \\
635 \\
657 \\
512 \\
602 \\
617 \\
542 \\
431 \\
344 \\
518 \\
462\end{array}$ \\
\hline
\end{tabular}


Table E-3 (continued)

SUMMARY OF TOTAL ANNUAL COSTS FOR THE TWO-REPOSITORY SYSTEM NO-NEW-ORDERS, END-OF-REACTOR-LIFE

CASE WITH INTACT DISPOSAL

(MILLIONS OF 1988 DOLLARS)

\begin{tabular}{|c|c|c|c|}
\hline YEAR & $\begin{array}{c}\text { TOTAL DEFENSE } \\
\text { WASTE } \$\end{array}$ & $\begin{array}{c}\text { TOTAL CIVIL } \\
\text { WASTE } \$\end{array}$ & TOTAL \\
\hline $\begin{array}{l}2036 \\
2037 \\
2038 \\
2039 \\
2040 \\
2041 \\
2042 \\
2043 \\
2044 \\
2045 \\
2046 \\
2047 \\
2048 \\
2049 \\
2050 \\
2051 \\
2052 \\
2053 \\
2054 \\
2055 \\
2056 \\
2057 \\
2058 \\
2059 \\
2060 \\
2061 \\
2062 \\
2063 \\
2064 \\
2065 \\
2066 \\
2067 \\
2068 \\
2069 \\
2070 \\
2071 \\
2072 \\
2073 \\
2074 \\
2075 \\
2076 \\
2077 \\
2078 \\
2079 \\
2080 \\
2081 \\
2082 \\
2083 \\
2084 \\
2085 \\
2086 \\
2087 \\
T 0 T A L\end{array}$ & 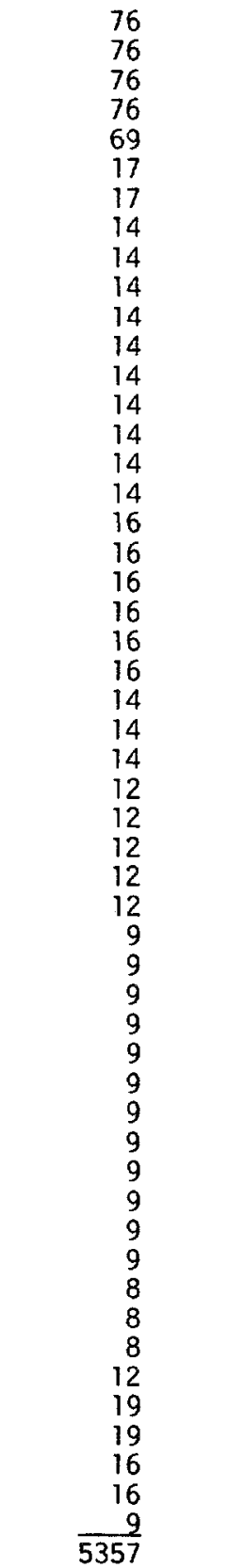 & 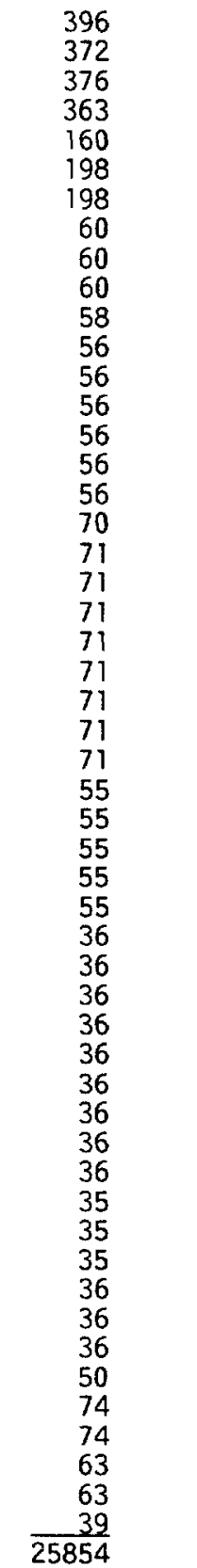 & $\begin{array}{r}472 \\
448 \\
452 \\
439 \\
229 \\
215 \\
215 \\
74 \\
74 \\
74 \\
72 \\
70 \\
70 \\
70 \\
70 \\
70 \\
70 \\
86 \\
87 \\
87 \\
87 \\
87 \\
87 \\
85 \\
85 \\
85 \\
67 \\
67 \\
67 \\
67 \\
67 \\
45 \\
45 \\
45 \\
45 \\
45 \\
45 \\
45 \\
45 \\
45 \\
44 \\
44 \\
44 \\
44 \\
44 \\
44 \\
62 \\
93 \\
93 \\
79 \\
79 \\
48 \\
31211\end{array}$ \\
\hline
\end{tabular}


Table E-4

SUMMARY OF TOTAL ANNUAL COSTS FOR THE TWO-REPOSITORY SYSTEM NO-NEW-ORDERSEND-OF-REACTOR-LIFE CASE WITH

CONSOLIDATION

(MILLIONS OF 1988 DOLLARS)

\begin{tabular}{|c|c|c|c|}
\hline YEAR & $\begin{array}{c}\text { TOTAL DEFENSE } \\
\text { WASIE } \$\end{array}$ & $\begin{array}{l}\text { TOTAL CIVIL } \\
\text { WASTE } \$\end{array}$ & TOTAL \\
\hline $\begin{array}{l}1983 \\
1984 \\
1985 \\
1986 \\
1987 \\
1988 \\
1989 \\
1990 \\
1991 \\
1992 \\
1993 \\
1994 \\
1995 \\
1996 \\
1997 \\
1998 \\
1999 \\
2000 \\
2001 \\
2002 \\
2003 \\
2004 \\
2005 \\
2006 \\
2007 \\
2008 \\
2009 \\
2010 \\
2011 \\
2012 \\
2013 \\
2014 \\
2015 \\
2016 \\
2017 \\
2018 \\
2019 \\
2020 \\
2021 \\
2022 \\
2023 \\
2024 \\
2025 \\
2026 \\
2027 \\
2028 \\
2029 \\
2030 \\
2031 \\
2032 \\
2033 \\
2034 \\
2035\end{array}$ & 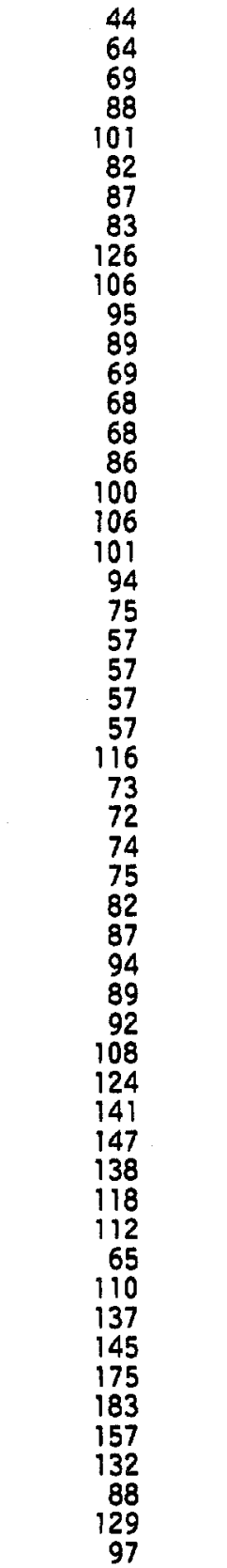 & 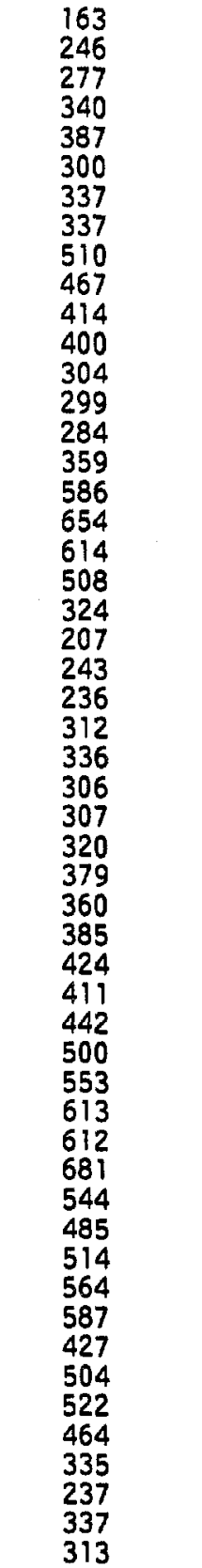 & $\begin{array}{l}207 \\
310 \\
346 \\
428 \\
488 \\
382 \\
424 \\
420 \\
636 \\
573 \\
509 \\
489 \\
373 \\
367 \\
352 \\
445 \\
686 \\
760 \\
715 \\
602 \\
399 \\
264 \\
300 \\
293 \\
369 \\
452 \\
379 \\
379 \\
394 \\
454 \\
442 \\
472 \\
518 \\
500 \\
534 \\
608 \\
677 \\
754 \\
759 \\
819 \\
662 \\
597 \\
579 \\
674 \\
724 \\
572 \\
679 \\
705 \\
621 \\
467 \\
325 \\
466 \\
410\end{array}$ \\
\hline
\end{tabular}


Tabie E-4 (continued)

SUMMARY OF TOTAL ANNUAL COSTS FOR THE TWO-REPOSITORY SYSTEM NO-NEW-ORDERSEND-OF-REACTOR-LIFE CASE WITH CONSOLIDATION

(MILLIONS OF 1988 DOLLARS)

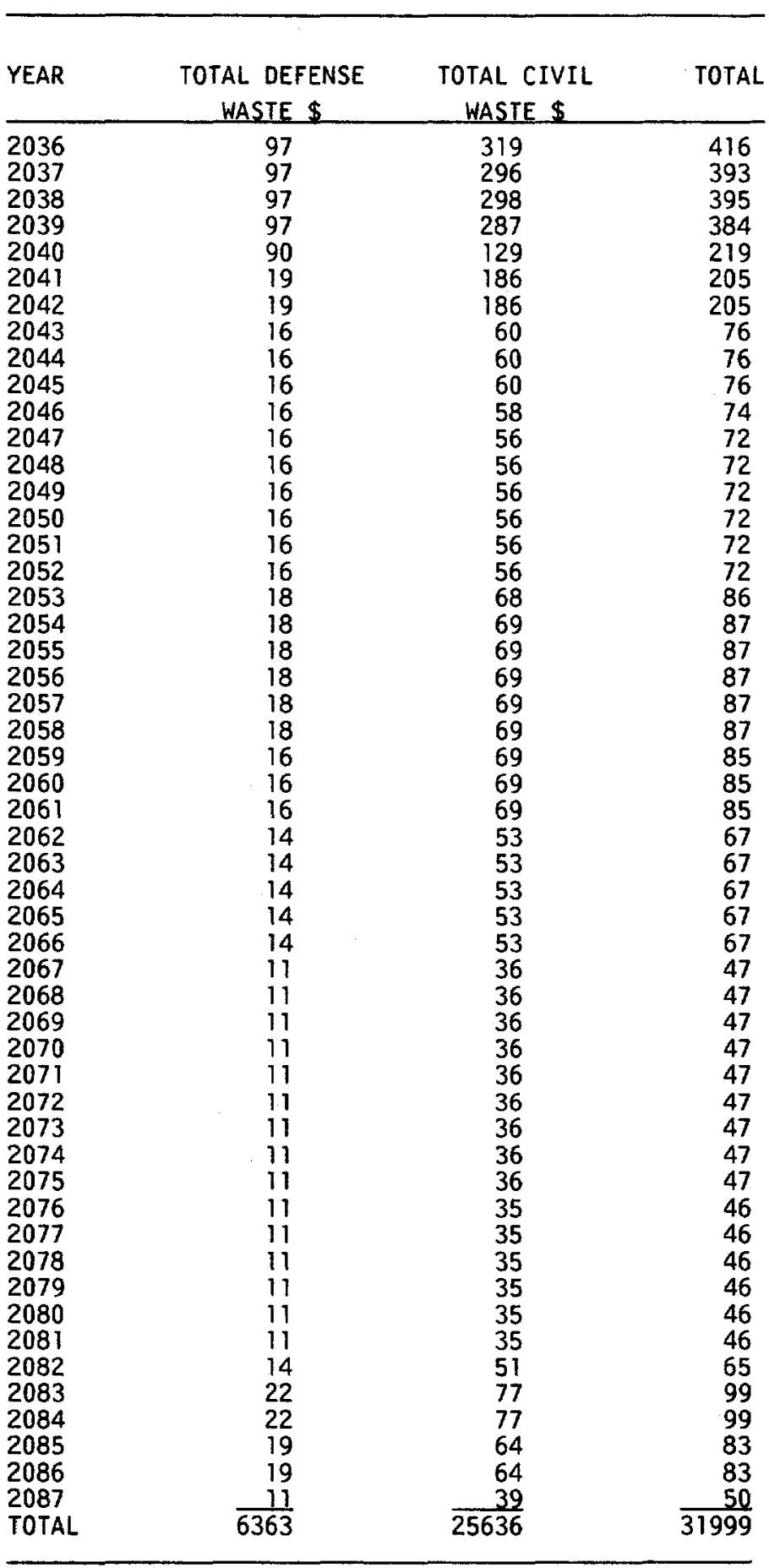


SUMMARY OF TOTAL ANNUAL COSTS FOR THE TWO-REPOSITORY SYSTEM UPPER REFERENCE CASE WITH CONSOLIDATION

(MILLIONS OF 1988 DOLLARS)

\begin{tabular}{|c|c|c|c|}
\hline YEAR & $\begin{array}{c}\text { TOTAL DEFENSE } \\
\text { WASTE } \$\end{array}$ & $\begin{array}{c}\text { TOTAL CIVIL } \\
\text { WASTE } \$ \\
\end{array}$ & TOTAL \\
\hline $\begin{array}{l}1983 \\
1984 \\
1985 \\
1986 \\
1987 \\
1988 \\
1989 \\
1990 \\
1991 \\
1992 \\
1993 \\
1994 \\
1995 \\
1996 \\
1997 \\
1998 \\
1999 \\
2000 \\
2001 \\
2002 \\
2003 \\
2004 \\
2005 \\
2006 \\
2007 \\
2008 \\
2009 \\
2010 \\
2011 \\
2012 \\
2013 \\
2014 \\
2015 \\
2016 \\
2017 \\
2018 \\
2019 \\
2020 \\
2021 \\
2022 \\
2023 \\
2024 \\
2025 \\
2026 \\
2027 \\
2028 \\
2029 \\
2030 \\
2031 \\
2032 \\
2033 \\
2034 \\
2035\end{array}$ & 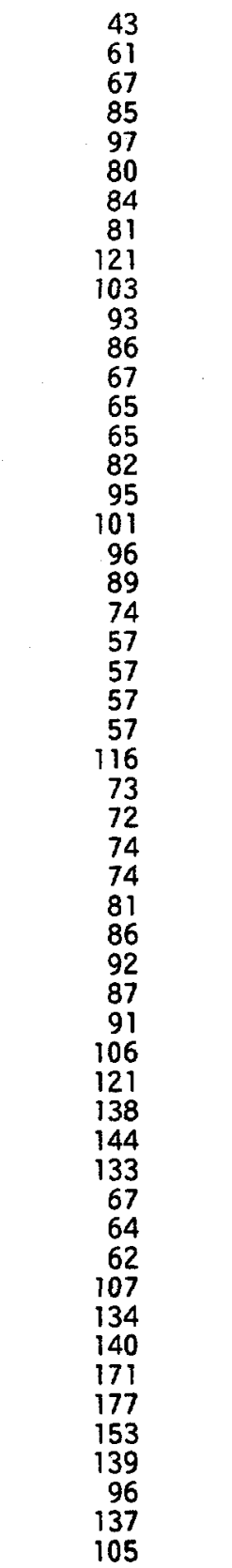 & 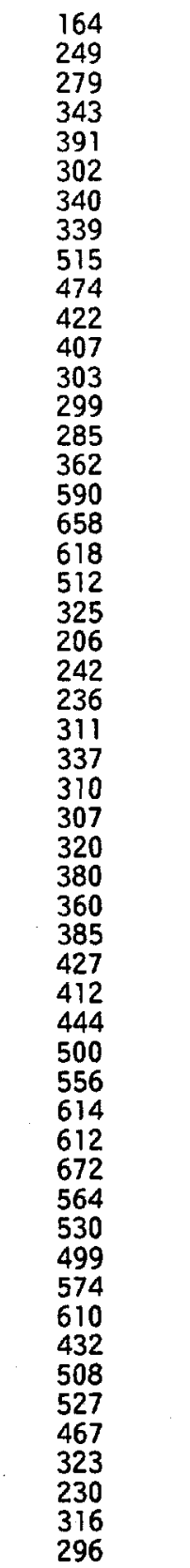 & $\begin{array}{l}207 \\
310 \\
346 \\
428 \\
488 \\
382 \\
424 \\
420 \\
636 \\
577 \\
515 \\
493 \\
370 \\
364 \\
350 \\
444 \\
685 \\
759 \\
714 \\
601 \\
399 \\
263 \\
299 \\
293 \\
368 \\
453 \\
383 \\
379 \\
394 \\
454 \\
441 \\
471 \\
519 \\
499 \\
535 \\
606 \\
677 \\
752 \\
756 \\
805 \\
631 \\
594 \\
561 \\
681 \\
744 \\
572 \\
679 \\
704 \\
620 \\
462 \\
326 \\
453 \\
401\end{array}$ \\
\hline
\end{tabular}


Table E-5 (continued)

SUMMARY OF TOTAL ANNUAL COSTS FOR THE TWO-REPOSITORY SYSTEM UPPER REFERENCE CASE WITH CONSOLIDATION

(MILLIONS OF 1988 DOLLARS)

\begin{tabular}{|c|c|c|c|}
\hline YEAR & $\begin{array}{c}\text { TOTAL DEFENSE } \\
\text { WASTE } \$ \\
\end{array}$ & $\begin{array}{l}\text { TOTAL CIVIL } \\
\text { WASTE } \$ \\
\end{array}$ & TOTAL \\
\hline $\begin{array}{l}2036 \\
2037 \\
2038 \\
2039 \\
2040 \\
2041 \\
2042 \\
2043 \\
2044 \\
2045 \\
2046 \\
2047 \\
2048 \\
2049 \\
2050 \\
2051 \\
2052 \\
2053 \\
2054 \\
2055 \\
2056 \\
2057 \\
2058 \\
2059 \\
2060 \\
2061 \\
2062 \\
2063 \\
2064 \\
2065 \\
2066 \\
2067 \\
2068 \\
2069 \\
2070 \\
2071 \\
2072 \\
2073 \\
2074 \\
2075 \\
2076 \\
2077 \\
2078 \\
2079 \\
2080 \\
2081 \\
2082 \\
2083 \\
2084 \\
2085 \\
2086 \\
2087 \\
T 07 A L\end{array}$ & $\begin{array}{r}105 \\
105 \\
105 \\
105 \\
105 \\
103 \\
18 \\
18 \\
18 \\
15 \\
15 \\
15 \\
15 \\
15 \\
15 \\
15 \\
15 \\
17 \\
17 \\
17 \\
17 \\
17 \\
17 \\
15 \\
15 \\
15 \\
12 \\
12 \\
12 \\
12 \\
12 \\
10 \\
10 \\
10 \\
10 \\
10 \\
10 \\
10 \\
10 \\
10 \\
10 \\
10 \\
10 \\
10 \\
10 \\
10 \\
15 \\
22 \\
22 \\
18 \\
18 \\
11 \\
6268 \\
15\end{array}$ & $\begin{array}{r}289 \\
288 \\
285 \\
283 \\
280 \\
261 \\
320 \\
313 \\
173 \\
61 \\
61 \\
59 \\
57 \\
57 \\
57 \\
57 \\
57 \\
69 \\
70 \\
70 \\
70 \\
70 \\
70 \\
70 \\
70 \\
70 \\
55 \\
55 \\
55 \\
55 \\
55 \\
37 \\
37 \\
37 \\
37 \\
37 \\
37 \\
37 \\
37 \\
37 \\
36 \\
36 \\
36 \\
36 \\
36 \\
36 \\
53 \\
79 \\
79 \\
65 \\
65 \\
39 \\
26475\end{array}$ & $\begin{array}{r}394 \\
393 \\
390 \\
388 \\
385 \\
364 \\
338 \\
331 \\
191 \\
76 \\
76 \\
74 \\
72 \\
72 \\
72 \\
72 \\
72 \\
86 \\
87 \\
87 \\
87 \\
87 \\
87 \\
85 \\
85 \\
85 \\
67 \\
67 \\
67 \\
67 \\
67 \\
47 \\
47 \\
47 \\
47 \\
47 \\
47 \\
47 \\
47 \\
47 \\
46 \\
46 \\
46 \\
46 \\
46 \\
46 \\
68 \\
101 \\
101 \\
83 \\
83 \\
50 \\
32743\end{array}$ \\
\hline
\end{tabular}


Appendix F

REFERENCE DEFENSE WASTE COST ALLOCATION FACTORS 
Table F-1

DEFENSE WASTE COST ALLOCATION FACTORS FOR THE SINGLE-REPOSITORY SYSTEM

NO NEW ORDERS, END OF REACTOR LIFE CASE HITH INTACT DISPOSAL

(Millions of 1988 dollars)

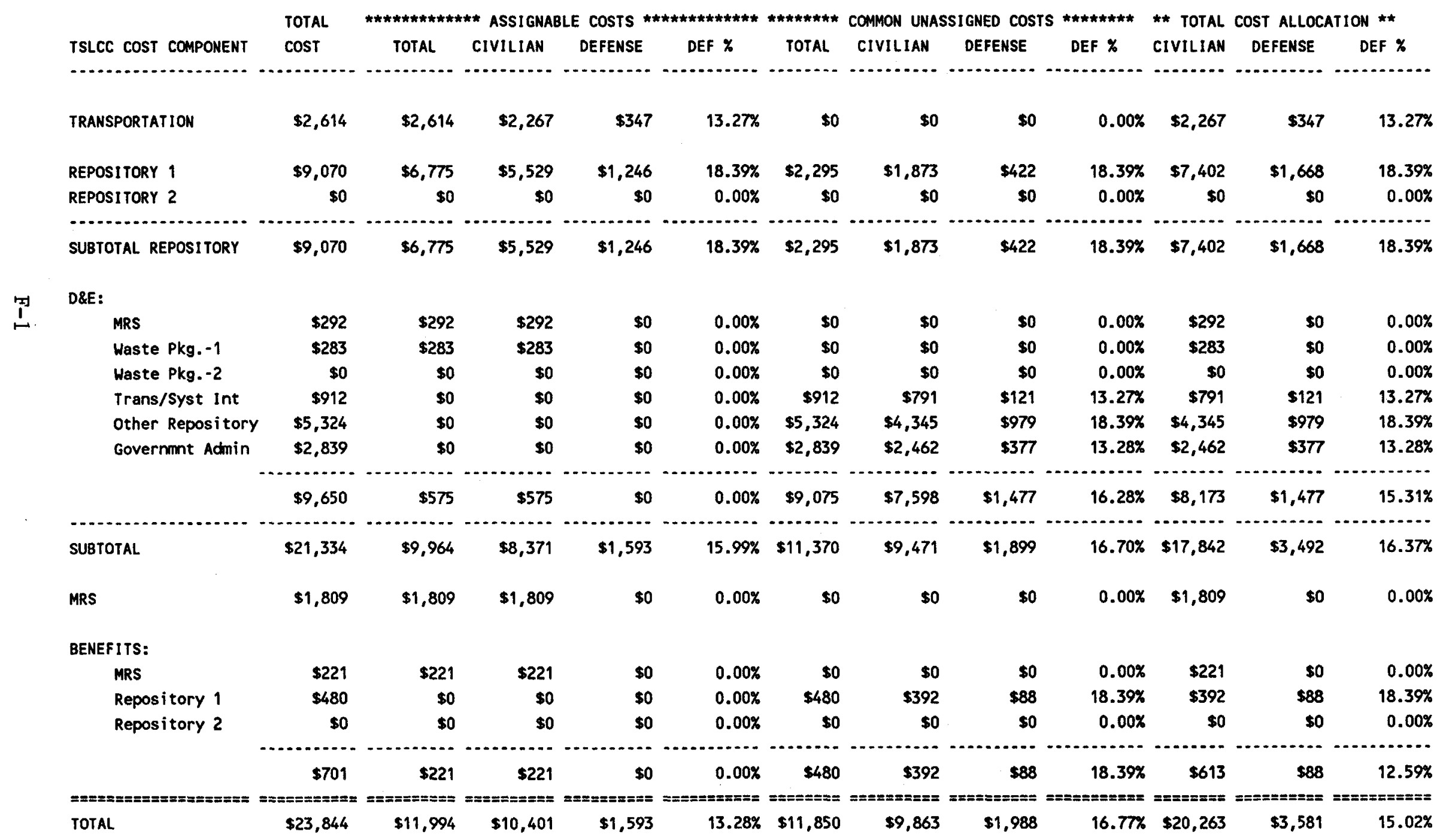


Table F-1 (continued)

DEFENSE WASTE COST ALLOCATION FACTORS FOR THE SINGLE-REPOSITORY SYSTEM

NO NEW ORDERS, END OF REACTOR LIFE CASE WITH INTACT OISPOSAL

(Millions of 1988 dollars)

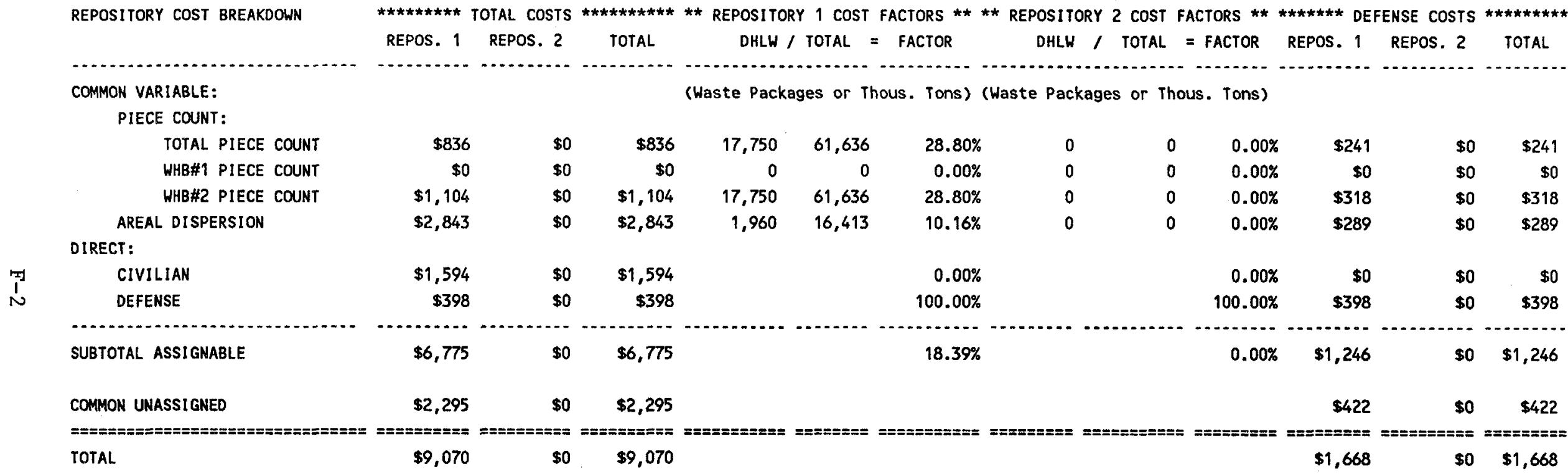

* Costs shown above represent the component costs prior to annualization. 
DEFENSE WASTE COST ALLOCATION FACTORS FOR THE SINGLE-REPOSITORY SYSTEM

NO NEW ORDERS, END OF REACTOR LIFE CASE WITH CONSOLIDATION

(Millions of 1988 dollars)

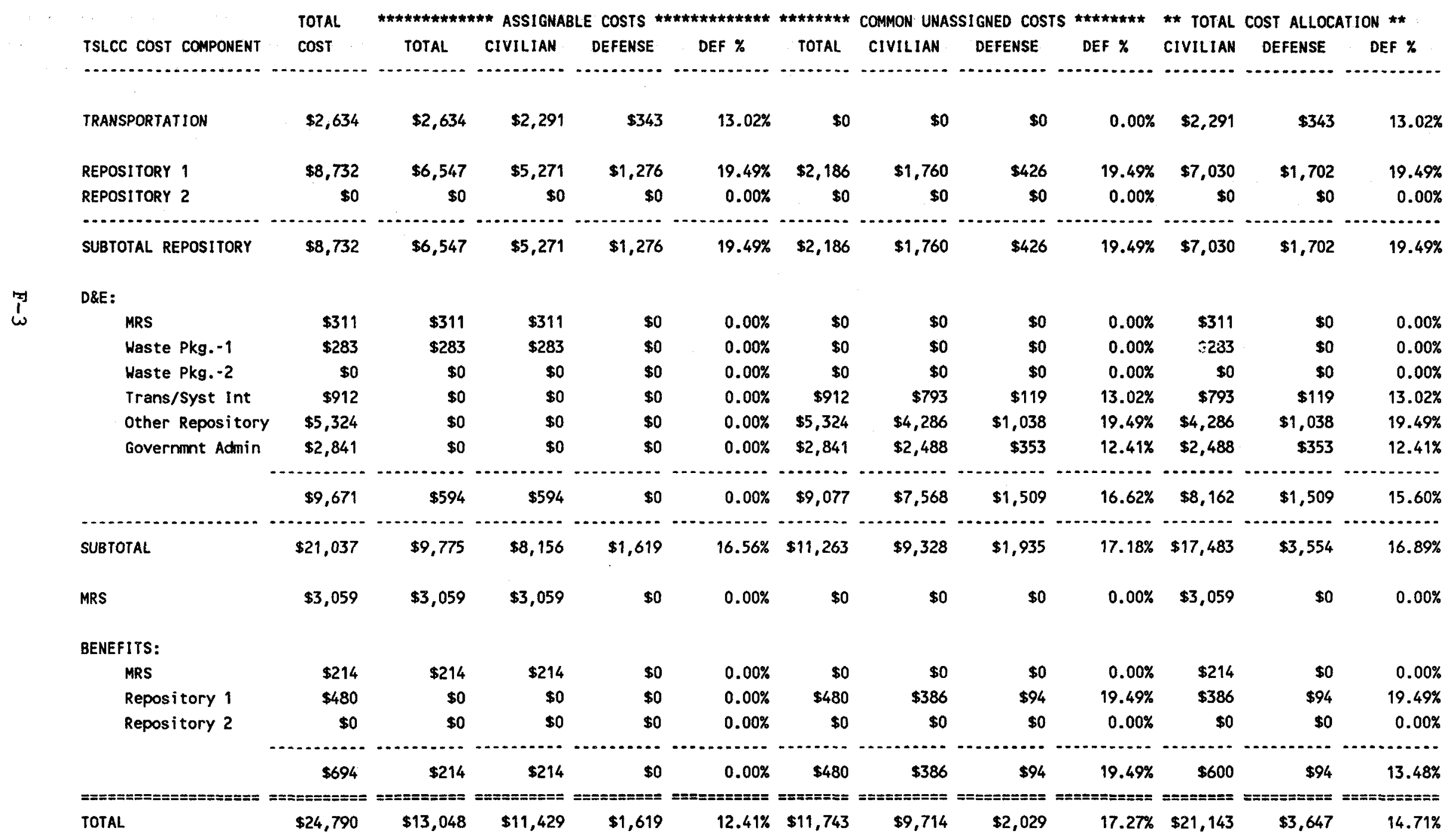


Table F-2 (continued)

DEFENSE WASTE COST ALLOCATION FACTORS FOR THE SINGLE-REPOSITORY SYSTEM

NO NEW ORDERS, END OF REACTOR LIFE CASE WITH CONSOLIDATION

(Millions: of 1988 dollars)

REPOSITORY COST BREAKDOWN

COMMON VARIABLE:

PIECE COUNT:

TOTAL PIECE COUNT

WHBH1 PIECE COUNT

WHB\#2 PIECE COUNT

AREAL DISPERSION

DIRECT :

DEFENSE

DEFES

SUBTOTAL ASSIGNABLE

$\star * * \star * \star * * *$ TOTAL COSTS

REPOS. 1 REPOS. 2

TOTAL

$$
\text { DHLH / TOTAL = FACTOR }
$$

DHLW / TOTAL = FACTOR

******* DEFENSE COSTS *********

REPOS. 1 REPOS, 5 T TOTAL

(Waste Packages or Thous. Tons) (Waste Packages or Thous. Tons)

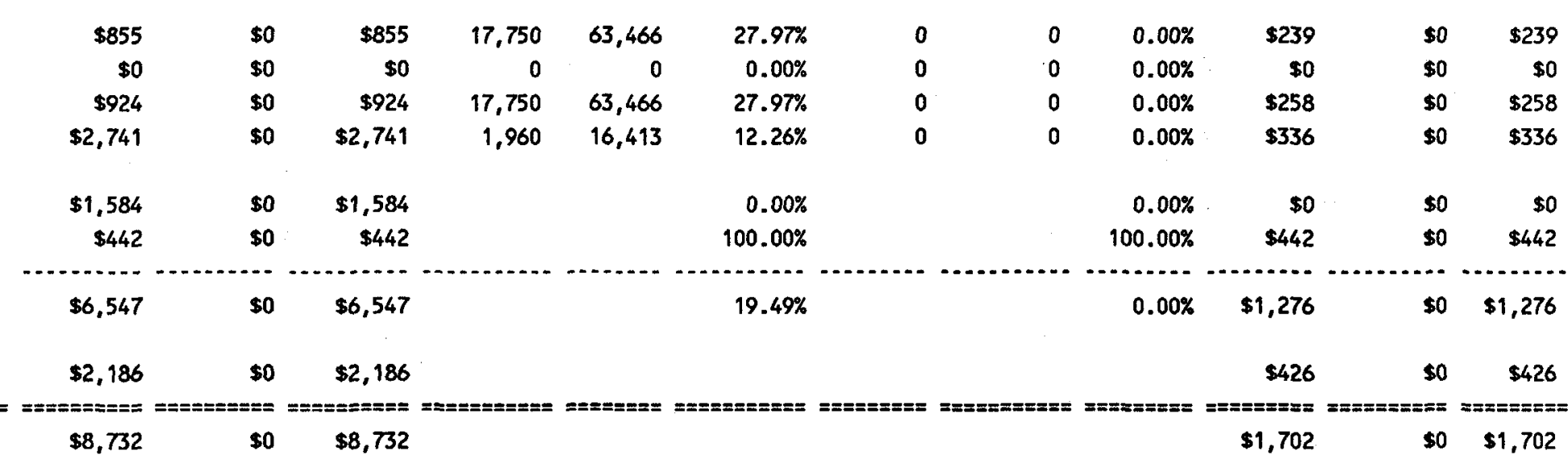

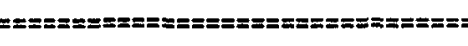

TOTAL.

* Costs shown above represent the component costs prior to annualization. 
DEFENSE WASTE COST ALLOCATION FACTORS FOR THE THO-REPOSITORY SYSTEM

NO NEW ORDERS, END OF REACTOR LIFE CASE WITH INTACT DISPOSAL

(Millions of 1988 dollars)

\begin{tabular}{|c|c|c|c|c|c|c|c|c|c|c|c|c|}
\hline & TOTAL & 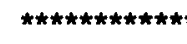 & *** ASSIGNAB & BLE CosTS * & 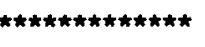 & 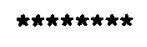 & COMMON UNAS & SSIGNED COST & TS $\star * \star \star \star * \star \star * *$ & ** TOTAL & COST ALLOCA & ITION ** \\
\hline TSLCC COST COMPONENT & $\cos T$ & TOTAL & CIVILIAN & DEFENSE & DEF \% & TOTAL & CIVILIAN & DEFENSE & DEF \% & CIVILIAN & DEFENSE & DEF \% \\
\hline TRANSPORTATION & $\$ 2,325$ & $\$ 2,325$ & $\$ 1,970$ & $\$ 355$ & $15.27 \%$ & $\$ 0$ & $\$ 0$ & $\$ 0$ & $0.00 \%$ & $\$ 1,970$ & $\$ 355$ & $15.27 \%$ \\
\hline REPOSITORY 1 & $\$ 7,004$ & $\$ 5,117$ & $\$ 4,133$ & $\$ 984$ & $19.24 \%$ & $\$ 1,887$ & $\$ 1,524$ & $\$ 363$ & $19.24 \%$ & $\$ 5,657$ & $\$ 1,348$ & $19.24 \%$ \\
\hline REPOSITORY 2 & $\$ 6,592$ & $\$ 4,712$ & $\$ 3,792$ & $\$ 920$ & $19.52 \%$ & $\$ 1,881$ & $\$ 1,514$ & $\$ 367$ & $19.52 \%$ & $\$ 5,306$ & $\$ 1,287$ & $19.52 \%$ \\
\hline SUBTOTAL REPOSITORY & $\$ 13,597$ & $\$ 9,829$ & $\$ 7,925$ & $\$ 1,904$ & $19.37 \%$ & $\$ 3,768$ & $\$ 3,038$ & $\$ 730$ & $19.38 \%$ & $\$ 10,962$ & $\$ 2,634$ & $19.38 \%$ \\
\hline D\&E: & & & & & & & & & & & & \\
\hline MRS & $\$ 292$ & $\$ 292$ & $\$ 292$ & $\$ 0$ & $0.00 \%$ & $\$ 0$ & so & so & $0.00 \%$ & $\$ 292$ & so & $0.00 \%$ \\
\hline Waste Pkg. - I & $\$ 283$ & $\$ 283$ & $\$ 283$ & $\$ 0$ & $0.00 \%$ & $\$ 0$ & $\$ 0$ & \$o & $0.00 \%$ & $\$ 283$ & $\$ 0$ & $0.00 \%$ \\
\hline Waste Pkg.-2 & $\$ 117$ & $\$ 117$ & $\$ 117$ & $\$ 0$ & $0.00 \%$ & $\$ 0$ & $\$ 0$ & so & $0.00 \%$ & $\$ 117$ & $\$ 0$ & $0.00 \%$ \\
\hline Trans/Syst Int & $\$ 1,225$ & $\$ 0$ & $\$ 0$ & so & $0.00 \%$ & $\$ 1,225$ & $\$ 1,038$ & $\$ 187$ & $15.27 \%$ & $\$ 1,038$ & $\$ 187$ & $15.27 \%$ \\
\hline Other Repository & $\$ 7,857$ & $\$ 0$ & $\$ 0$ & $\$ 0$ & $0.00 \%$ & $\$ 7,857$ & $\$ 6,335$ & $\$ 1,522$ & $19.37 \%$ & $\$ 6,335$ & $\$ 1,522$ & $19.37 \%$ \\
\hline Governmnt Admin & $\$ 3,281$ & $\$ 0$ & so & $\$ 0$ & $0.00 \%$ & $\$ 3,281$ & $\$ 2,767$ & $\$ 514$ & $15.67 \%$ & $\$ 2,767$ & $\$ 514$ & $15.67 \%$ \\
\hline & $\$ 13,055$ & $\$ 692$ & $\$ 692$ & $\$ 0$ & $0.00 \%$ & $\$ 12,363$ & $\$ 10,140$ & $\$ 2,223$ & $17.98 \%$ & $\$ 10,832$ & $\$ 2,223$ & $17.03 \%$ \\
\hline SUBTOTAL & $\$ 28,977$ & $\$ 12,846$ & $\$ 10,587$ & $\$ 2,259$ & $17.59 \%$ & $\$ 16,131$ & $\$ 13,178$ & $\$ 2,954$ & $18.31 \%$ & $\$ 23,764$ & $\$ 5,213$ & $17.99 \%$ \\
\hline MRS & $\$ 1,387$ & $\$ 1,387$ & $\$ 1,387$ & $\$ 0$ & $0.00 \%$ & $\$ 0$ & $\$ 0$ & $\$ 0$ & $0.00 \%$ & $\$ 1,387$ & $\$ 0$ & $0.00 \%$ \\
\hline BENEFITS: & & & & & & & & & & & & \\
\hline MRS & $\$ 187$ & $\$ 187$ & $\$ 187$ & $\$ 0$ & $0.00 \%$ & $\$ 0$ & so & $\$ 0$ & $0.00 \%$ & $\$ 187$ & $\$ 0$ & $0.00 \%$ \\
\hline Repository 1 & $\$ 476$ & $\$ 0$ & $\$ 0$ & $\$ 0$ & $0.00 \%$ & $\$ 476$ & $\$ 384$ & $\$ 92$ & $19.37 \%$ & $\$ 384$ & $\$ 92$ & $19.37 \%$ \\
\hline Repository 2 & $\$ 193$ & so & $\$ 0$ & $\$ 0$ & $0.00 \%$ & $\$ 193$ & $\$ 156$ & $\$ 37$ & $19.37 \%$ & $\$ 156$ & $\$ 37$ & $19.37 \%$ \\
\hline & $\$ 856$ & $\$ 187$ & $\$ 187$ & $\$ 0$ & $0.00 \%$ & $\$ 669$ & $\$ 539$ & $\$ 130$ & $19.37 \%$ & $\$ 726$ & $\$ 130$ & $15.14 \%$ \\
\hline & 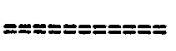 & 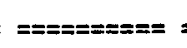 & $:=====$ & $==z==0$ & 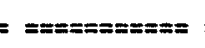 & $=======$ & $===0==x=x=$ & $======= \pm==$ & $=== \pm==x==x=$ & $==x== \pm==$ & $=\equiv=\pi===x==$ & 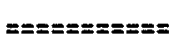 \\
\hline TOTAL & $\$ 31,220$ & $\$ 14,420$ & $\$ 12,161$ & $\$ 2,259$ & $15.67 \%$ & $\$ 16,800$ & $\$ 13,717$ & $\$ 3,083$ & $18.35 \%$ & $\$ 25,877$ & $\$ 5,342$ & $17.11 \%$ \\
\hline
\end{tabular}


Table F-3 (continued)

DEFENSE WASTE COST ALLOCATION FACTORS FOR THE TWO-REPOSITORY SYSTEM

NO NEW ORDERS, END OF REACTOR LIFE CASE HITH INTACT DISPOSAL

(Millions of 1988 dollars)

REPOSITORY COST BREAKDOWN

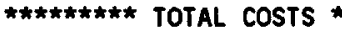

REPOS. 1 REPOS. 2

TOTAL

DHIW 1 TOTAL

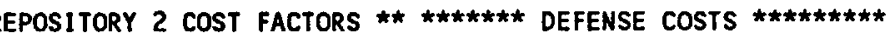

COMMON VARIABLE:

PIECE COUNT:

TOTAL PIECE COUNT

WHB\#1 PIECE COUNT

WHB\#2 PIECE COUNT

AREAL DISPERSION

REPOS. TOL

(Waste Packages or Thous. Tons) (Waste Packages or Thous. Tons) IRECT:

CIVILIAN

DEFENSE

SUBTOTAL ASSIGNABLE

\begin{tabular}{|c|c|c|c|c|c|c|c|c|c|c|c|}
\hline$\$ 643$ & $\$ 215$ & $\$ 858$ & 12,906 & 44.771 & $28.83 \%$ & 4,844 & 19,897 & $24.35 \%$ & $\$ 185$ & $\$ 52$ & $\$ 238$ \\
\hline$\$ 0$ & so & so & 0 & 0 & $0.00 \%$ & 0 & 0 & $0.00 \%$ & $\$ 0$ & $\$ 0$ & $\$ 0$ \\
\hline$\$ 852$ & $\$ 1,052$ & $\$ 1,904$ & 12,906 & 44,771 & $28.83 \%$ & 4,844 & 19,897 & $24.35 \%$ & $\$ 246$ & $\$ 256$ & $\$ 502$ \\
\hline$\$ 2,176$ & $\$ 1,843$ & $\$ 4,018$ & 1,960 & 16,413 & $12.11 \%$ & 2,855 & 14,226 & $19.91 \%$ & $\$ 263$ & $\$ 367$ & $\$ 630$ \\
\hline$\$ 1,157$ & $\$ 1,358$ & $\$ 2,514$ & & & $0.00 \%$ & & & $0.00 \%$ & \$o & $\$ 0$ & $\$ 0$ \\
\hline$\$ 290$ & $\$ 244$ & $\$ 535$ & & & $100.00 \%$ & & & $100.00 \%$ & $\$ 290$ & $\$ 244$ & $\$ 535$ \\
\hline 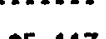 & 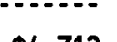 & (n) & 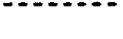 & & - & $\cdots$ & $\cdots$ & 烈 & -1 & .... & 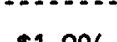 \\
\hline$\$ 5,117$ & $\$ 4,712$ & $\$ 9,829$ & & & $19.24 \%$ & & & $19.52 \%$ & $\$ 984$ & $\$ 920$ & $\$ 1,904$ \\
\hline$\$ 1,887$ & $\$ 1,881$ & $\$ 3,768$ & & & & & & & $\$ 363$ & $\$ 367$ & $\$ 730$ \\
\hline $\begin{array}{l}===== \\
\$ 7,004\end{array}$ & $\begin{array}{l}====== \\
\$ 6,592\end{array}$ & $\begin{array}{l}======= \\
\$ 13,597\end{array}$ & & 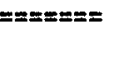 & $z==x=x==$ & $=== \pm==$ & & & $\begin{array}{l}===== \\
\$ 1,348\end{array}$ & $\begin{array}{l}====:= \\
\$ 1,287\end{array}$ & $\begin{array}{l}======= \\
\$ 2,634\end{array}$ \\
\hline
\end{tabular}

* Costs shown above represent the component costs prior to annualization. 
DEFENSE HASTE COST ALLOCATION FACTORS FOR THE TWO-REPOSITORY SYSTEM NO NEW ORDERS, END OF REACTOR LIFE CASE WITH CONSOLIDATION (Millions of 1988 dollars)

\begin{tabular}{|c|c|c|c|c|c|c|c|c|c|c|c|c|}
\hline & TOTAL & 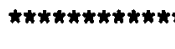 & I** ASSIGNAB & E costs $* *$ & 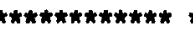 & 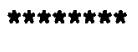 & COMMON UNAS & SIGNED COST & 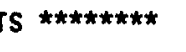 & ** TOTAL & COST ALLOCA & TION ** \\
\hline TSLCC COST COMPONENT & $\cos T$ & TOTAL & CIVILIAN & DEFENSE & DEF \% & TOTAL & CIVILIAN & DEFENSE & DEF $\%$ & CIVILIAN & DEFENSE & DEF \% \\
\hline TRANSPORTATION & $\$ 2,287$ & $\$ 2,287$ & $\$ 1,935$ & $\$ 352$ & $15.39 \%$ & $\$ 0$ & $\$ 0$ & $\$ 0$ & $0.00 \%$ & $\$ 1,935$ & $\$ 352$ & $15.39 \%$ \\
\hline REPOSITORY 1 & $\$ 6,668$ & $\$ 4,855$ & $\$ 3,879$ & $\$ 976$ & $20.10 \%$ & $\$ 1,813$ & $\$ 1,449$ & $\$ 365$ & $20.10 \%$ & $\$ 5,327$ & $\$ 1,340$ & $20.10 \%$ \\
\hline REPOSITORY 2 & $\$ 6,763$ & $\$ 4,723$ & $\$ 3,414$ & $\$ 1,309$ & $27.71 \%$ & $\$ 2,040$ & $\$ 1,475$ & $\$ 565$ & $27.71 \%$ & $\$ 4,889$ & $\$ 1,874$ & $27.71 \%$ \\
\hline SUBTOTAL REPOSITORY & $\$ 13,431$ & $\$ 9,577$ & $\$ 7,293$ & $\$ 2,285$ & $23.86 \%$ & $\$ 3,853$ & $\$ 2,923$ & $\$ 930$ & $24.13 \%$ & $\$ 10,216$ & $\$ 3,215$ & $23.94 \%$ \\
\hline D\&E: & & & & & & & & & & & & \\
\hline MRS & $\$ 311$ & $\$ 311$ & $\$ 311$ & $\$ 0$ & $0.00 \%$ & $\$ 0$ & $\$ 0$ & so & $0.00 \%$ & $\$ 311$ & $\$ 0$ & $0.00 \%$ \\
\hline Haste Pkg.-1 & $\$ 283$ & $\$ 283$ & $\$ 283$ & $\$ 0$ & $0.00 \%$ & $\$ 0$ & \$o & $\$ 0$ & $0.00 \%$ & $\$ 283$ & $\$ 0$ & $0.00 \%$ \\
\hline Waste Pkg.-2 & $\$ 117$ & $\$ 117$ & $\$ 117$ & so & $0.00 \%$ & so & so & \$o & $0.00 \%$ & $\$ 117$ & $\$ 0$ & $0.00 \%$ \\
\hline Trans/Syst Int & $\$ 1,225$ & \$o & so & \$o & $0.00 \%$ & $\$ 1,225$ & $\$ 1,036$ & $\$ 189$ & $15.39 \%$ & $\$ 1,036$ & $\$ 189$ & $15.39 \%$ \\
\hline Other Repository & $\$ 7,857$ & $\$ 0$ & $\$ 0$ & $\$ 0$ & $0.00 \%$ & $\$ 7,857$ & $\$ 5,983$ & $\$ 1,874$ & $23.86 \%$ & $\$ 5,983$ & $\$ 1,874$ & $23.86 \%$ \\
\hline Governmt Admin & $\$ 3,283$ & $\$ 0$ & $\$ 0$ & $\$ 0$ & $0.00 \%$ & $\$ 3,283$ & $\$ 2,710$ & $\$ 573$ & $17.46 \%$ & $\$ 2,710$ & $\$ 573$ & $17.46 \%$ \\
\hline & $\$ 13,076$ & $\$ 711$ & $\$ 711$ & $\$ 0$ & $0.00 \%$ & $\$ 12,365$ & $\$ 9,729$ & $\$ 2,636$ & $21.32 \%$ & $\$ 10,440$ & $\$ 2,636$ & $20.16 \%$ \\
\hline SUBTOTAL & $\$ 28,794$ & $\$ 12,575$ & $\$ 9,939$ & $\$ 2,637$ & $20.97 \%$ & $\$ 16,218$ & $\$ 12,652$ & $\$ 3,566$ & $21.99 \%$ & $\$ 22,591$ & $\$ 6,203$ & $21.54 \%$ \\
\hline MRS & $\$ 2,345$ & $\$ 2,345$ & $\$ 2,345$ & $\$ 0$ & $0.00 \%$ & $\$ 0$ & $\$ 0$ & $\$ 0$ & $0.00 \%$ & $\$ 2,345$ & $\$ 0$ & $0.00 \%$ \\
\hline BENEF ITS: & & & & & & & & & & & & \\
\hline MRS & $\$ 182$ & $\$ 182$ & $\$ 182$ & $\$ 0$ & $0.00 \%$ & $\$ 0$ & $\$ 0$ & $\$ 0$ & $0.00 \%$ & $\$ 182$ & $\$ 0$ & $0.00 \%$ \\
\hline Repository 1 & $\$ 476$ & $\$ 0$ & $\$ 0$ & $\$ 0$ & $0.00 \%$ & $\$ 476$ & $\$ 362$ & $\$ 114$ & $23.86 \%$ & $\$ 362$ & $\$ 114$ & $23.86 \%$ \\
\hline Repository 2 & $\$ 193$ & $\$ 0$ & so & so & $0.00 \%$ & $\$ 193$ & $\$ 147$ & $\$ 46$ & $23.86 \%$ & $\$ 147$ & $\$ 46$ & $23.86 \%$ \\
\hline & $\$ 851$ & $\$ 182$ & $\$ 182$ & $\$ 0$ & $0.00 \%$ & $\$ 669$ & $\$ 509$ & $\$ 160$ & $23.86 \%$ & $\$ 691$ & $\$ 160$ & $18.75 \%$ \\
\hline$== \pm= \pm$ & =s=z=z=I= & $=== \pm===$ & $= \pm= \pm= \pm$ & $f=====$ & $= \pm==5=$ & 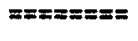 & $z== \pm== \pm$ & :=:=="= & 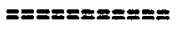 & 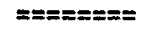 & & $== \pm== \pm==$ \\
\hline TOTAL & $\$ 31,990$ & $\$ 15,102$ & $\$ 12,466$ & $\$ 2,637$ & $17.46 \%$ & $\$ 16,887$ & $\$ 13,162$ & $\$ 3,726$ & $22.06 \%$ & $\$ 25,627$ & $\$ 6,362$ & $19.89 \%$ \\
\hline
\end{tabular}


Table F-4 (continued)

DEFENSE WASTE COST ALLOCATION FACTORS FOR THE TWO-REPOSITORY SYSTEM

NO NEW ORDERS, END OF REACTOR LIFE CASE WITH CONSOLIDATION

(Millions of 1988 dollars)

REPOSITORY COST BREAKDOWN

COMMON VARIABLE:

PIECE COUNT:

TOTAL PIECE COUNT

WHB\#1 PIECE COUNT

HHB\#2 PIECE COUNT AREAL DISPERSION DIRECT:

CIVILIAN

DEFENSE

SUBTOTAL ASSIGNABLE

COMMON UNASSIGNED

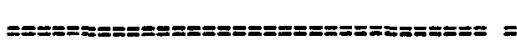

TOTAL

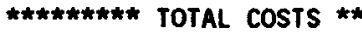

REPOS. 1 REPOS. 2

DHLH / TOTAL = FACTOR

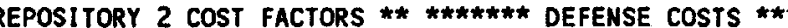
DHLH / TOTAL = FACTOR REPOS. 1 REPOS. 2 TOTAL

(Waste Packages or Thous. Tons) (Waste Packages or Thous. Tons)

$\begin{array}{rr}\$ 644 & \$ 205 \\ \$ 0 & \$ 0 \\ \$ 700 & \$ 1,674\end{array}$

$\$ 850$
$\$ 0$
$\$ 2,374$

12,906
0
12,906

45,048

$\$ 2,077$

$\$ 1,880$

$\$ 3,957$

2,088

0
45,048

$28.65 \%$

$0.00 \%$

4,844

$28.65 \%$

16,148

$12.93 \%$

0
4,844

13,061

061
0
3,061

$37.09 \%$

$0.00 \%$

2,728

15,191

$37.09 \%$

$17.81 \%$

\section{$0.00 \%$}

$100.00 \%$

......

$\$ 599$

$20.10 \%$

$0.00 \%$

$100.00 \%$

$\$ 9,577$

$27.71 \%$

$\$ 3,853$

$\$ 1,813 \quad \$ 2,040$

$\$ 13,431$

$\$ 6,668$

$\$ 6,763$

ior to antuth

* Costs shown above represent the component costs prior to annualization. 
DEFENSE WASTE COST ALLOCATION FACTORS FOR THE THO-REPOSITORY SYSTEM UPPER REFERENCE CASE WITH CONSOLIDATION

(Millions of 1988 dollars)

\begin{tabular}{|c|c|c|c|c|c|c|c|c|c|c|c|c|}
\hline TSLCC COST COMPONENT & $\begin{array}{l}\text { TOTAL } \\
\text { COST }\end{array}$ & $\begin{array}{c}\star \star \star \star \star \star \star \star \star \star \star \star \star \star \star \star * \\
\text { TOTAI }\end{array}$ & ** ASSIGNAB & $\begin{array}{l}\text { LE COSTS ** } \\
\text { DEFENSE }\end{array}$ & $\begin{array}{l}k \star \star \star \star \star \star \star \star \star \star \star \star \star \star * \\
\text { DEF } \%\end{array}$ & $\begin{array}{c}* * * * \star * \star * * \\
\text { TOTAL }\end{array}$ & COMMON UNAS & $\begin{array}{l}\text { SSIGNED COSTS } \\
\text { DFFENSE }\end{array}$ & $\begin{array}{l}\star \star \star \star \star \star \star \star \star \star * * \\
\text { DEF }\end{array}$ & ** TOTAL & COST ALLOCA & 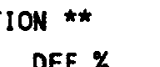 \\
\hline & & & & & & & & & & & & \\
\hline TRANSPORTATION & $\$ 2,377$ & $\$ 2,377$ & $\$ 2,021$ & $\$ 356$ & $14.98 \%$ & \$o & $\$ 0$ & so & $0.00 \%$ & $\$ 2,021$ & $\$ 356$ & $14.98 \%$ \\
\hline REPOSITORY 1 & $\$ 6,632$ & $\$ 4,820$ & $\$ 3,926$ & $\$ 894$ & $18.54 \%$ & $\$ 1,812$ & $\$ 1,476$ & $\$ 336$ & $18.54 \%$ & $\$ 5,402$ & $\$ 1,229$ & $18.54 \%$ \\
\hline REPOSITORY 2 & $\$ 7,426$ & $\$ 5,260$ & $\$ 3,844$ & $\$ 1,416$ & $26.92 \%$ & $\$ 2,165$ & $\$ 1,582$ & $\$ 583$ & $26: 92 \%$ & $\$ 5,427$ & $\$ 1,999$ & $26.92 \%$ \\
\hline SUBTOTAL REPOSITORY & $\$ 14,057$ & $\$ 10,080$ & $\$ 7,770$ & $\$ 2,310$ & $22.91 \%$ & $\$ 3,978$ & $\$ 3,059$ & $\$ 919$ & $23.10 \%$ & $\$ 10,829$ & $\$ 3,229$ & $22.97 \%$ \\
\hline D\&E: & & & & & & & & & & & & \\
\hline MRS & $\$ 311$ & $\$ 311$ & $\$ 311$ & $\$ 0$ & $0.00 \%$ & so & \$o & so & $0.00 \%$ & $\$ 311$ & \$o & $0.00 \%$ \\
\hline Waste Pkg. -1 & $\$ 283$ & $\$ 283$ & $\$ 283$ & $\$ 0$ & $0.00 \%$ & $\$ 0$ & \$0 & $\$ 0$ & $0.00 \%$ & $\$ 283$ & $\$ 0$ & $0.00 \%$ \\
\hline Waste Pkg.-2 & $\$ 117$ & $\$ 117$ & $\$ 117$ & so & $0.00 \%$ & $\$ 0$ & $\$ 0$ & so & $0.00 \%$ & $\$ 117$ & \$o & $0.00 \%$ \\
\hline Trans/Syst Int & $\$ 1,225$ & so & so & so & $0.00 \%$ & $\$ 1,225$ & $\$ 1,042$ & $\$ 183$ & $14.98 \%$ & $\$ 1,042$ & $\$ 183$ & $14.98 \%$ \\
\hline Other Repository & $\$ 7,857$ & $\$ 0$ & $\$ 0$ & $\$ 0$ & $0.00 \%$ & $\$ 7,857$ & $\$ 6,057$ & $\$ 1,800$ & $22.91 \%$ & $\$ 6,057$ & $\$ 1,800$ & $22.91 \%$ \\
\hline Governmt Admin & $\$ 3,307$ & so & so & \$o & $0.00 \%$ & $\$ 3,307$ & $\$ 2,745$ & $\$ 562$ & $16.98 \%$ & $\$ 2,745$ & $\$ 562$ & $16.98 \%$ \\
\hline & $\$ 13,100$ & $\$ 711$ & $\$ 711$ & $\$ 0$ & $0.00 \%$ & $\$ 12,389$ & $\$ 9,844$ & $\$ 2,545$ & $20.55 \%$ & $\$ 10,555$ & $\$ 2,545$ & $19.43 \%$ \\
\hline SUBTOTAL & $\$ 29,534$ & $\$ 13,168$ & $\$ 10,502$ & $\$ 2,666$ & $20.24 \%$ & $\$ 16,367$ & $\$ 12,902$ & $\$ 3,464$ & $21.17 \%$ & $\$ 23,405$ & $\$ 6,130$ & $20.76 \%$ \\
\hline MRS & $\$ 2,344$ & $\$ 2,344$ & $\$ 2,344$ & so & $0.00 \%$ & so & so & so & $0.00 \%$ & $\$ 2,344$ & so & $0.00 \%$ \\
\hline BENEFITS: & & & & & & & & & & & & \\
\hline MRS & $\$ 182$ & $\$ 182$ & $\$ 182$ & \$o & $0.00 \%$ & so & \$o & so & $0.00 \%$ & $\$ 182$ & $\$ 0$ & $0.00 \%$ \\
\hline Repository 1 & $\$ 476$ & $\$ 0$ & \$o & so & $0.00 \%$ & $\$ 476$ & $\$ 367$ & $\$ 109$ & $22.91 \%$ & $\$ 367$ & $\$ 109$ & $22.91 \%$ \\
\hline Repository 2 & $\$ 193$ & so & so & so & $0.00 \%$ & $\$ 193$ & $\$ 149$ & $\$ 44$ & $22.91 \%$ & $\$ 149$ & $\$ 44$ & $22.91 \%$ \\
\hline & $\$ 851$ & $\$ 182$ & $\$ 182$ & so & $0.00 \%$ & $\$ 669$ & $\$ 516$ & $\$ 153$ & $22.91 \%$ & $\$ 698$ & $\$ 153$ & $18.01 \%$ \\
\hline & $\ldots$ & $\ldots$ & & & & & & - & $\cdots$ & $\cdots$ & $====-==$ & \\
\hline TOTAL & $\$ 32,729$ & $\$ 15,694$ & $\$ 13,028$ & $\$ 2,666$ & $16.98 \%$ & $\$ 17,036$ & $\$ 13,418$ & $\$ 3,618$ & $21.24 \%$ & $\$ 26,446$ & $\$ 6,283$ & $19.20 \%$ \\
\hline
\end{tabular}


Table F-5 (cont inued)

DEFENSE WASTE COST ALLOCATION FACTORS FOR THE THO-REPOSITORY SYSTEM UPPER REFERENCE CASE WITH CONSOLIDATION

(Millions of 1988 dollars)

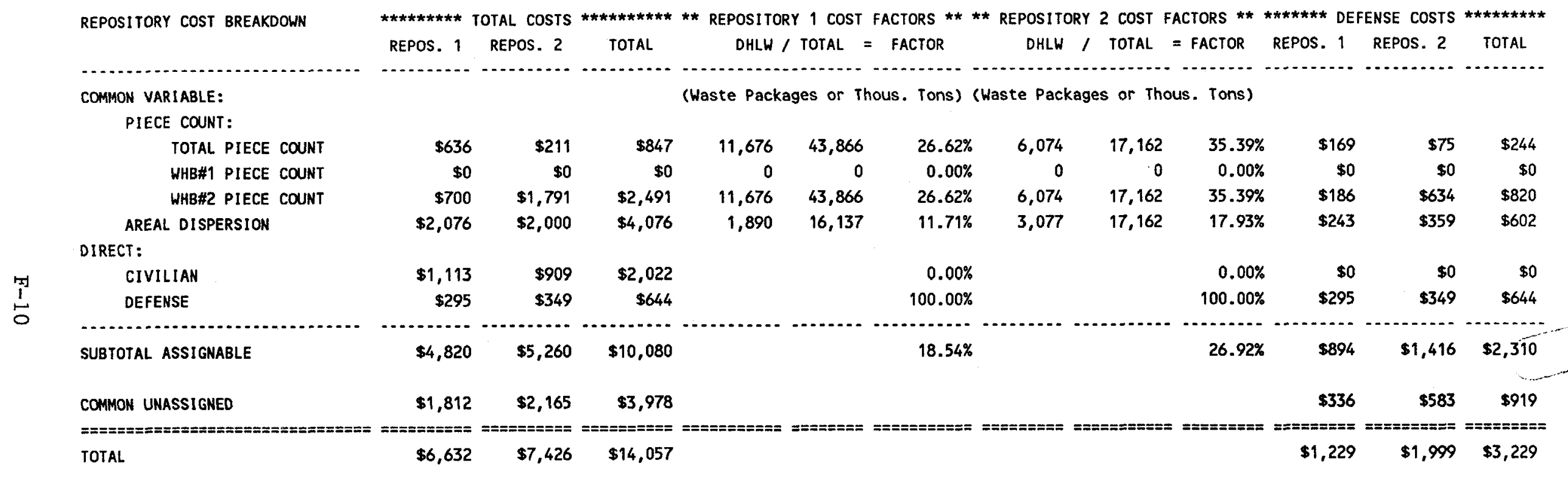

* Costs shown above represent the component costs prior to annualization. 